\title{
The Technical Synthesis of 1,5,9-Cyclododecatriene
}

\section{Revisited - Surprising By-products from a Venerable}

\section{Industrial Process}

\author{
Frauke Thrun, ${ }^{\dagger}$ Volker Hickmann, ${ }^{\dagger}$ Christoph Stock, ${ }^{\dagger}$ Ansgar Schäfer, ${ }^{\ddagger}$ Walter Maier,${ }^{\searrow}$ \\ Martin Breugst, ${ }^{\S}$ Nils Schlörer, ${ }^{\S}$ Albrecht Berkessel, ${ }^{\S}$ and J. Henrique Teles $*, \uparrow$ \\ $\dagger$ Process Research and Chemical Engineering, BASF SE, 67056 Ludwigshafen, Germany \\ \$ Quantum Chemistry, BASF SE, 67056 Ludwigshafen, Germany \\ $\diamond$ Competence Center Analytics, Physics \& Formulation, BASF SE, 67056 Ludwigshafen, Germany \\ $\S$ Department of Chemistry, Organic Chemistry, University of Cologne, Greinstraße 4, 50939 Cologne, Germany
}

\section{Table of Contents}

1. Procedure to separate saturated by-products from excess $1,5,9$-cyclododecatriene..........S2

2. Distillation protocol for the enrichment of by-products...............................S3

3. GC trace of recycled 1,5,9-cyclododecatriene from the production plant................ S5

4. ${ }^{13} \mathrm{C}$-NMR from the product obtained by GC cold-trap fraction collection...................S6

5. ${ }^{13} \mathrm{C}-2 \mathrm{D}-\mathrm{INADEQUATE}$ spectra of chosen fractions and derived carbon backbones......... S7

6. Computed ${ }^{13} \mathrm{C}$-NMR spectra and energies of possible isomers........................S38

7. Correlation diagrams of measured and computed ${ }^{13} \mathrm{C}-\mathrm{NMR}$ spectra...................... S49

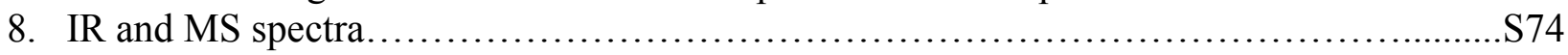

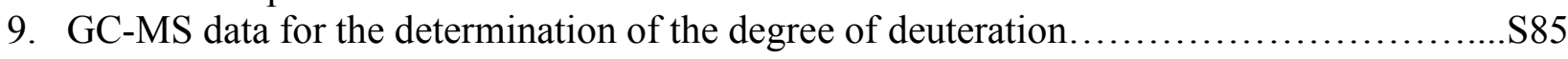

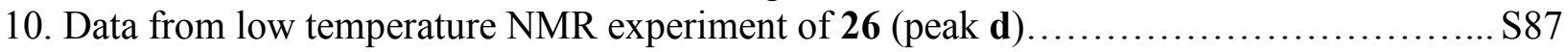

11. Enumeration of $\mathrm{C}_{12} \mathrm{H}_{18}$ isomers derivable from a $\mathrm{C}_{12}$-ring $\ldots \ldots \ldots \ldots \ldots \ldots \ldots \ldots \ldots \ldots . . . . \ldots \ldots$

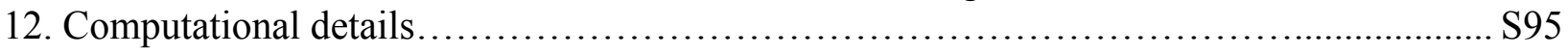


1. Procedure to separate saturated by-products from excess 1,5,9-cyclododecatriene The procedure is described in the experimental part of the publication. 


\section{Distillation protocol for the enrichment of by-products}

The distillation protocol is described in the experimental part of the publication. Temperature and concentration profiles of all fractions are shown in Figure S1.

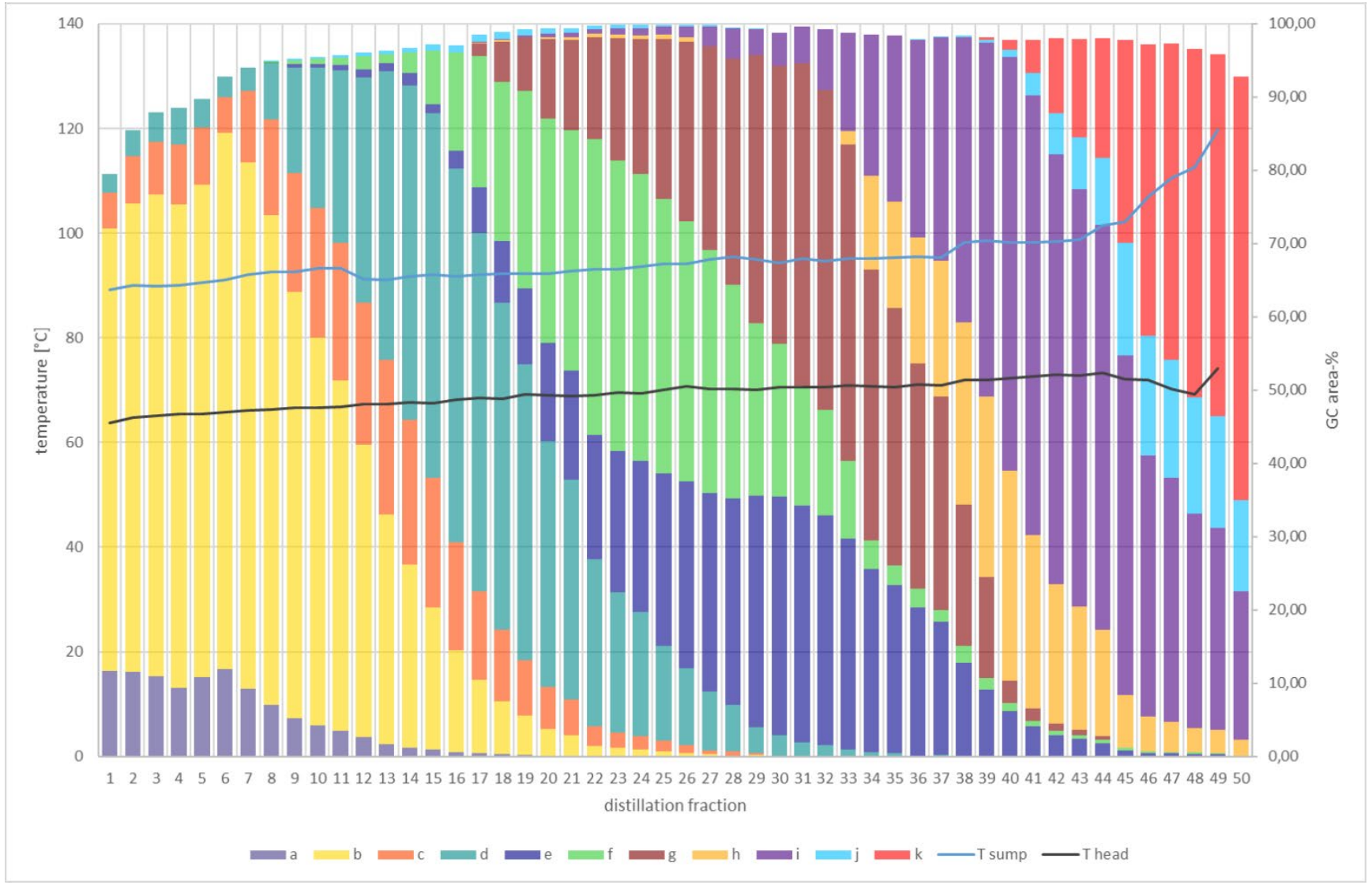

Figure S1: Temperature and concentration profiles of the distillation

A GC chromatogram of the starting material of the distillation is shown in Figure S2 (solvent peak at 6.14 min r.t.). The insert shows the enlarged region between 14.3 - $16.7 \mathrm{~min}$ r.t. (GC conditions: $30 \mathrm{~m} \mathrm{DB}-1701$ column, inner diameter $0.32 \mathrm{~mm}$; starting temperature $50^{\circ} \mathrm{C}$, then heat to $240{ }^{\circ} \mathrm{C}$ with $7{ }^{\circ} \mathrm{C} / \mathrm{min}$, keep $240{ }^{\circ} \mathrm{C}$ for $8 \mathrm{~min}$ ). The chromatogram showed 11 larger peaks (components a - k) and a few minor peaks. Figure S1 shows the distribution of the major components in the 50 distillation fractions. 5 fractions were chosen for detailed NMR analysis (fractions $6,15,29,40,50$ ). As will be discussed later, component $\mathbf{h}$ is actually a mixture of two inseparable components $\mathbf{h}^{\mathbf{1}}$ and $\mathbf{h}^{2}$. 


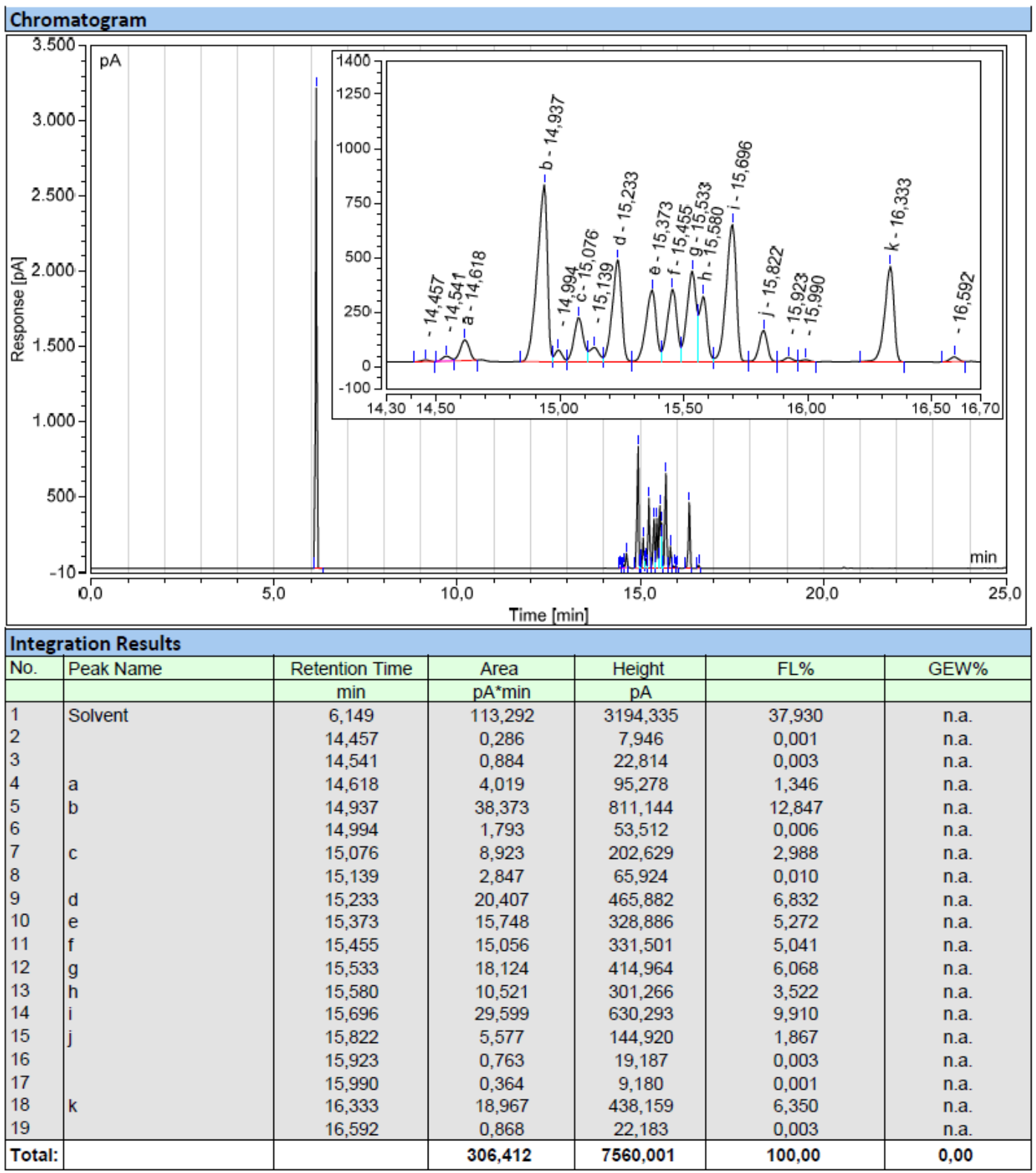

Figure S2: GC-chromatogram of the starting mixture used for the distillation diluted in toluene. Inset shows a magnification of the region of interest. 


\section{GC trace of recycled 1,5,9-cyclododecatriene from the production plant}

As described in the manuscript, the accumulation of unknown by-products first came visible in the gas chromatograms of the recycle stream of cyclododecatriene around the oxidation reactor. A typical GC from the production plant is shown in Figure S3. The inset shows the same region as taken from Figure S2. The greyed region in the inset shows the region obscured by the large peak of cis,trans,trans-1,5,9-cyclododecatriene.

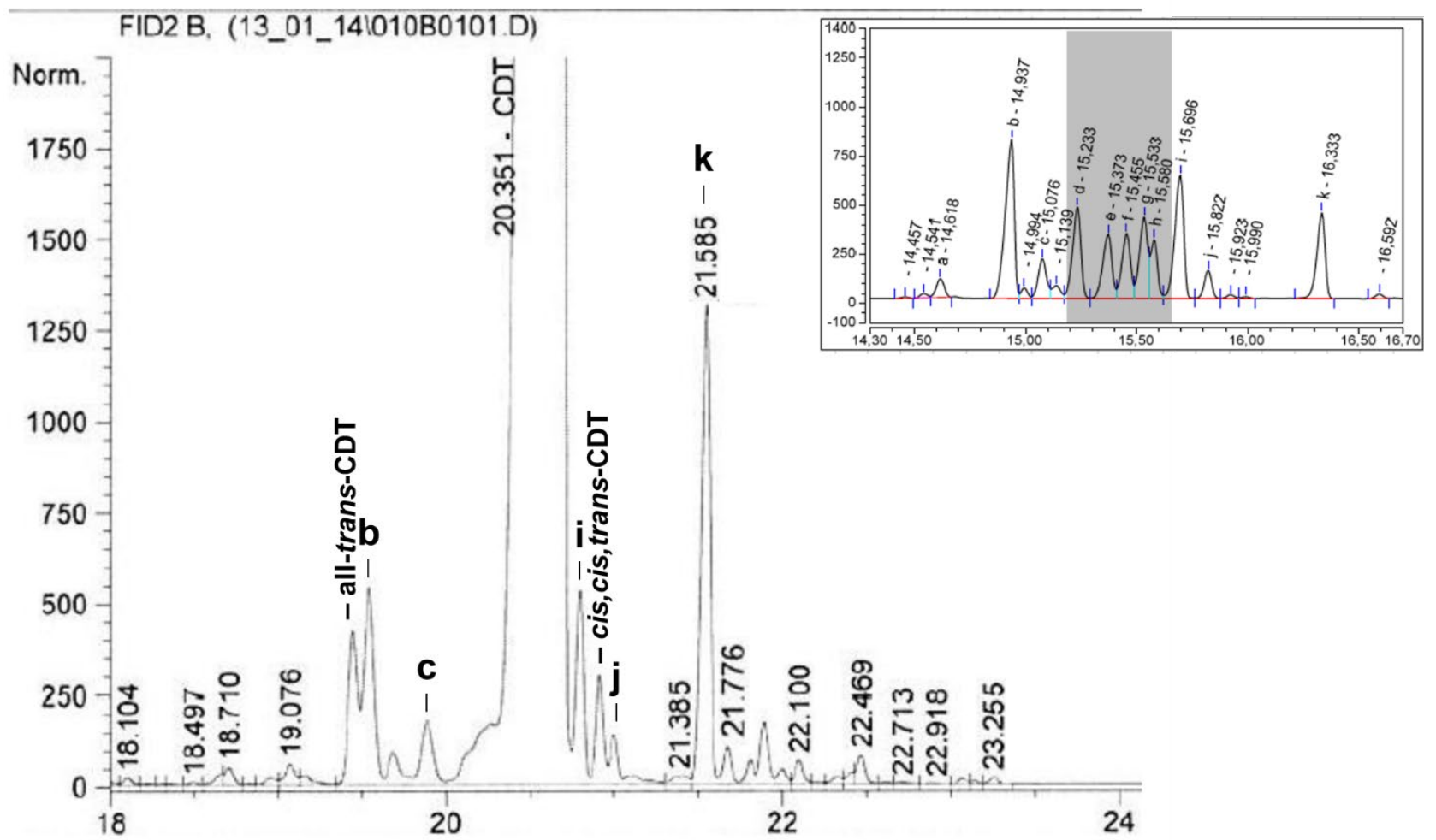

Figure S3: GC from a sample of the recycled stream of cyclododecatriene around the oxidation reactor after a few months of operation. The inset shows the same region of the GC from Figure $\mathrm{S} 2$ for comparison. The region greyed out in the inset is the one obscured by the large peak of cis,trans,trans-1,5,9-cyclododecatriene. This sample was taken at a different time than the one used for the chemical isolation of the saturated by-products. 


\section{4. ${ }^{13} \mathrm{C}$-NMR from the product obtained by GC cold-trap fraction collection}

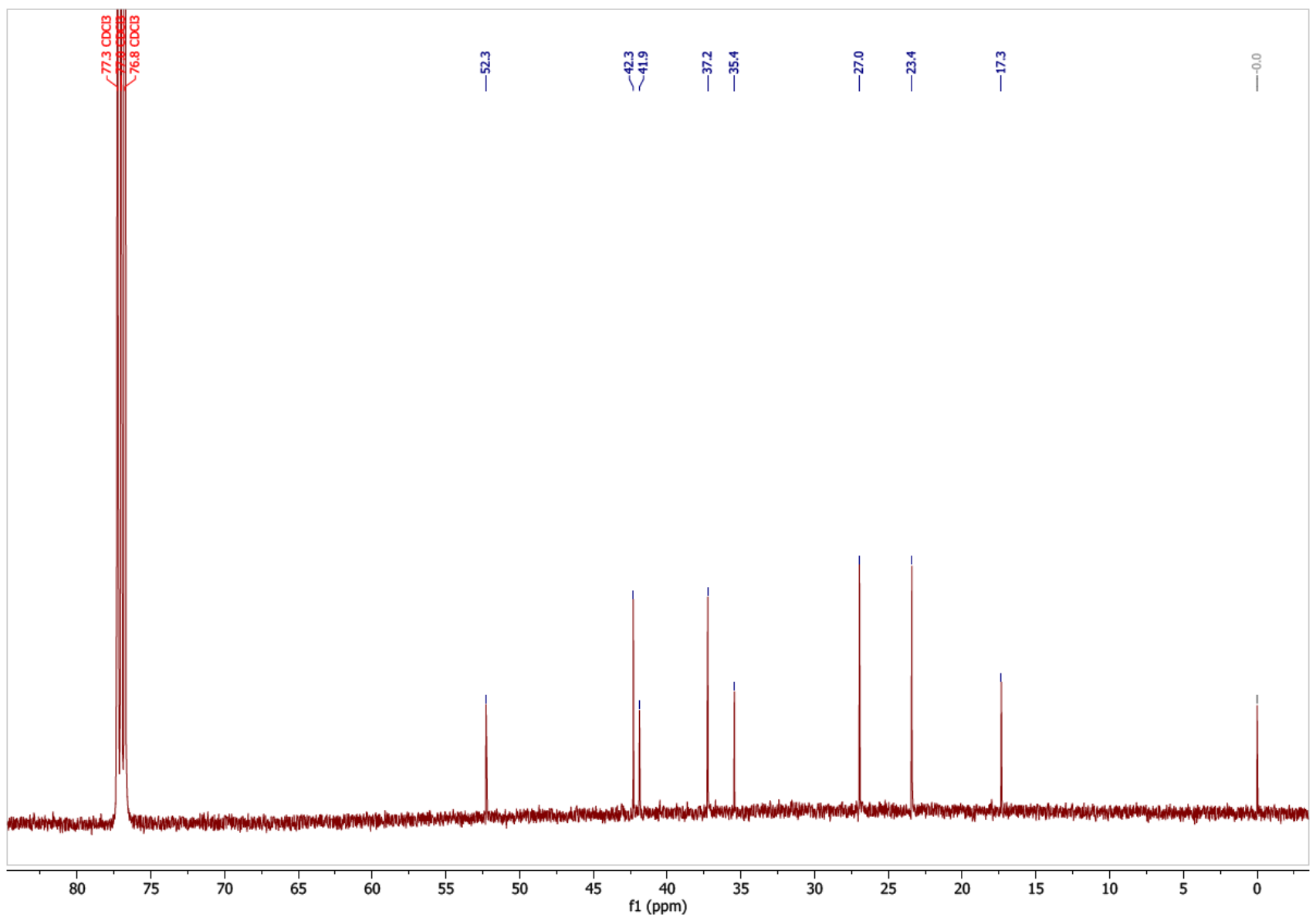

Figure S4: ${ }^{13} \mathrm{C}$-NMR spectrum of the sample obtained after 200 injections and cold-trap fraction collection of the peak at $21.585 \mathrm{~min}$ in Figure S3. Peaks at 52.3, 42.3, 41.9 and 37.2 are $\mathrm{CH}$-groups and the remaining ones are $\mathrm{CH}_{2}$-groups. 


\section{5. ${ }^{13} \mathrm{C}-2 D-I N A D E Q U A T E$ spectra of chosen fractions and derived carbon backbones}

NMR spectra were recorded in deuterated solvents $\left(\mathrm{CDCl}_{3}\right.$ and $\left.\mathrm{C}_{6} \mathrm{D}_{6}\right)$ on a Bruker Avance III 500 ( ${ }^{1} \mathrm{H}: 500.13$ $\left.\mathrm{MHz},{ }^{13} \mathrm{C}: 125.77 \mathrm{MHz}\right)$ or a Bruker Avance III HD spectrometer $\left({ }^{1} \mathrm{H}: 700.31 \mathrm{MHz},{ }^{13} \mathrm{C}: 176.11 \mathrm{MHz}\right)$ at $298 \mathrm{~K}$. Spectra were calibrated against the solvent signals: $\mathrm{CDCl}_{3}: \delta_{\mathrm{C}} 77.00 \mathrm{ppm}, \delta_{\mathrm{H}} 7.26 \mathrm{ppm} ; \mathrm{C}_{6} \mathrm{D}_{6}: \delta_{\mathrm{C}} 128.06 \mathrm{ppm}, \delta_{\mathrm{H}}$ $7.16 \mathrm{ppm}$.

All fractions contained more than one compound. In the following spectra, peak assignments for component 1 are shown in orange, for component 2 in green, and for component 3 in light blue.

In general, carbon shifts are given with one digit. However, when two signals were very close but still separated and the rounded shift would be identical, two digits are given. 


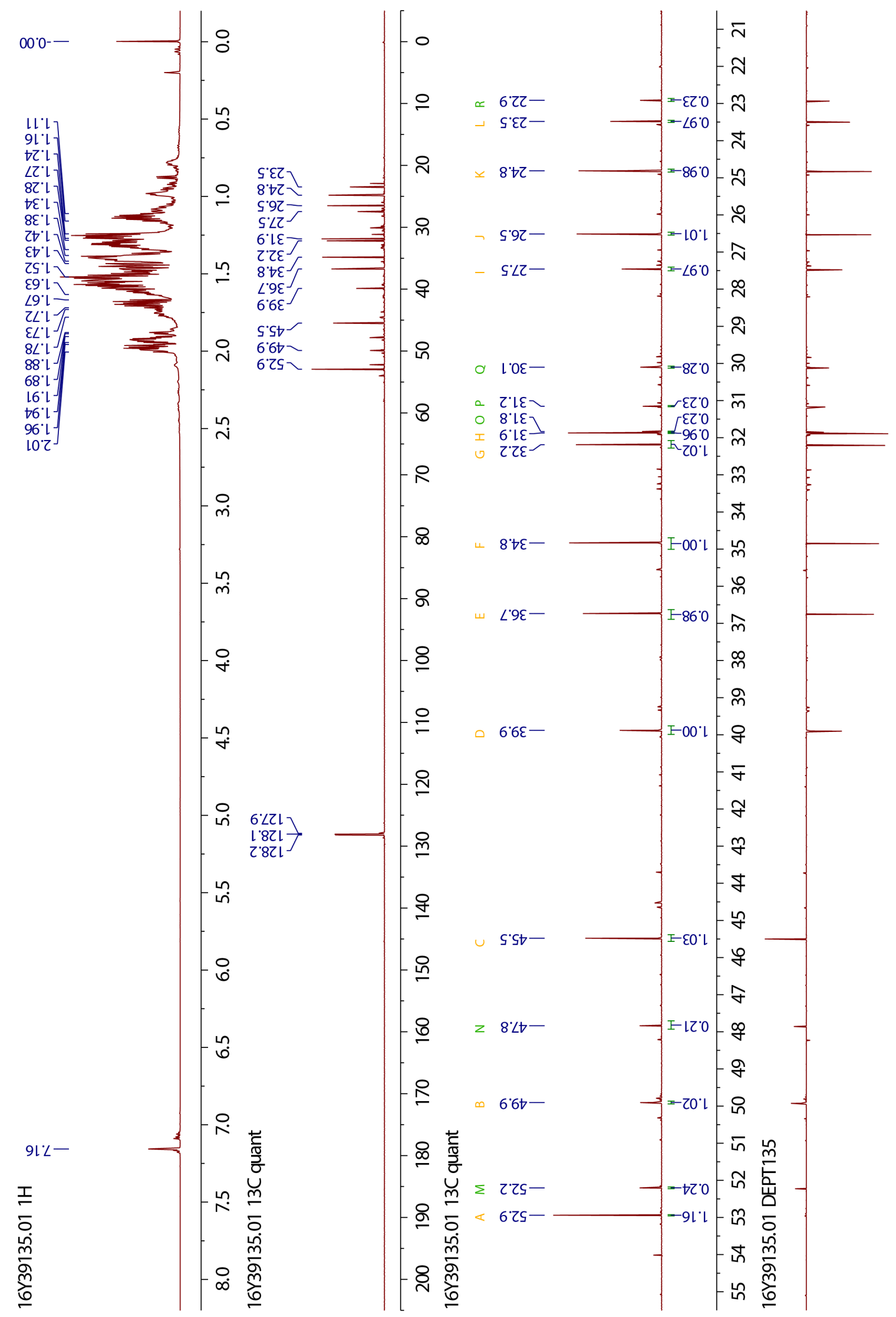

Figure S5: Fraction 6 (2 components): ${ }^{1} \mathrm{H}-\mathrm{NMR}\left(700 \mathrm{MHz}, \mathrm{C}_{6} \mathrm{D}_{6}\right)$ and ${ }^{13} \mathrm{C}-\mathrm{NMR}\left(176 \mathrm{MHz}, \mathrm{C}_{6} \mathrm{D}_{6}\right)$ 
Table S1: peak assignments for compound 22

component 1 in fraction 6

(73.2 GC area\%)

peak (b)

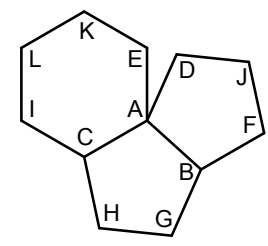

\begin{tabular}{|c|c|c|c|}
\hline Carbon & $\begin{array}{c}{ }^{13} \mathrm{C} \text { measured } \\
\left(176 \mathrm{MHz}, \mathrm{C}_{6} \mathrm{D}_{6}\right){ }^{*}\end{array}$ & multiplicity & $\begin{array}{c}{ }^{13} \mathrm{C} \text { measured } \\
\left.\left(176 \mathrm{MHz} \mathrm{CDCl}_{3}\right){ }^{* *}\right)\end{array}$ \\
\hline A & 52.9 & $\mathrm{C}$ & 52.5 \\
\hline B & 49.9 & $\mathrm{CH}$ & 49.4 \\
\hline $\mathrm{C}$ & 45.5 & $\mathrm{CH}$ & 45.0 \\
\hline $\mathrm{D}$ & 39.9 & $\mathrm{CH}_{2}$ & 39.4 \\
\hline $\mathrm{E}$ & 36.7 & $\mathrm{CH}_{2}$ & 36.3 \\
\hline $\mathrm{F}$ & 34.8 & $\mathrm{CH}_{2}$ & 34.4 \\
\hline G & 32.2 & $\mathrm{CH}_{2}$ & 31.7 \\
\hline $\mathrm{H}$ & 31.9 & $\mathrm{CH}_{2}$ & 31.43 \\
\hline I & 27.5 & $\mathrm{CH}_{2}$ & 27.1 \\
\hline $\mathrm{J}$ & 26.5 & $\mathrm{CH}_{2}$ & 26.0 \\
\hline $\mathrm{K}$ & 24.8 & $\mathrm{CH}_{2}$ & 24.4 \\
\hline $\mathrm{L}$ & 23.5 & $\mathrm{CH}_{2}$ & 23.0 \\
\hline
\end{tabular}


Table S2: peak assignments for compound $\mathbf{1 8}$

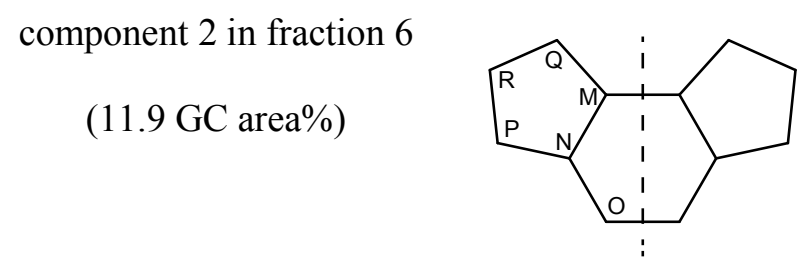

peak (a)

\begin{tabular}{|c|c|c|c|}
\hline Carbon & $\begin{array}{c}{ }^{13} \mathrm{C} \text { measured } \\
\left.\left(176 \mathrm{MHz}, \mathrm{C}_{6} \mathrm{D}_{6}\right){ }^{*}\right)\end{array}$ & multiplicity & $\begin{array}{c}{ }^{13} \mathrm{C} \text { measured } \\
\left.\left(176 \mathrm{MHz} \mathrm{CDCl}_{3}\right){ }^{* *}\right)\end{array}$ \\
\hline $\mathrm{M}$ & 52.2 & $\overline{\mathrm{C \textrm {CH }}}$ & 51.8 \\
\hline $\mathrm{N}$ & 47.8 & $\mathrm{CH}$ & 47.4 \\
\hline $\mathrm{O}$ & 31.8 & $\mathrm{CH}_{2}$ & 31.37 \\
\hline $\mathrm{P}$ & 31.2 & $\mathrm{CH}_{2}$ & 30.7 \\
\hline Q & 30.1 & $\mathrm{CH}_{2}$ & 29.7 \\
\hline $\mathrm{R}$ & 22.9 & $\mathrm{CH}_{2}$ & 22.4 \\
\hline
\end{tabular}

*) assignment from ${ }^{13} \mathrm{C}-2 \mathrm{D}$-INADEQUATE spectra

**) assignment from 1D spectra 


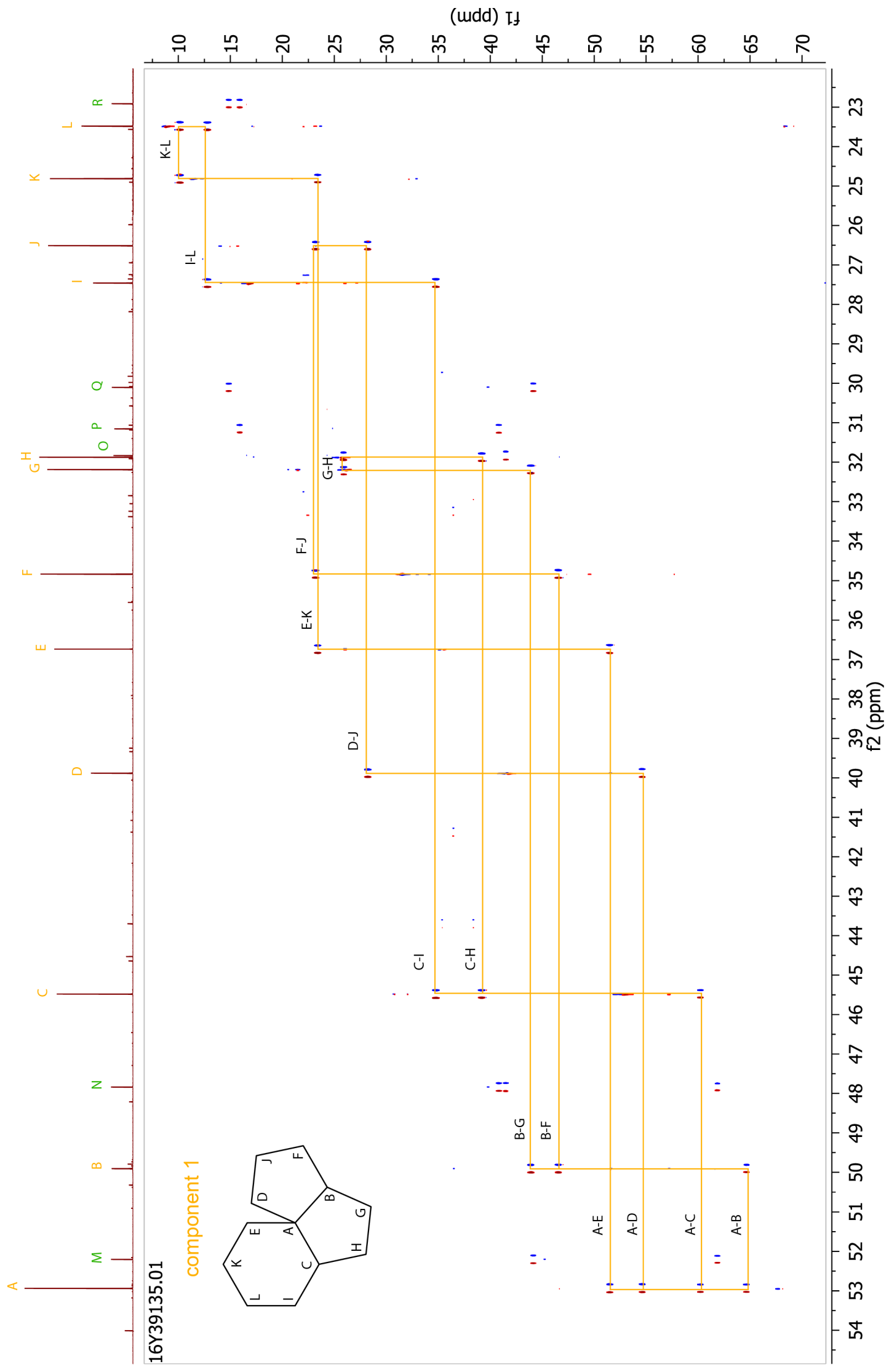

Figure S6: Fraction 6, component 1: 22 (b), ${ }^{13} \mathrm{C}-2 \mathrm{D}-\mathrm{INADEQUATE}, 176 \mathrm{MHz}, \mathrm{C}_{6} \mathrm{D}_{6}$ 


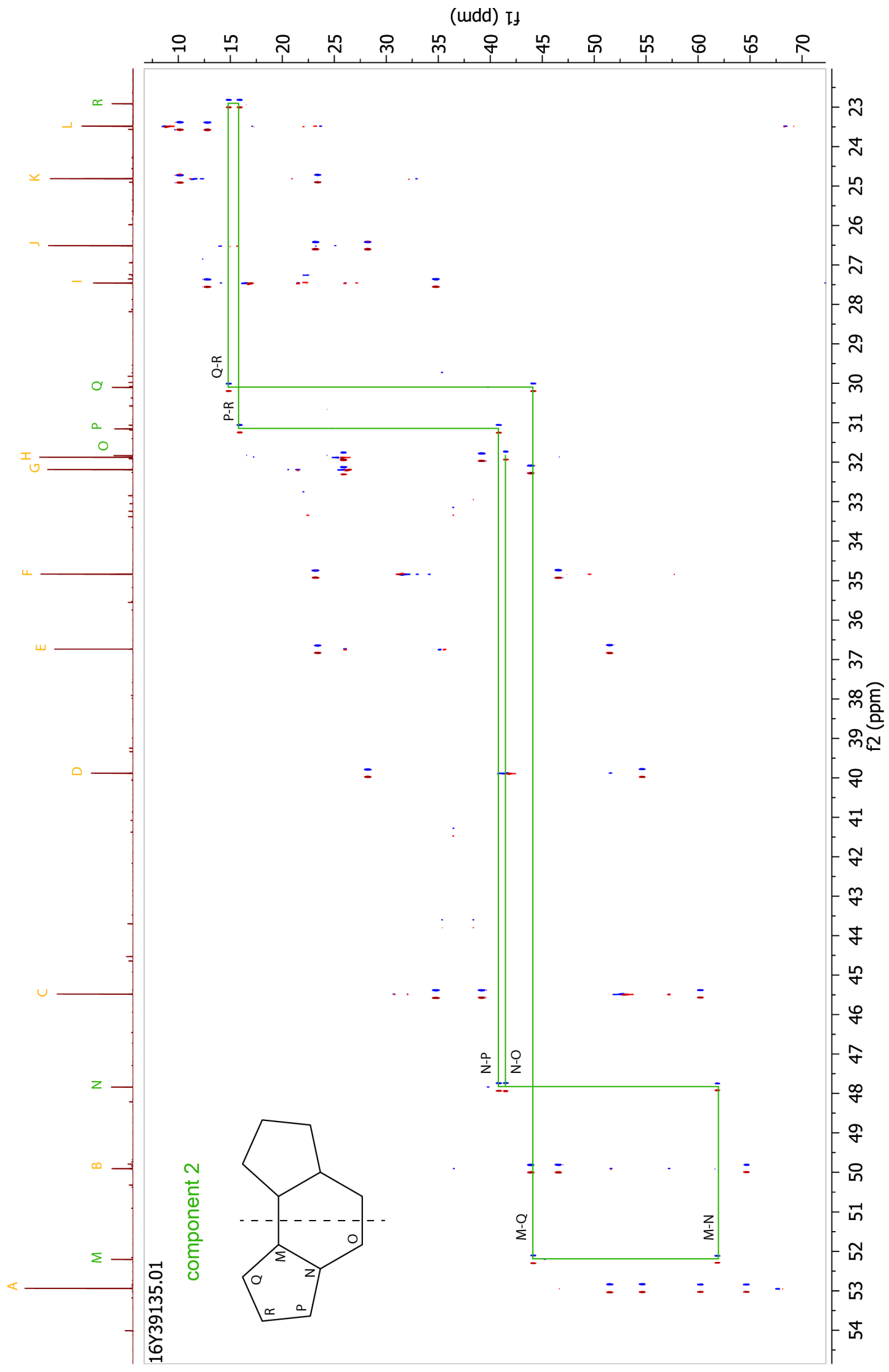

Figure S7: Fraction 6, component 2: 18 (a), ${ }^{13} \mathrm{C}-2 \mathrm{D}-\mathrm{INADEQUATE}, 176 \mathrm{MHz}, \mathrm{C}_{6} \mathrm{D}_{6}$ 


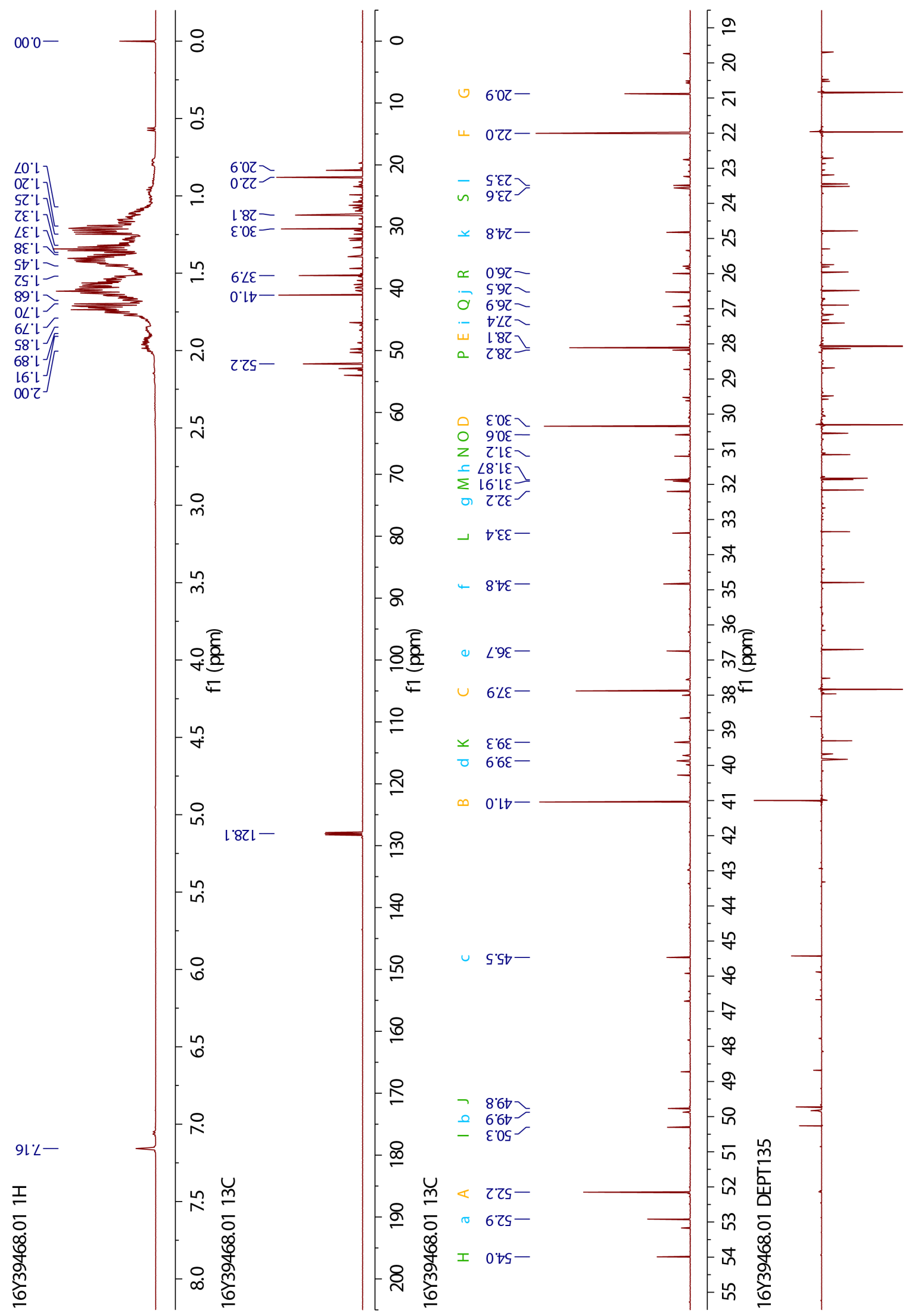

Figure S8: Fraction 15 (3 components): ${ }^{1} \mathrm{H}-\mathrm{NMR}\left(500 \mathrm{MHz}, \mathrm{C}_{6} \mathrm{D}_{6}\right)$ and ${ }^{13} \mathrm{C}-\mathrm{NMR}\left(126 \mathrm{MHz}, \mathrm{C}_{6} \mathrm{D}_{6}\right)$ 
Table S3: peak assignments for compound $\mathbf{2 6}$

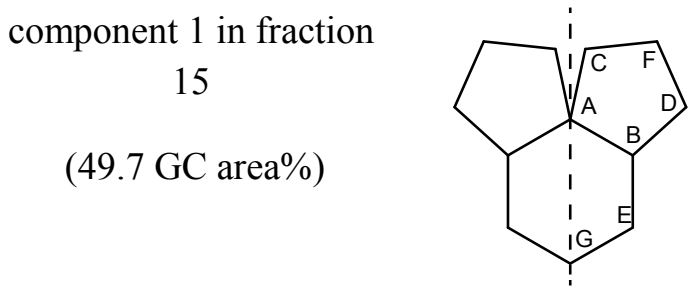

peak (d)

\begin{tabular}{|c|c|c|c|}
\hline Carbon & $\begin{array}{c}{ }^{13} \mathrm{C} \text { measured } \\
\left(126 \mathrm{MHz}, \mathrm{C}_{6} \mathrm{D}_{6}\right){ }^{*)}\end{array}$ & multiplicity & $\begin{array}{c}{ }^{13} \mathrm{C} \text { measured } \\
\left.\left(126 \mathrm{MHz}, \mathrm{CDCl}_{3}\right)^{* * *}\right)\end{array}$ \\
\hline A & 52.2 & $\mathrm{C}$ & 51.7 \\
\hline B & 41.0 & $\mathrm{CH}$ & 40.6 \\
\hline $\mathrm{C}$ & 37.9 & $\mathrm{CH}_{2}$ & 37.4 \\
\hline D & 30.3 & $\mathrm{CH}_{2}$ & 29.9 \\
\hline E & 28.1 & $\mathrm{CH}_{2}$ & 27.66 \\
\hline F & 22.0 & $\mathrm{CH}_{2}$ & 21.5 \\
\hline G & 20.9 & $\mathrm{CH}_{2}$ & 20.4 \\
\hline
\end{tabular}


Table S4: peak assignments for compound $\mathbf{2 3}$

component 2 in fraction 15

$(17.7 \mathrm{GC}$ area\%)

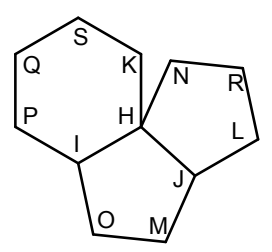

peak (c)

\begin{tabular}{|c|c|c|c|}
\hline Carbon & $\begin{array}{c}{ }^{13} \mathrm{C} \text { measured } \\
\left(126 \mathrm{MHz}, \mathrm{C}_{6} \mathrm{D}_{6}\right)^{*)}\end{array}$ & multiplicity & $\begin{array}{c}{ }^{13} \mathrm{C} \text { measured } \\
\left(126 \mathrm{MHz}, \mathrm{CDCl}_{3}\right){ }^{* *)}\end{array}$ \\
\hline$\overline{\mathrm{H}}$ & 54.0 & $\bar{C}$ & 53.6 \\
\hline I & 50.3 & $\mathrm{CH}$ & 49.9 \\
\hline $\mathrm{J}$ & 49.8 & $\mathrm{CH}$ & 49.2 \\
\hline $\mathrm{K}$ & 39.3 & $\mathrm{CH}_{2}$ & 38.9 \\
\hline $\mathrm{L}$ & 33.4 & $\mathrm{CH}_{2}$ & 32.9 \\
\hline M & 31.91 & $\mathrm{CH}_{2}$ & 31.4 \\
\hline $\mathrm{N}$ & 31.2 & $\mathrm{CH}_{2}$ & 30.8 \\
\hline $\mathrm{O}$ & 30.6 & $\mathrm{CH}_{2}$ & 30.1 \\
\hline $\mathrm{P}$ & 28.2 & $\mathrm{CH}_{2}$ & 27.72 \\
\hline Q & 26.9 & $\mathrm{CH}_{2}$ & 26.4 \\
\hline $\mathrm{R}$ & 26.0 & $\mathrm{CH}_{2}$ & 25.5 \\
\hline $\mathrm{S}$ & 23.6 & $\mathrm{CH}_{2}$ & 23.1 \\
\hline
\end{tabular}

*) assignment from ${ }^{13} \mathrm{C}-2 \mathrm{D}-\mathrm{INADEQUATE}$ spectra

**) assignment from 1D spectra

Component 3 (19.4 GC area\%; labelled as carbons a - 1) in fraction 15 corresponds to compound 22 in fraction 6. 


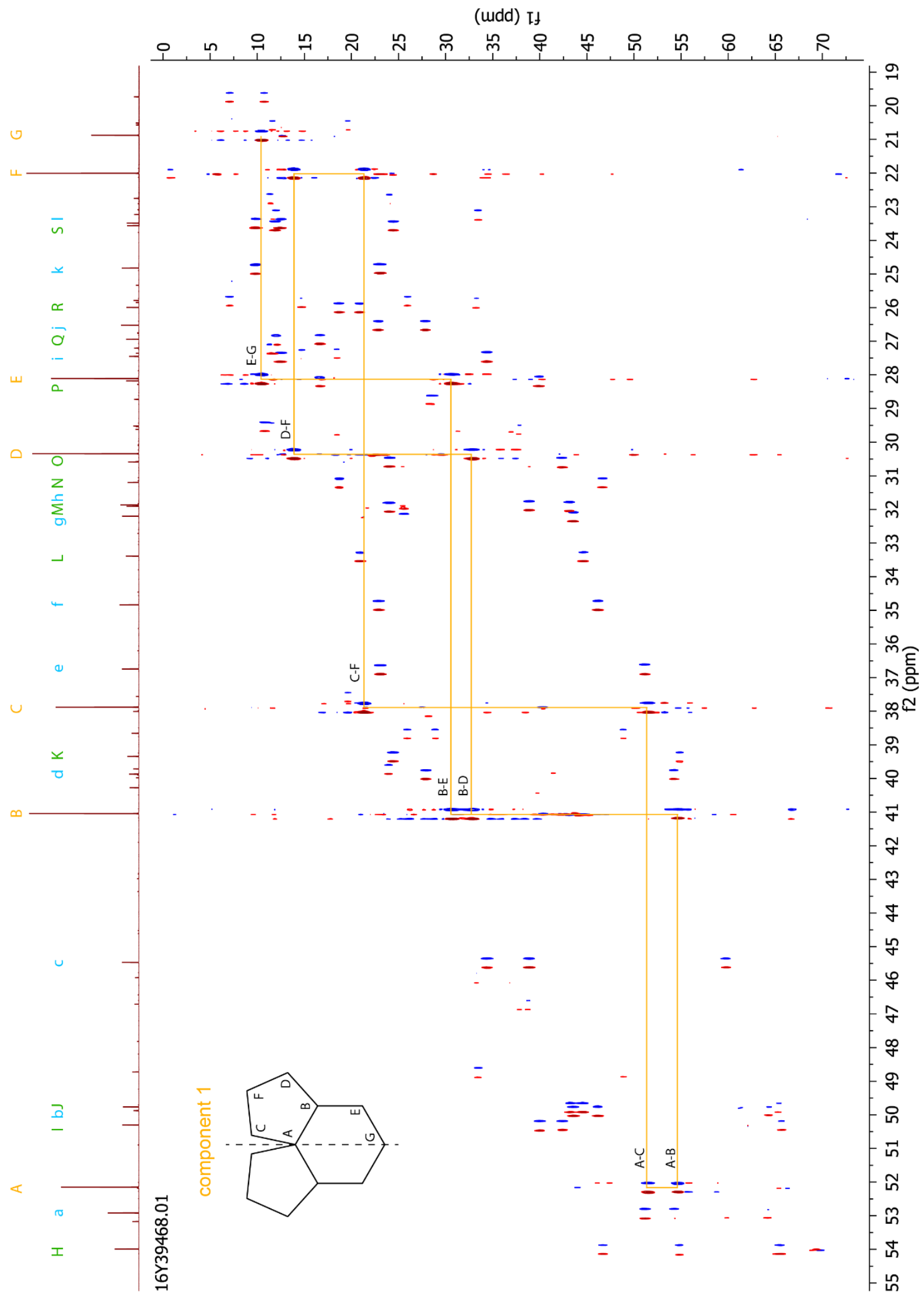

Figure S9: Fraction 15, component 1: 26 (d), ${ }^{13} \mathrm{C}-2 \mathrm{D}-\mathrm{INADEQUATE}, 126 \mathrm{MHz}, \mathrm{C}_{6} \mathrm{D}_{6}$ 


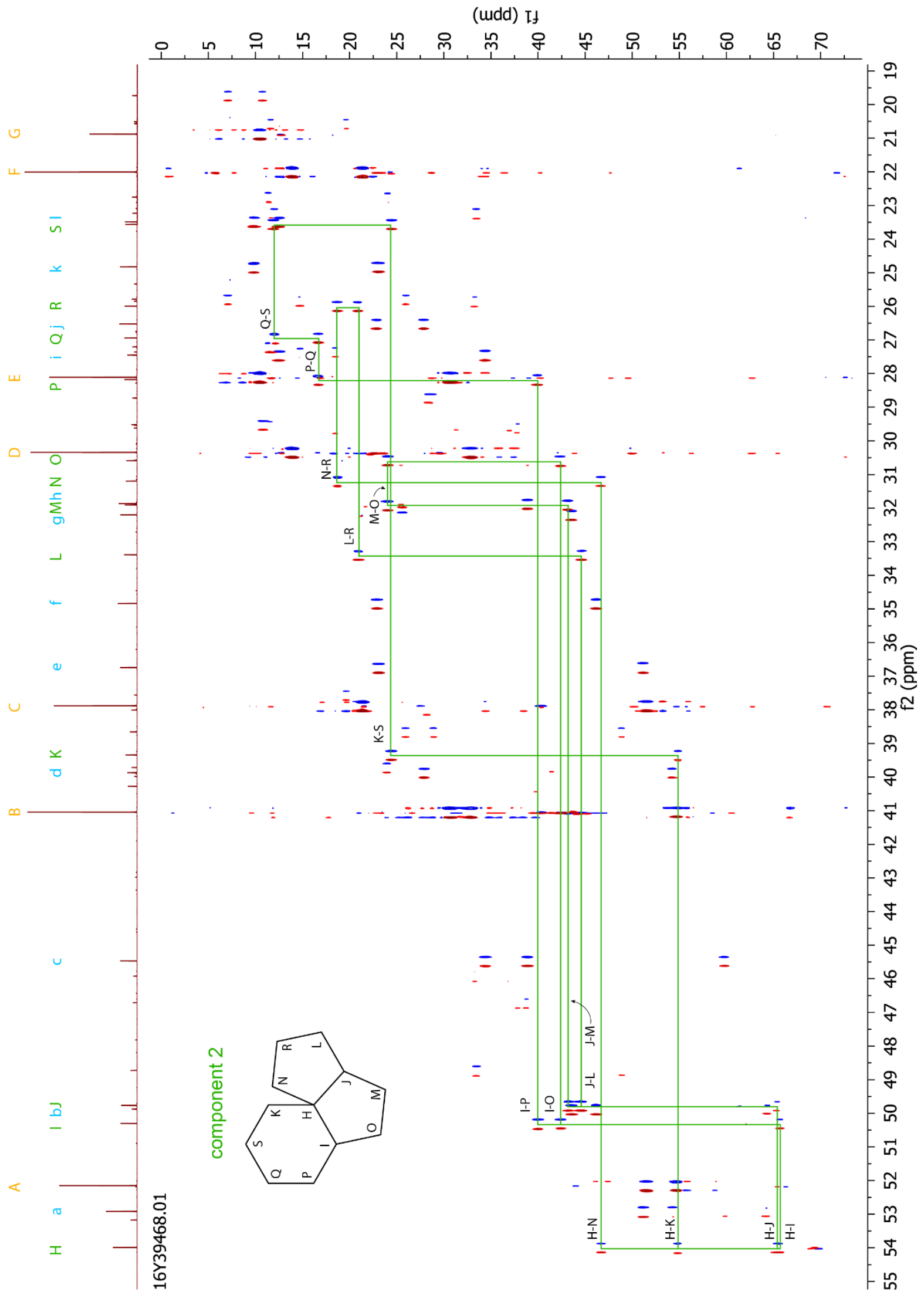

Figure S10: Fraction 15, component 2: 23 (c), ${ }^{13} \mathrm{C}-2 \mathrm{D}-\mathrm{INADEQUATE}, 126 \mathrm{MHz}, \mathrm{C}_{6} \mathrm{D}_{6}$ 


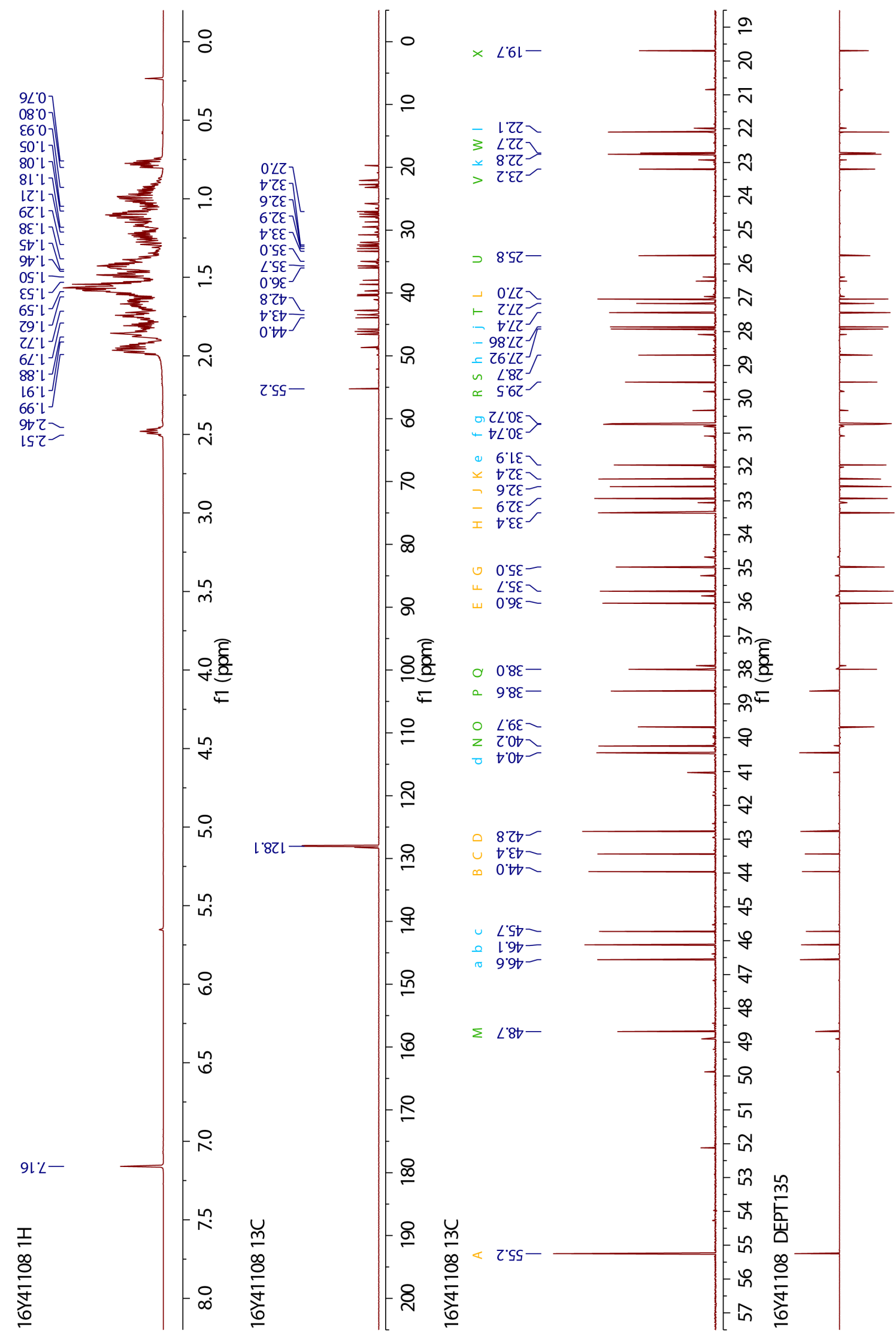

Figure S11: Fraction 29 (3 components): ${ }^{1} \mathrm{H}-\mathrm{NMR}\left(700 \mathrm{MHz}, \mathrm{C}_{6} \mathrm{D}_{6}\right)$ and ${ }^{13} \mathrm{C}-\mathrm{NMR}\left(176 \mathrm{MHz}, \mathrm{C}_{6} \mathrm{D}_{6}\right)$ 
Table S5: peak assignments for compound $\mathbf{2 7}$

component 1 in fraction 29

(31.6 GC area\%)

peak (e)

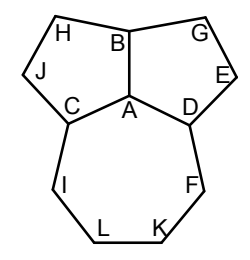

\begin{tabular}{c|cc|c}
\hline Carbon & $\begin{array}{c}{ }^{13} \mathbf{C} \text { measured } \\
\left.\left(\mathbf{1 7 6} \mathbf{M H z}, \mathbf{C}_{\mathbf{6}} \mathbf{D}_{\mathbf{6}}\right)^{*}\right)^{*}\end{array}$ & multiplicity & $\begin{array}{c}{ }^{13} \mathbf{C} \text { measured } \\
\left.\left(\mathbf{1 7 6} \mathbf{~ M H z}, \mathbf{C D C l}_{\mathbf{3}}\right)^{* *}\right)\end{array}$ \\
\hline A & 55.2 & $\mathrm{CH}$ & 54.9 \\
C & 44.0 & $\mathrm{CH}$ & 43.5 \\
D & 43.4 & $\mathrm{CH}$ & 43.0 \\
E & 42.8 & $\mathrm{CH}$ & 42.5 \\
F & 36.0 & $\mathrm{CH}_{2}$ & 35.6 \\
G & 35.7 & $\mathrm{CH}_{2}$ & 35.3 \\
H & 35.0 & $\mathrm{CH}_{2}$ & 34.6 \\
I & 33.4 & $\mathrm{CH}_{2}$ & 32.9 \\
J & 32.9 & $\mathrm{CH}_{2}$ & 32.6 \\
K & 32.6 & $\mathrm{CH}_{2}$ & 32.2 \\
L & 32.4 & $\mathrm{CH}_{2}$ & 32.0 \\
\hline
\end{tabular}


Table S6: peak assignments for compound $\mathbf{2 8}$

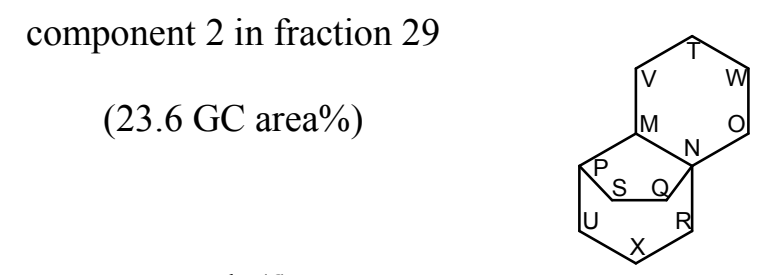

peak (f)

\begin{tabular}{c|cc|c}
\hline Carbon & $\begin{array}{c}{ }^{13} \mathbf{C} \text { measured } \\
\left(\mathbf{1 7 6} \mathbf{M H z}, \mathbf{C}_{\mathbf{6}} \mathbf{D}_{\mathbf{6}}\right)^{*}{ }^{*}\end{array}$ & multiplicity & $\begin{array}{c}{ }^{13} \mathbf{C} \text { measured } \\
\left.\left(\mathbf{1 7 6} \mathbf{M H z}, \mathbf{C D C l}_{\mathbf{3}}\right)^{* * *}\right)\end{array}$ \\
\hline \hline $\mathrm{M}$ & 48.7 & $\mathrm{CH}$ & 48.4 \\
$\mathrm{O}$ & 40.2 & $\mathrm{C}$ & 39.9 \\
$\mathrm{P}$ & 39.7 & $\mathrm{CH}_{2}$ & 39.3 \\
$\mathrm{Q}$ & 38.6 & $\mathrm{CH}$ & 38.2 \\
$\mathrm{R}$ & 38.0 & $\mathrm{CH}_{2}$ & 37.5 \\
$\mathrm{~S}$ & 29.5 & $\mathrm{CH}_{2}$ & 29.1 \\
$\mathrm{~T}$ & 28.7 & $\mathrm{CH}_{2}$ & 28.3 \\
$\mathrm{U}$ & 27.2 & $\mathrm{CH}_{2}$ & 26.8 \\
$\mathrm{~V}$ & 25.8 & $\mathrm{CH}_{2}$ & 25.4 \\
$\mathrm{~W}$ & 23.2 & $\mathrm{CH}_{2}$ & 22.8 \\
$\mathrm{X}$ & 22.7 & $\mathrm{CH}_{2}$ & 22.29 \\
\hline
\end{tabular}


Table S7: peak assignments for compound 19

component 3 in fraction 29

(36.7 GC area\%)

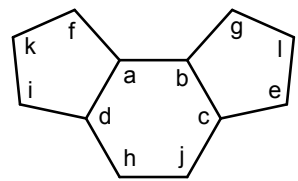

peak $(\mathbf{g})$

\begin{tabular}{|c|c|c|c|}
\hline Carbon & $\begin{array}{c}{ }^{13} \mathrm{C} \text { measured } \\
\left(176 \mathrm{MHz}, \mathrm{C}_{6} \mathrm{D}_{6}\right)^{*)}\end{array}$ & multiplicity & $\begin{array}{c}{ }^{13} \mathrm{C} \text { measured } \\
\left.\left(176 \mathrm{MHz} \mathrm{CDCl}_{3}\right) * *\right)\end{array}$ \\
\hline $\mathrm{a}$ & 46.6 & $\mathrm{CH}$ & 46.1 \\
\hline $\mathrm{b}$ & 46.1 & $\mathrm{CH}$ & 45.8 \\
\hline $\mathrm{c}$ & 45.7 & $\mathrm{CH}$ & 45.3 \\
\hline d & 40.4 & $\mathrm{CH}$ & 40.0 \\
\hline e & 31.9 & $\mathrm{CH}_{2}$ & 31.5 \\
\hline $\mathrm{f}$ & 30.74 & $\mathrm{CH}_{2}$ & 30.33 \\
\hline $\mathrm{g}$ & 30.72 & $\mathrm{CH}_{2}$ & 30.31 \\
\hline $\mathrm{h}$ & 27.92 & $\mathrm{CH}_{2}$ & 27.5 \\
\hline $\mathrm{i}$ & 27.86 & $\mathrm{CH}_{2}$ & 27.4 \\
\hline $\mathrm{j}$ & 27.4 & $\mathrm{CH}_{2}$ & 27.0 \\
\hline $\mathrm{k}$ & 22.8 & $\mathrm{CH}_{2}$ & 22.27 \\
\hline 1 & 22.1 & $\mathrm{CH}_{2}$ & 21.6 \\
\hline
\end{tabular}

*) assignment from ${ }^{13} \mathrm{C}-2 \mathrm{D}$-INADEQUATE spectra

**) assignment from 1D spectra 


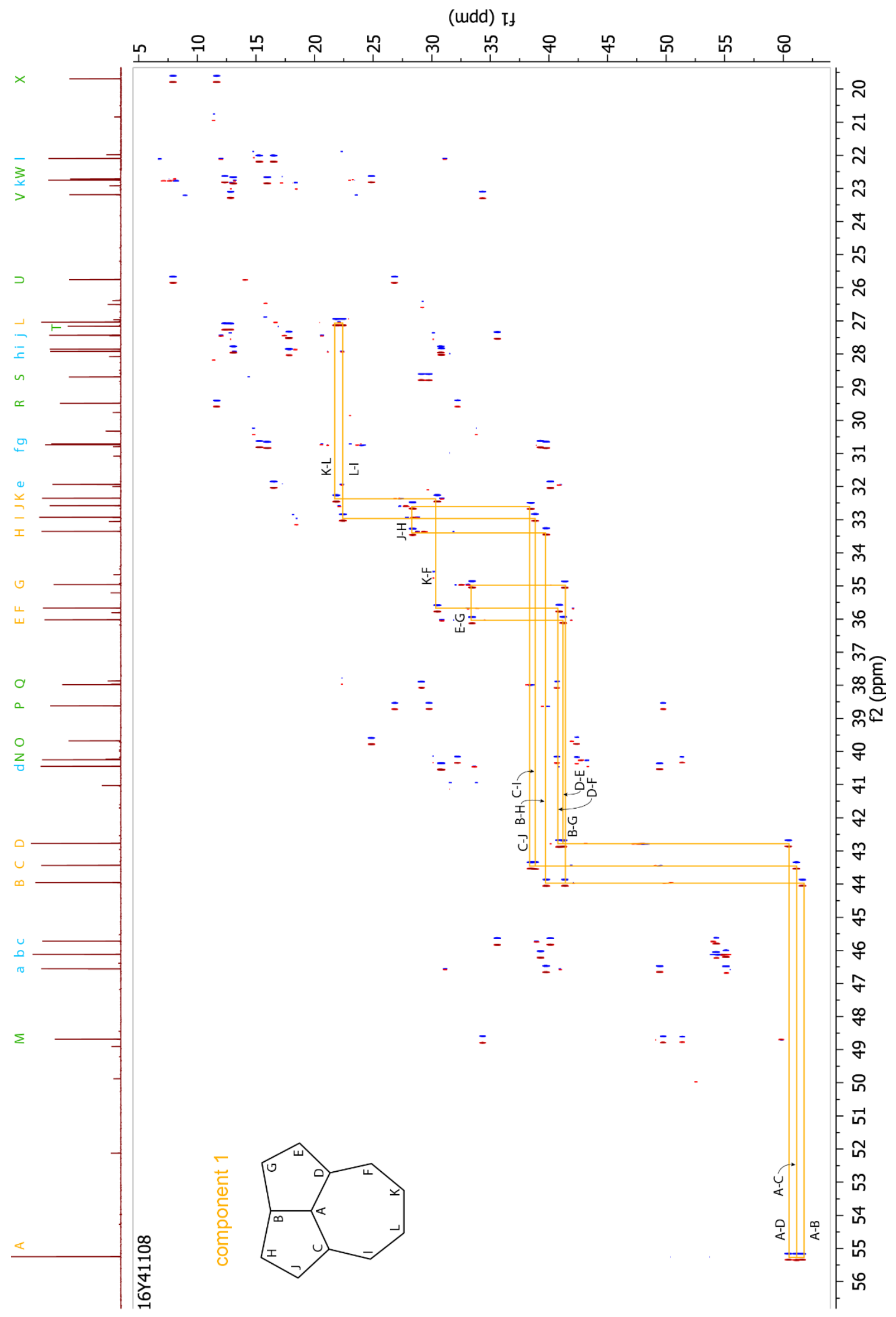

Figure S12: Fraction 29, component 1: 27 (e), ${ }^{13} \mathrm{C}-2 \mathrm{D}-\mathrm{INADEQUATE}, 176 \mathrm{MHz}, \mathrm{C}_{6} \mathrm{D}_{6}$ 


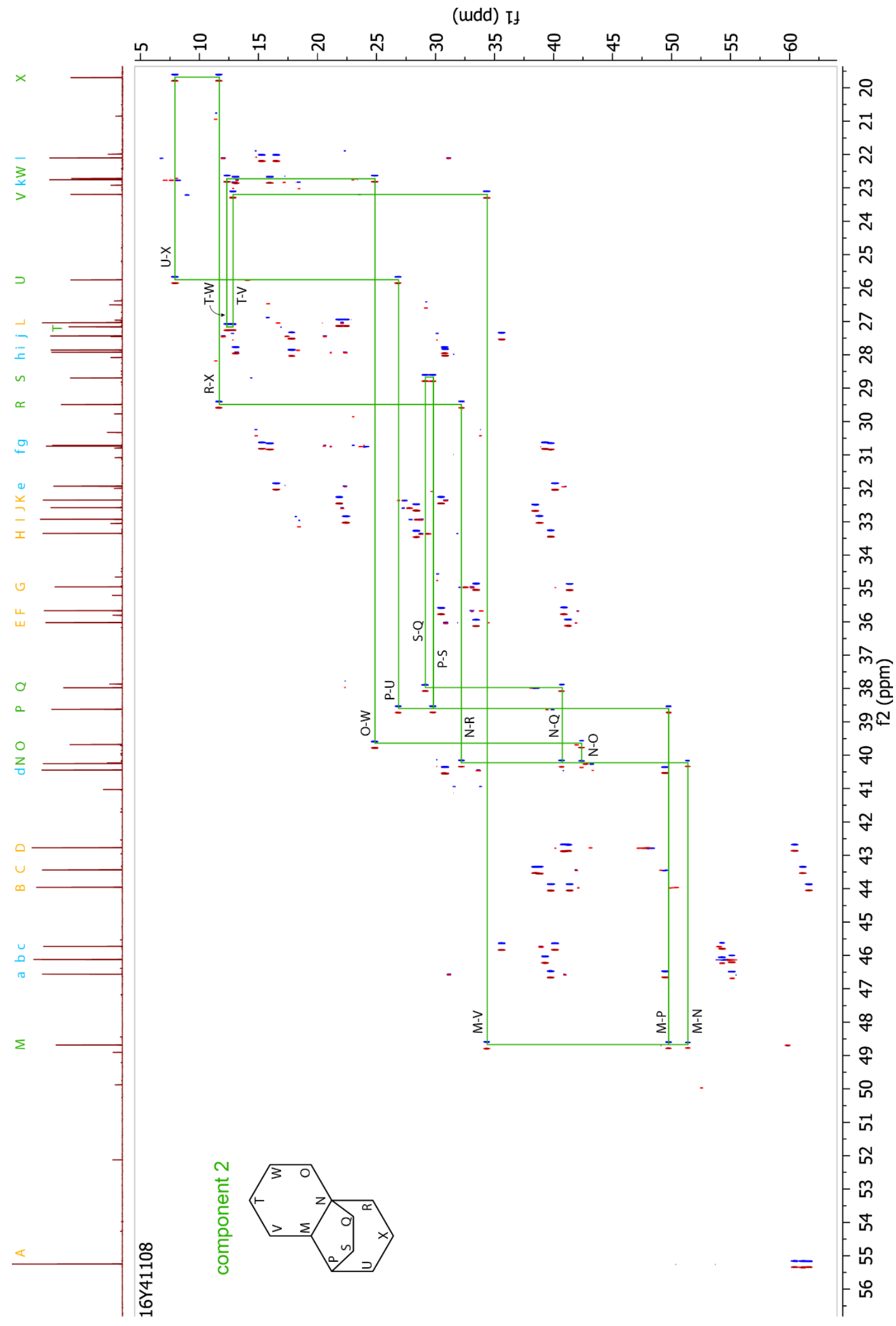

Figure S13: Fraction 29, component 2: 28 (f), ${ }^{13} \mathrm{C}-2 \mathrm{D}-\mathrm{INADEQUATE}, 176 \mathrm{MHz}, \mathrm{C}_{6} \mathrm{D}_{6}$ 


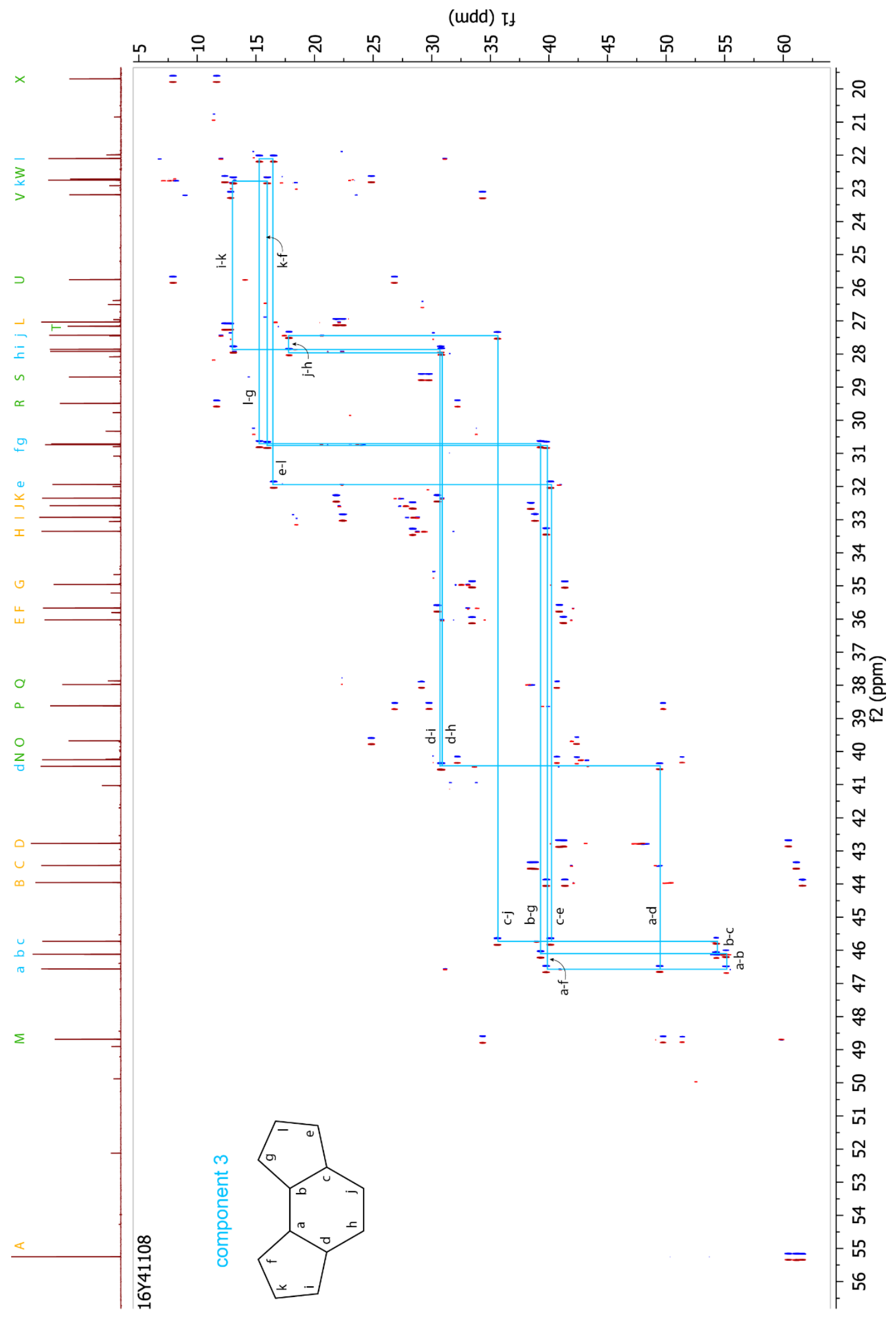

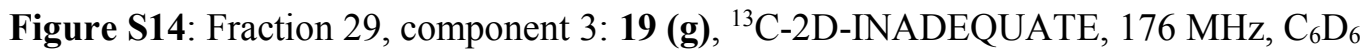




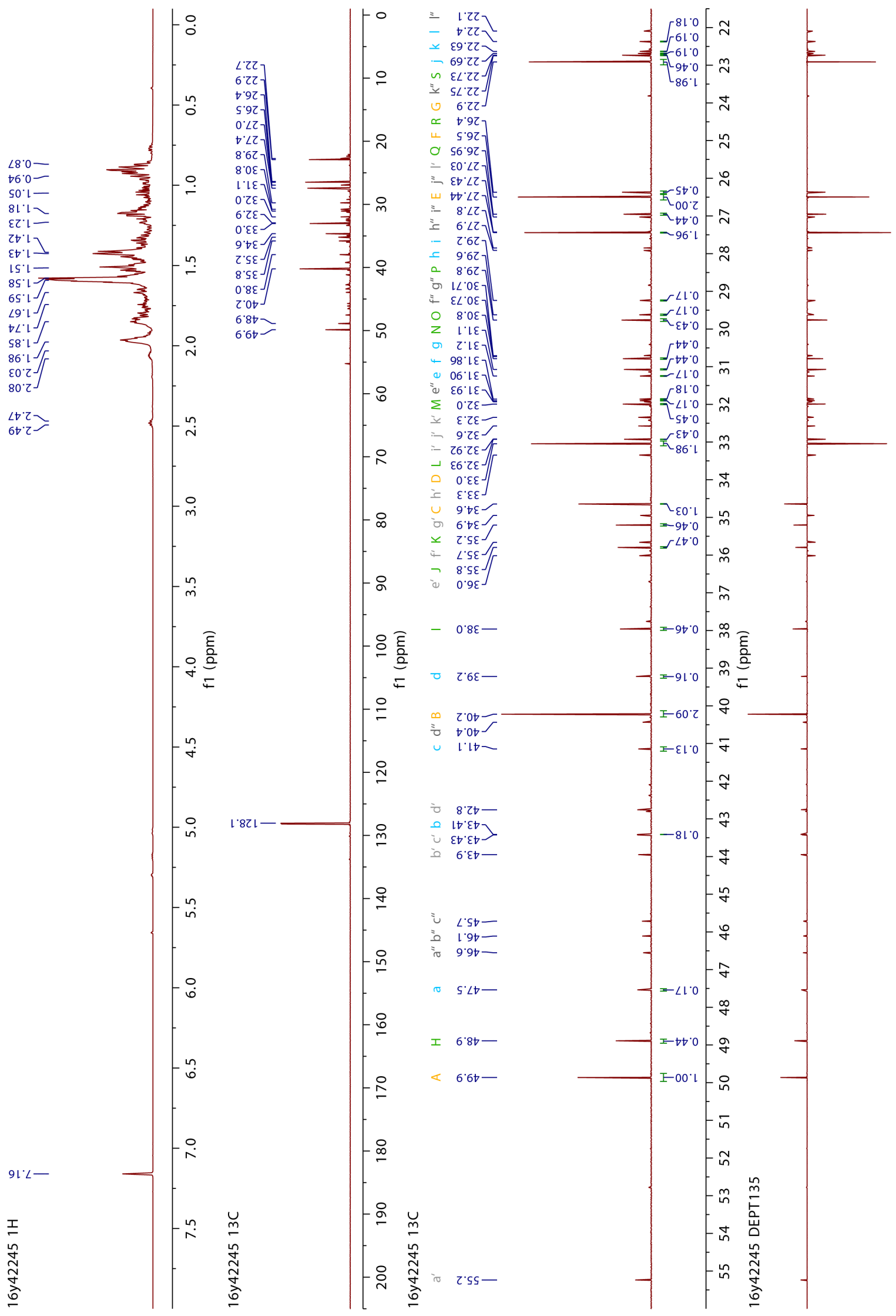

Figure S15: Fraction 40 (5 components): ${ }^{1} \mathrm{H}-\mathrm{NMR}\left(700 \mathrm{MHz}, \mathrm{C}_{6} \mathrm{D}_{6}\right)$ and ${ }^{13} \mathrm{C}-\mathrm{NMR}\left(176 \mathrm{MHz}, \mathrm{C}_{6} \mathrm{D}_{6}\right)$ 
Table S8: peak assignments for compound $\mathbf{2 5}$

component 1 in fraction 40

(56.5 GC area $\%)$

peak (i)

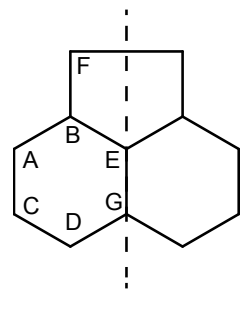

\begin{tabular}{c|cc|c}
\hline Carbon & $\begin{array}{c}{ }^{13} \mathbf{C} \text { measured } \\
\left.\left(\mathbf{1 7 6} \mathbf{~ M H z}, \mathbf{C}_{\mathbf{6}} \mathbf{D}_{\mathbf{6}}\right)^{*}\right)\end{array}$ & multiplicity & $\begin{array}{c}{ }^{13} \mathbf{C} \text { measured } \\
\left.\left(\mathbf{1 7 6} \mathbf{~ M H z}, \mathbf{C D C l}_{\mathbf{3}}\right)^{* *}\right)\end{array}$ \\
\hline \hline A & 49.9 & $\mathrm{CH}$ & 49.6 \\
B & 40.2 & $\mathrm{CH}$ & 39.8 \\
$\mathrm{C}$ & 34.6 & $\mathrm{CH}$ & 34.5 \\
D & 33.0 & $\mathrm{CH}_{2}$ & 32.7 \\
E & 27.4 & $\mathrm{CH}_{2}$ & 27.1 \\
F & 26.5 & $\mathrm{CH}_{2}$ & 26.1 \\
G & 22.9 & $\mathrm{CH}_{2}$ & 22.6 \\
\hline
\end{tabular}


Table S9: peak assignments for compound $\mathbf{2 4}$

component 2 in fraction 40

(28.7 GC area $\%$ for $\mathbf{h}^{1}+\mathbf{h}^{2}$ )

(19.1 \% for $\mathbf{h}^{\mathbf{1}}$ estimated

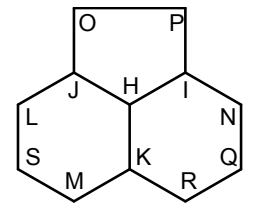

from NMR integration)

peak $\left(\mathbf{h}^{1}\right)$

\begin{tabular}{|c|c|c|c|}
\hline Carbon & $\begin{array}{c}{ }^{13} \mathrm{C} \text { measured } \\
\left.\left(176 \mathrm{MHz}, \mathrm{C}_{6} \mathrm{D}_{6}\right){ }^{*}\right)\end{array}$ & multiplicity & $\begin{array}{c}{ }^{13} \mathrm{C} \text { measured } \\
\left.\left(176 \mathrm{MHz} \mathrm{CDCl}_{3}\right){ }^{* *}\right)\end{array}$ \\
\hline $\mathrm{H}$ & 48.9 & $\overline{\mathrm{CH}}$ & 48.6 \\
\hline I & 38.0 & $\mathrm{CH}$ & 37.6 \\
\hline $\mathrm{J}$ & 35.8 & $\mathrm{CH}$ & 35.5 \\
\hline $\mathrm{K}$ & 35.2 & $\mathrm{CH}$ & 34.8 \\
\hline $\mathrm{L}$ & 32.9 & $\mathrm{CH}_{2}$ & 32.6 \\
\hline $\mathrm{M}$ & 32.0 & $\mathrm{CH}_{2}$ & 31.6 \\
\hline $\mathrm{N}$ & 31.1 & $\mathrm{CH}_{2}$ & 30.8 \\
\hline $\mathrm{O}$ & 30.8 & $\mathrm{CH}_{2}$ & 30.4 \\
\hline $\mathrm{P}$ & 29.8 & $\mathrm{CH}_{2}$ & 29.3 \\
\hline Q & 27.0 & $\mathrm{CH}_{2}$ & 26.5 \\
\hline $\mathrm{R}$ & 26.4 & $\mathrm{CH}_{2}$ & 26.1 \\
\hline $\mathrm{S}$ & 22.7 & $\mathrm{CH}_{2}$ & 22.3 \\
\hline
\end{tabular}


Table S10: peak assignments for compound 20

$$
\begin{aligned}
& \text { component } 3 \text { in fraction } 40 \\
& \text { (28.7 GC area\% for } \mathbf{h}^{1}+\mathbf{h}^{2} \text { ) } \\
& \text { (9.6 \% for } \mathbf{h}^{2} \text { estimated from } \\
& \text { NMR integration) }
\end{aligned}
$$

\begin{tabular}{|c|c|c|c|}
\hline Carbon & $\begin{array}{c}{ }^{13} \mathrm{C} \text { measured } \\
\left.\left(176 \mathrm{MHz}, \mathrm{C}_{6} \mathrm{D}_{6}\right){ }^{*}\right)\end{array}$ & multiplicity & $\begin{array}{c}{ }^{13} \mathrm{C} \text { measured } \\
\left.\left(176 \mathrm{MHz} \mathrm{CDCl}_{3}\right){ }^{* *}\right)\end{array}$ \\
\hline $\mathrm{a}$ & 47.5 & $\mathrm{CH}$ & 47.3 \\
\hline $\mathrm{b}$ & 43.4 & $\mathrm{CH}$ & 43.1 \\
\hline $\mathrm{c}$ & 41.1 & $\mathrm{CH}$ & 40.7 \\
\hline$d$ & 39.2 & $\mathrm{CH}$ & 38.9 \\
\hline e & 31.90 & $\mathrm{CH}_{2}$ & 31.51 \\
\hline $\mathrm{f}$ & 31.86 & $\mathrm{CH}_{2}$ & 31.45 \\
\hline $\mathrm{g}$ & 31.2 & $\mathrm{CH}_{2}$ & 30.9 \\
\hline $\mathrm{h}$ & 29.6 & $\mathrm{CH}_{2}$ & 29.3 \\
\hline $\mathrm{i}$ & 29.2 & $\mathrm{CH}_{2}$ & 28.8 \\
\hline $\mathrm{j}$ & 22.7 & $\mathrm{CH}_{2}$ & 22.29 \\
\hline $\mathrm{k}$ & 22.6 & $\mathrm{CH}_{2}$ & 22.27 \\
\hline 1 & 22.4 & $\mathrm{CH}_{2}$ & 21.9 \\
\hline
\end{tabular}

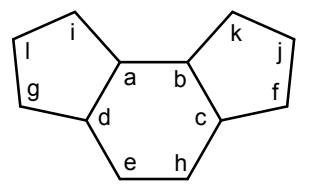

$$
\text { peak }\left(\mathbf{h}^{2}\right)
$$

*) assignment from ${ }^{13} \mathrm{C}$-2D-INADEQUATE spectra

**) assignment from 1D spectra

Fraction 40 also contained small amounts of compound 27 (peaks labelled a'-l') and of compound 19 (peaks labelled a'-1"). These compounds have been characterized in fraction 29. 


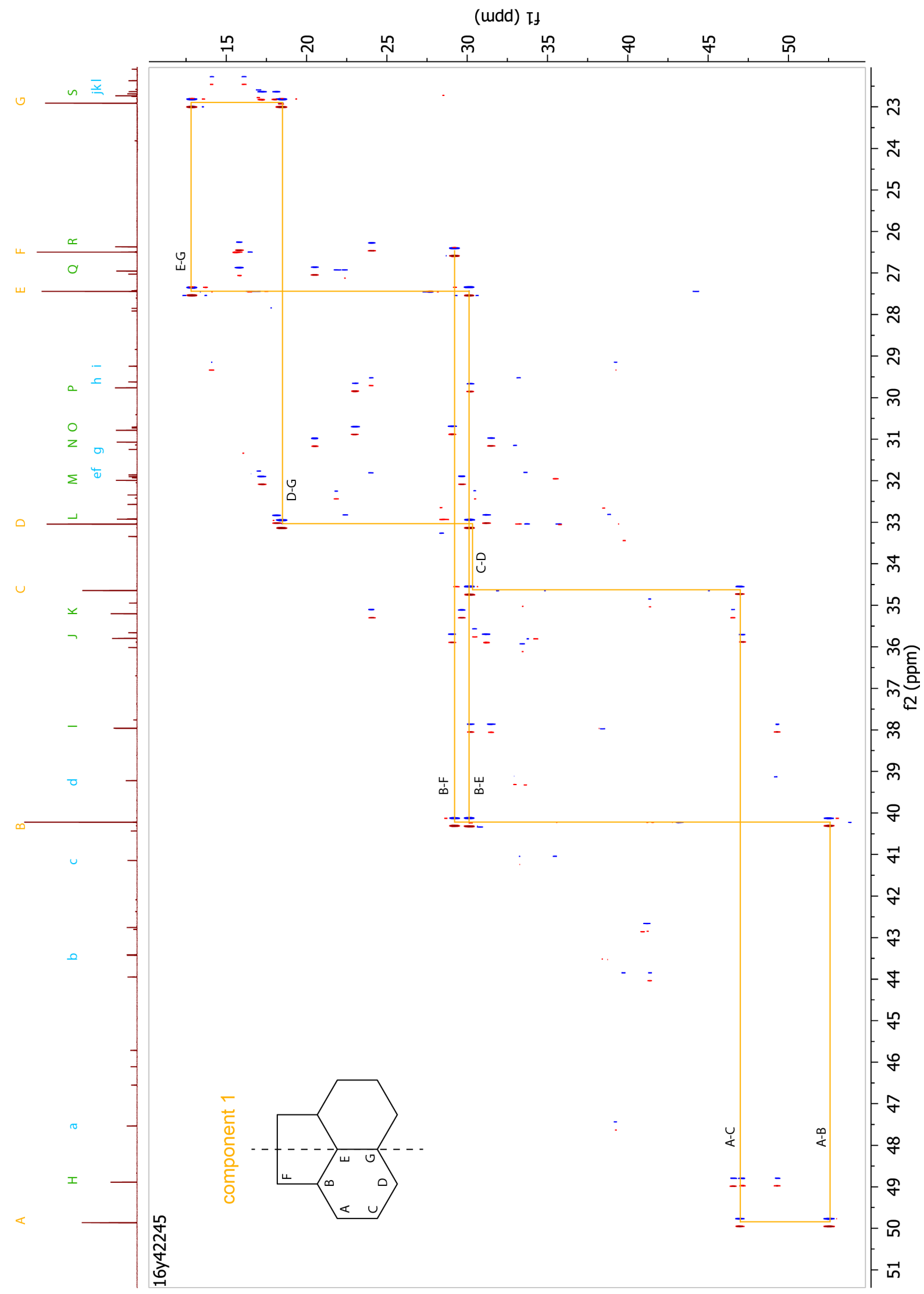

Figure S16: Fraction 40, component 1: 25 (i), ${ }^{13} \mathrm{C}-2 \mathrm{D}-\mathrm{INADEQUATE}, 176 \mathrm{MHz}, \mathrm{C}_{6} \mathrm{D}_{6}$ 


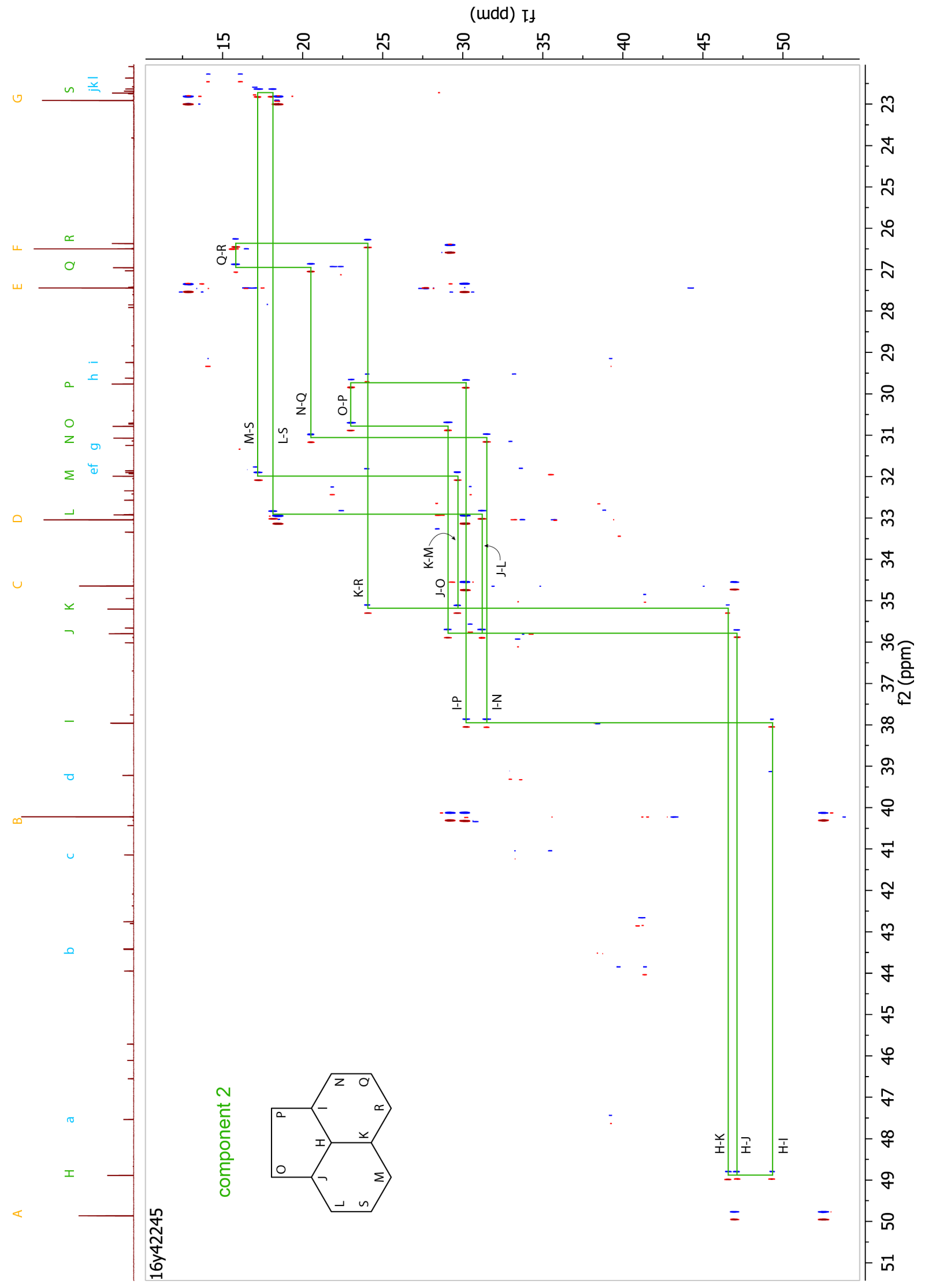

Figure S17: Fraction 40, component 2: $24\left(\mathbf{h}^{\mathbf{1}}\right),{ }^{13} \mathrm{C}-2 \mathrm{D}-\mathrm{INADEQUATE}, 176 \mathrm{MHz}, \mathrm{C}_{6} \mathrm{D}_{6}$ 


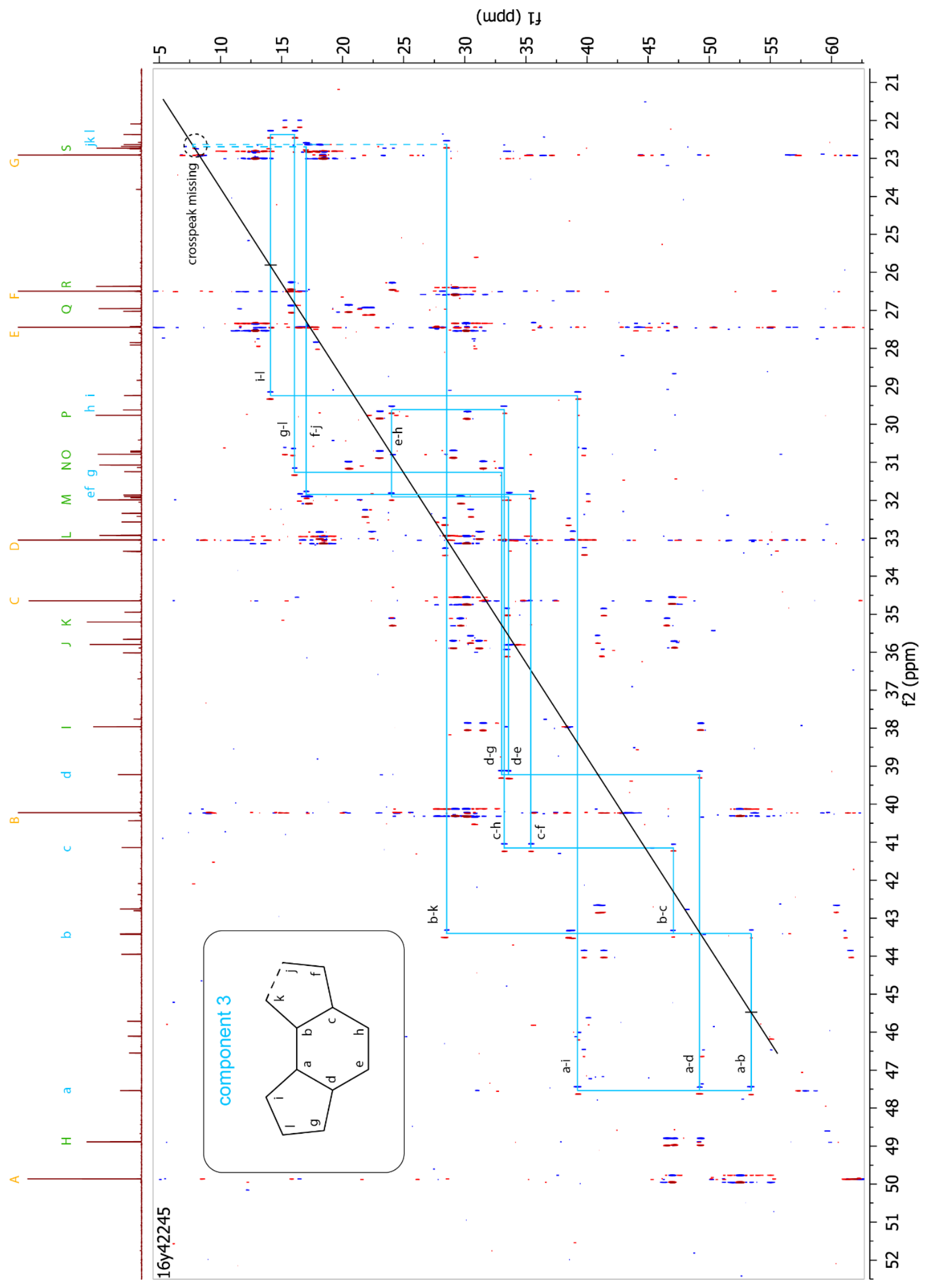

Figure S18: Fraction 40, component 3: $20\left(\mathbf{h}^{2}\right),{ }^{13} \mathrm{C}-2 \mathrm{D}-\mathrm{INADEQUATE}, 176 \mathrm{MHz}, \mathrm{C}_{6} \mathrm{D}_{6}$ 


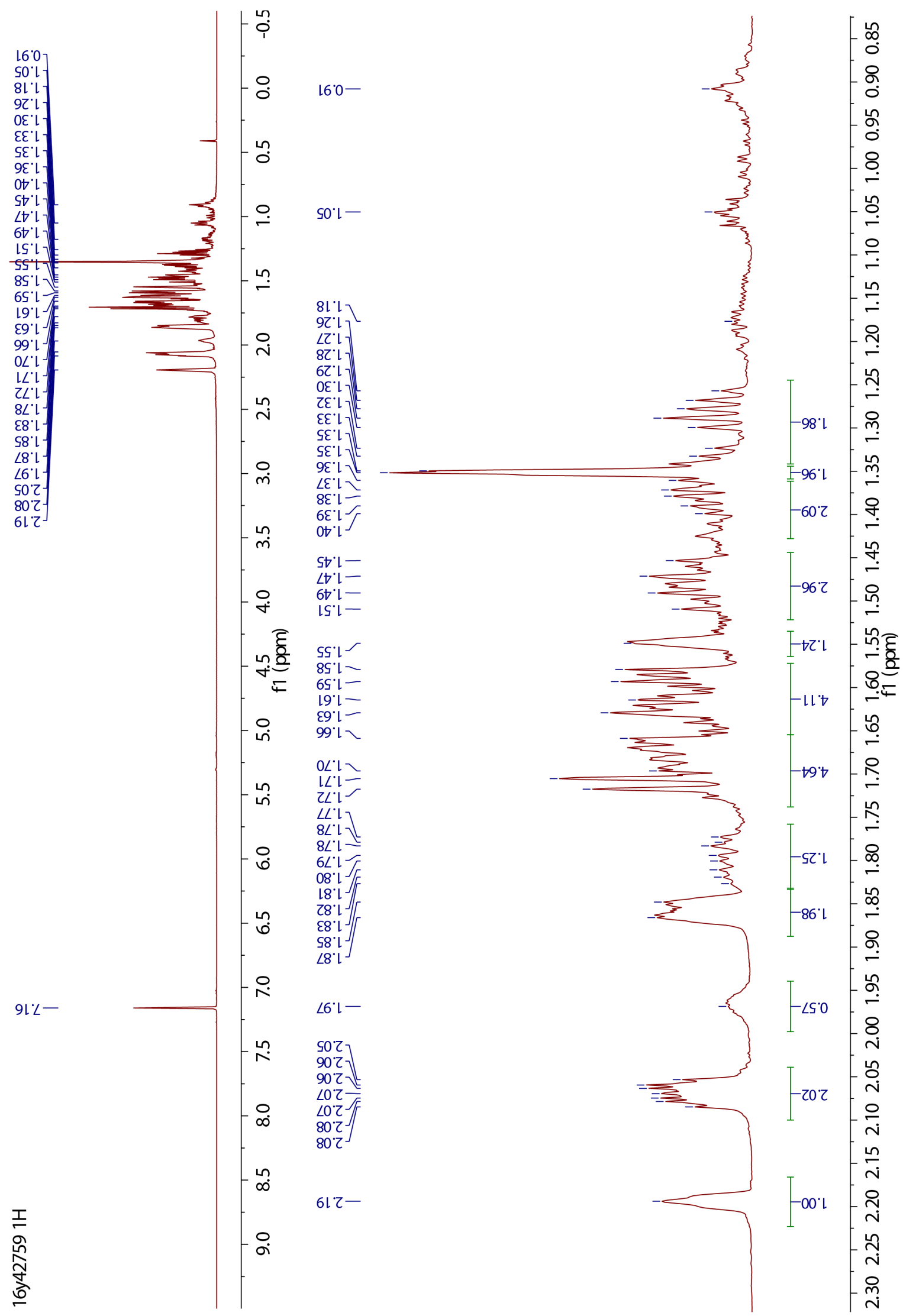

Figure S19: Fraction 50 (3 components): ${ }^{1} \mathrm{H}-\mathrm{NMR}\left(700 \mathrm{MHz}, \mathrm{C}_{6} \mathrm{D}_{6}\right)$ 


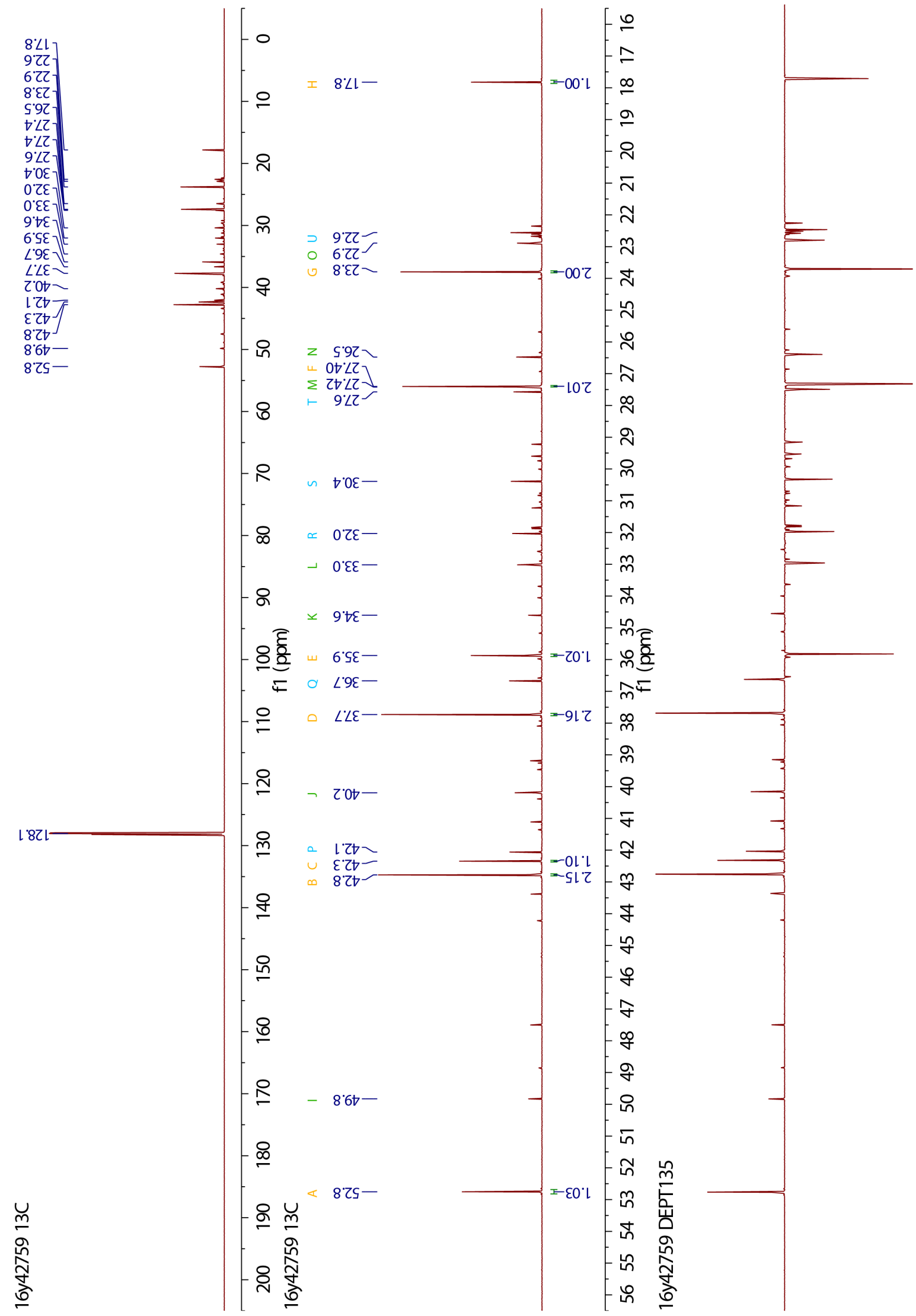

Figure S20: Fraction 50 (3 components): ${ }^{13} \mathrm{C}-\mathrm{NMR}\left(176 \mathrm{MHz}, \mathrm{C}_{6} \mathrm{D}_{6}\right)$; integration shown for component 1 
Table S11: peak assignments for compound $\mathbf{1 7}$

component 1 in fraction 50

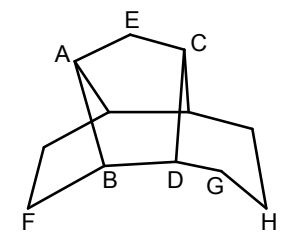

peak $(\mathbf{k})$

\begin{tabular}{|c|c|c|c|c|}
\hline Carbon & $\begin{array}{c}{ }^{13} \mathrm{C} \text { measured } \\
\left(176 \mathrm{MHz}, \mathrm{C}_{6} \mathrm{D}_{6}\right){ }^{*)}\end{array}$ & multiplicity & intensity & $\begin{array}{c}{ }^{13} \mathrm{C} \text { measured } \\
\left.\left(176 \mathrm{MHz}, \mathrm{CDCl}_{3}\right){ }^{* * *}\right)\end{array}$ \\
\hline A & 52.8 & $\mathrm{CH}$ & 1 & 52.3 \\
\hline B & 42.8 & $\mathrm{CH}$ & 2 & 42.3 \\
\hline $\mathrm{C}$ & 42.3 & $\mathrm{CH}$ & 1 & 41.9 \\
\hline $\mathrm{D}$ & 37.7 & $\mathrm{CH}$ & 2 & 37.2 \\
\hline E & 35.9 & $\mathrm{CH}_{2}$ & 1 & 35.4 \\
\hline $\mathrm{F}$ & 27.40 & $\mathrm{CH}_{2}$ & 2 & 27.0 \\
\hline $\mathrm{G}$ & 23.8 & $\mathrm{CH}_{2}$ & 2 & 23.4 \\
\hline $\mathrm{H}$ & 17.8 & $\mathrm{CH}_{2}$ & 1 & 17.3 \\
\hline
\end{tabular}

Component 2 (20.2 GC area\%; labelled as carbons I - O) in fraction 50 corresponds to compound 25 in fraction 40 . 
Table S12: peak assignments for compound 21

component 3 in fraction 50

(12.5 GC area\%)

peak (j)

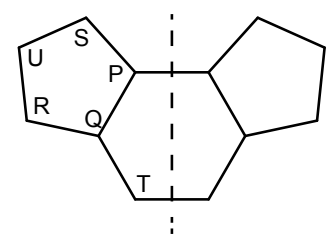

\begin{tabular}{c|cc|c}
\hline Carbon & $\begin{array}{c}{ }^{13} \mathbf{C} \text { measured } \\
\left.\left(\mathbf{1 7 6} \mathbf{~ M H z}, \mathbf{C}_{\mathbf{6}} \mathbf{D}_{\mathbf{6}}\right)^{*}\right)\end{array}$ & multiplicity & $\begin{array}{c}{ }^{13} \mathbf{C} \text { measured } \\
\left.\left(\mathbf{1 7 6} \mathbf{~ M H z}, \mathbf{C D C l}_{\mathbf{3}}\right)^{* *}\right)\end{array}$ \\
\hline $\mathrm{P}$ & 42.1 & $\mathrm{CH}$ & 41.7 \\
$\mathrm{Q}$ & 36.7 & $\mathrm{CH}$ & 36.3 \\
$\mathrm{R}$ & 32.0 & $\mathrm{CH}_{2}$ & 31.6 \\
$\mathrm{~T}$ & 30.4 & $\mathrm{CH}_{2}$ & 30.0 \\
$\mathrm{~T}$ & 27.6 & $\mathrm{CH}_{2}$ & 27.2 \\
\hline
\end{tabular}

*) assignment from ${ }^{13} \mathrm{C}-2 \mathrm{D}$-INADEQUATE spectra

**) assignment from 1D spectra 


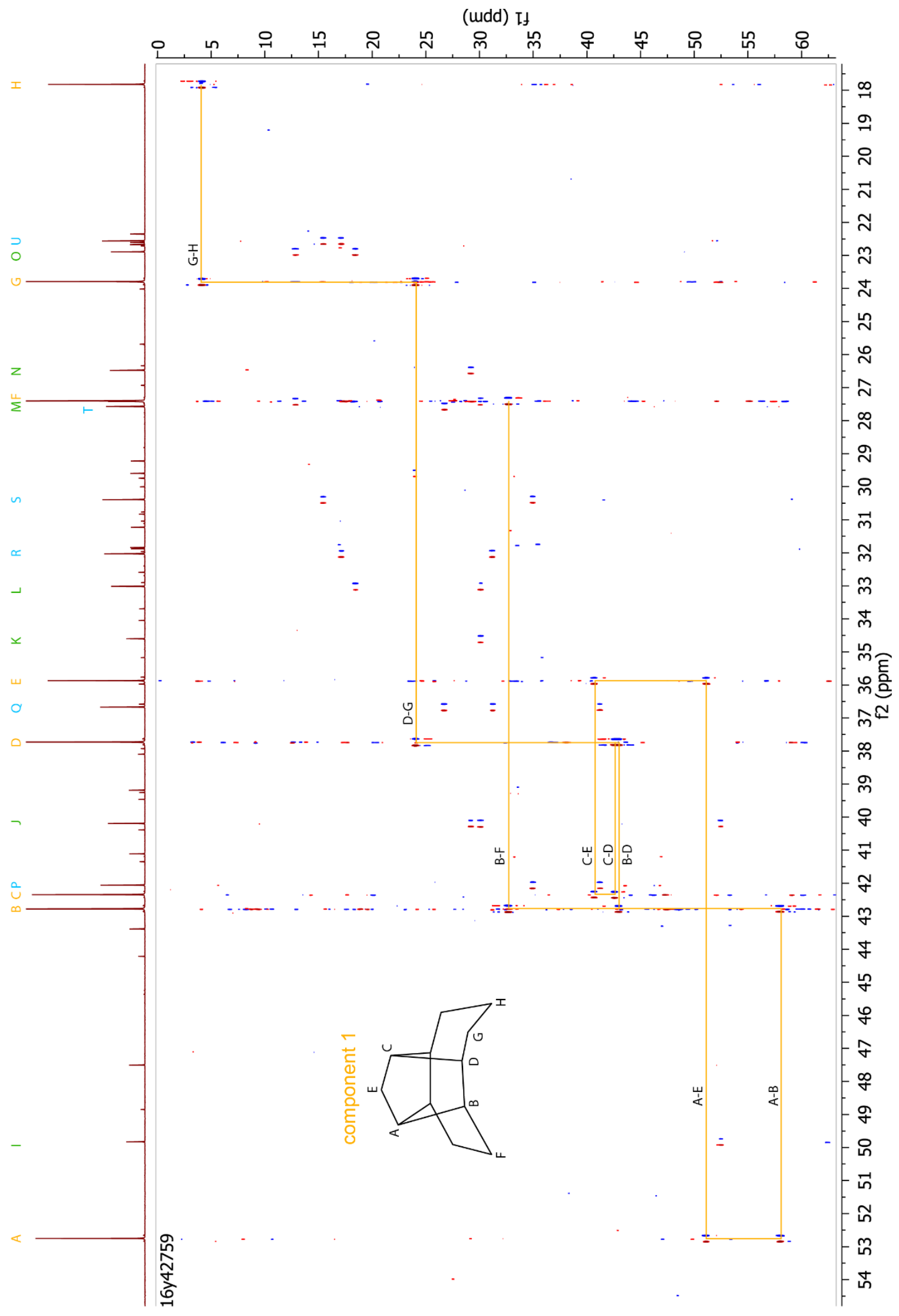

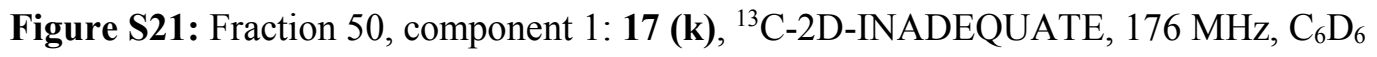




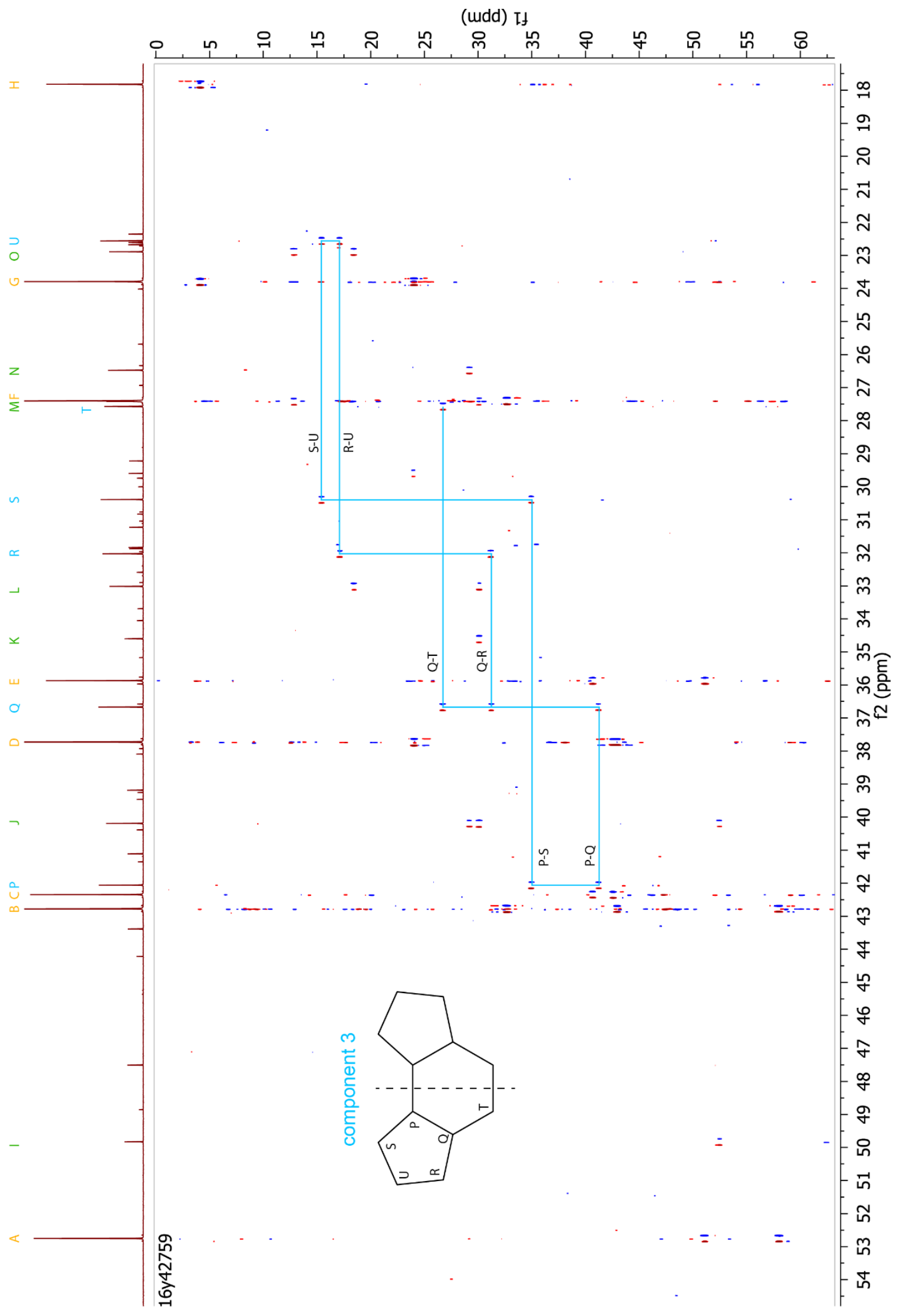

Figure S22: Fraction 50, component 3: 21 (j), ${ }^{13} \mathrm{C}-2 \mathrm{D}-\mathrm{INADEQUATE}, 176 \mathrm{MHz}, \mathrm{C}_{6} \mathrm{D}_{6}$ 


\section{Computed ${ }^{13} \mathrm{C}-\mathrm{NMR}$ spectra and energies of possible isomers}

\subsection{Short description of computational methods used (for more details see section 10):}

- Conformational analysis: modified Monte-Carlo search routine implemented in MacroModel, OPLS-2015 force field, energy cut-off $20 \mathrm{kcal} \cdot \mathrm{mol}^{-1}$, RMSD $0.5 \AA$

- Optimization: M06-2X-D3/6-31+G(d,p) in $\mathrm{C}_{6} \mathrm{H}_{6}$ or $\mathrm{CHCl}_{3}$

- Energy Calculation: M06-2X-D3/def2-QZVP in $\mathrm{C}_{6} \mathrm{H}_{6}$ or $\mathrm{CHCl}_{3}$

- NMR Calculation (all relative to TMS): B3LYP-D3BJ/6-311+G(2d,p) in $\mathrm{C}_{6} \mathrm{H}_{6}$ or $\mathrm{CHCl}_{3}$

- Boltzmann-averaged ensembles are used throughout this study

- Energies are given in $\mathrm{kcal} \cdot \mathrm{mol}^{-1}$

- The procedure used here follows the procedure recommended by Willoughby, P. H.; Jansma, M. J.; Hoye, T. R. A guide to small-molecule structure assignment through computation of $\left({ }^{1} \mathrm{H}\right.$ and $\left.{ }^{13} \mathrm{C}\right) \mathrm{NMR}$ chemical shifts. Nat. Protocols 2014, 9, 643-660

\subsection{Structures, relative energies and calculated ${ }^{13} \mathrm{C}-\mathrm{NMR}$-shifts for $\mathrm{C}_{12} \mathrm{H}_{20}$ isomers}

Energies are relative to the most stable isomer, $r e l-(2 \mathrm{aR}, 5 \mathrm{a} \alpha, 8 \mathrm{aS}, 8 \mathrm{~b} \beta)$-dodecahydro-acenaphthylene. All the calculated ${ }^{13} \mathrm{C}$-NMR shifts are relative to TMS.

\subsubsection{Perhydro-as-indacenes}

Table S13: Structures, relative energies and calculated ${ }^{13} \mathrm{C}-\mathrm{NMR}$-shifts for perhydro-as-indacenes

\begin{tabular}{|c|c|c|c|}
\hline Structure & $\begin{array}{l}\text { Relative energy in } \\
\mathrm{d}_{6} \text {-benzene / } \\
\mathrm{CDCl}_{3} \\
\mathrm{kcal} \cdot \mathrm{mol}^{-1}\end{array}$ & $\begin{array}{l}\text { Computed }{ }^{13} \mathrm{C} \text {-NMR shifts } \\
\text { in } \mathrm{d}_{6} \text {-benzene } \\
\text { ppm }\end{array}$ & $\begin{array}{l}\text { Computed }{ }^{13} \mathrm{C} \text {-NMR shifts in } \\
\mathrm{CDCl}_{3} \\
\text { ppm }\end{array}$ \\
\hline & $+8.0 /+8.0$ & $\begin{array}{l}\text { Molecule is symmetric on the NMR } \\
\text { time scale. The averaged shifts are as } \\
\text { follows: }\end{array}$ & $\begin{array}{l}\text { Molecule is symmetric on the NMR time } \\
\text { scale. The averaged shifts are as follows: }\end{array}$ \\
\hline
\end{tabular}




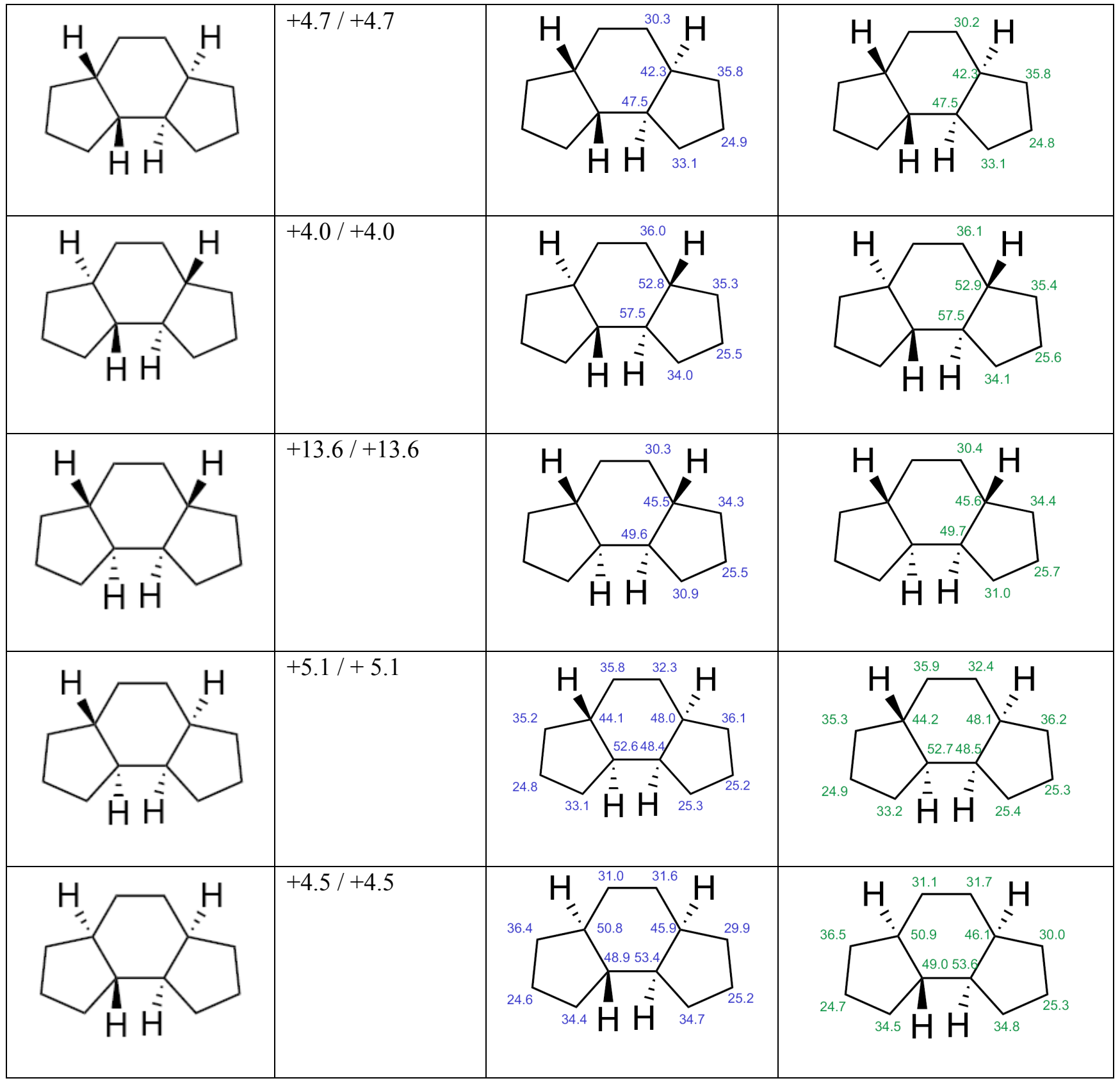




\subsubsection{Decahydro- $1 H$-cyclopent $[c]$ indenes}

Table S14: Structures, relative energies and calculated ${ }^{13} \mathrm{C}$-NMR-shifts for decahydro- $1 H$-cyclopent $[c]$ indenes

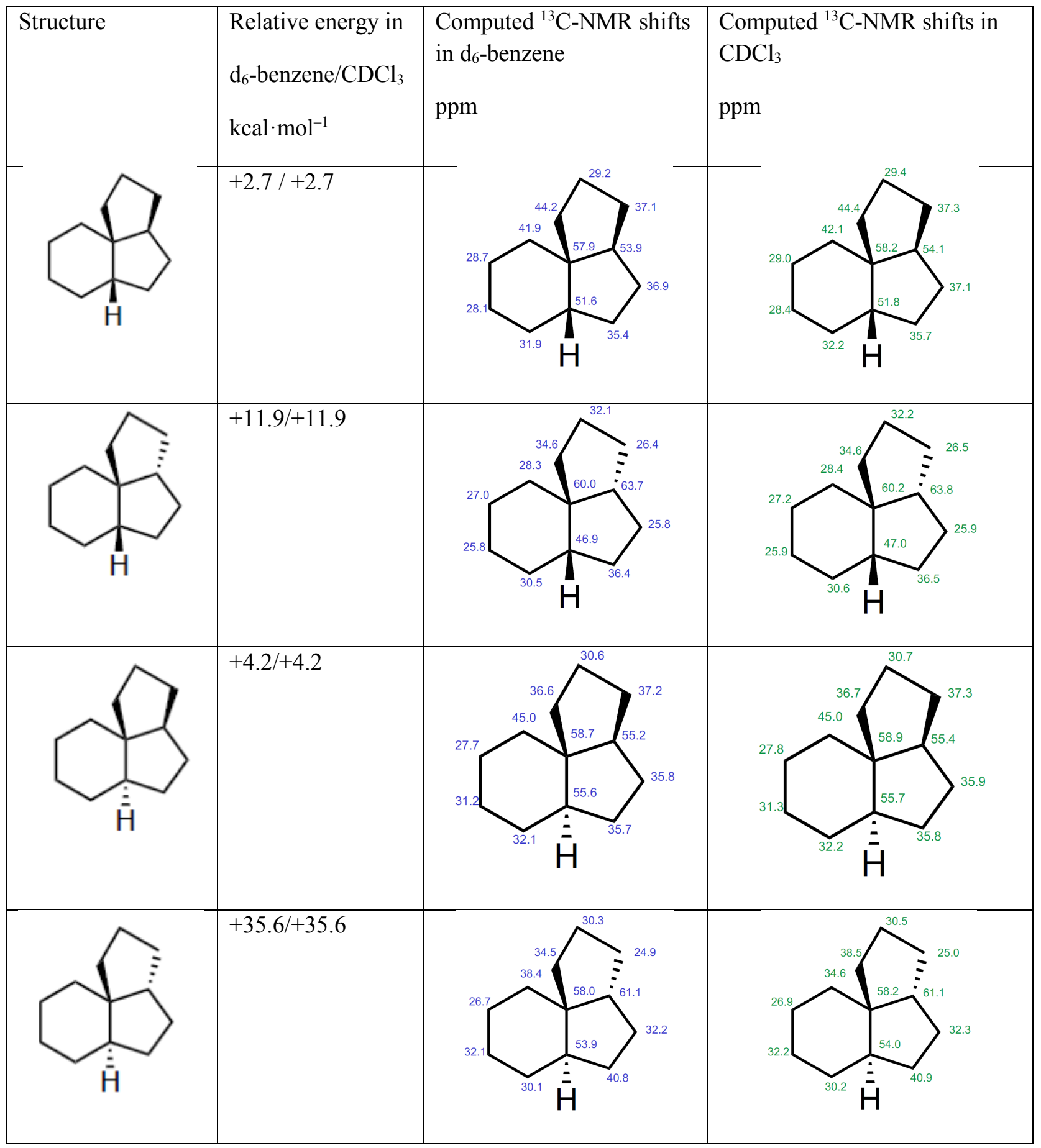




\subsubsection{Decahydro- $1 H$-cyclopent $[d]$ indenes}

Table S15: Structures, relative energies and calculated ${ }^{13} \mathrm{C}$-NMR-shifts for decahydro- $1 H$-cyclopent $[d]$ indenes

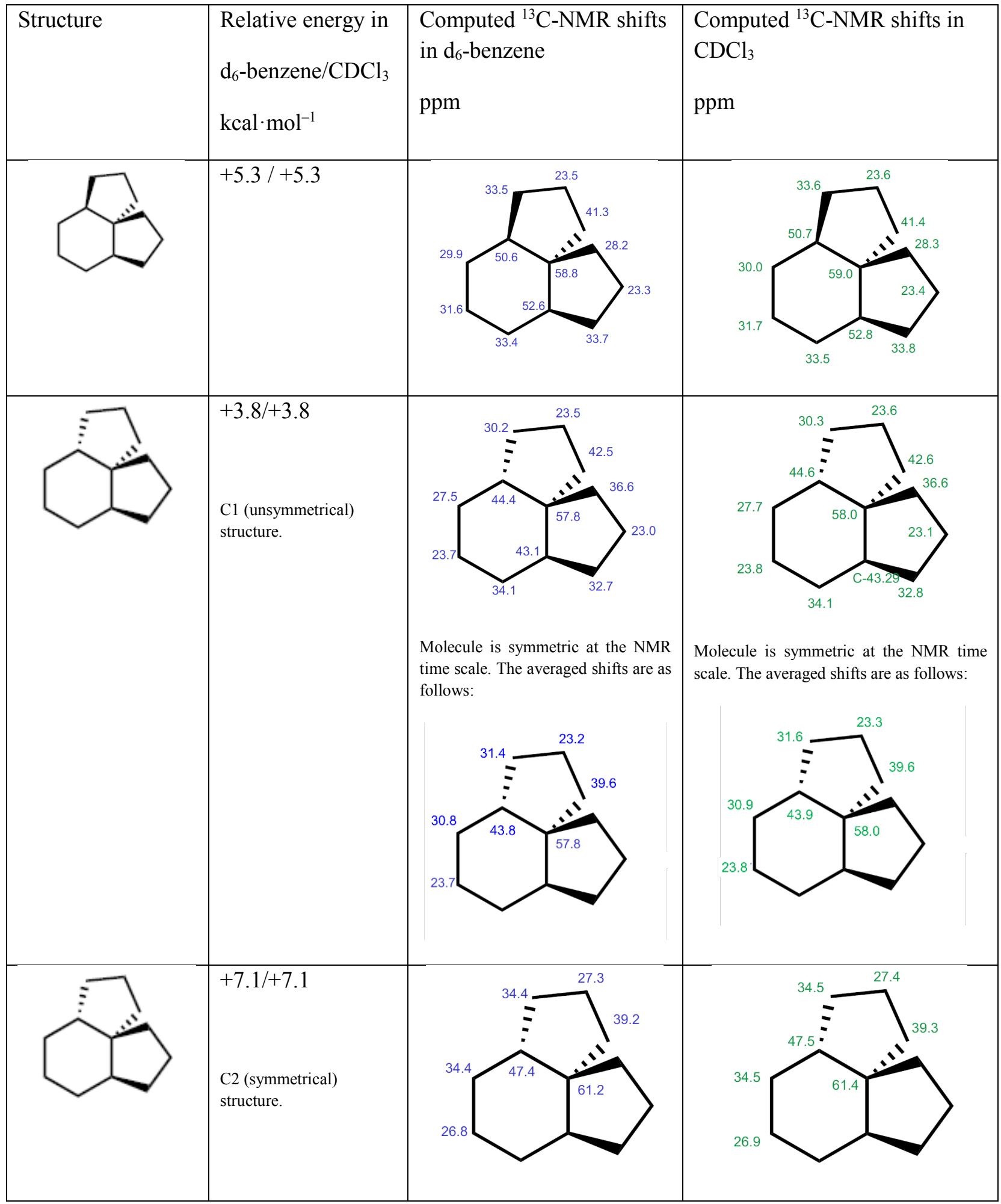




\subsubsection{Dodecahydro-cyclopent $[c d]$ azulenes}

Table S16: Structures, relative energies and calculated ${ }^{13} \mathrm{C}-\mathrm{NMR}$-shifts for dodecahydro-cyclopent $[c d]$ azulenes

\begin{tabular}{|c|c|c|c|}
\hline Structure & $\begin{array}{l}\text { Relative energy in } \\
\mathrm{d}_{6} \text {-benzene } / \mathrm{CDCl}_{3} \\
\mathrm{kcal} \cdot \mathrm{mol}^{-1}\end{array}$ & $\begin{array}{l}\text { Computed }{ }^{13} \mathrm{C} \text {-NMR shifts } \\
\text { in } \mathrm{d}_{6} \text {-benzene } \\
\text { ppm }\end{array}$ & $\begin{array}{l}\text { Computed }{ }^{13} \mathrm{C}-\mathrm{NMR} \text { shifts in } \\
\mathrm{CDCl}_{3} \\
\text { ppm }\end{array}$ \\
\hline & $+8.5 /+8.5$ & $\underbrace{37.1}_{\vdots 5.4}$ & $\underbrace{50}_{50.5}$ \\
\hline & $+4.7 /+4.7$ & $\underbrace{39.9}$ & $\begin{array}{l}47.8 \\
40.0\end{array}$ \\
\hline 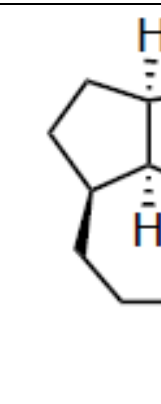 & $+8.6 /+8.5$ & $\overbrace{31.7}^{38.6}$ & $\overbrace{51.4}^{38.7}$ \\
\hline
\end{tabular}




\subsubsection{Perhydro-2H-1,4a-ethanonaphthalenes}

Table S17: Structures, relative energies and calculated ${ }^{13} \mathrm{C}-\mathrm{NMR}$-shifts for perhydro- $2 \mathrm{H}-1,4 \mathrm{a}-\mathrm{ethano-}$ naphthalenes

\begin{tabular}{|c|c|c|c|}
\hline Structure & $\begin{array}{l}\text { Relative energy in } \\
\mathrm{d}_{6} \text {-benzene } / \mathrm{CDCl}_{3} \\
\mathrm{kcal} \cdot \mathrm{mol}^{-1}\end{array}$ & $\begin{array}{l}\text { Computed }{ }^{13} \mathrm{C} \text {-NMR shifts } \\
\text { in } \mathrm{d}_{6} \text {-benzene } \\
\text { ppm }\end{array}$ & $\begin{array}{l}\text { Computed }{ }^{13} \mathrm{C}-\mathrm{NMR} \text { shifts in } \\
\mathrm{CDCl}_{3} \\
\text { ppm }\end{array}$ \\
\hline & $+0.1 /+0.1$ & & 38.6 \\
\hline & $+2.8 /+2.8$ & 31.7 & 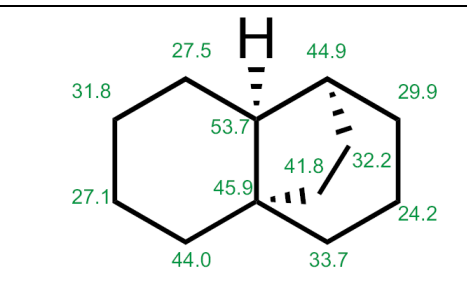 \\
\hline
\end{tabular}




\subsubsection{Perhydro-acenaphthylenes (Ufolanes)}

Table S18: Structures, relative energies and calculated ${ }^{13} \mathrm{C}-\mathrm{NMR}$-shifts for perhydro-acenaphthylenes (Ufolanes)

\begin{tabular}{|c|c|c|c|}
\hline Structure & $\begin{array}{l}\text { Relative energy in } \\
\mathrm{d}_{6} \text {-benzene } / \mathrm{CDCl}_{3} \\
\mathrm{kcal} \cdot \mathrm{mol}^{-1}\end{array}$ & $\begin{array}{l}\text { Computed }{ }^{13} \mathrm{C} \text {-NMR shifts } \\
\text { in } \mathrm{d}_{6} \text {-benzene } \\
\text { ppm }\end{array}$ & $\begin{array}{l}\text { Computed }{ }^{13} \mathrm{C} \text {-NMR shifts in } \\
\mathrm{CDCl}_{3} \\
\text { ppm }\end{array}$ \\
\hline $\mathrm{H}$ & $+0.6 /+0.6$ & $\overbrace{32.6}^{30.5}$ & (10) \\
\hline & $+4.5 /+4.5$ & $\mathrm{H}^{\prime \prime} \underbrace{}_{36.9} \mathrm{H}{ }_{38.0}$ & $H^{\prime \prime} \bigsqcup_{37.0}$ \\
\hline & $0.0 / 0.0$ & $\mathrm{H}_{37.6}$ & \\
\hline $\mathrm{H}$ & $+0.7 /+0.7$ & 29.7 & r \\
\hline$H^{\prime \prime \prime}$ & $+5.2 /+5.2$ & $29.1 \underbrace{22.0}_{35.8}$ & 29.3 \\
\hline
\end{tabular}




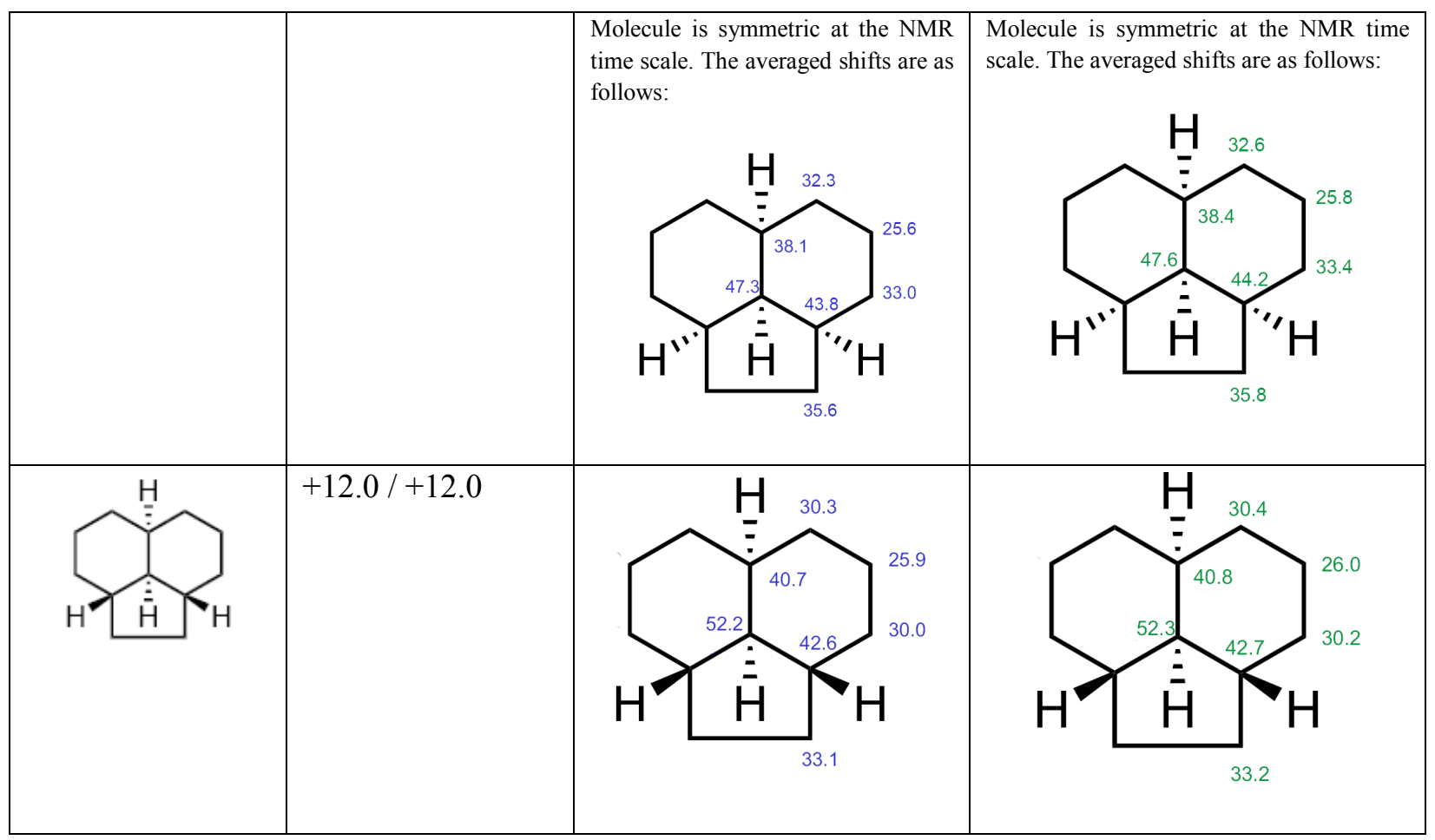




\subsection{Structures, relative energies and calculated ${ }^{13} \mathrm{C}$-NMR-shifts for $\mathrm{C}_{12} \mathrm{H}_{18}$ isomers}

Shown are all the possible $\mathrm{C}_{12} \mathrm{H}_{18}$ isomers that do not contain small rings and have the same symmetry as compound 17. Energies are relative to cis,trans,trans-1,5,9-cyclododecatriene. All the calculated ${ }^{13} \mathrm{C}-\mathrm{NMR}$ shifts are relative to TMS.

\subsubsection{Tetracyclic $\mathrm{C}_{12} \mathrm{H}_{18}$ isomers with the same symmetry as 17}

Table S19: Structures, relative energies and calculated ${ }^{13} \mathrm{C}-\mathrm{NMR}$-shifts for tetracyclic $\mathrm{C}_{12} \mathrm{H}_{18}$ isomers with the same symmetry as $\mathbf{1 7}$

\begin{tabular}{|c|c|c|c|}
\hline Structure & $\begin{array}{l}\text { Relative energy in } \\
\mathrm{d}_{6} \text {-benzene } / \mathrm{CDCl}_{3} \\
\mathrm{kcal} \cdot \mathrm{mol}^{-1}\end{array}$ & $\begin{array}{l}\text { Computed }{ }^{13} \mathrm{C} \text {-NMR shifts } \\
\text { in } \mathrm{d}_{6} \text {-benzene } \\
\text { ppm }\end{array}$ & $\begin{array}{l}\text { Computed }{ }^{13} \mathrm{C} \text {-NMR shifts in } \\
\mathrm{CDCl}_{3} \\
\text { ppm }\end{array}$ \\
\hline$\underline{17}$ & $-29.1 /-28.7$ & 27.9 & $\widehat{\gamma}$ \\
\hline$\underline{10}$ & $-42.6 /-42.2$ & 45.9 & 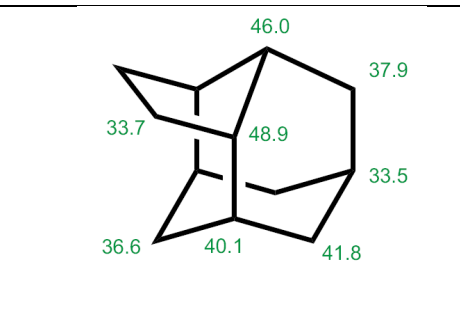 \\
\hline$\underline{12}$ & $-37.8 /-37.4$ & & 47.4 \\
\hline$\underline{13}$ & $-32.7 /-32.3$ & 37.7 & \\
\hline
\end{tabular}




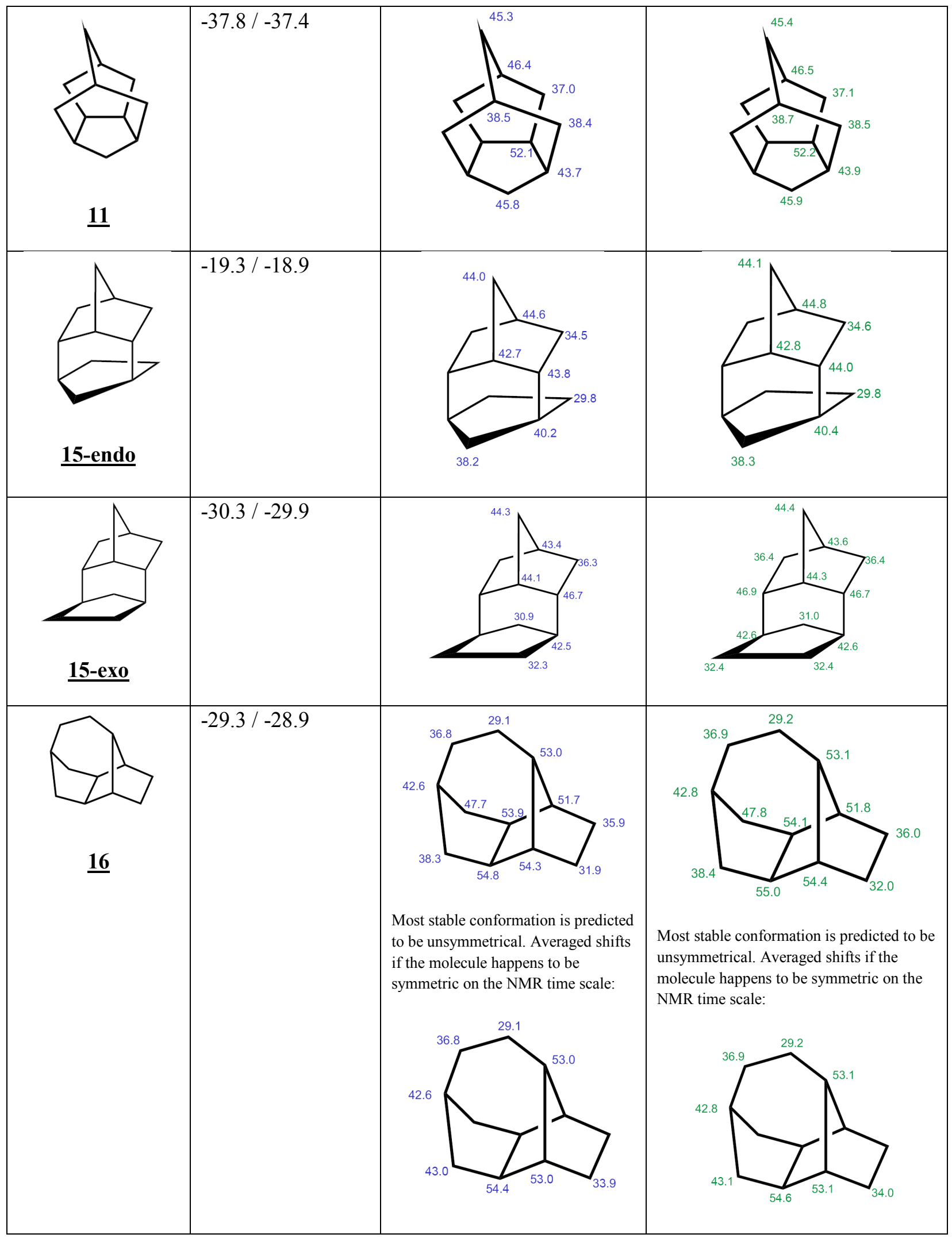




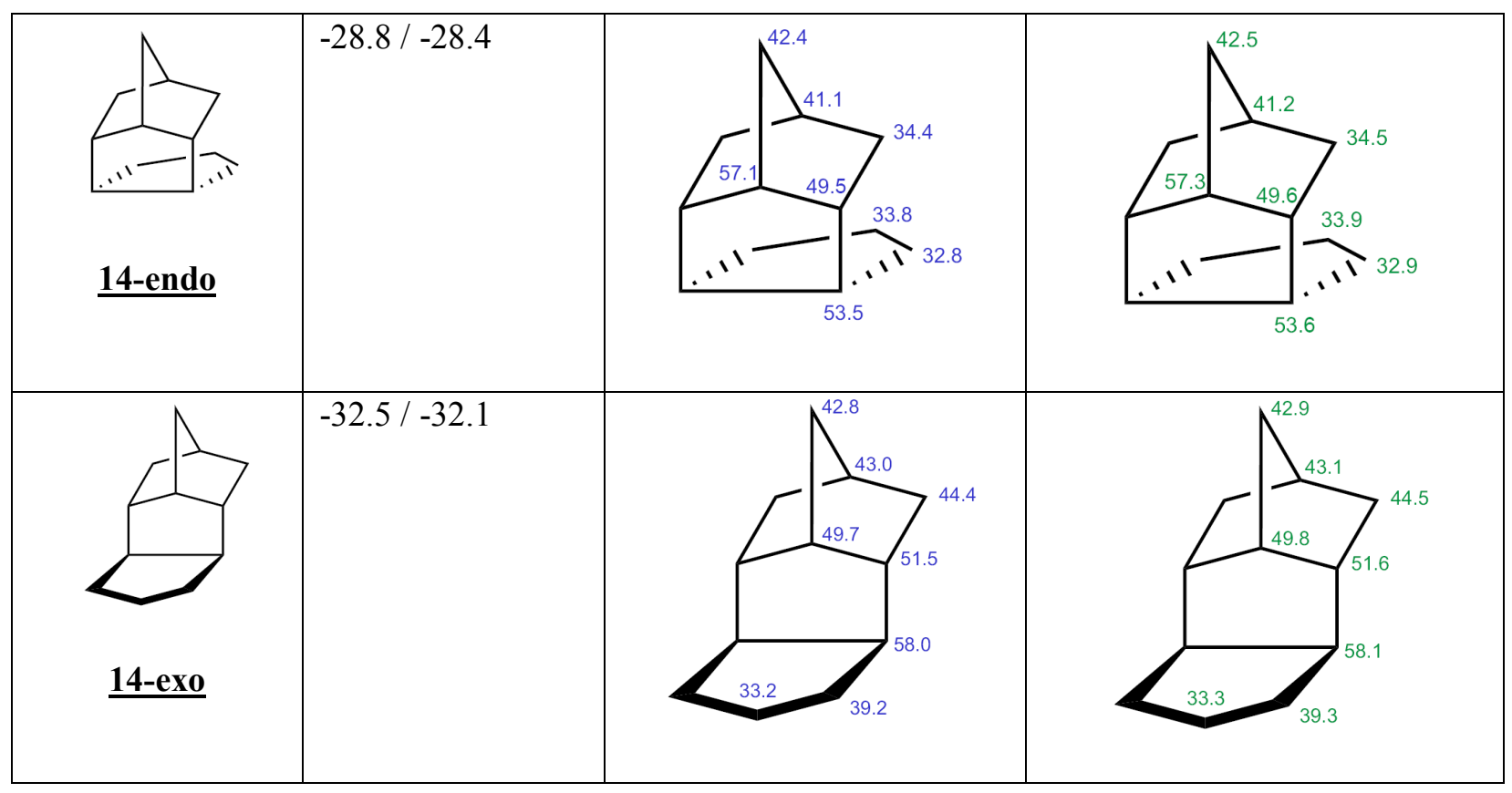

S48 


\section{Correlation diagrams of measured and computed ${ }^{13} \mathrm{C}$-NMR spectra}

\subsection{Component $\underline{\mathbf{a}}(\mathbf{1 8})$}

This component has a symmetrical perhydro- $a s$-indacene backbone (with just 6 signals in the ${ }^{13} \mathrm{C}-\mathrm{NMR}$ ). There are four possible isomers which are formally symmetrical. The correlation diagrams (computed vs measured ${ }^{13} \mathrm{C}$-NMR shifts in $\mathrm{C}_{6} \mathrm{D}_{6}$ for component a versus all possible isomers is shown below. The first isomer, although formally symmetrical, is computed to have an unsymmetrical lowest energy conformation. Comparison was thus made with averaged shifts.

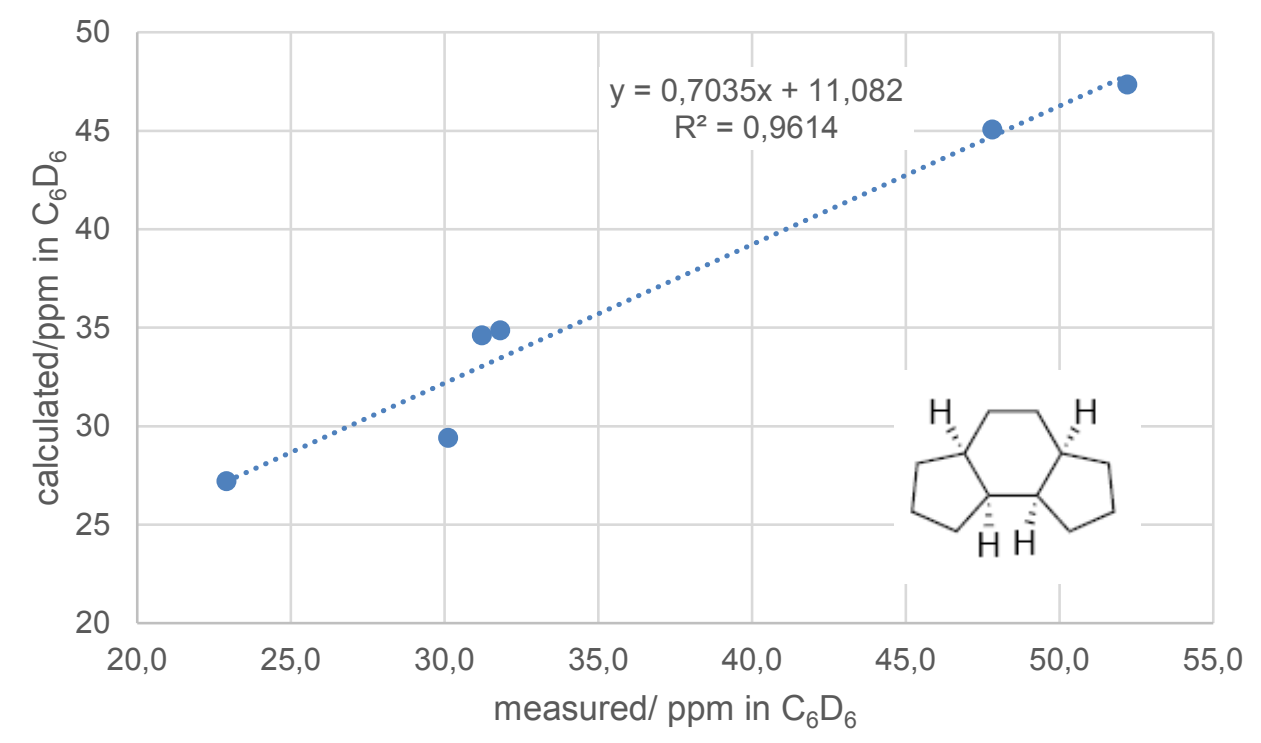

Figure S23: Correlation diagram for cis,syn,cis-perhydro-as-indacene

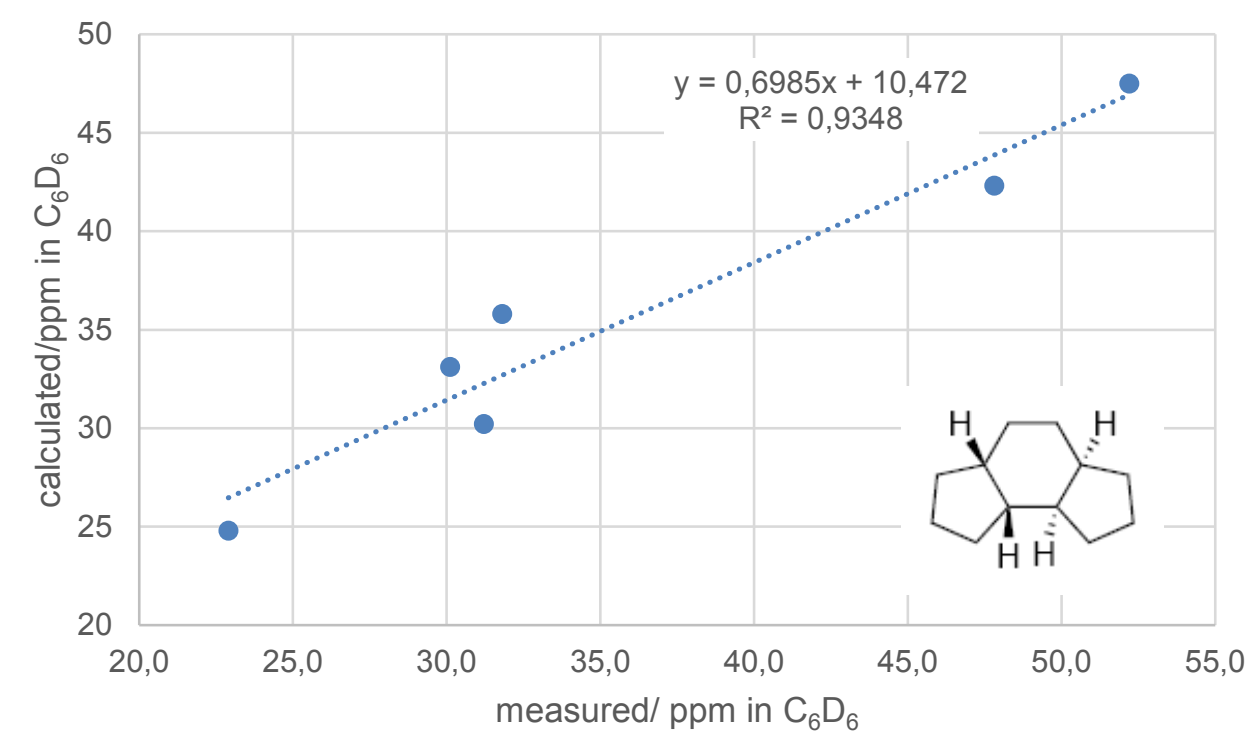

Figure S24: Correlation diagram for cis,anti,cis-perhydro-as-indacene 


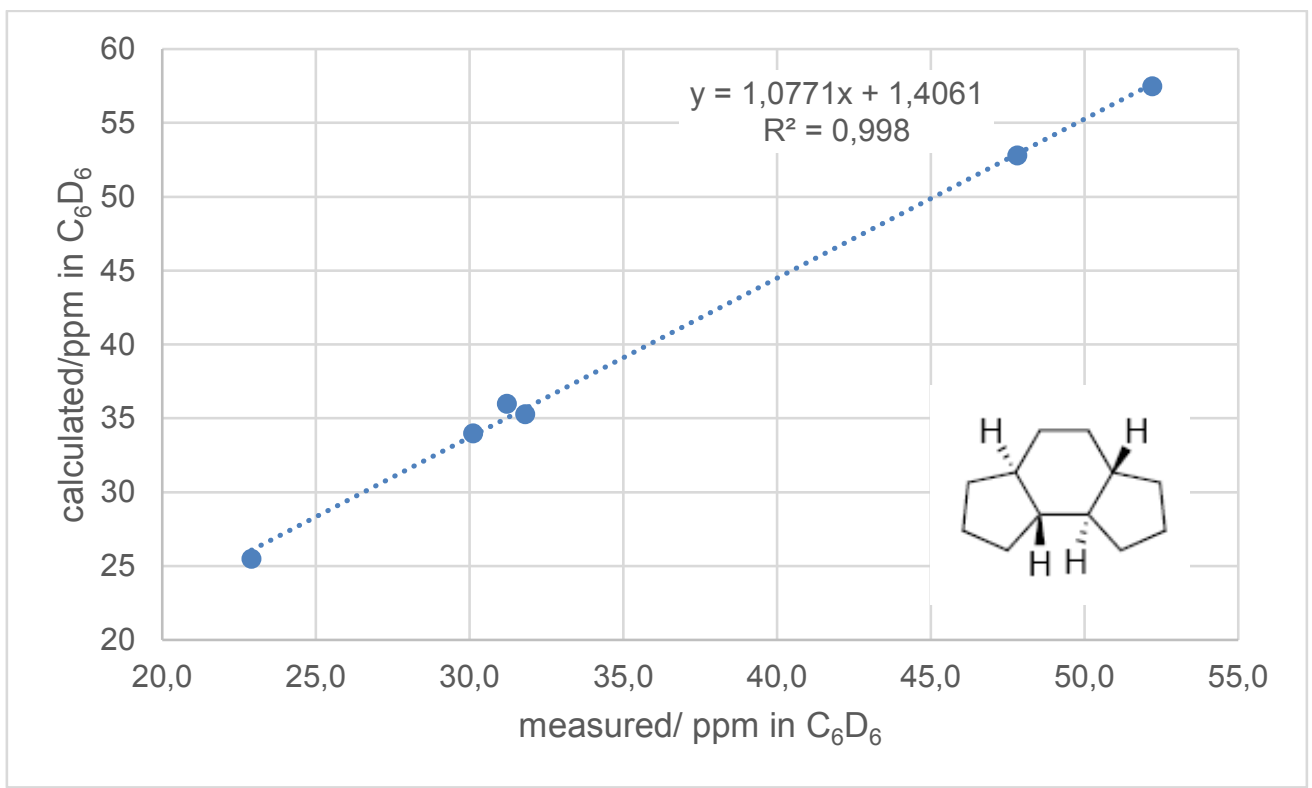

Figure S25: Correlation diagram for trans, anti,trans-perhydro-as-indacene (best fit to component a: 18)

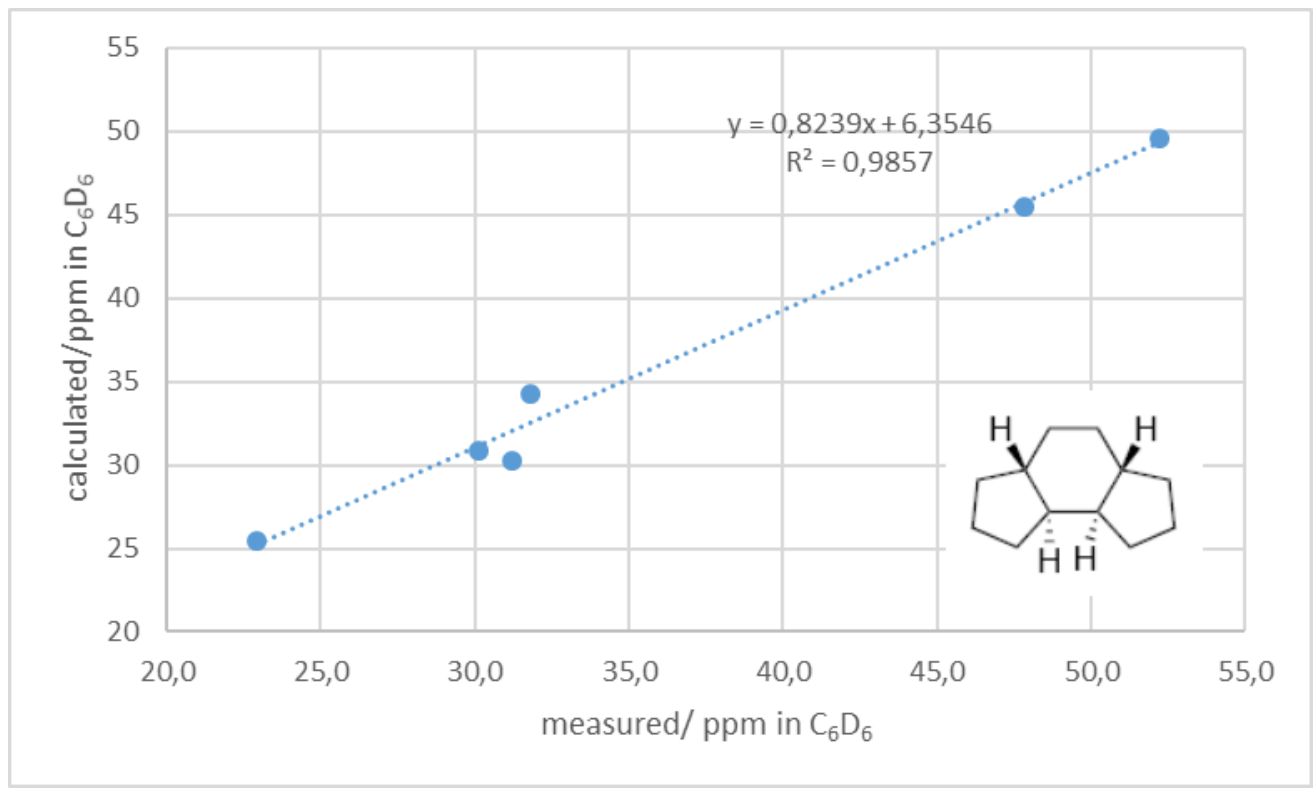

Figure S26: Correlation diagram for trans,syn,trans-perhydro-as-indacene

From all the possible isomers, the best fit between measured and calculated shift is found for the trans,anti,transperhydro- $a s$-indacene isomer.

This isomer has been described by Petrov and coworkers. ${ }^{1}$ The correlation diagram between the shifts of component a and the shifts given by Petrov (both in $\mathrm{CDCl}_{3}$ ) are shown below (Figure S27). This clearly establishes the structure of component a as trans, anti,trans-perhydro-as-indacene and confirms the assignment made by Petrov and coworkers. This isomer is also the most stable of the four symmetrical isomers.

\footnotetext{
${ }^{1}$ N. S. Vorob'eva, T. I. Pekhk, Z. K. Zemskova, A. A. Petrov Stereochemistry of vicinal perhydroindacene and perhydrotriphenylene. Neftekhimiya (1989), 29(5), 658-64
} 


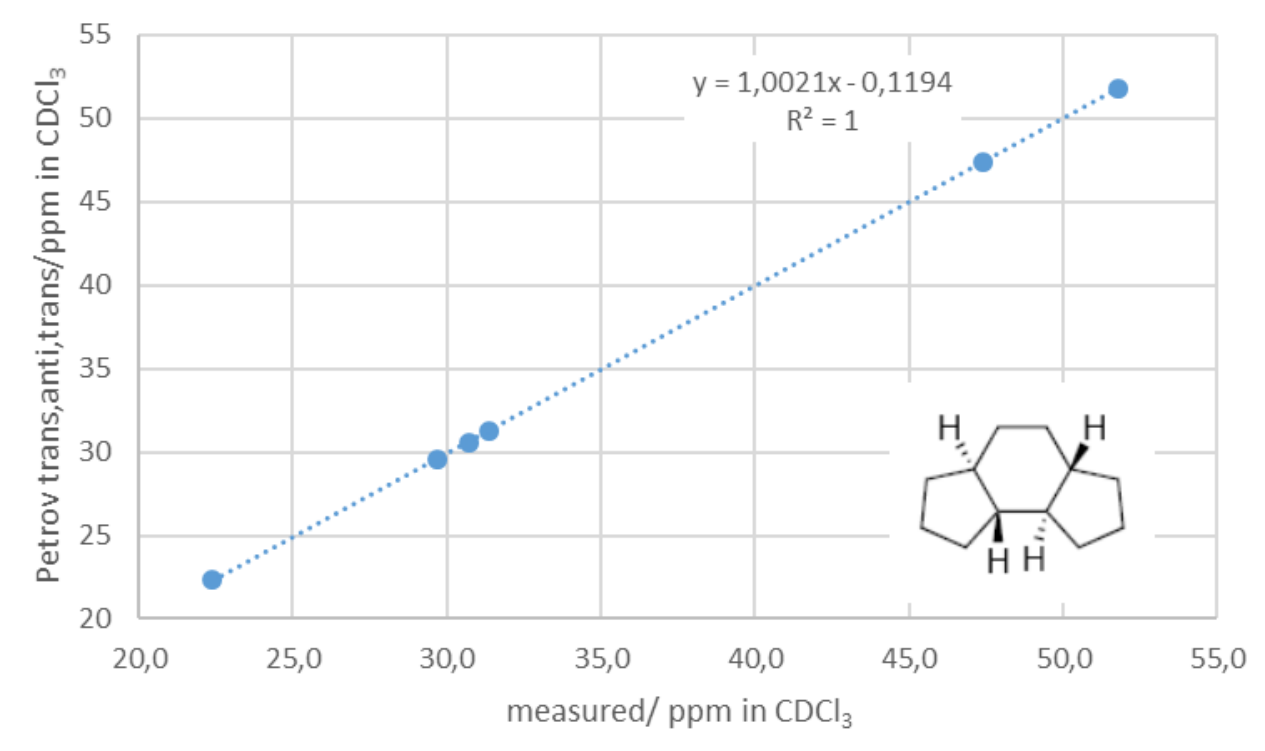

Figure S27: Correlation diagram for trans,anti,trans-perhydro-as-indacene (literature vs own measurement)

We also compared the shifts for the two other symmetrical isomers given by Petrov with our calculated data (in $\mathrm{CDCl}_{3}$ ). The results are shown in the next two correlation diagrams.

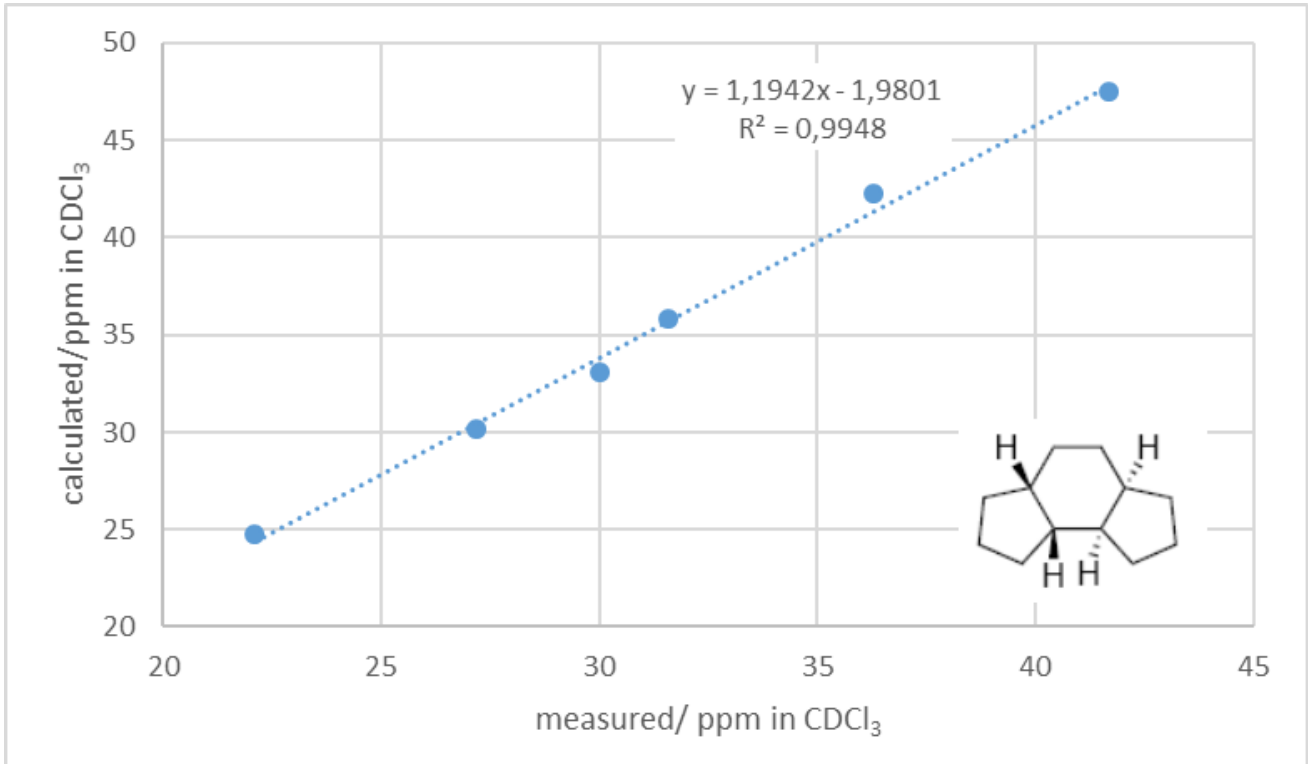

Figure S28: Correlation diagram for cis,anti,cis-perhydro-as-indacene vs calculation (in $\mathrm{CDCl}_{3}$ ) 


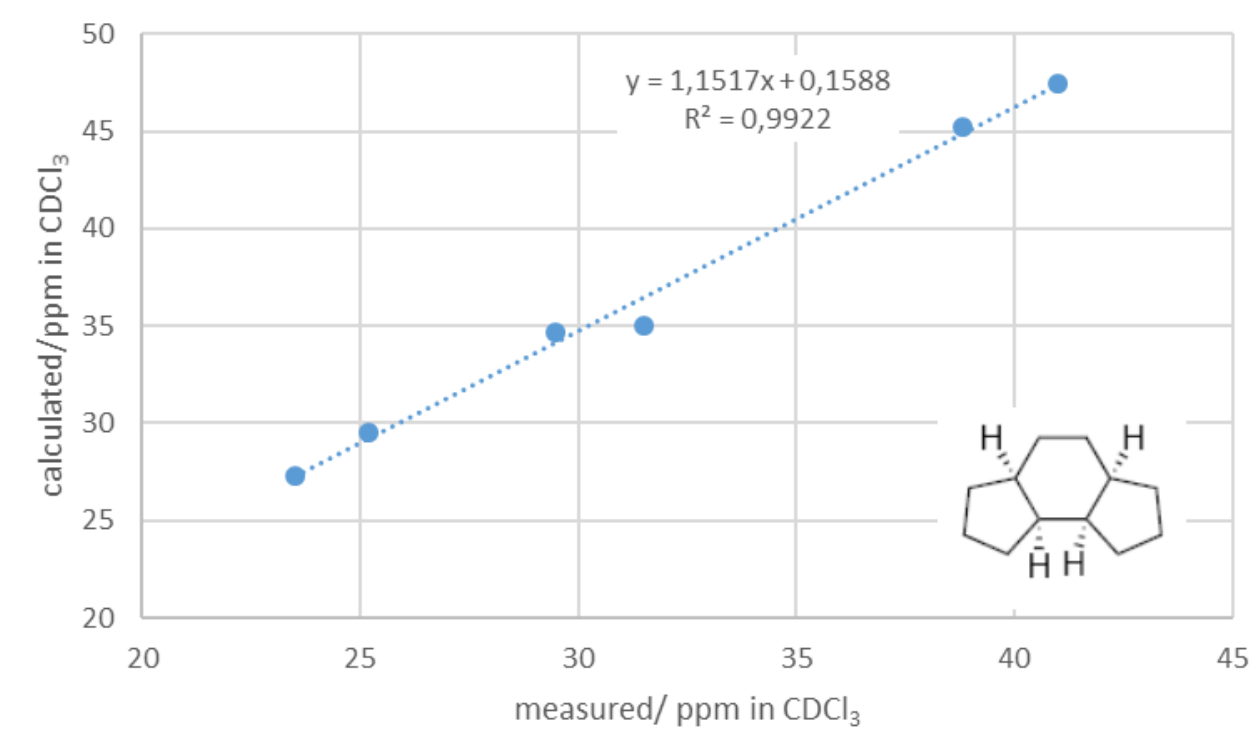

Figure S29: Correlation diagram for cis,syn,cis-perhydro-as-indacene vs calculation (in $\mathrm{CDCl}_{3}$ )

In both cases a very good agreement is found thus confirming the assignments made by Petrov and coworkers. The only isomer which is still unknown is the symmetrical trans,syn,trans, which is not surprising, since according to computations this is the highest energy isomer.

\subsection{Component $\underline{b}$ (22)}

Component $\mathbf{b}$ has the perhydro- $1 H$-cyclopent $[c]$ indene backbone. There are four possible isomers with this carbon backbone. The correlation diagrams (computed vs measured ${ }^{13} \mathrm{C}-\mathrm{NMR}$ shifts in $\mathrm{C}_{6} \mathrm{D}_{6}$ for component $\mathbf{b}$ versus all possible isomers are shown below.

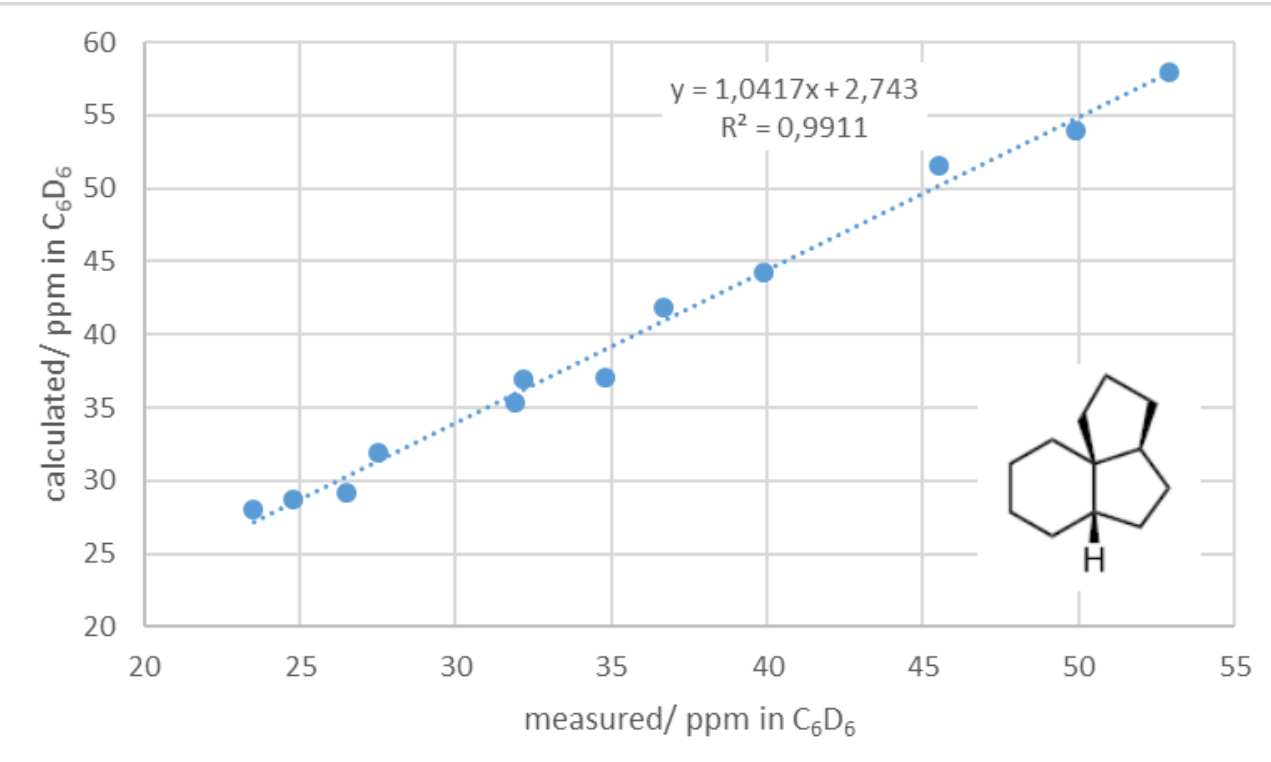

Figure S30: Correlation diagram for cis, cis-perhydro- $1 H$-cyclopent $[c]$ indene (best fit to component b: 22) 


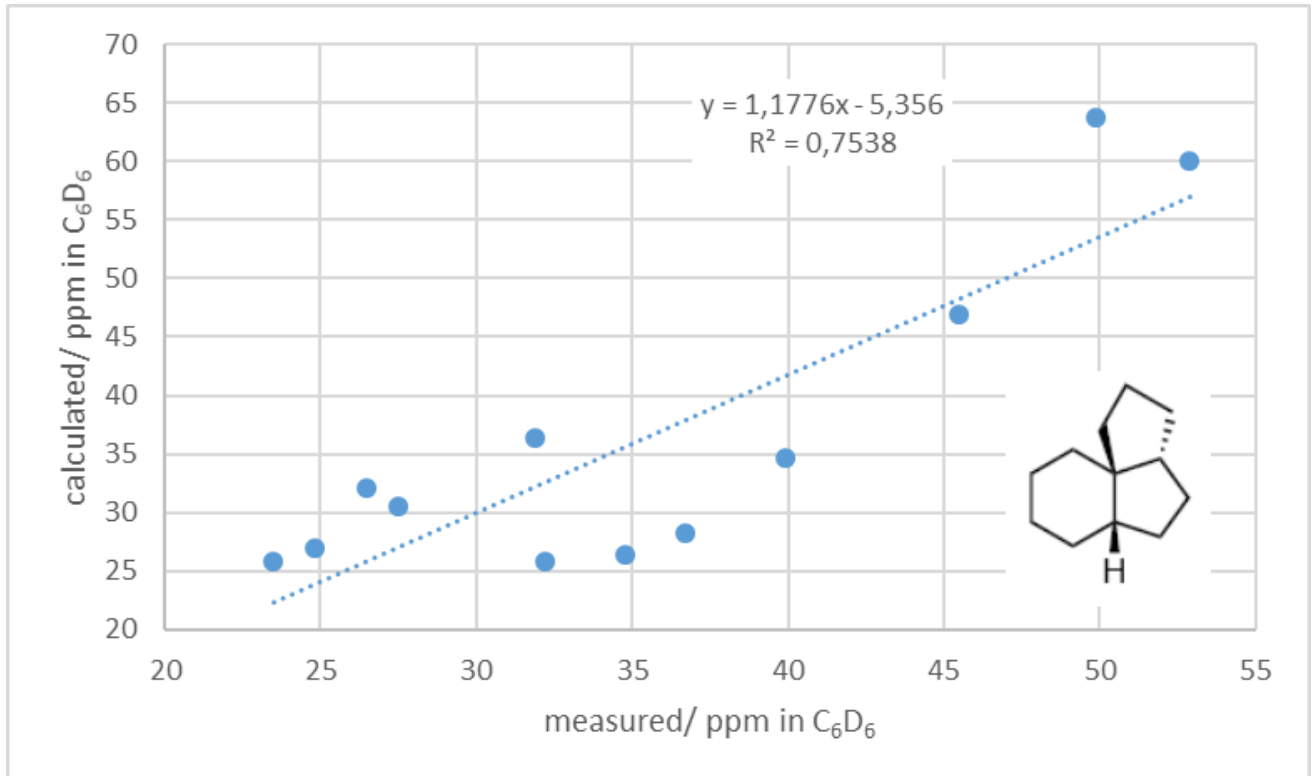

Figure S31: Correlation diagram for cis,trans-perhydro- $1 H$-cyclopent $[c]$ indene

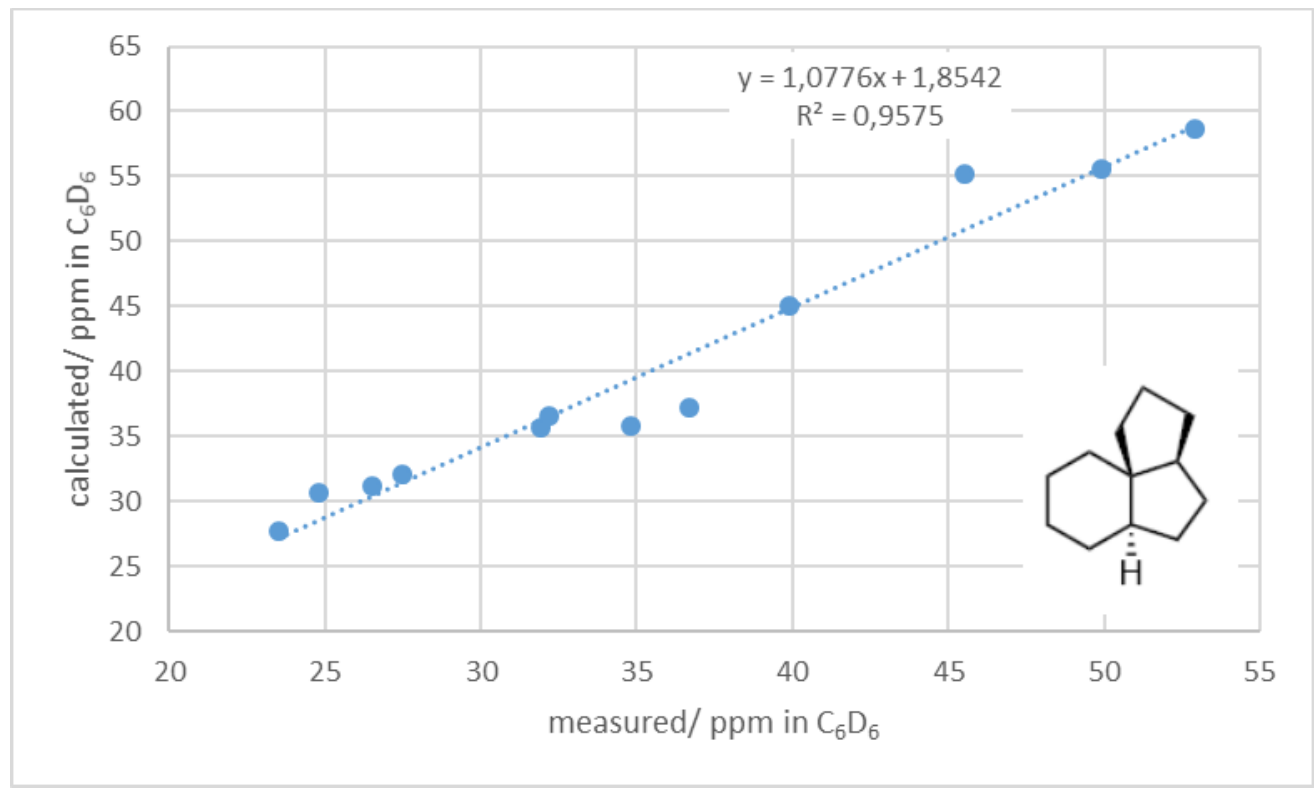

Figure S32: Correlation diagram for trans, cis-perhydro- $1 H$-cyclopent $[c]$ indene 


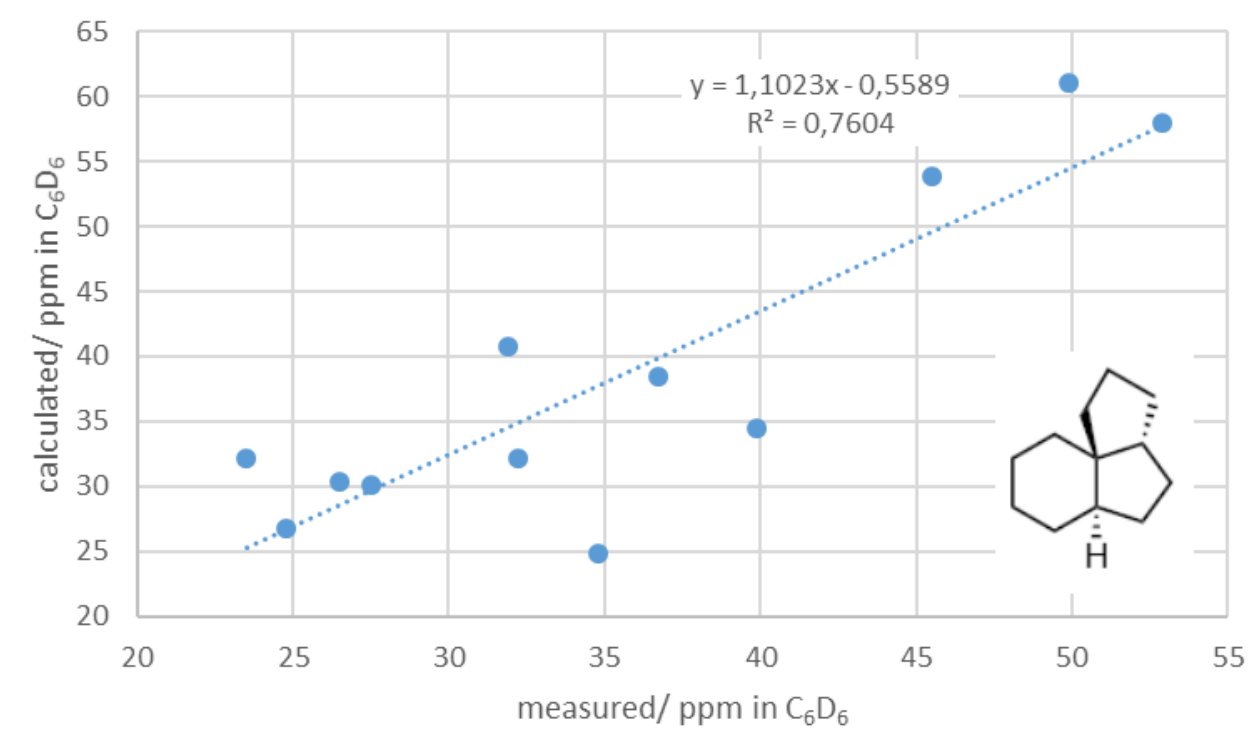

Figure S33: Correlation diagram for trans,trans-perhydro- $1 H$-cyclopent $[c]$ indene

A good correlation is found only to the cis,cis-perhydro- $1 H$-cyclopent $[c]$ indene. This compound has been previously described by Kakiuchi and coworkers. ${ }^{2}$ The correlation diagram between the shifts of component $\mathbf{b}$ and the shifts given by Kakiuchi (both in $\mathrm{CDCl}_{3}$ ) is shown below. This clearly establishes the structure of component b as $c i s$, cis-perhydro- $1 H$-cyclopent [ $c]$ indene and confirms the assignment made by Kakiuchi and coworkers. This isomer is also the most stable of the four isomers.

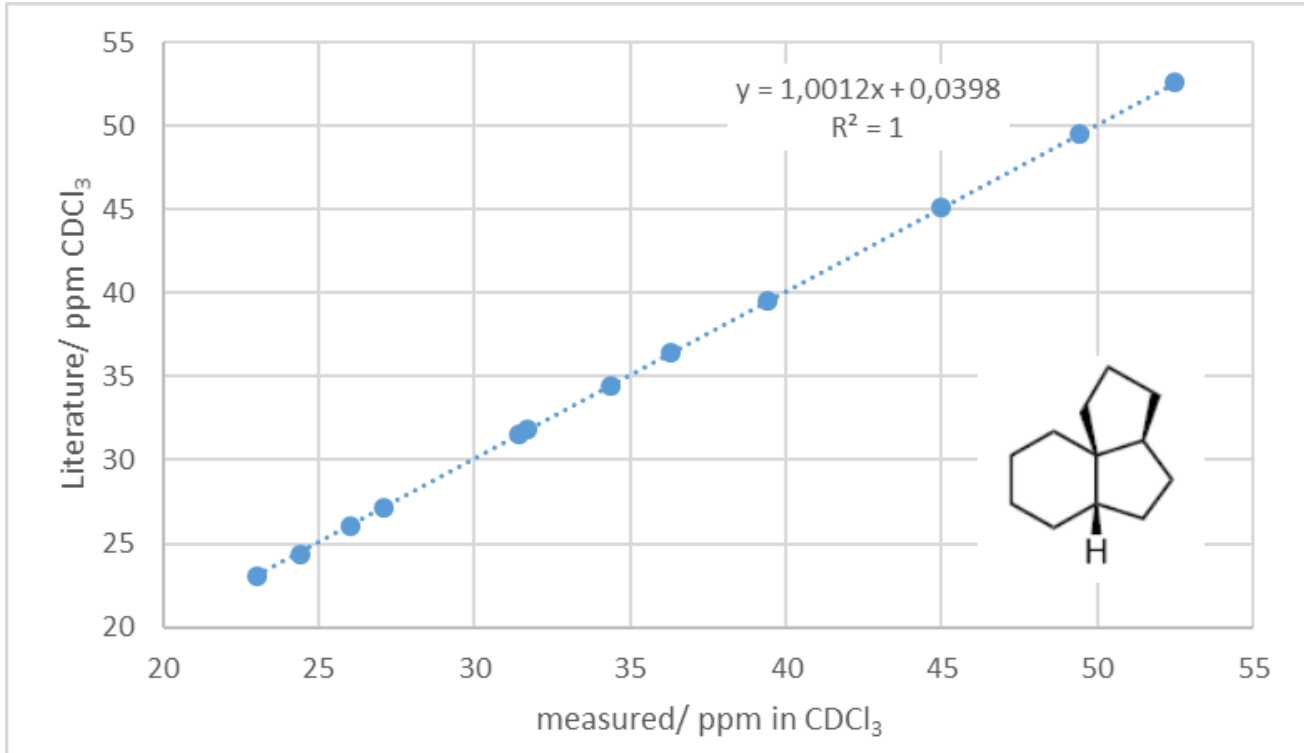

Figure S34: Correlation diagram for $c i s, c i s$-perhydro- $1 H$-cyclopent $[c]$ indene (literature vs. own measurement)

\footnotetext{
${ }^{2}$ Kakiuchi, K.; Ue, M., Tsukahara, H., Shimizu, T.; Miyao, T.; Tobe, Y.; Odaira, Y.; Yasuda, M., Shima, K. Novel Rearrangement of 5,6-Disubstituted Bicyclo[4.2.0]octan-2-ones with $\mathrm{AlCl}_{3}$. Application to Total Synthesis of ( \pm )-5-Oxosilphiperfol-6-ene and ( \pm )-Silphiperfol-6-ene. J. Am. Chem. Soc., 1989, 111, 3707-3712 (see compound 101 in scheme VIII of the supporting information)
} 


\subsection{Component $\underline{\mathbf{c}}(\mathbf{2 3})$}

Component $\mathbf{c}$ has the same perhydro- $1 H$-cyclopent $[c]$ indene backbone as component $\mathbf{b}$. The correlation diagrams (computed vs measured ${ }^{13} \mathrm{C}-\mathrm{NMR}$ shifts in $\mathrm{C}_{6} \mathrm{D}_{6}$ for component $\mathbf{c}$ versus the four possible isomers are shown below.

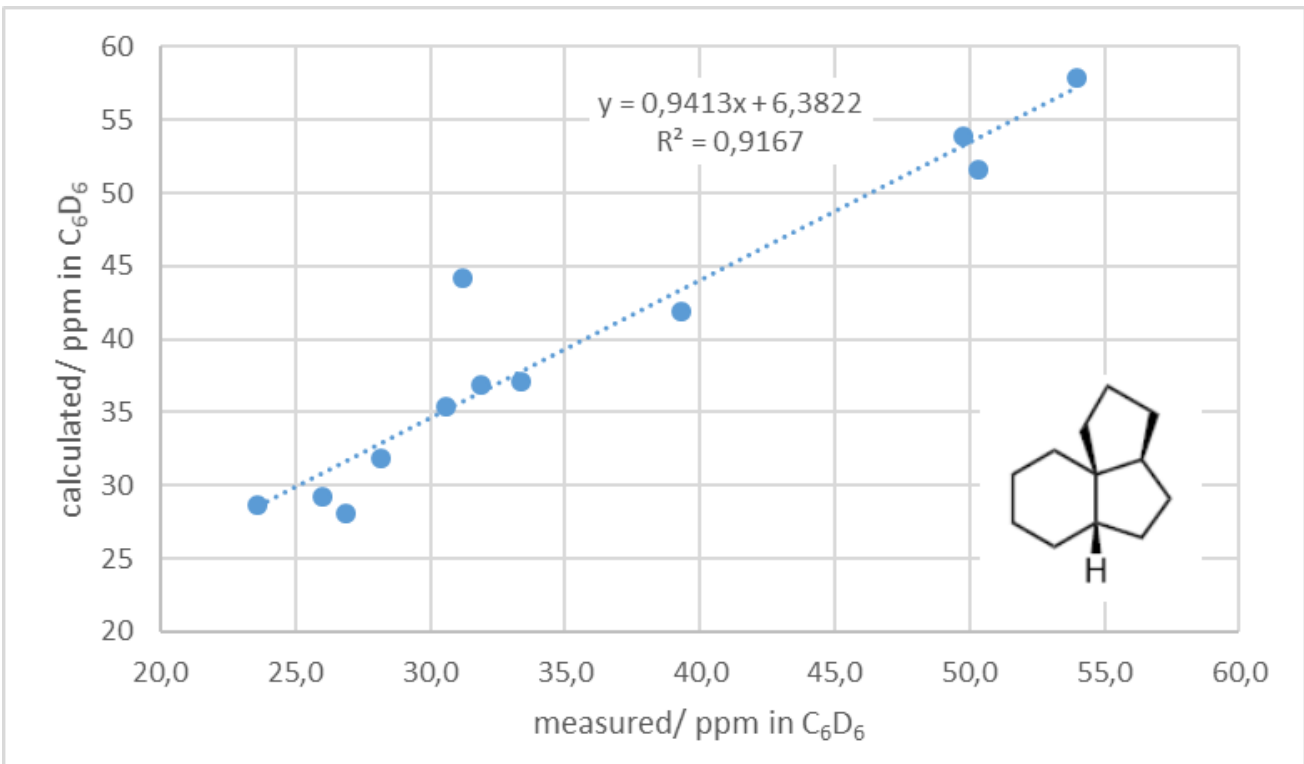

Figure S35: Correlation diagram for $c i s$, cis-perhydro- $1 H$-cyclopent $[c]$ indene

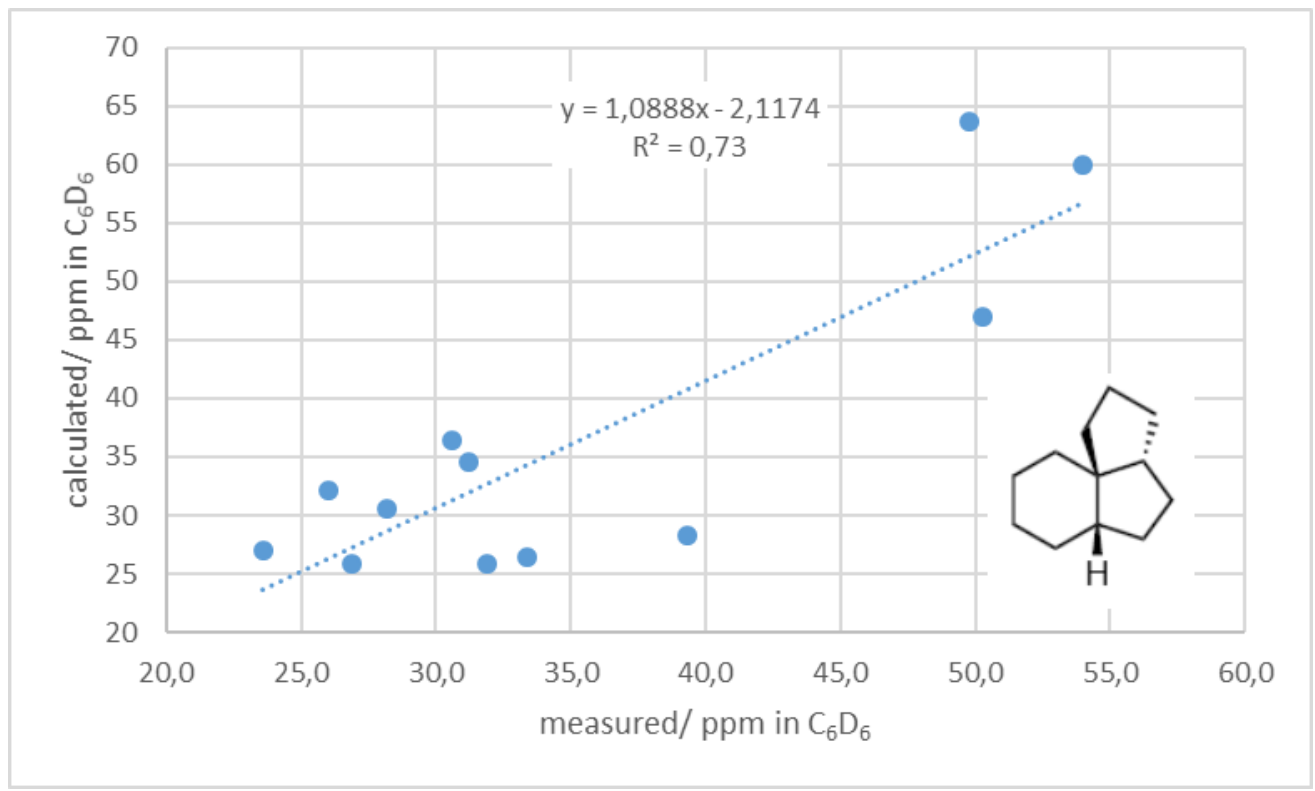

Figure S36: Correlation diagram for $\operatorname{cis}$, trans-perhydro- $1 H$-cyclopent $[c]$ indene 


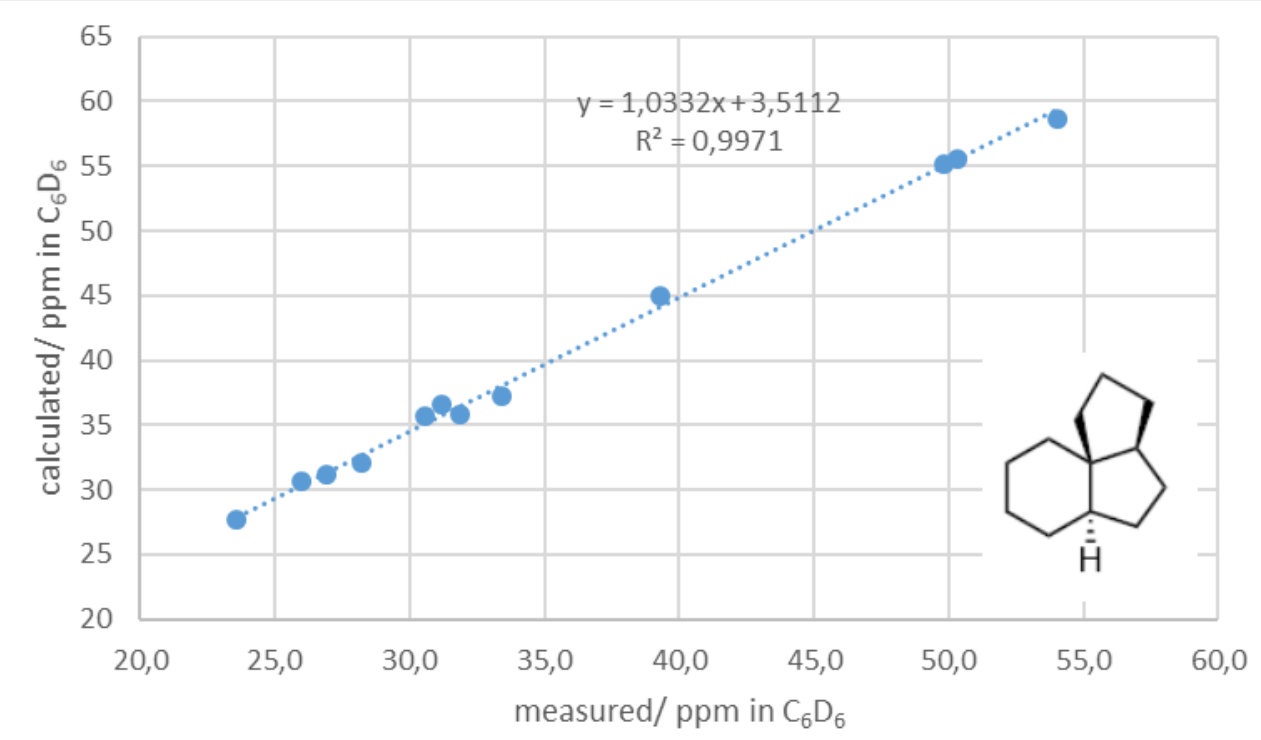

Figure S37: Correlation diagram for trans, cis-perhydro- $1 H$-cyclopent $[c]$ indene (best fit to component c: 23 )

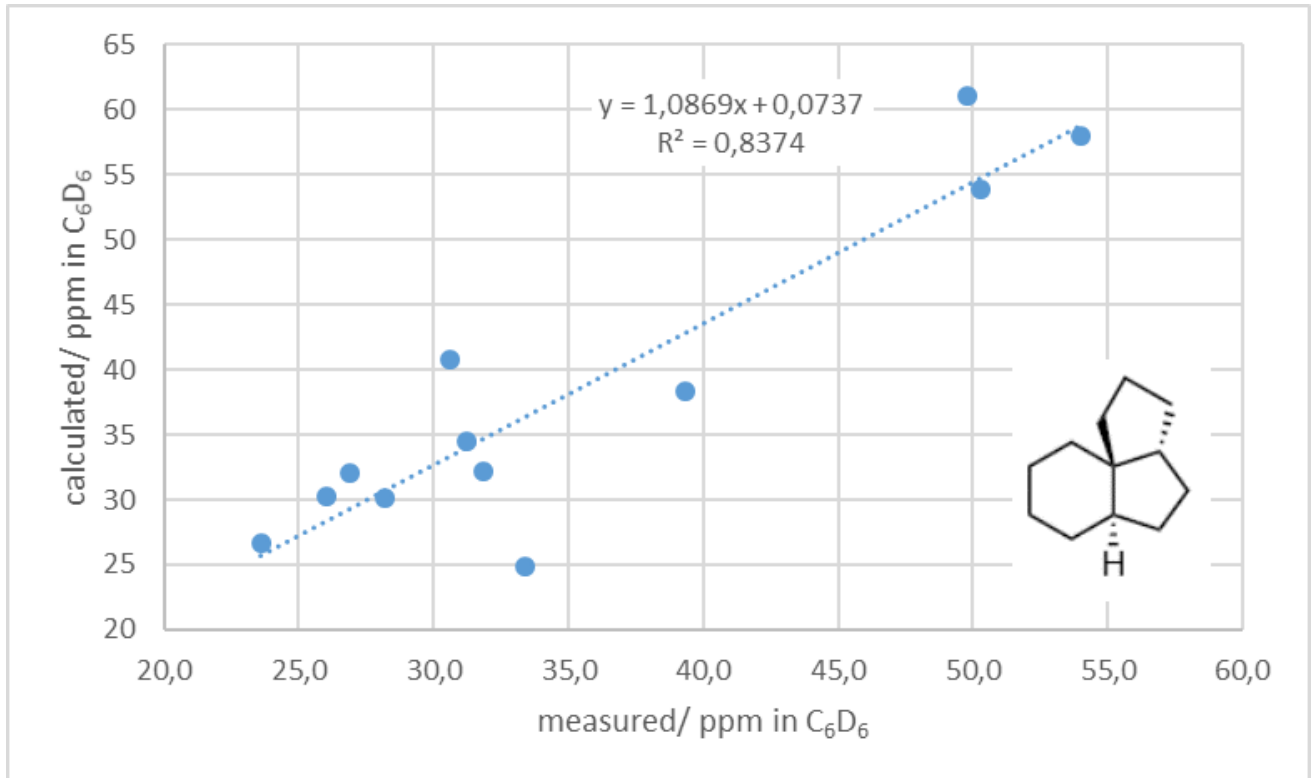

Figure S38: Correlation diagram for trans,trans-perhydro- $1 H$-cyclopent $[c]$ indene

A good correlation is found only to the trans,cis-perhydro- $1 H$-cyclopent $[c]$ indene. This compound has been previously described by Kakiuchi and coworkers. ${ }^{3}$ The correlation diagram between the shifts of component $\mathbf{c}$ and the shifts given by Kakiuchi (both in $\mathrm{CDCl}_{3}$ ) is shown below (Figure S39). This establishes the structure of component $\mathbf{c}$ as trans, $c i s$-perhydro- $1 H$-cyclopent $[c]$ indene and confirms the assignment made by Kakiuchi and coworkers. This isomer is the second most stable of the four isomers.

\footnotetext{
${ }^{3}$ Kakiuchi, K.; Ue, M., Tsukahara, H., Shimizu, T.; Miyao, T.; Tobe, Y.; Odaira, Y.; Yasuda, M., Shima, K. Novel Rearrangement of 5,6-Disubstituted Bicyclo[4.2.0] octan-2-ones with $\mathrm{AlCl}_{3}$. Application to Total Synthesis of ( \pm )-5-Oxosilphiperfol-6-ene and (士)-Silphiperfol-6-ene. J. Am. Chem. Soc., 1989, 111, 3707-3712 (see compound 102 in scheme VIII of the supporting information)
} 


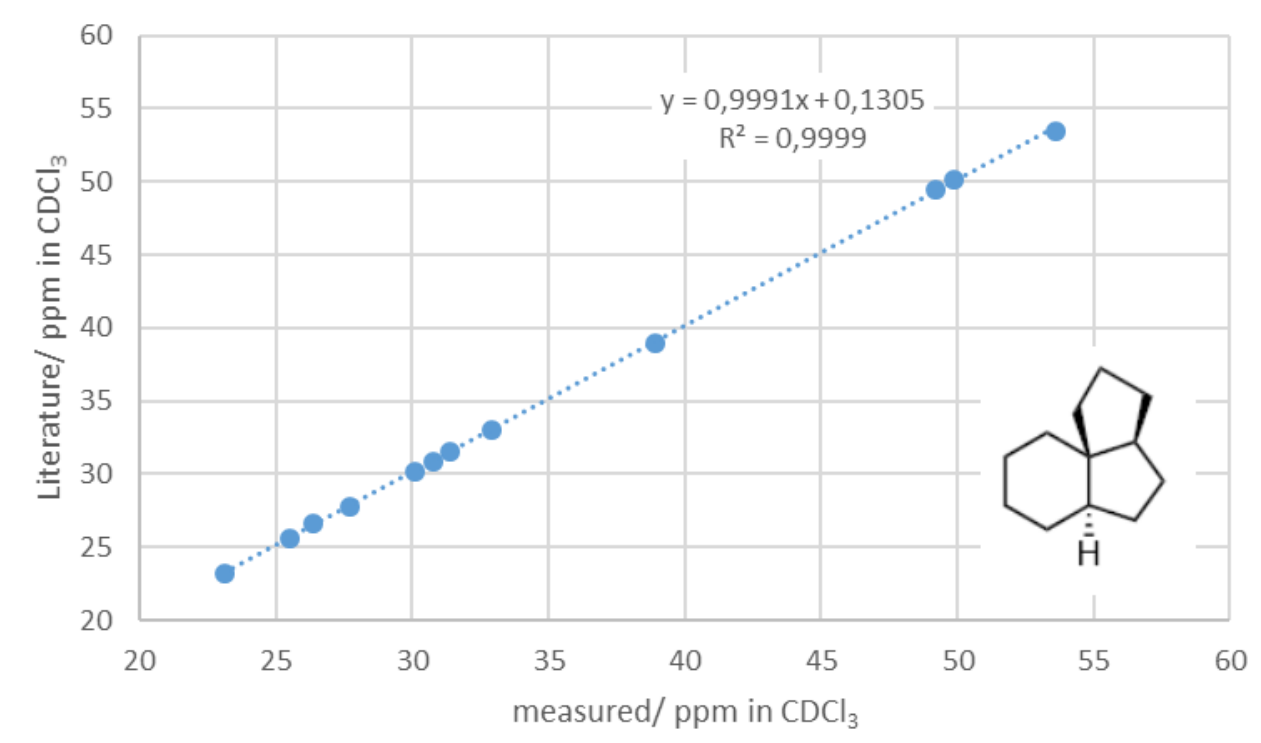

Figure S39: Correlation diagram for trans, cis-perhydro- $1 H$-cyclopent $[c]$ indene (literature vs. own measurement)

\subsection{Component $\underline{\mathrm{d}}(\mathbf{2 6})$}

Component $\mathbf{d}$ has the perhydro- $1 H$-cyclopent $[d]$ indene backbone. For this backbone, only two isomers are possible, a symmetrical one and an unsymmetrical one. Since the ${ }^{13} \mathrm{C}-\mathrm{NMR}$ spectrum of component d shows only 7 signals, it must have the symmetrical structure. However, the calculation predicts that the lowest energy conformation is indeed unsymmetrical. If one however assumes that flipping is fast on the time scale of NMR, one can average the computed shifts in order to compare them with the measured ones (see also section 8 on the low temperature NMR). The correlation diagram (measured ${ }^{13} \mathrm{C}-\mathrm{NMR}$ shifts in $\mathrm{C}_{6} \mathrm{D}_{6}$ for component $\mathbf{d}$ versus the averaged calculated shifts of the computed $\mathrm{C} 1$ structure of the cis,cis-perhydro- $1 H$-cyclopent[d]indene isomer is shown below.

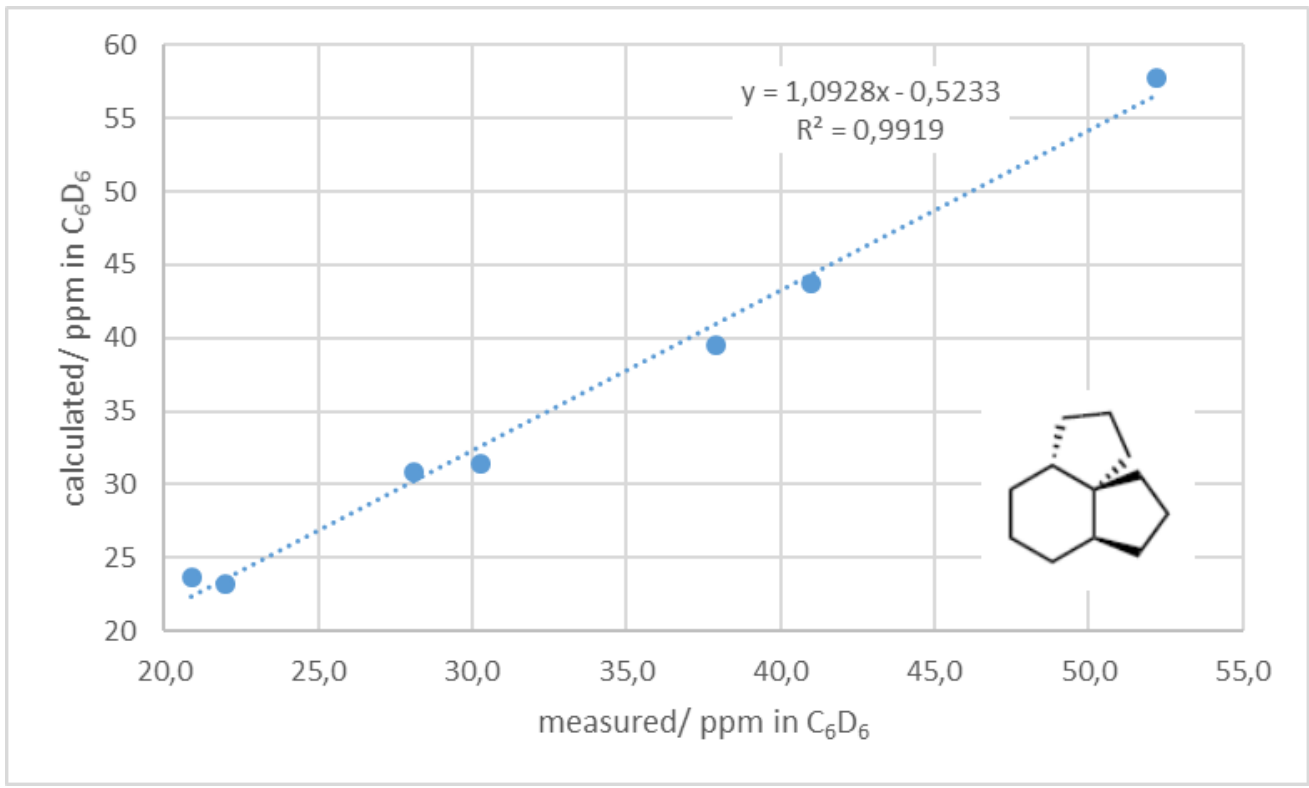


Figure S40: Correlation diagram for cis, cis-perhydro- $1 H$-cyclopent $[d]$ indene (averaged computed shifts of C1symmetric structure) (best fit to component $\mathbf{d}: \mathbf{2 6}$ )

The agreement between calculated and measured shifts is excellent. This is also the most stable of both isomers. Computation predicts that a C2-symmetric structure is also a local minimum on the energy surface, but it lies 3.3 $\mathrm{kcal} / \mathrm{mol}$ higher than the $\mathrm{C} 1$ structure. A comparison of the measured shifts with the shifts calculated for the $\mathrm{C} 1$ structure is shown in the next diagram.

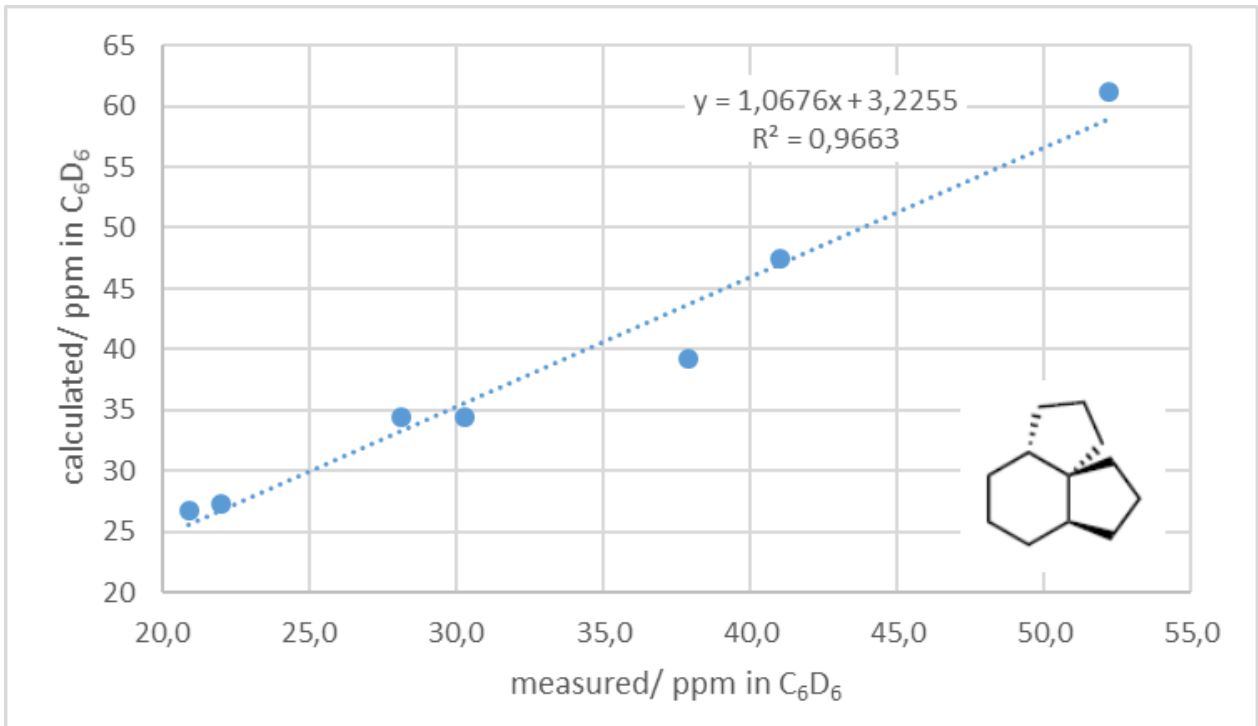

Figure S41: Correlation diagram for cis, cis-perhydro-1H-cyclopent $[d]$ indene (computed shifts of the C2symmetrical structure)

The correlation is rather poor, so the molecule has indeed an unsymmetrical ground state, but is symmetrical on the time scale of NMR.

Since this molecule was not known in literature, no comparison can be made with literature data. However, the unsymmetrical isomer has been described by Kakiuchi and coworkers. ${ }^{4}$ The correlation diagram between the literature and the calculated shifts for the unsymmetrical isomer is shown below (Figure S42). The good agreement confirms the assignment made in literature.

\footnotetext{
${ }^{4}$ Tobe, Y.; Iseki, T., Kakiuchi, K.; Odaira, Y. A New Strategy for Construction of Angularly Fused Tricyclic Ring Systems. Transannular Bond Formation of Bicyclic Enones via Photochemical Intramolecular Hydrogen Abstraction. Tetrahedron Lett., 1984, 25, 3895-3896
} 


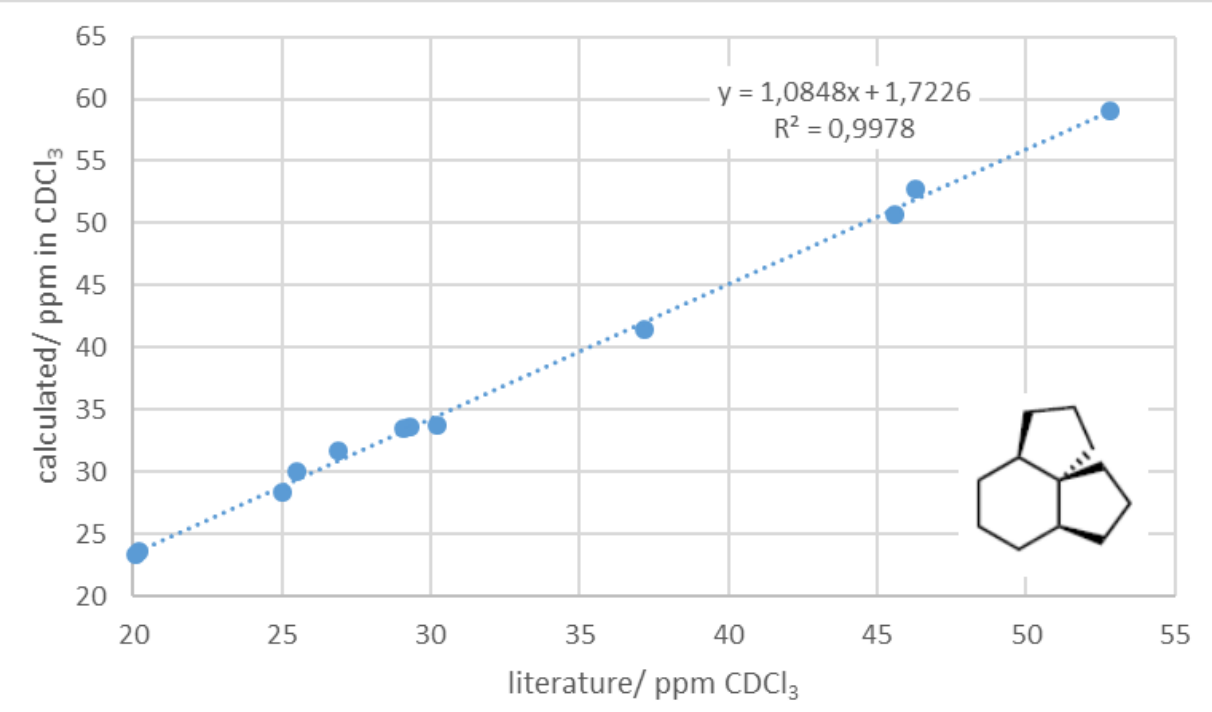

Figure S42: Correlation diagram for cis,trans-perhydro- $1 H$-cyclopent $[d]$ indene (our calculation vs. literature) 7.5 Component $\underline{\text { e }}$ (27)

Component $\mathbf{e}$ has the perhydro-cyclopent $[c d]$ azulene backbone and shows a full set of 12 signals. There are overall six possible isomers with this backbone, but since the three isomers with trans-fused cyclopentane rings are expected to be very strained, only the three isomers with cis-fused cyclopentane rings were calculated. Of these three isomers, on paper two are symmetrical and only one is unsymmetrical. However, calculations predict that the most stable conformation of the on paper symmetrical isomers are in fact not symmetrical and should also give rise to 12 signals, all three isomers were compared with the observed shifts. The correlation diagrams (computed vs measured ${ }^{13} \mathrm{C}-\mathrm{NMR}$ shifts in $\mathrm{C}_{6} \mathrm{D}_{6}$ for component $\mathbf{e}$ versus the three isomers with cis-fused cyclopentane rings are shown below (Figures S43 to S45).

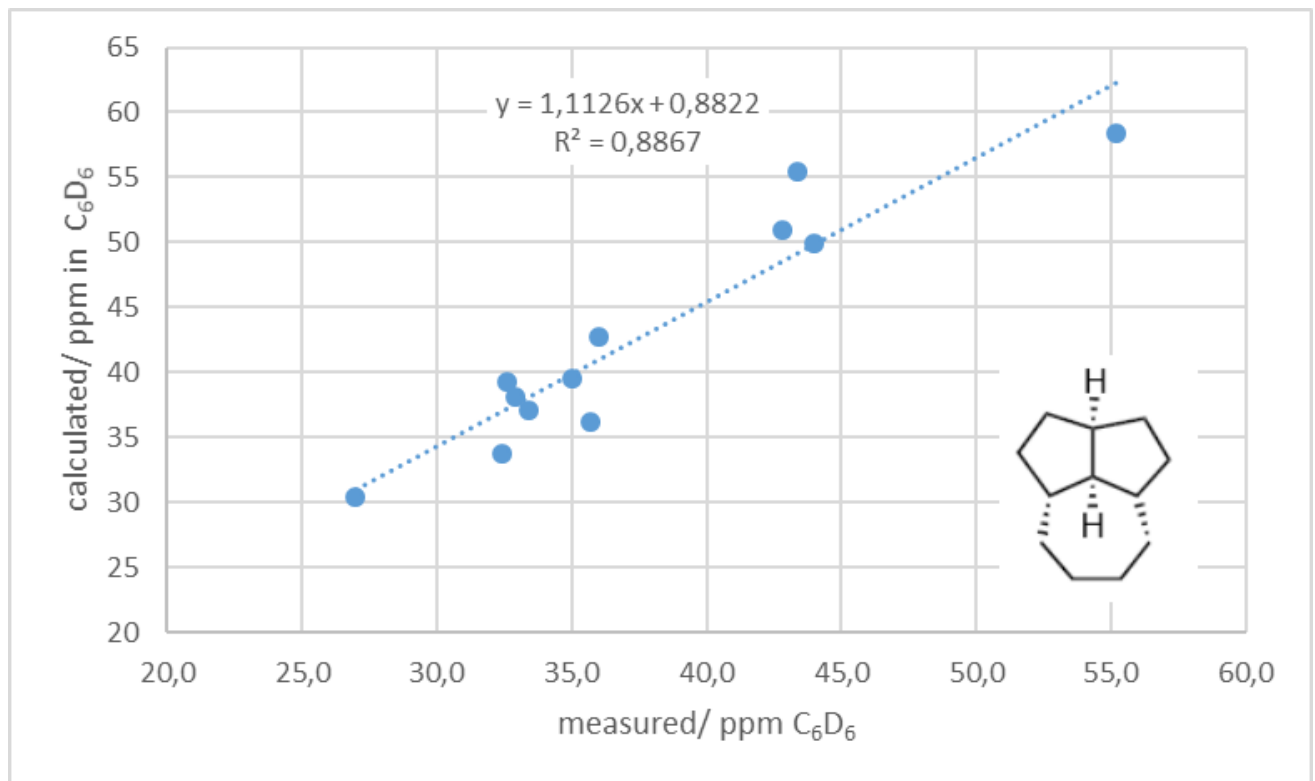

Figure S43: Correlation diagram for syn,cis-perhydro-cyclopent $[c d]$ azulene 


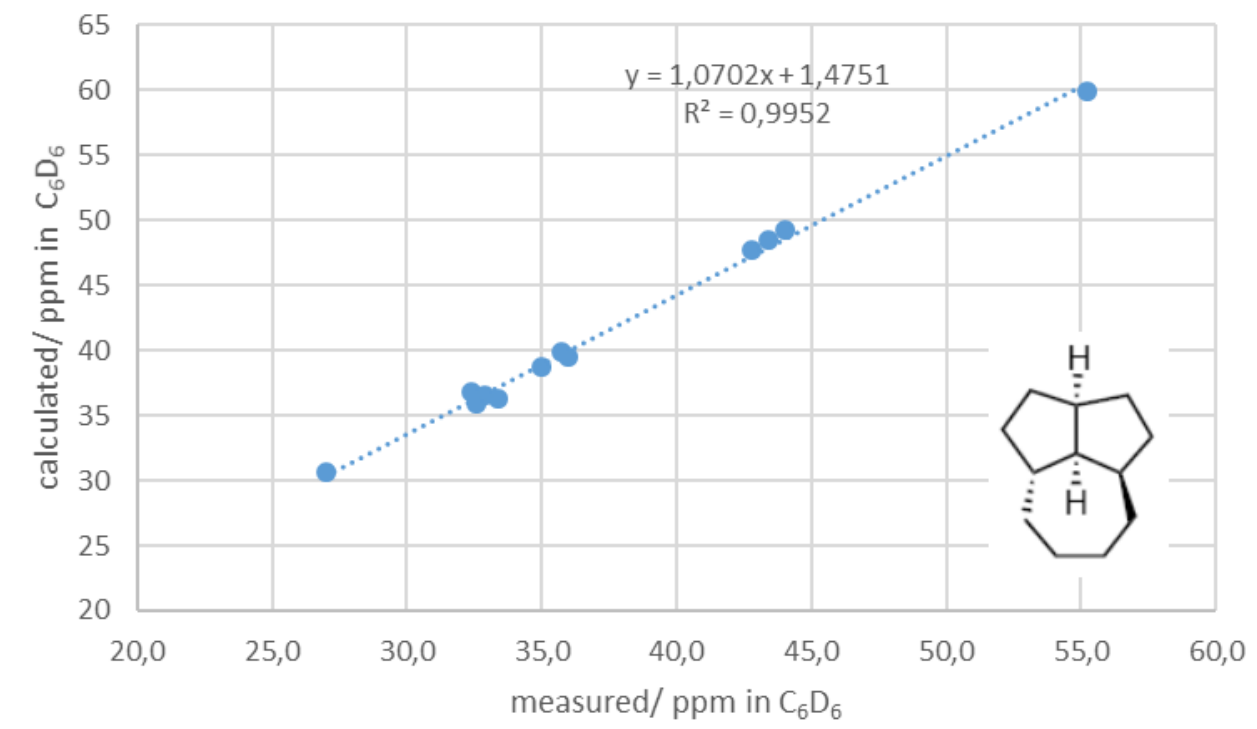

Figure S44: Correlation diagram for trans-perhydro-cyclopent $[c d]$ azulene (best fit to component e: 27) 


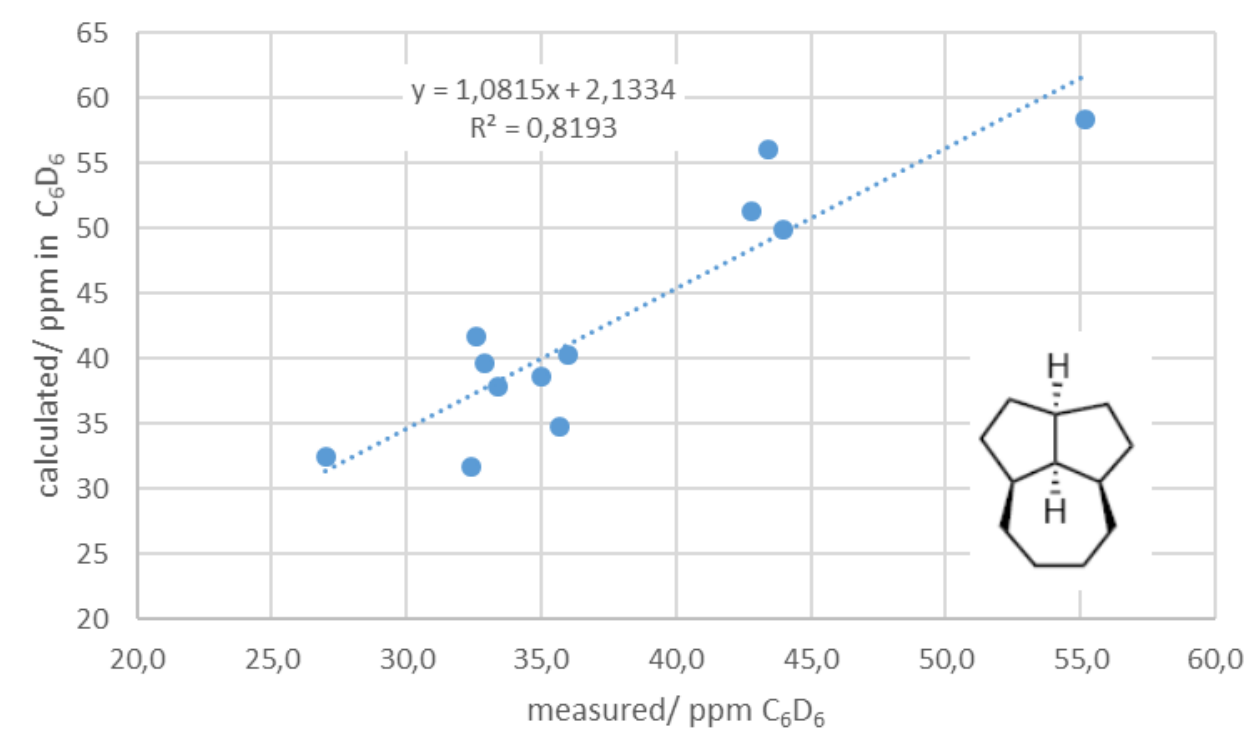

Figure S45: Correlation diagram for anti,cis-perhydro-cyclopent $[c d]$ azulene

As can be seen from the correlation diagrams an excellent fit is found for the trans-perhydro-cyclopent $[c d]$ azulene structure. This isomer is also the most stable of the three. Since this structure was hitherto unknown in literature, no comparison with literature data is possible.

\subsection{Component $\underline{\mathbf{f}}(\mathbf{2 8})$}

Component $\mathbf{f}$ has the perhydro- $2 \mathrm{H}-1,4 \mathrm{a}$-ethanonaphthalene backbone. With this backbone there are only two possible isomers. The correlation diagrams (computed vs. measured ${ }^{13} \mathrm{C}-\mathrm{NMR}$ shifts in $\mathrm{C}_{6} \mathrm{D}_{6}$ for component $\mathbf{f}$ versus the two isomers are shown below (Figures S46 and S47).

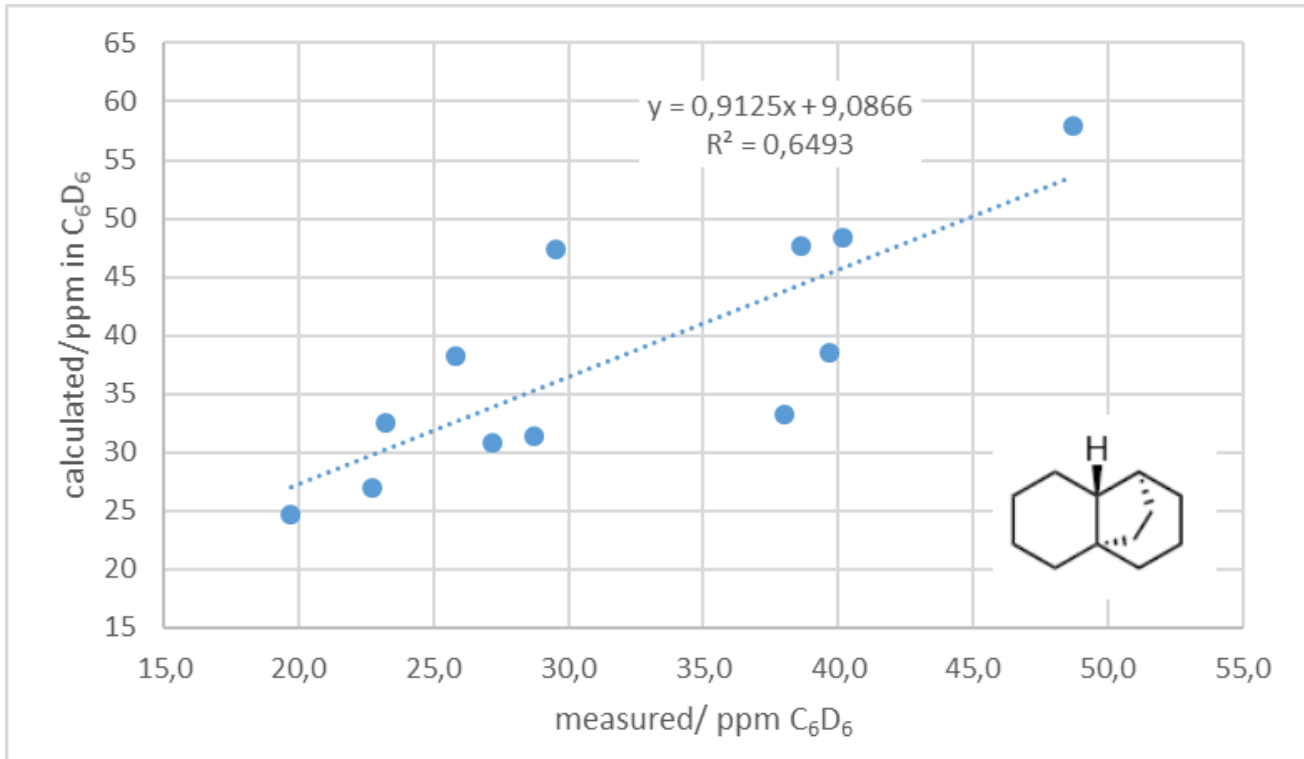

Figure S46: Correlation diagram for trans-perhydro- $2 H$-1,4a-ethanonaphthalene 


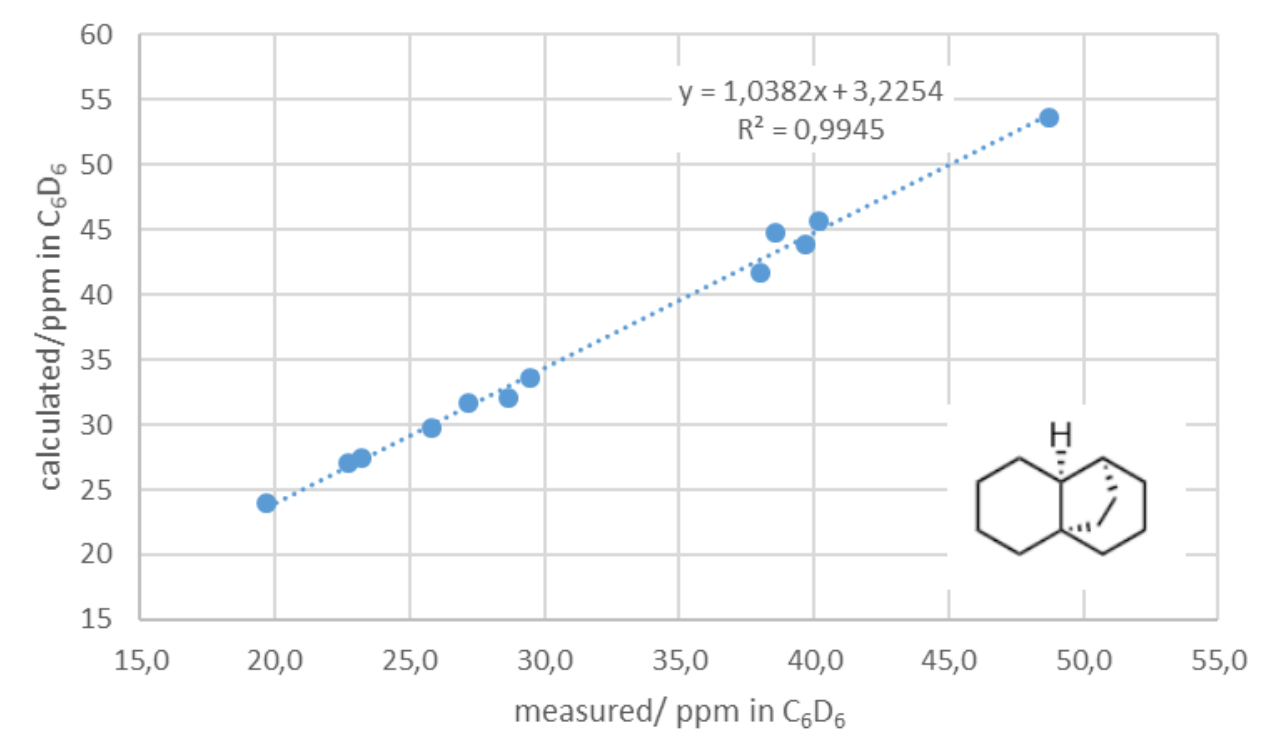

Figure S47: Correlation diagram for $c i s$-perhydro- $2 H$-1,4a-ethanonaphthalene (best fit to component f: 28 )

As can be seen, there is an excellent agreement with the shift calculated for the cis-perhydro- $2 \mathrm{H}$-1,4aethanonaphthalene isomer, which is actually calculated to be the less stable of the two isomers.

Both isomers have been described in the literature by Kakiuchi and coworkers. ${ }^{5}$

The following diagram (Figure S48) compares the shifts given in the paper of Kakiuchi with shifts measured for component $\mathbf{f}$. The excellent correlation shows that our component $\mathbf{f}$ is identical to compound 27 described in the paper by Kakiuchi and coworkers.

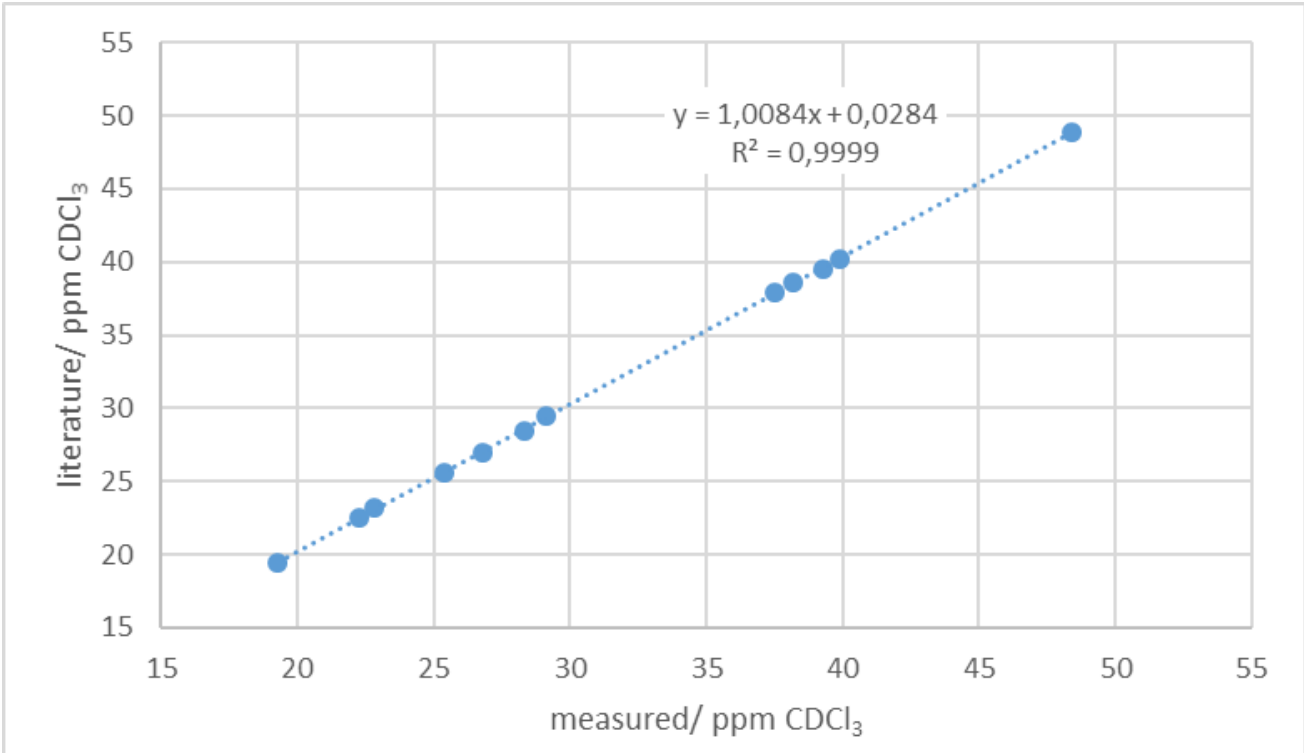

Figure S48: Correlation diagram for $c i s$-perhydro- $2 \mathrm{H}$-1,4a-ethanonaphthalene (literature vs. own measurement)

\footnotetext{
${ }^{5}$ Kakiuchi, K.; Tsugaru, T.; Takeda, M.; Wakaki, I.; Tobe, Y., Odaira, Y. Acid-Catalyzed Rearrangement of [m.3.2]Propellanols. J. Org. Chem., 1985, 50, 488-493
} 
Since Kakiushi also describes the trans-isomer (compound 26 in Kakiuchi's paper), we also compared the shifts given for the trans-isomer with the ones that we calculated. The excellent correlation observed, thus confirms the assignments made by Kakiuchi (see Figure S49).

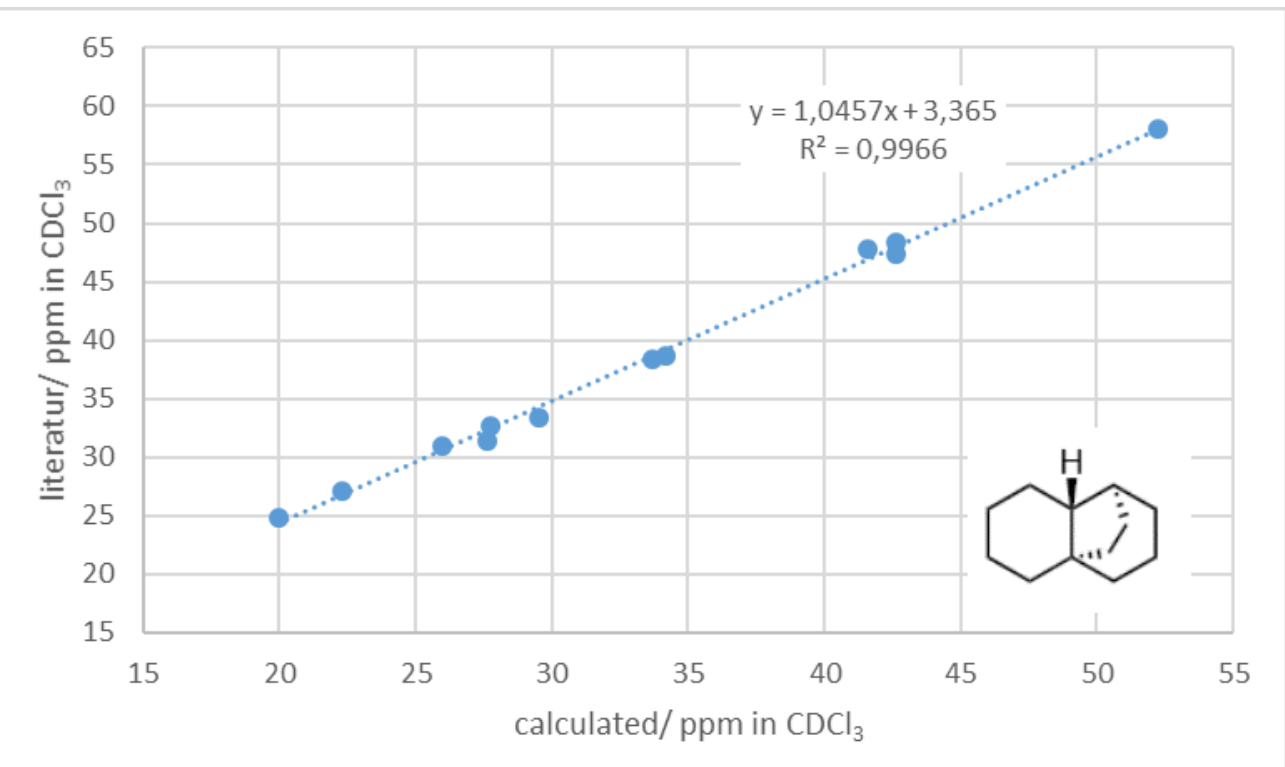

Figure S49: Correlation diagram for trans-perhydro- $2 H$-1,4a-ethanonaphthalene (literature vs. own calculation)

\subsection{Component g (19)}

Component $\mathbf{g}$ has an unsymmetrical perhydro- $a$ s-indacene backbone (with 12 signals in the ${ }^{13} \mathrm{C}-\mathrm{NMR}$ ). Formally, there are only two unsymmetrical isomers with this backbone, the trans,syn,cis and trans, anti,cis. However, the formally symmetrical cis,syn,cis isomer is also computed to have a most stable conformation which is unsymmetrical due to steric strain. The correlation diagrams computed vs measured ${ }^{13} \mathrm{C}-\mathrm{NMR}$ shifts in $\mathrm{C}_{6} \mathrm{D}_{6}$ for the above mentioned three isomers are shown below (Figures S50 to S52).

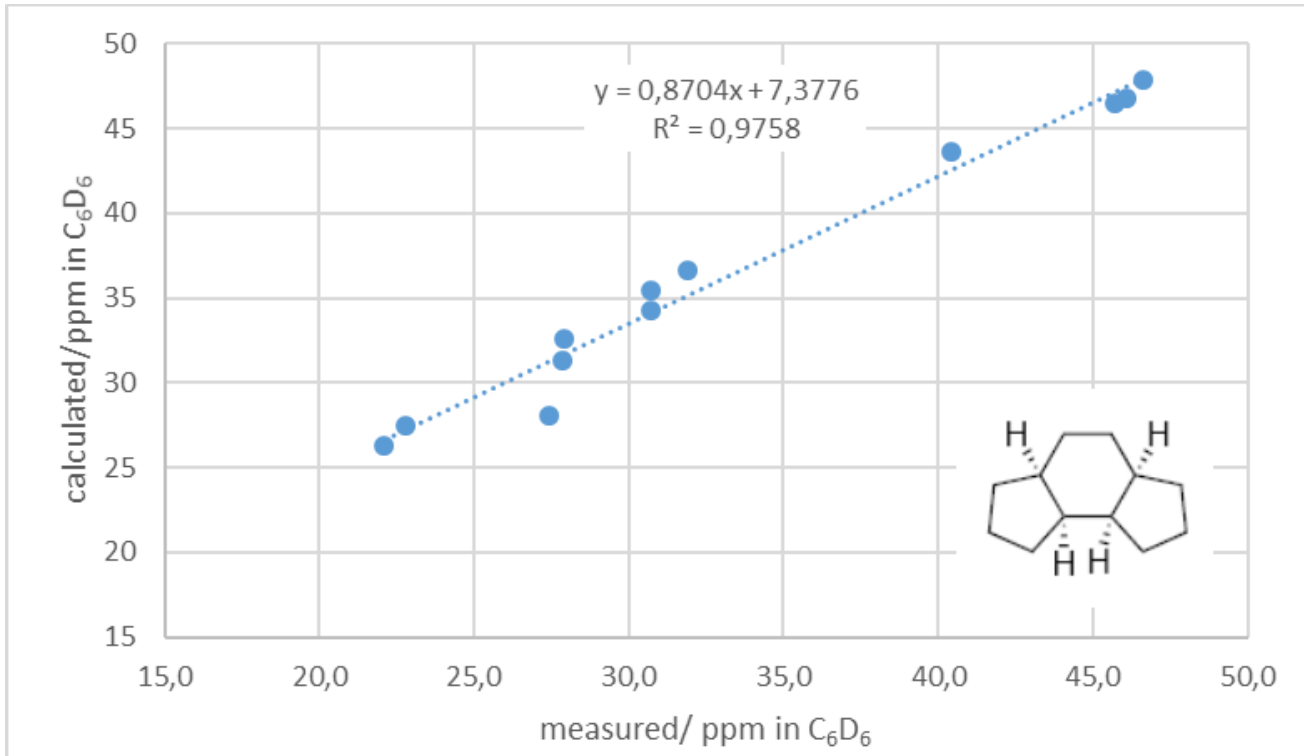

Figure S50: Correlation diagram for cis,syn,cis-perhydro-as-indacene 


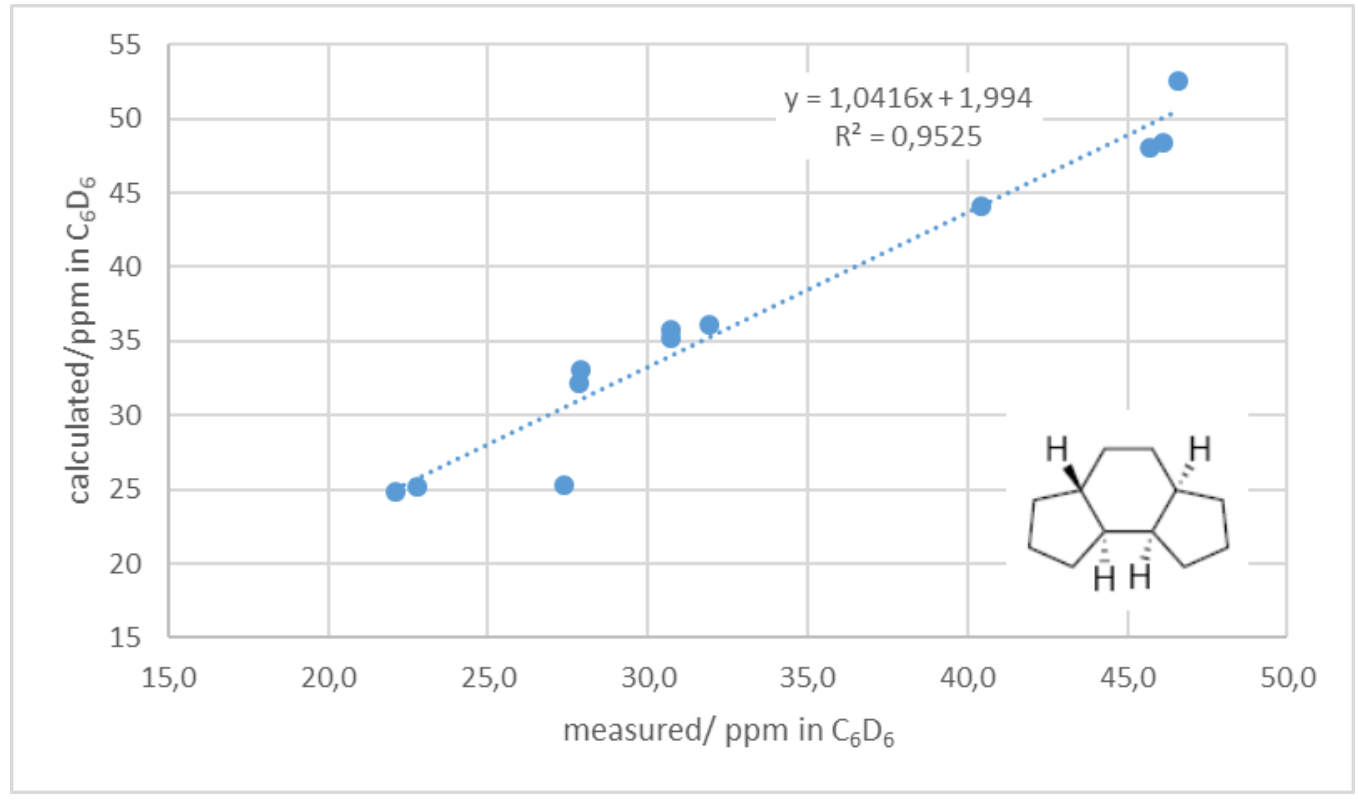

Figure S51: Correlation diagram for trans,syn,cis-perhydro-as-indacene

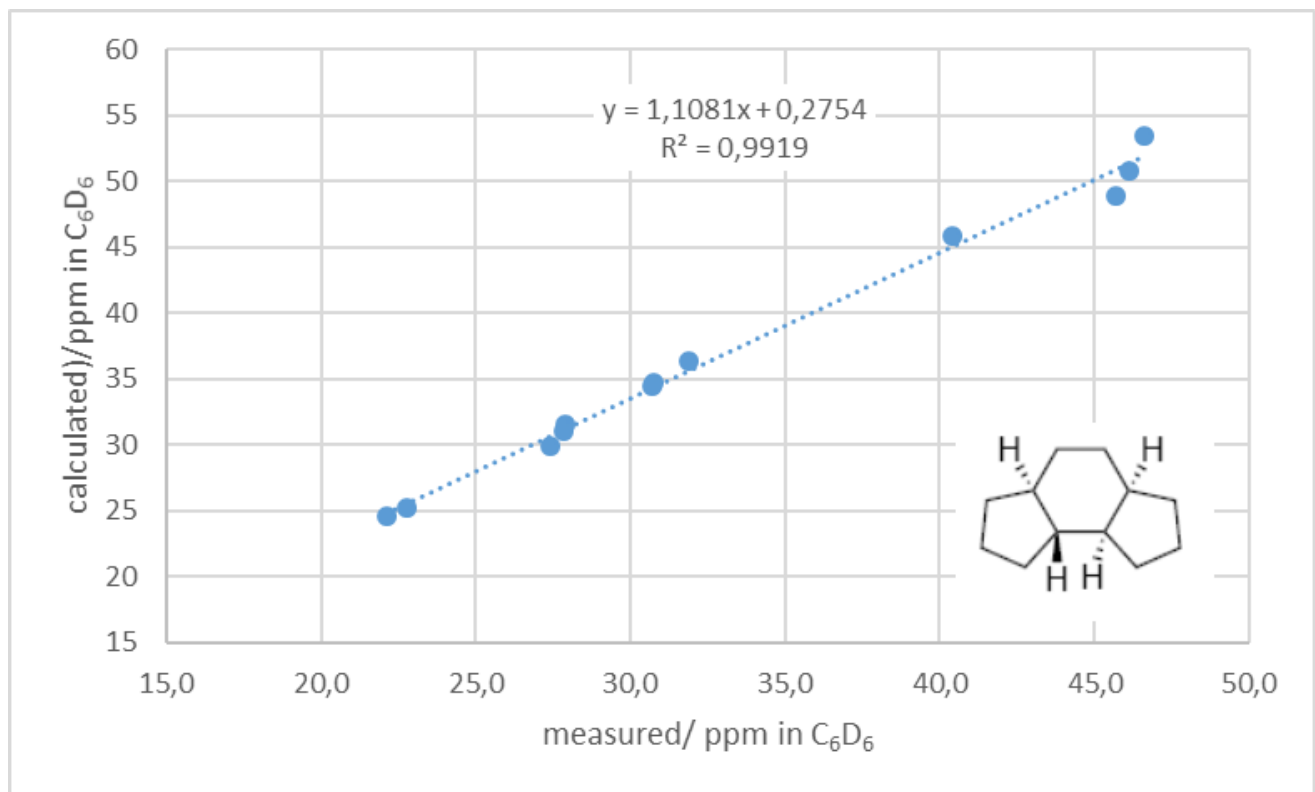

Figure S52: Correlation diagram for trans,anti,cis-perhydro- $a$-indacene (best fit to component g: 19)

The best fit is observed for the trans, anti,cis-perhydro-as-indacene isomer (Figure S52).

The measured shifts (in $\mathrm{CDCl}_{3}$ ) were also compared with the values given in the literature by Petrov and coworkers for the trans,anti,cis-isomer, and as shown in the following correlation diagram (Figure S53) the agreement is perfect. 


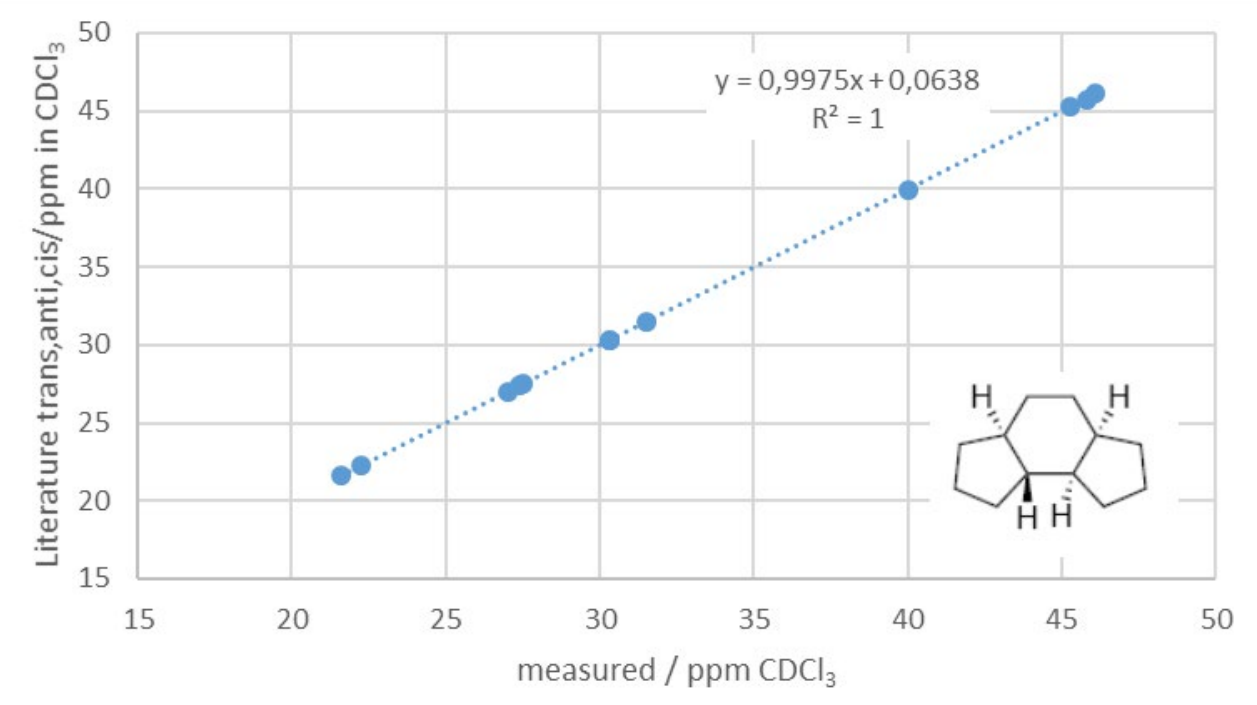

Figure S53: Correlation diagram for trans,anti,cis-perhydro-as-indacene (literature vs. own measurement)

\subsection{Component $\underline{h}(24$ and 20$)$}

Peak $\mathbf{h}$ appears in the GC as a single unresolved peak, but GC-MS reveals that peak $\mathbf{h}$ is actually due to two substances $\left(\mathbf{h}^{\mathbf{1}}\right.$ and $\left.\mathbf{h}^{\mathbf{2}}\right)$ with overlapping peaks. From the integration of the ${ }^{13} \mathrm{C}$-NMR signals the ratio of these two compounds $h^{1}$ and $h^{2}$ is approximately $2: 1$. The major peak $\left(\mathbf{h}^{1}\right)$ has an unsymmetrical perhydro-acenaphthylene backbone, which is also known under the trivial name of ufolane, with 12 separate ${ }^{13} \mathrm{C}-\mathrm{NMR}$ signals. There are six possible dodecahydroacenaphthylene, but only two of them are formally unsymmetrical. Another isomer which is formally symmetrical, the cis, cis, cis-ufolane, is calculated to be also unsymmetrical, due to steric strain, so it is also included in the comparison. The correlation diagrams (computed vs measured ${ }^{13} \mathrm{C}-\mathrm{NMR}$ shifts in $\mathrm{C}_{6} \mathrm{D}_{6}$ for component $\mathbf{h}^{1}$ versus the three isomers mentioned above are shown below.

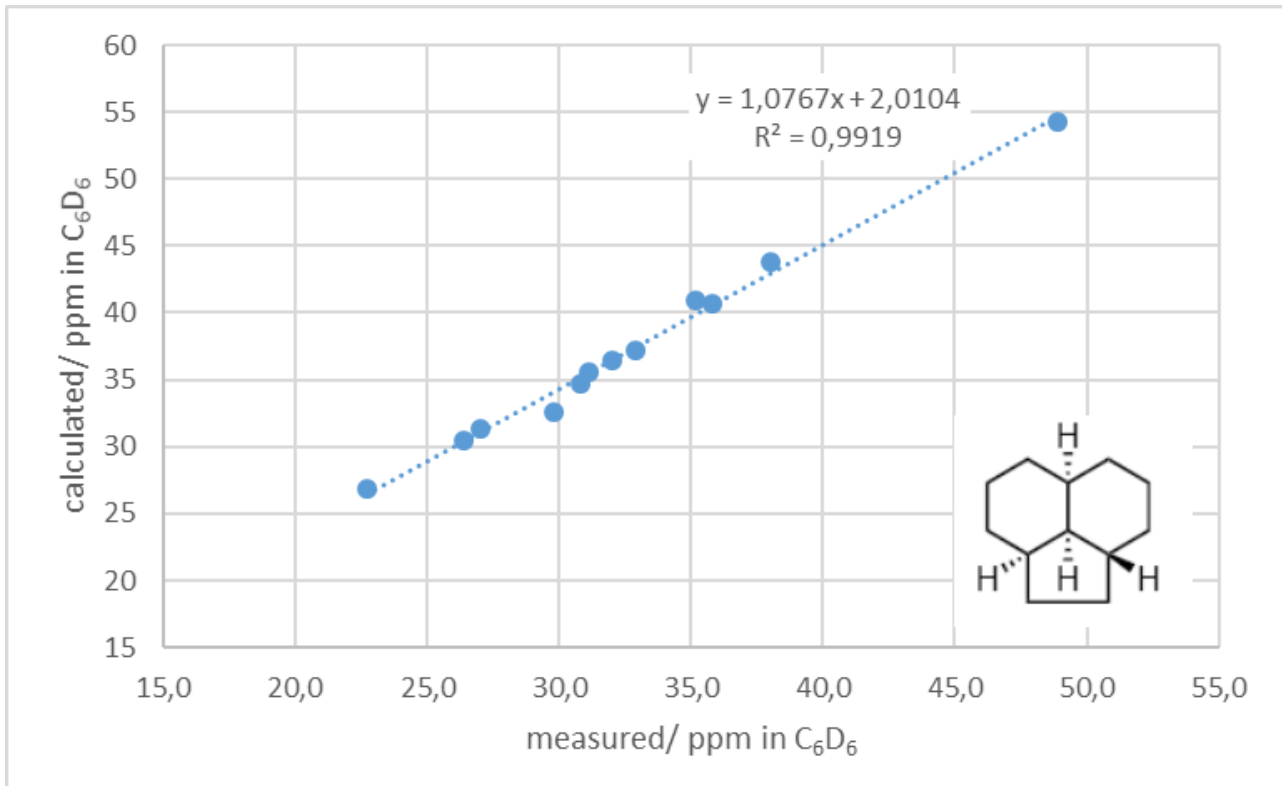

Figure S54: Correlation diagram for cis, cis, trans-ufolane

(best fit for component $\mathbf{h}^{1}: \mathbf{2 4}$ ) 


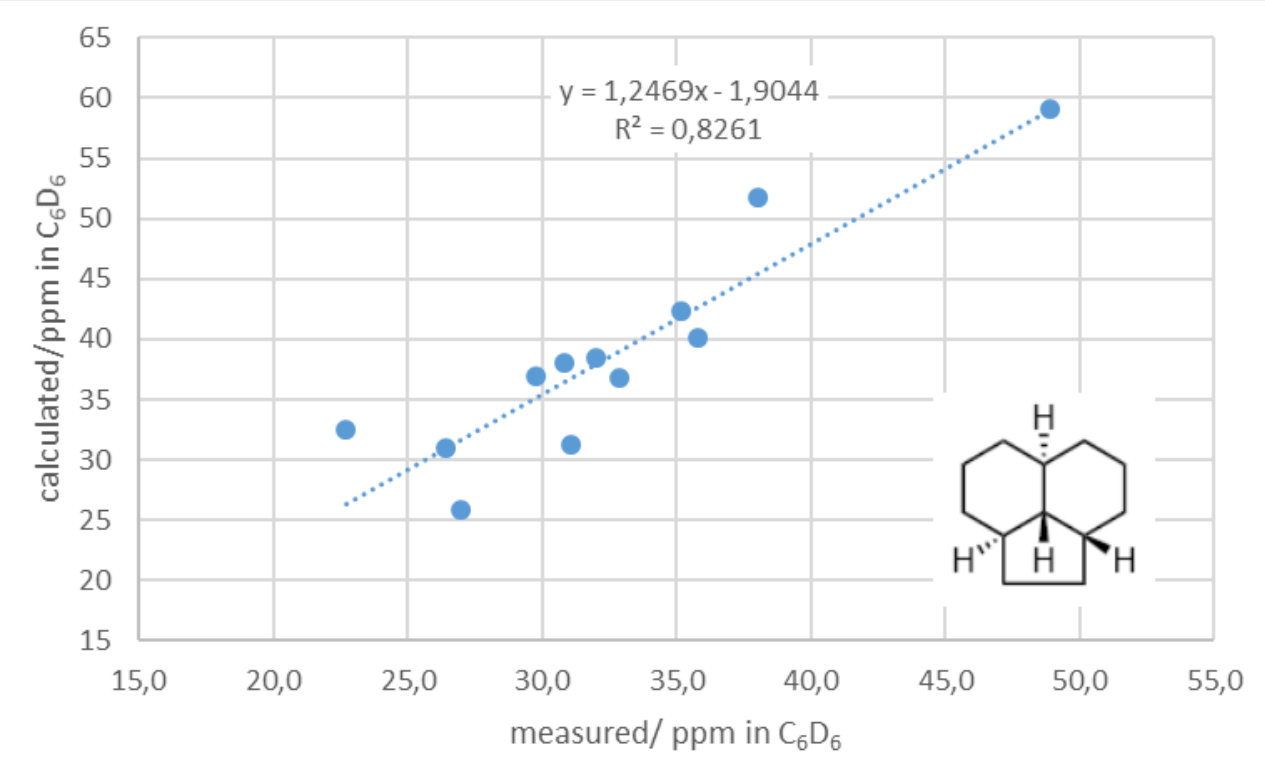

Figure S55: Correlation diagram for cis,trans,trans-ufolane

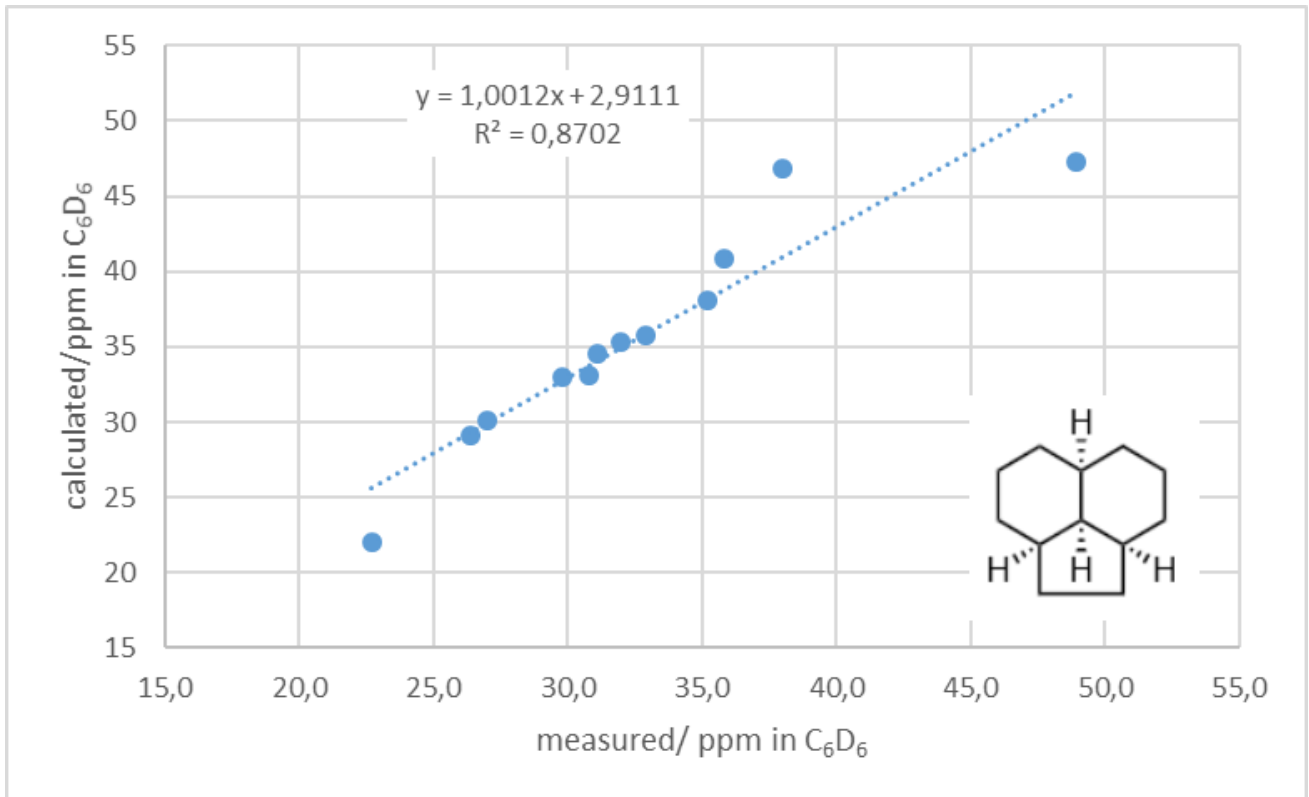

Figure S56: Correlation diagram for cis,cis, cis-ufolane

A good fit is obtained only for the cis,cis,trans-ufolane (Figure S54). This isomer has been described by Boldt and coworkers ${ }^{6}$ and a comparison of the ${ }^{13} \mathrm{C}$-NMR shifts measured in $\mathrm{CDCl}_{3}$ shows they are identical. The calculation thus not only establishes the structure of compound $\mathbf{h}^{\mathbf{1}}$, but also confirms the assignment of Boldt and coworkers. The other unsymmetrical isomer, cis,trans,trans-ufolane, was observed by Boldt as a minor isomer in the GC, but it was not isolated and no ${ }^{13} \mathrm{C}-\mathrm{NMR}$ shifts are given, so no comparison with calculated shifts is possible.

The minor component $\left(\mathbf{h}^{2}\right)$ has an unsymmetrical perhydro-as-indacene backbone (with 12 signals in the ${ }^{13} \mathrm{C}$ NMR). There are only two possible unsymmetrical perhydro-as-indacenes (the trans,syn,cis- and the trans, anti,cis-isomers), but the trans, anti,cis-isomer has already been assigned to component $\mathbf{g}$, so for $\mathbf{h}^{2}$ there is

\footnotetext{
${ }^{6}$ Boldt, P.; Arensmann, E.; Blenkle, M.; Kersten, H.; Tendler, H., Trog, R.-S.; Jones, P. G.; Döring, D. Synthesis of
} Stereoisomeric Ufolanes. Chem. Ber., 1992, 125, 1147-1157 
only the trans,syn,cis-structure left. The following correlation (Figure S57) diagram shows the very good agreement between the measured and the calculated shifts, thus confirming that component $\mathbf{h}^{\mathbf{2}}$ is indeed trans,syn,cis-perhydro-as-indacene.

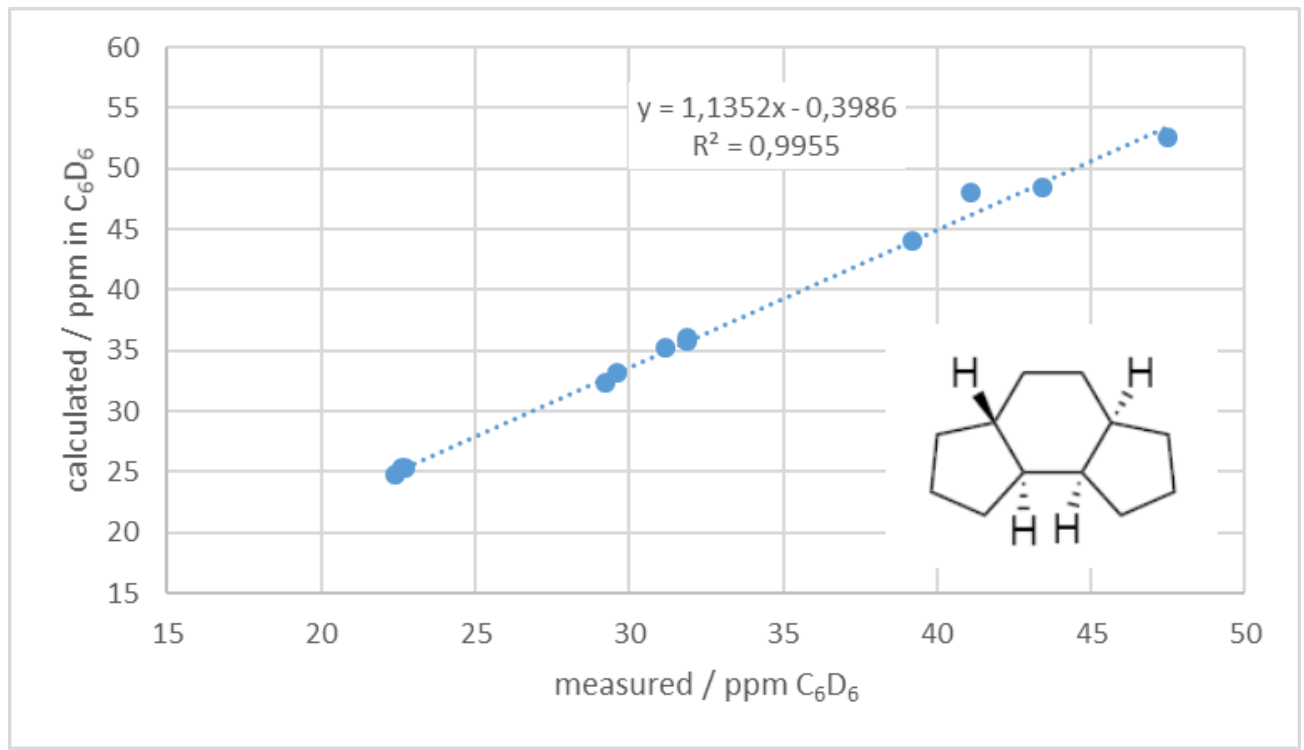

Figure S57: Correlation diagram for trans,syn,cis-perhydro-as-indacene (best fit for component $\mathbf{h}^{\mathbf{2}}: \mathbf{2 0}$ )

This isomer has also been described by Petrov and coworkers (see reference 1 on page S50). The following correlation diagram (Figure S58) shows the fit between the shifts given by Petrov and the ones found for component $\mathbf{h}^{2}$.

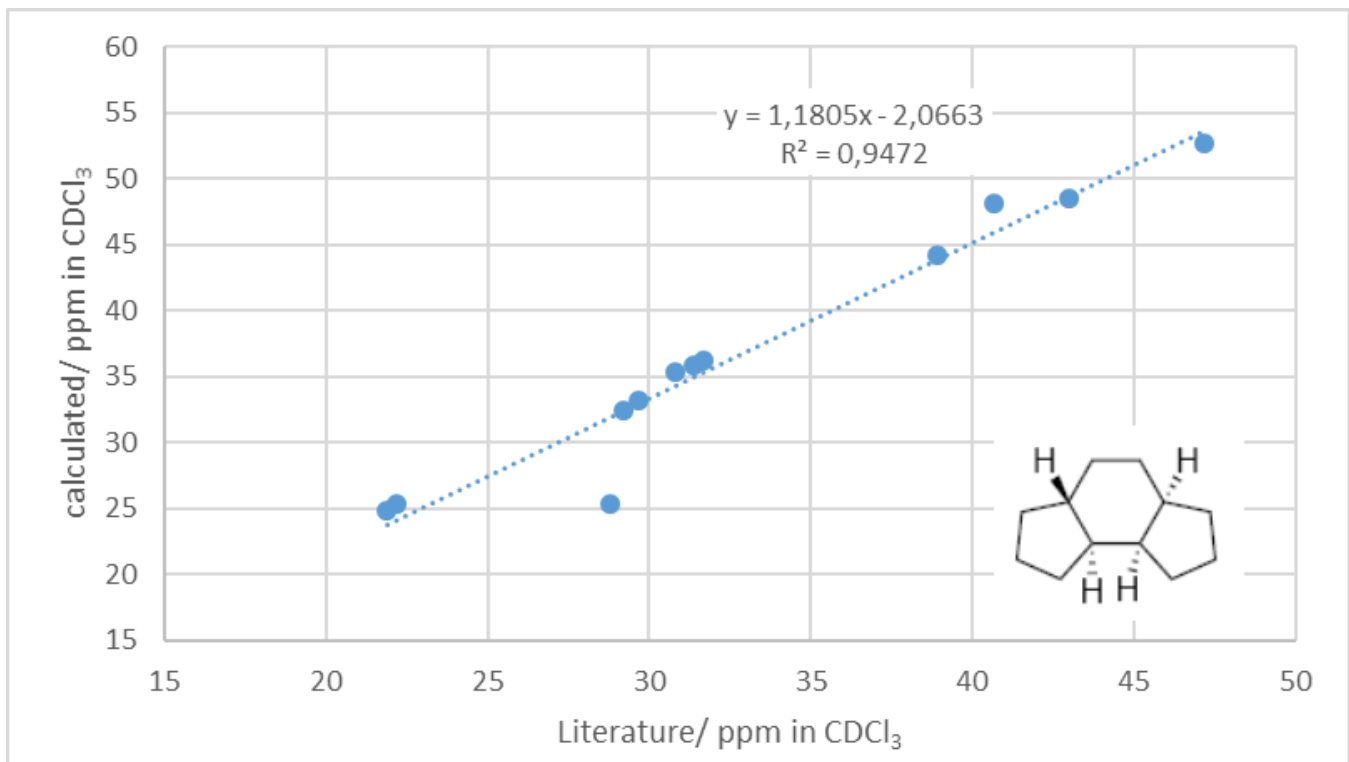

Figure S58: Correlation diagram for trans,syn,cis-perhydro- $a$ s-indacene (literature vs. own measurement)

As can be seen, except for one peak, the agreement is excellent (if this peak is left out, the correlation coefficient $\mathrm{R}^{2}$ increases to 0,9994 and the slope is very close to one $(1,0008)$ ). Since the calculated shifts are in very good agreement with the observed ones, it is most likely that this shift given by Petrov is incorrect. 


\subsection{Component ị (25)}

Component $\mathbf{i}$ has a symmetrical dodecahydroacenaphthylene backbone, which is also known under the trivial name of ufolane, with 7 separate ${ }^{13} \mathrm{C}-\mathrm{NMR}$ signals. There are six possible perhydro-acenaphthylenes, but only four of them are formally symmetrical. One of the formally symmetrical isomers, cis,cis,cis-ufolane, is predicted by calculation to have a lowest energy conformation which is unsymmetrical and thus shows 12 different signals. However, according to Boldt and coworkers this isomer is still symmetrical at the time scale of the NMR measurement at ambient temperature. For this reason, we also used the averaged calculated shifts in the comparison with the measured ones. The correlation diagrams (computed vs measured ${ }^{13} \mathrm{C}-\mathrm{NMR}$ shifts in $\mathrm{C}_{6} \mathrm{D}_{6}$ for component i versus the above mentioned four isomers are shown below (Figures S59 to S62).

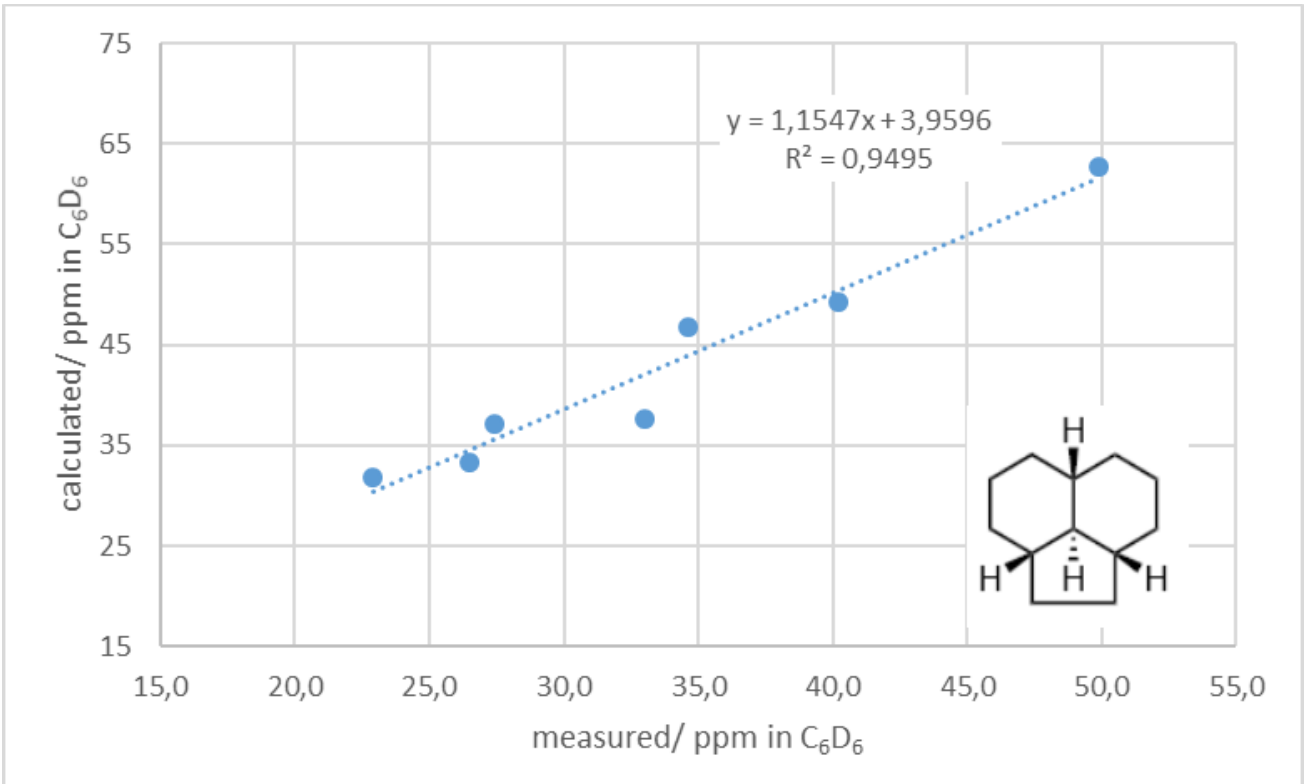

Figure S59: Correlation diagram for trans,trans,trans-ufolane

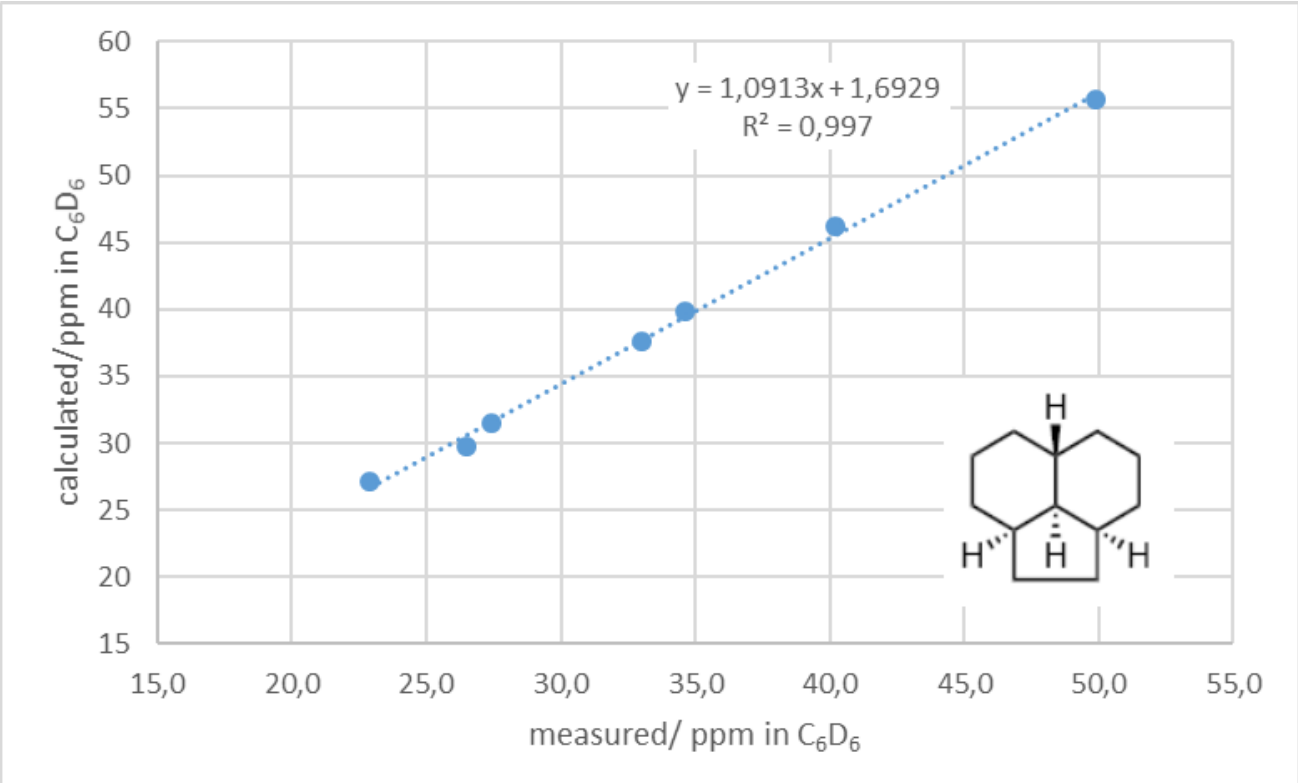

Figure S60: Correlation diagram for cis,trans, cis-ufolane

(best fit for component i: 25) 


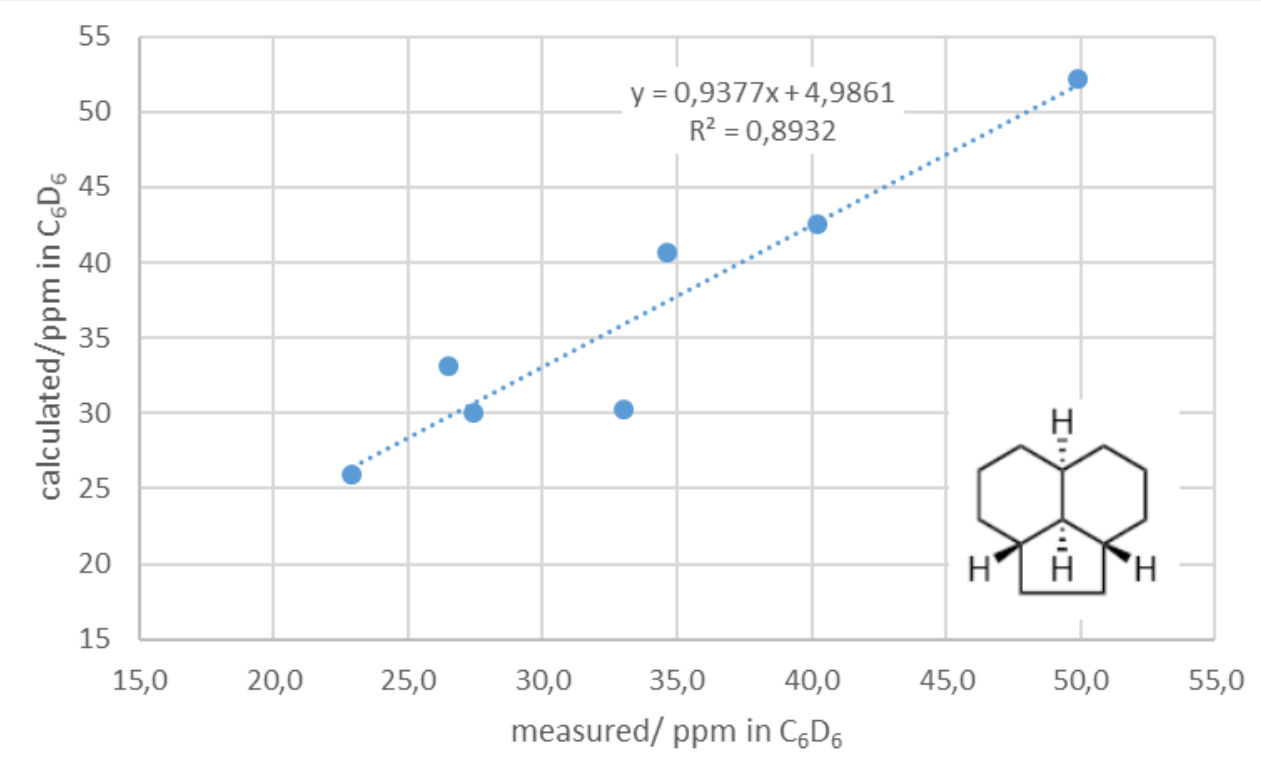

Figure S61: Correlation diagram for trans, cis,trans-ufolane

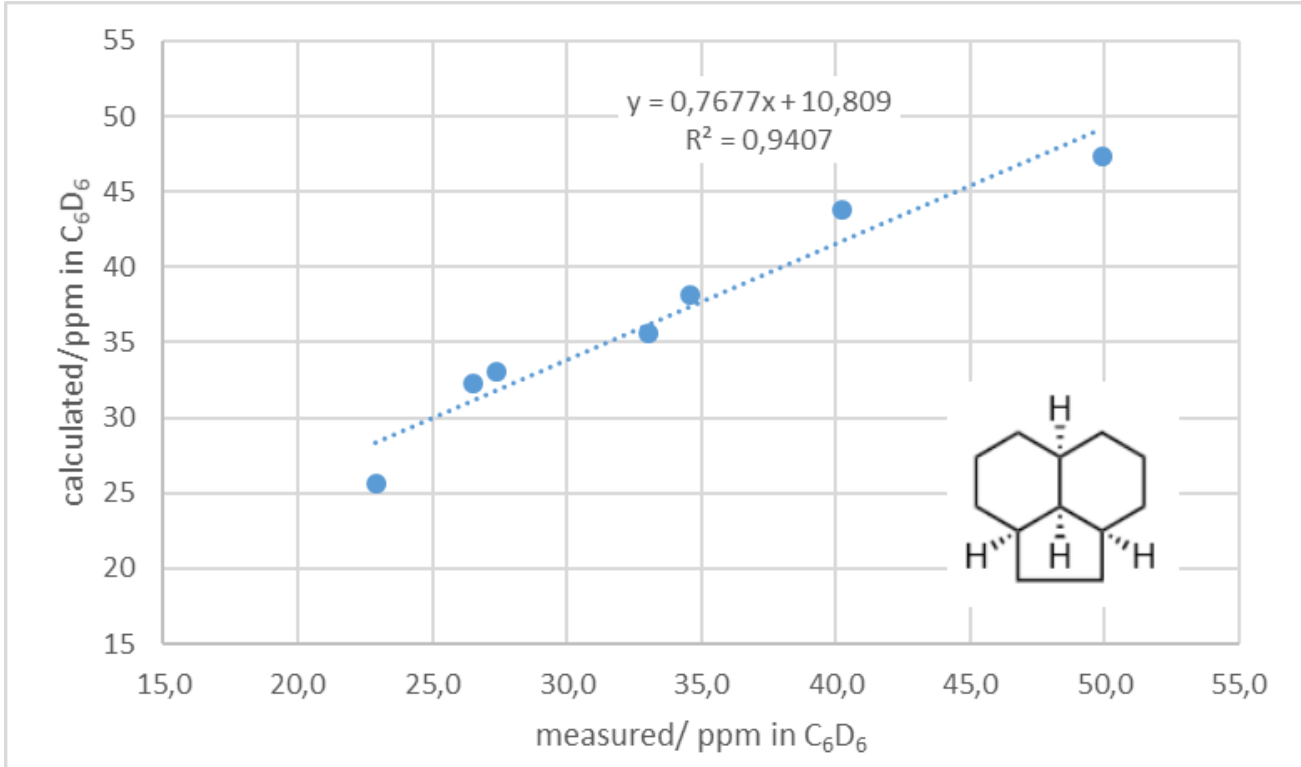

Figure S62: Correlation diagram for cis,cis, cis-ufolane (symmetrically averaged)

The best fit is obtained for cis,trans,cis-ufolane (Figure S60). This isomer is also mentioned by Boldt and coworkers, but it was not isolated, and no ${ }^{13} \mathrm{C}-\mathrm{NMR}$ shift are given in the paper.

Interestingly, the two ufolane isomers contained in our by-product mixture are exactly the same isomers formed in the acid catalyzed isomerization of 1,5,9-cyclododecatriene with polyphosphoric acid, as described by Boldt (see reference 6 on page S65).

To further check the assignments, we compared the ${ }^{13} \mathrm{C}-\mathrm{NMR}$ shifts given by Boldt and coworkers for the symmetrical cis,cis,cis, and trans,trans,trans isomers with the calculated values (all in $\mathrm{CDCl}_{3}$ ). The correlation diagrams are shown below (Figures S63 and S64). 


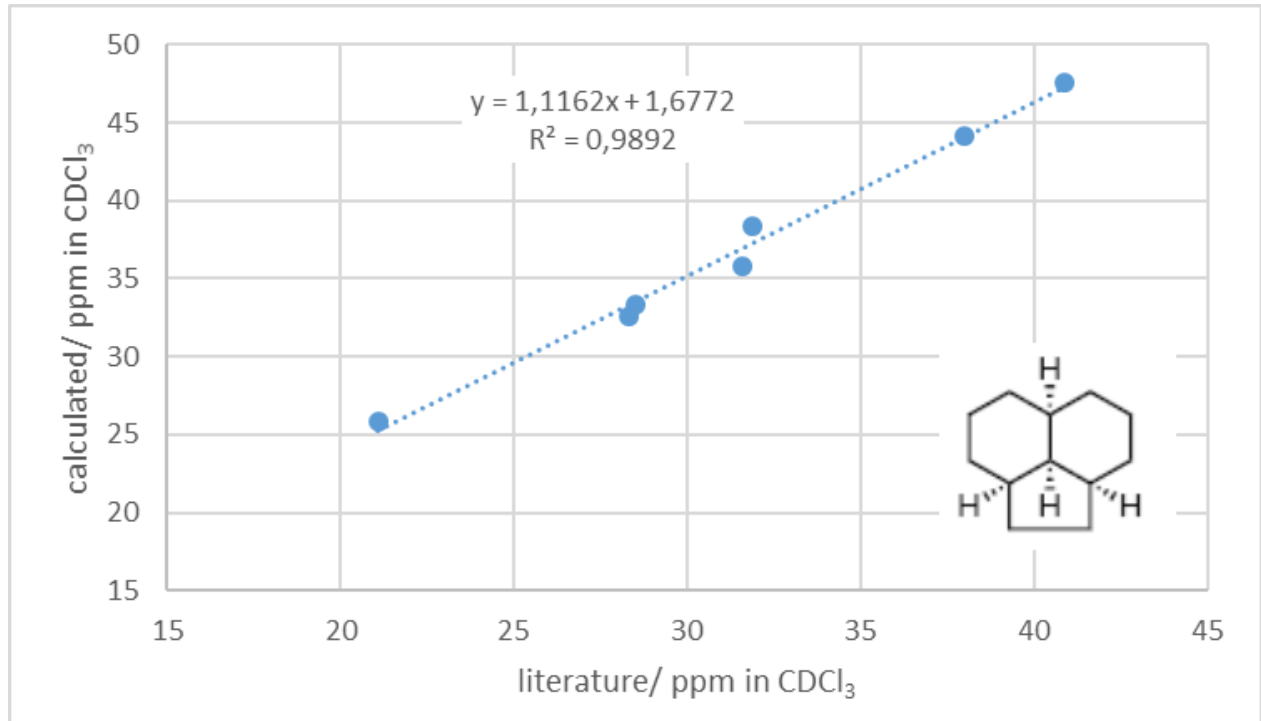

Figure S63: Correlation diagram for cis,cis,cis-ufolane (data from Boldt and coworkers vs averaged calculated values, in $\mathrm{CDCl}_{3}$ )

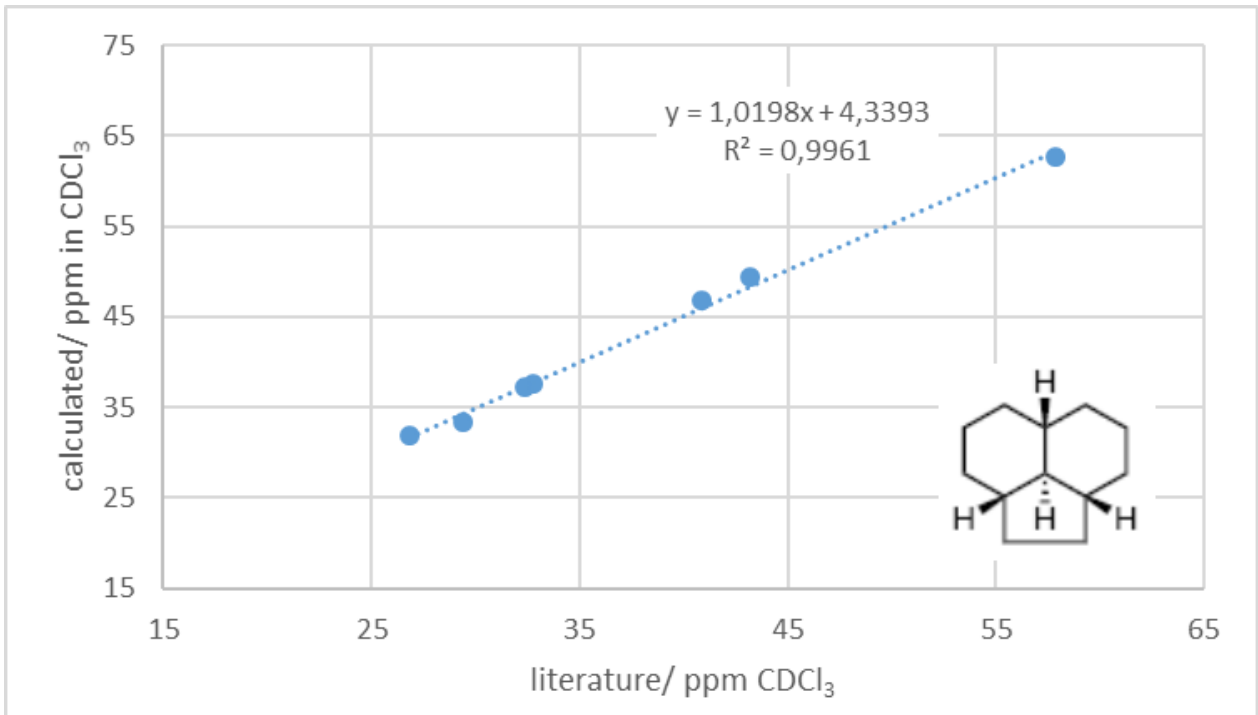

Figure S64: Correlation diagram for trans,trans,trans-ufolane (data from Boldt and coworkers vs calculated values, in $\mathrm{CDCl}_{3}$ )

In both cases a good to very good correlation is found. The good fit obtained in Figure S63 also demonstrates, that, although the calculations predict an unsymmetrical ground state for the cis,cis, cis isomer it is still symmetrical on the time scale of NMR at ambient temperature. 


\subsection{Component i (21)}

Component $\mathbf{j}$ has a symmetrical perhydro-as-indacene backbone (with just 6 signals in the ${ }^{13} \mathrm{C}-\mathrm{NMR}$ ).

There are four possible isomers which are formally symmetrical, but the trans, anti,trans-isomer can in principle be excluded, because it was already assigned to component $\mathbf{a}$. For the sake of completeness all the four isomers are compared. The correlation diagrams (computed vs measured ${ }^{13} \mathrm{C}-\mathrm{NMR}$ shifts in $\mathrm{C}_{6} \mathrm{D}_{6}$ for component $\mathbf{j}$ for the four symmetrical isomers is shown below (Figures S65 to S68). The cis,syn,cis isomer, although formally symmetrical, is computed to have an unsymmetrical lowest energy conformation. Comparison was thus made with averaged shifts.

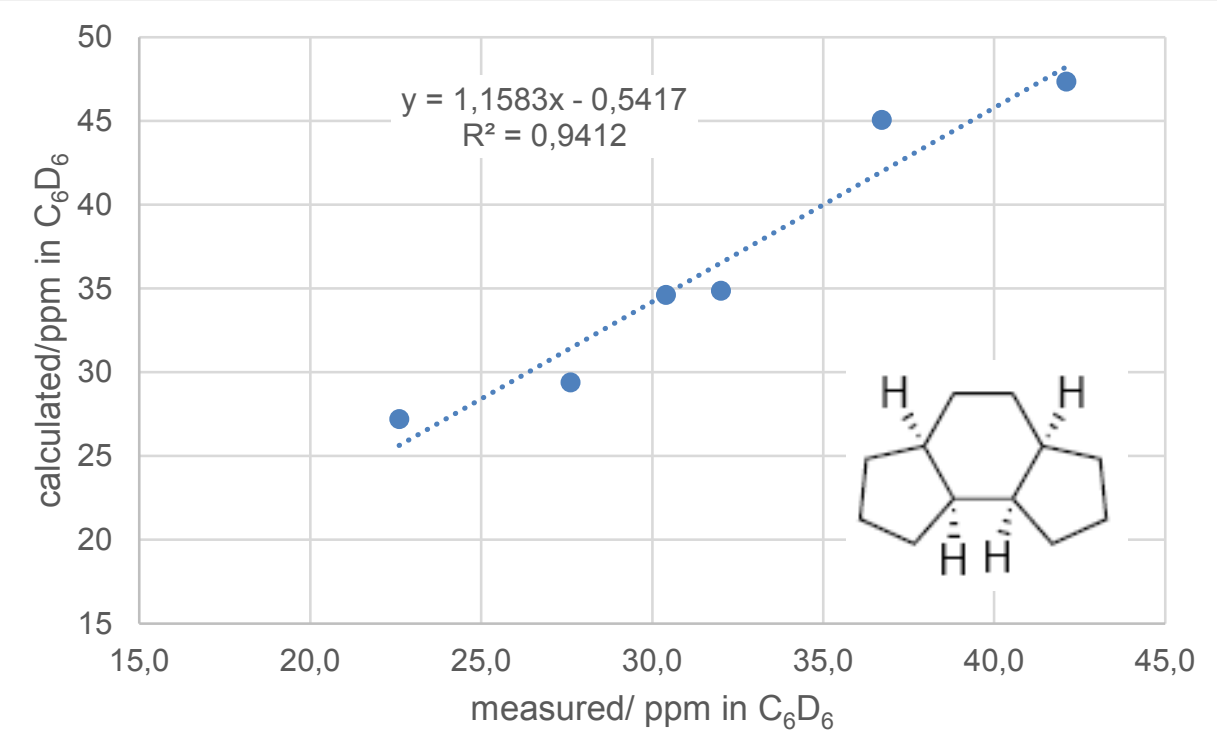

Figure S65: Correlation diagram for cis,syn,cis-perhydro-as-indacene

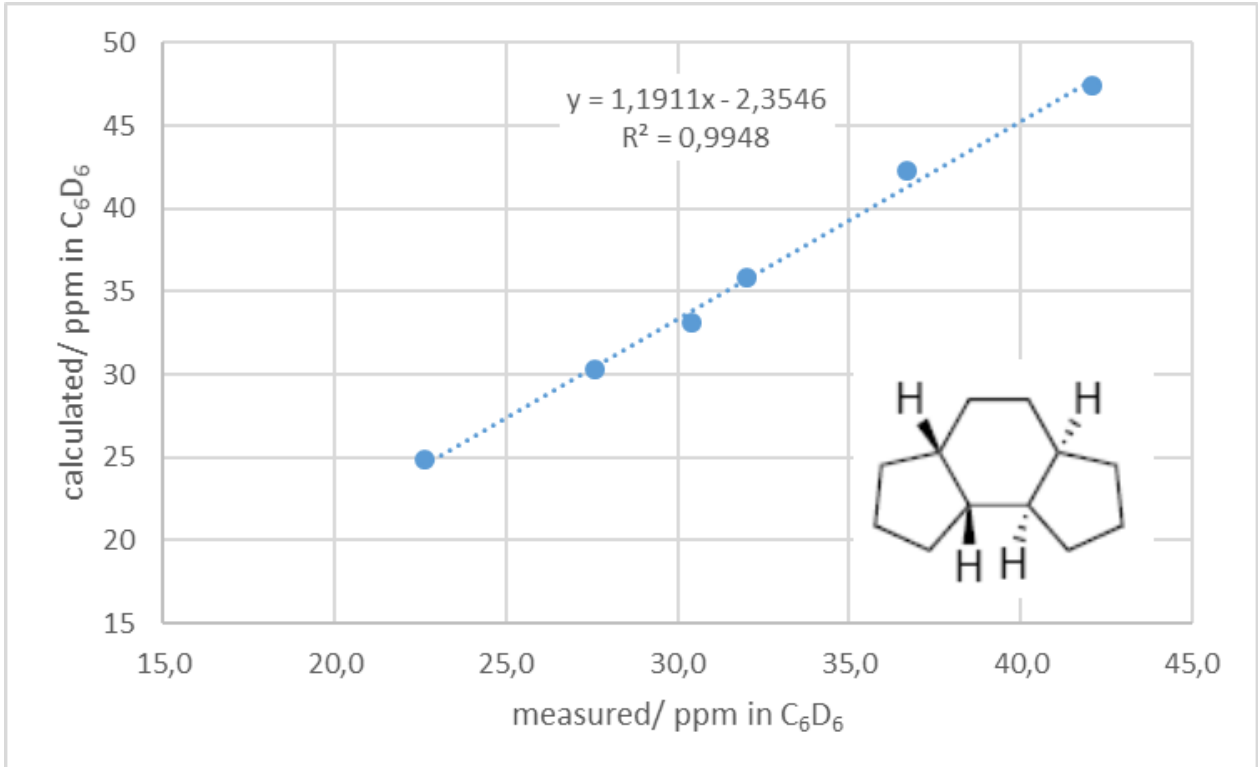

Figure S66: Correlation diagram for cis,anti,cis-perhydro-as-indacene (best fit for component $\mathbf{j}: \mathbf{2 1}$ ) 


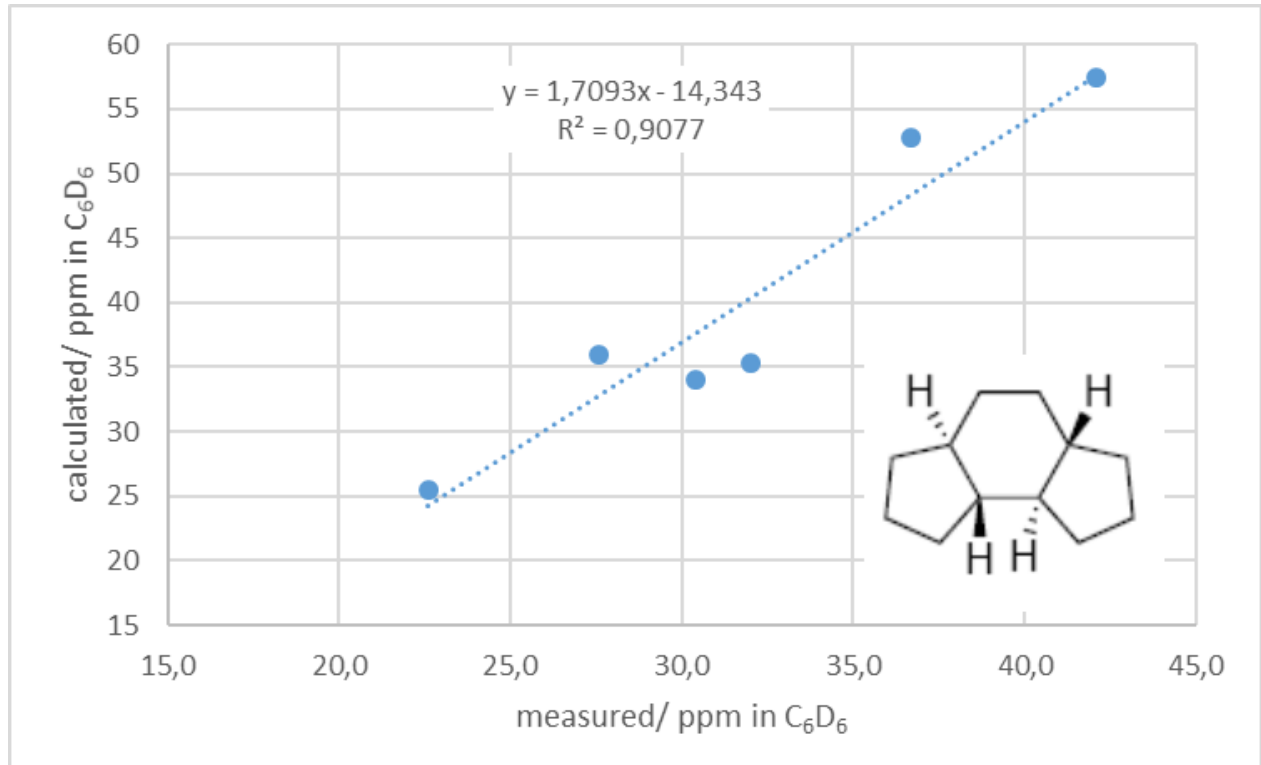

Figure S67: Correlation diagram for trans,anti,trans-perhydro-as-indacene (already assigned to component a)

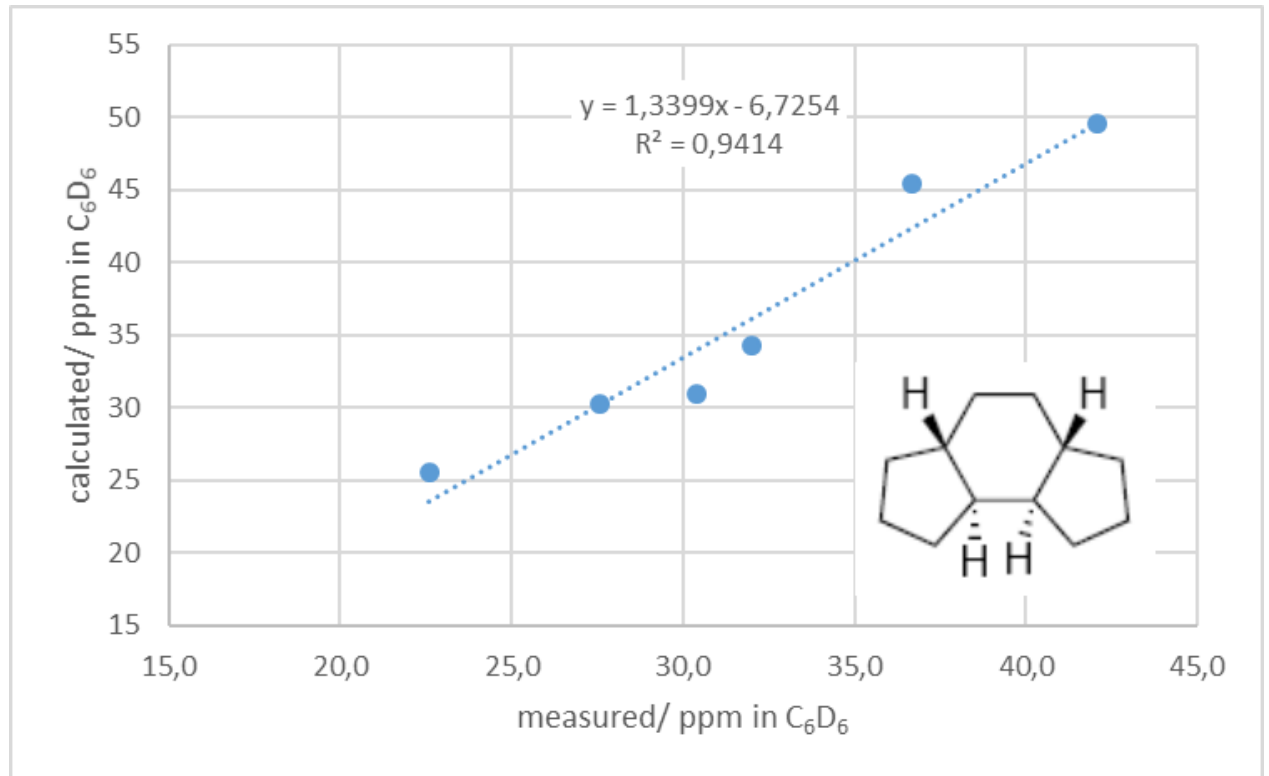

Figure S68: Correlation diagram for trans,syn,trans-perhydro-as-indacene

The results show the best fit for the cis,anti,cis-perhydro-as-indacene isomer (Figure S66). This isomer has been described by Petrov and coworkers (see reference 1 on page S50).

A comparison of the ${ }^{13} \mathrm{C}$-NMR shifts given by Petrov and coworkers for cis,anti,cis-perhydro-as-indacene and component $\mathbf{j}$ shows that these are identical (see Figure S69 below). 


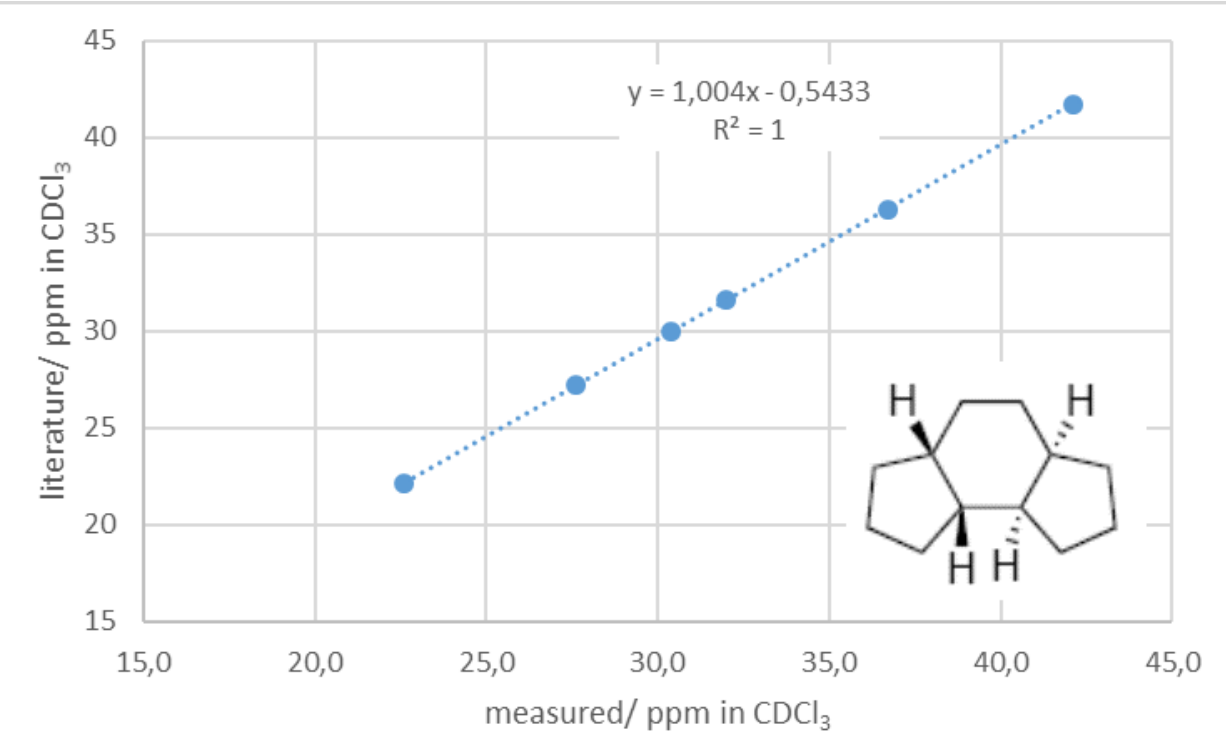

Figure S69: Correlation diagram for cis,anti,cis-perhydro-as-indacene (literature vs. own measurements, both in $\left.\mathrm{CDCl}_{3}\right)$

Petrov and coworkers describe two other symmetrical perhydro-as-indacenes, the trans,anti,trans and the cis,syn,cis isomers, which are not found in our by-product mixture. To further test the quality of our calculations, the literature data for these two isomers was compared with the calculated data (both in $\mathrm{CDCl}_{3}$ ). The correlation diagrams are shown below (Figures S70 and S71).

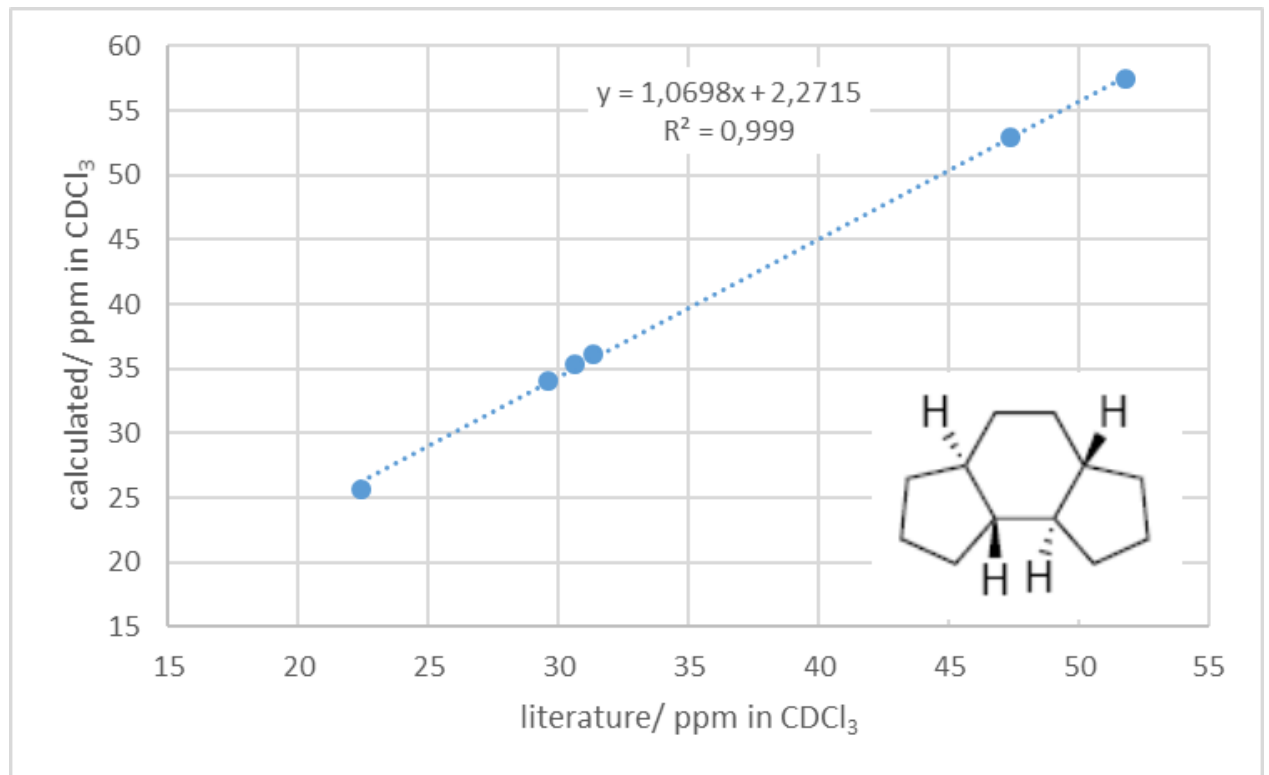

Figure S70: Correlation diagram for trans, anti,trans-perhydro-as-indacene (literature vs. own calculations, both in $\mathrm{CDCl}_{3}$ ) 


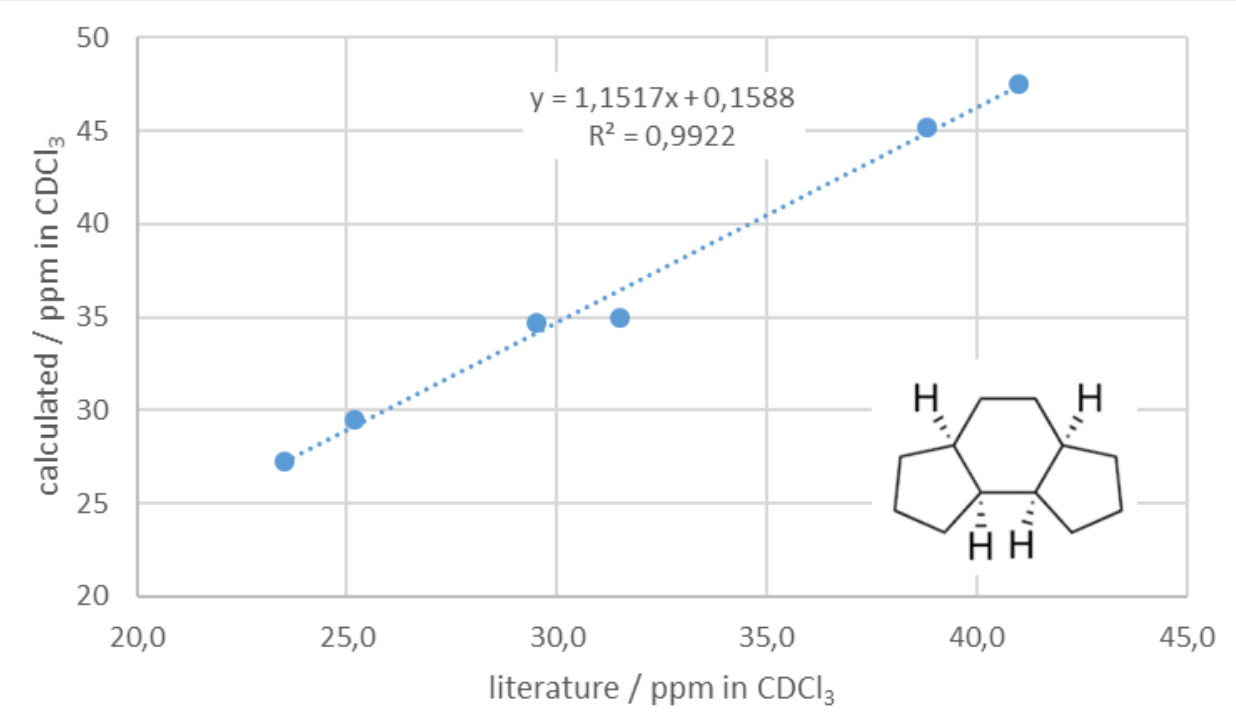

Figure S71: Correlation diagram for cis,syn,cis-perhydro-as-indacene (literature vs. own calculations, both in $\left.\mathrm{CDCl}_{3}\right)$

In both cases, the agreement between calculation and literature data is good. This both substantiates the quality of the calculations and confirms the assignments made by Petrov and coworkers.

\subsection{Component $\underline{\mathbf{k}}$ (17)}

Component $\mathbf{k}$ is the only component with a tetracyclic backbone. Although the carbon backbone is unequivocally determined by the ${ }^{13} \mathrm{C}-2 \mathrm{D}$-INADEQUATE measurement (no other isomers are possible with this connectivity) it was still interesting to compare the measured and the computed shifts. The correlation diagram (computed vs measured ${ }^{13} \mathrm{C}-\mathrm{NMR}$ shifts in $\mathrm{C}_{6} \mathrm{D}_{6}$ ) for component $\mathbf{k}$ is shown below (Figure S72). As expected, a good correlation is obtained.

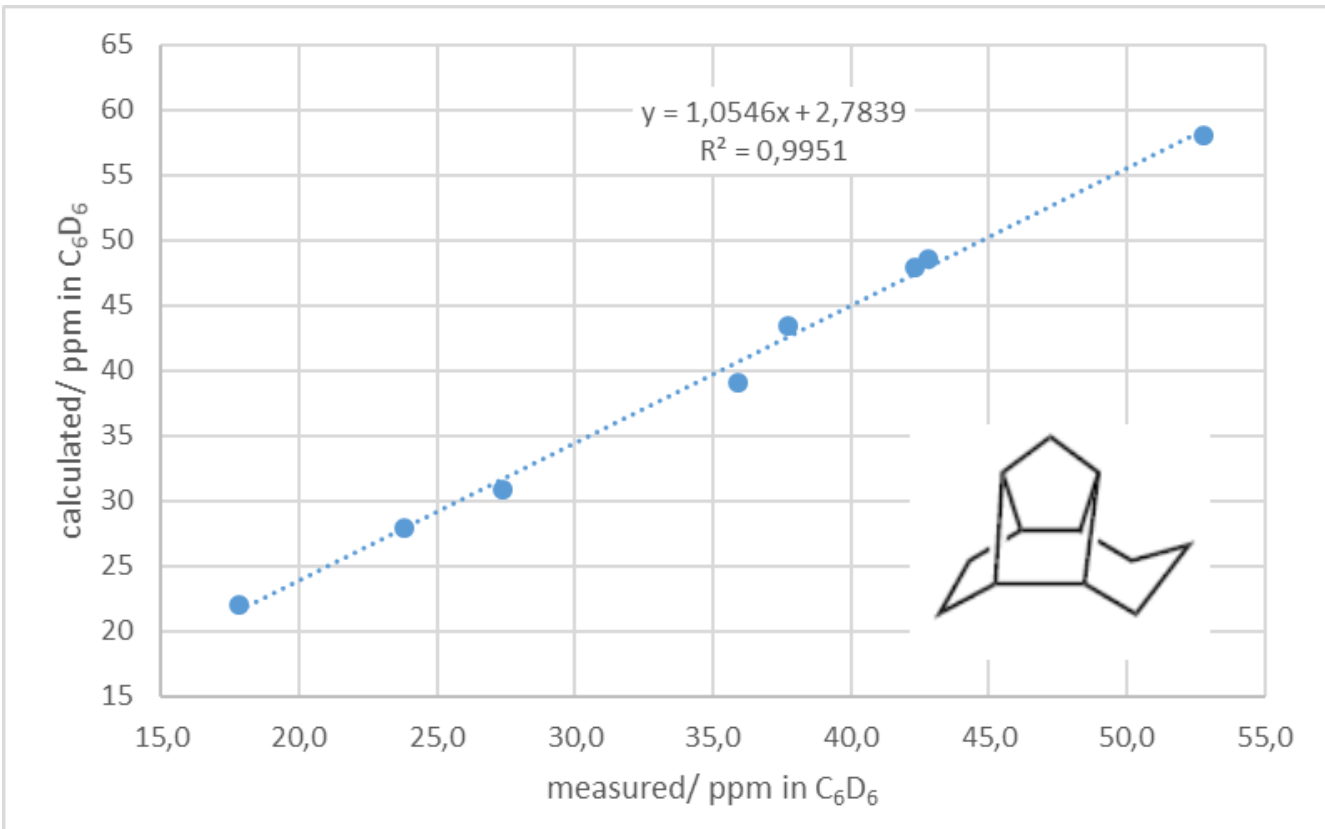

Figure S72: Correlation diagram for 17 


\section{IR and EI-MS spectra}

These were taken from a GC-MS/IR coupling.

\subsection{Component a (18)}

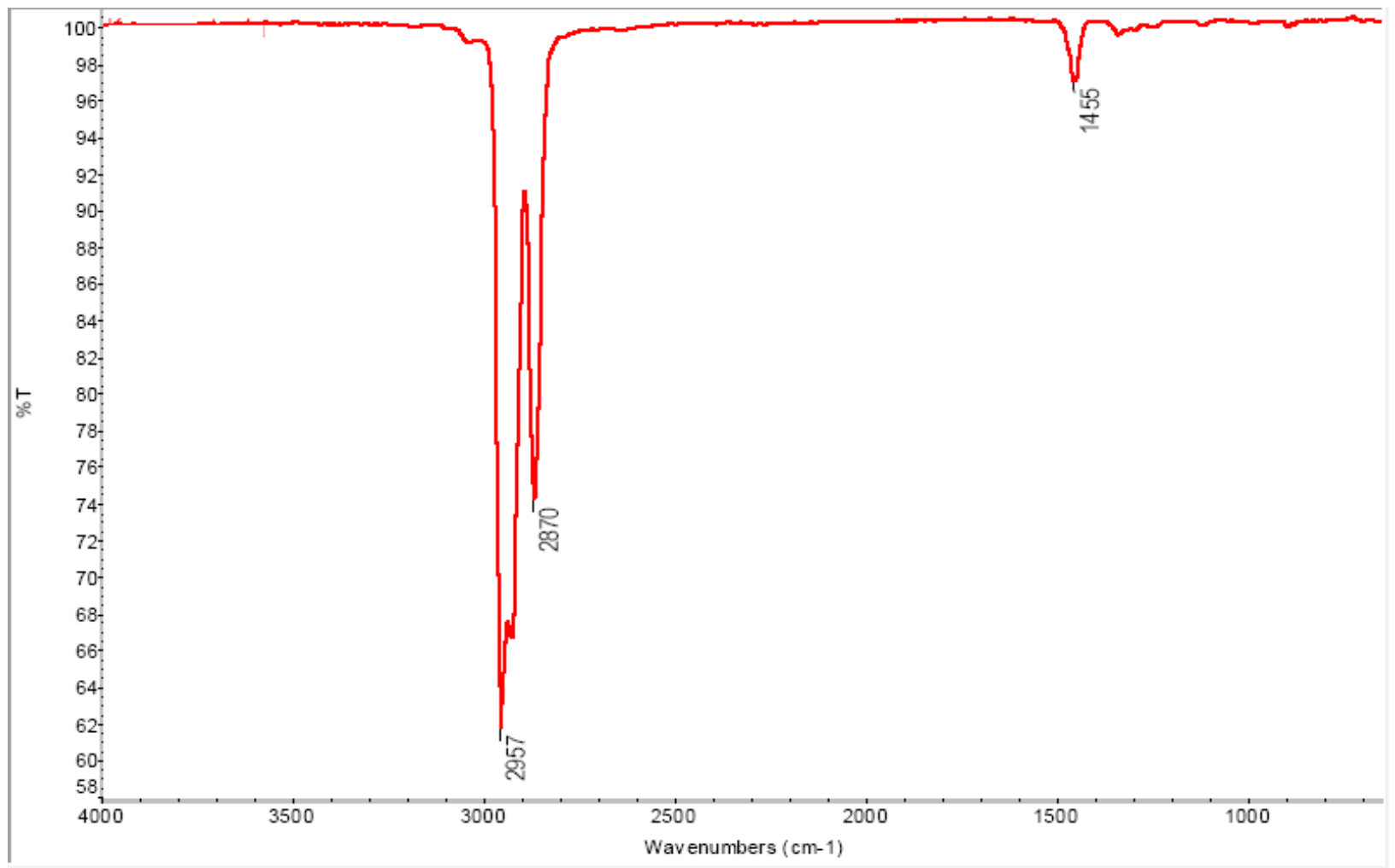

Figure S73: IR spectrum

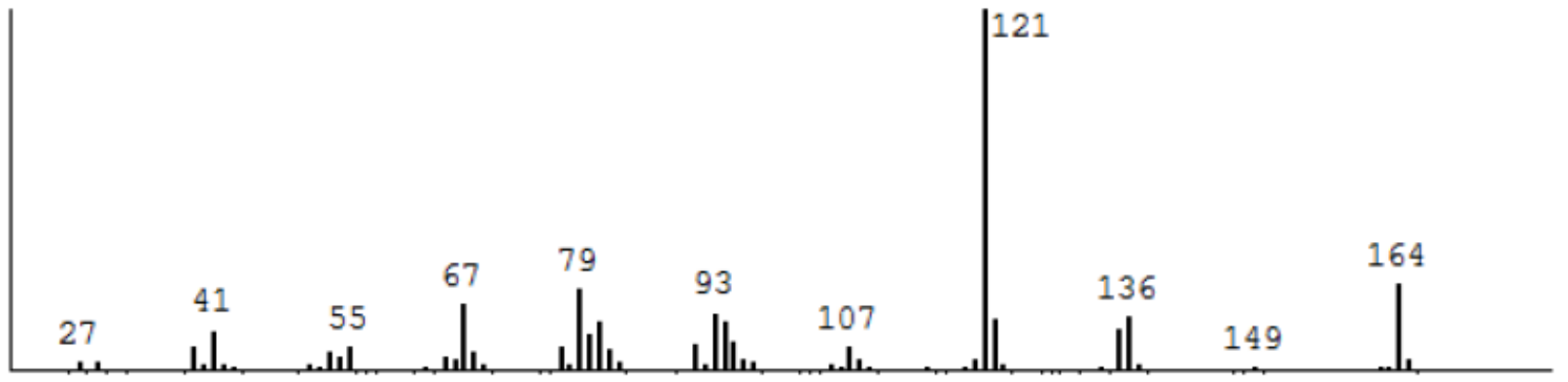

Figure S74: EI-MS spectrum 


\subsection{Component $\underline{b}$ (22)}

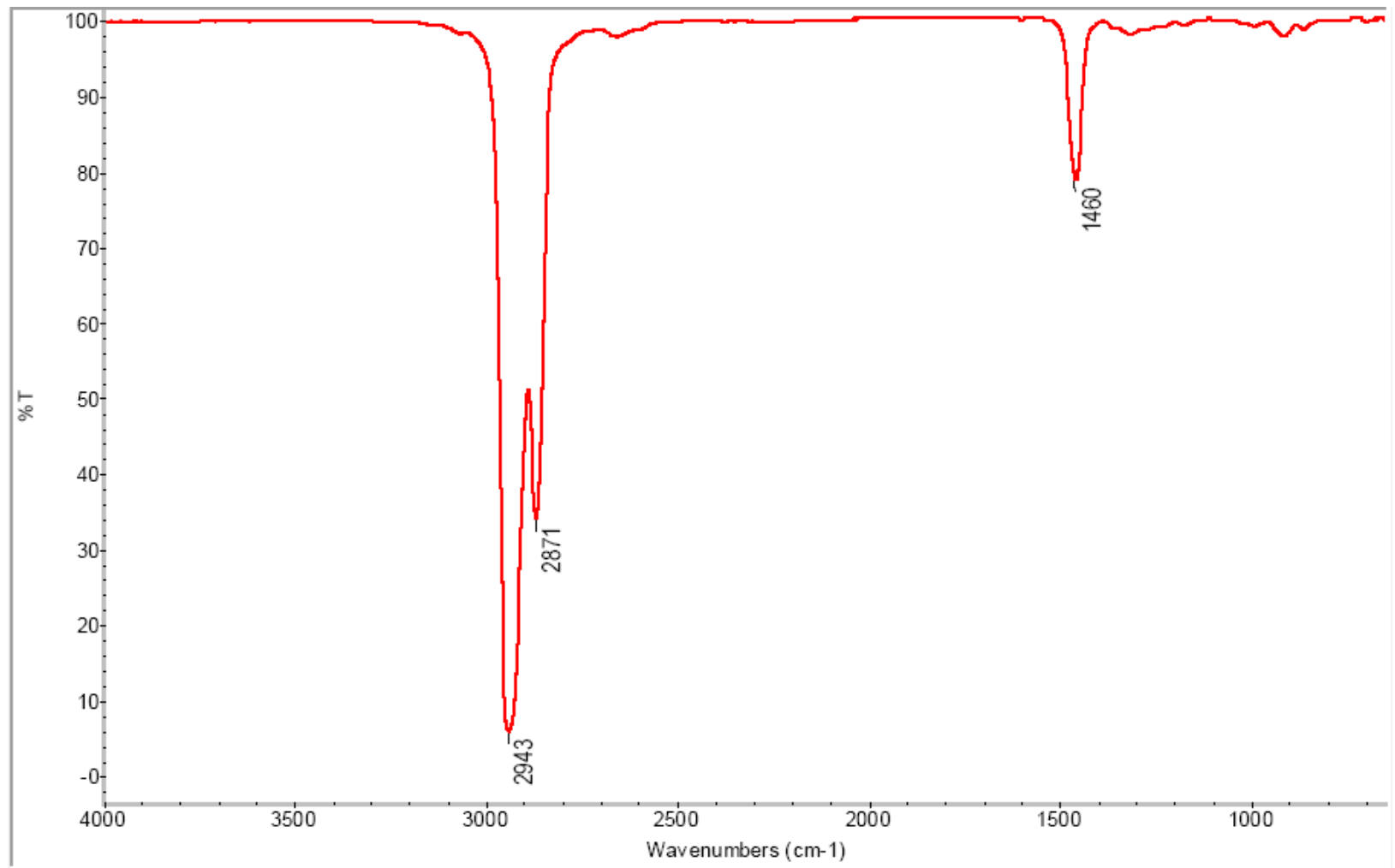

Figure S75: IR spectrum

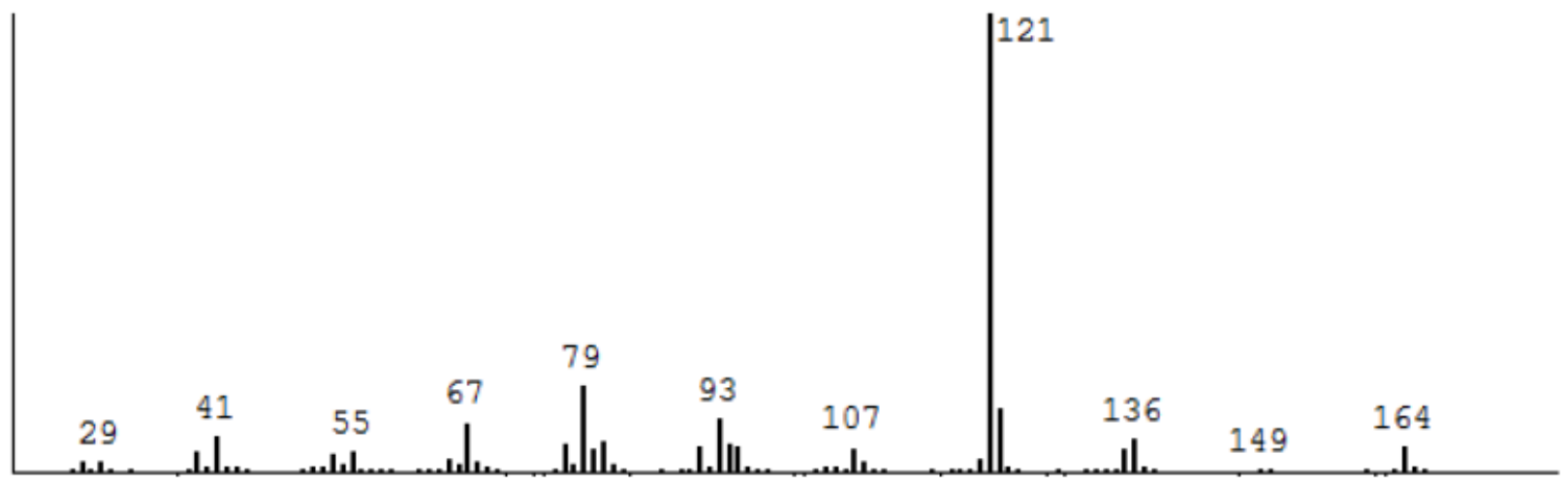

Figure S76: EI-MS spectrum 


\subsection{Component $\underline{\text { c }}$ (23)}

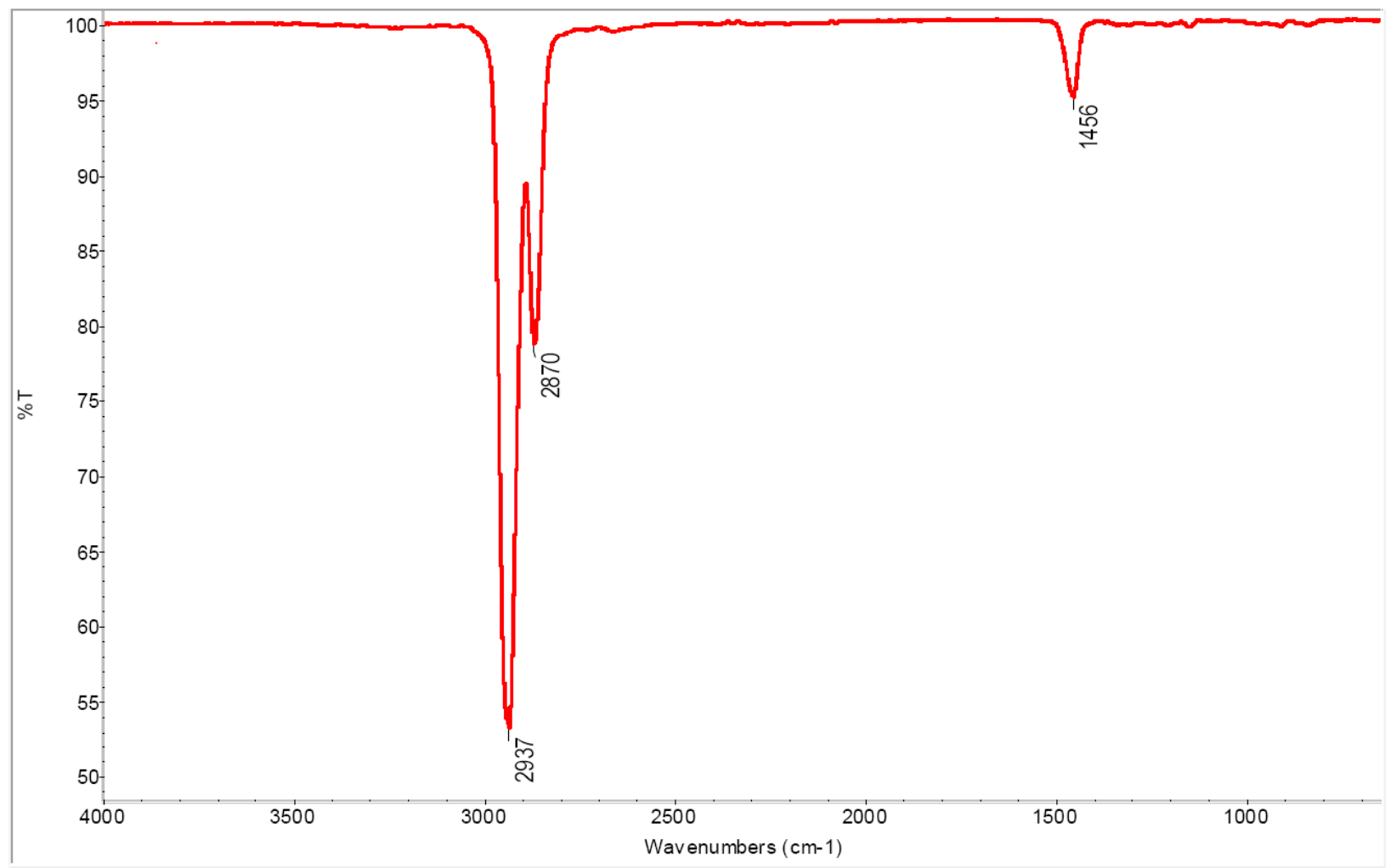

Figure S77: IR spectrum

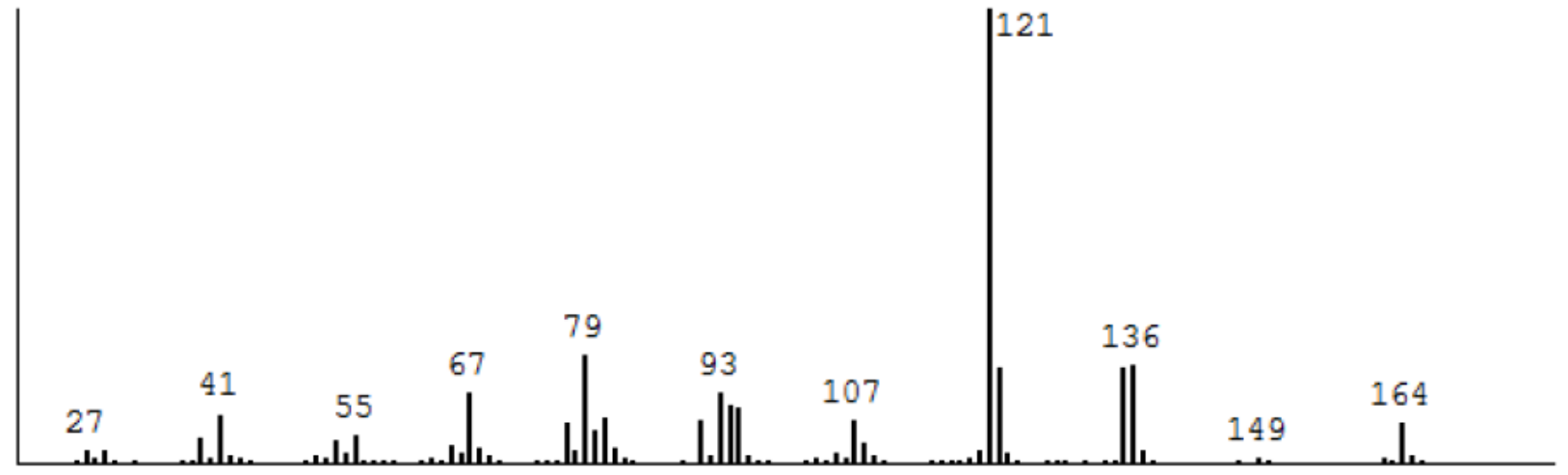

Figure S78: EI-MS spectrum 


\subsection{Component $\underline{\text { d }}$ (26)}

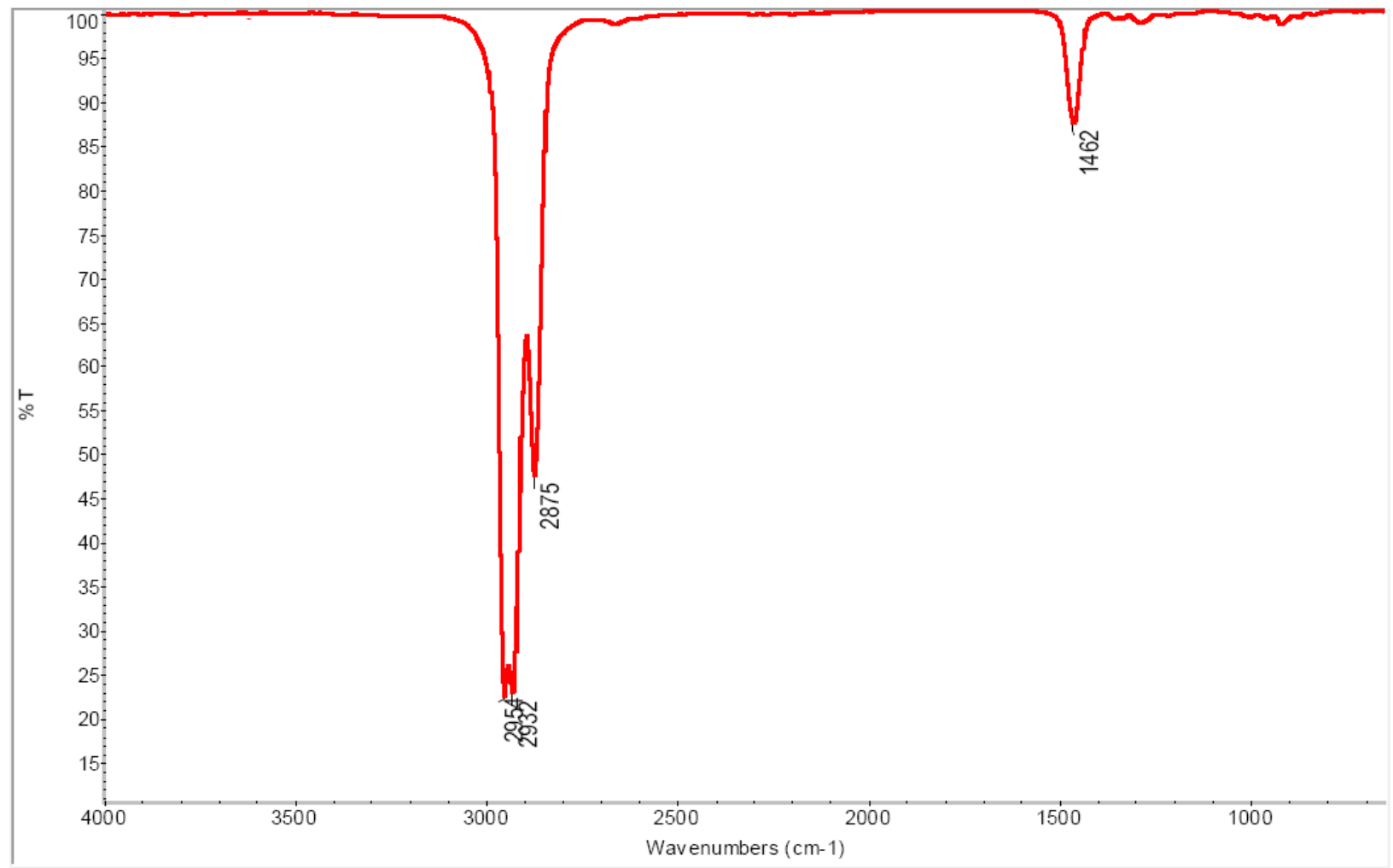

Figure S79: IR spectrum

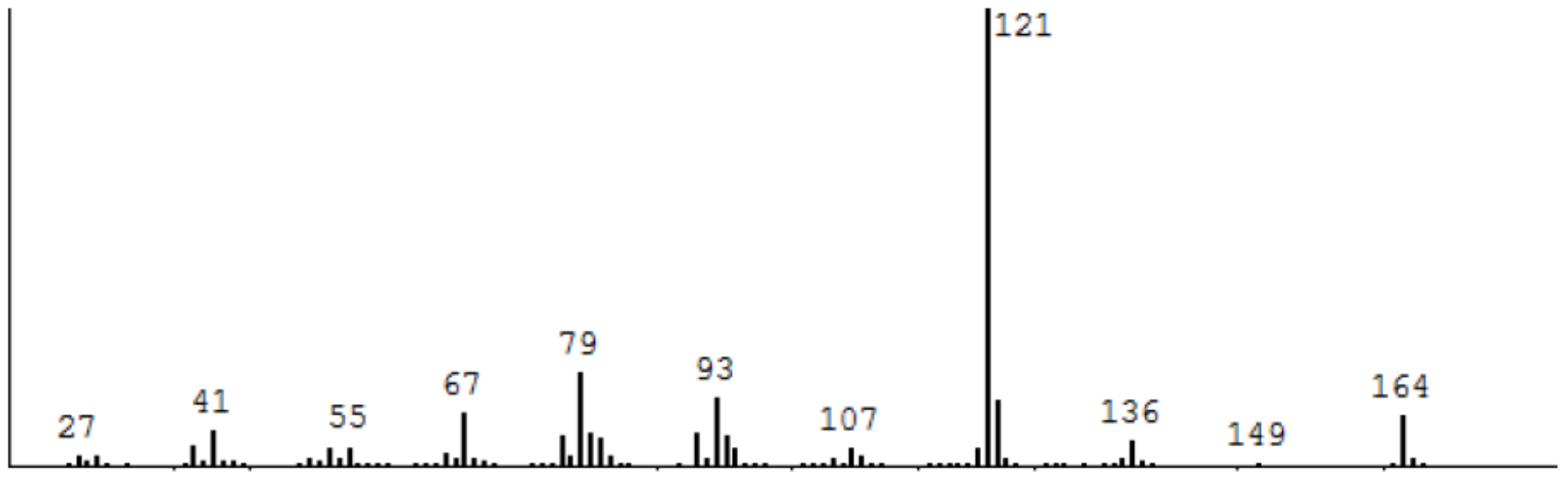

Figure S80: EI-MS spectrum 
8.5 Component e (27)

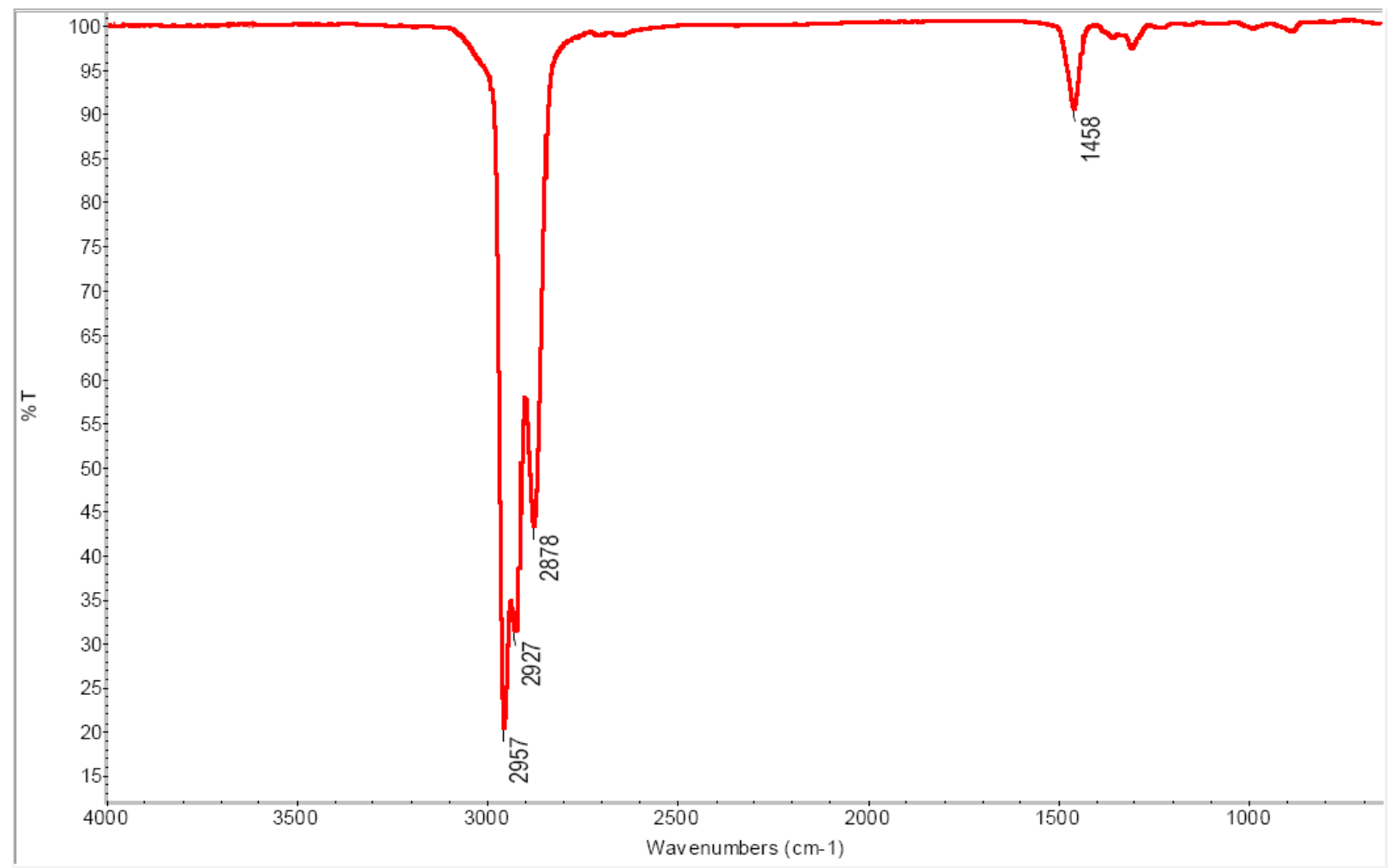

Figure S81: IR spectrum

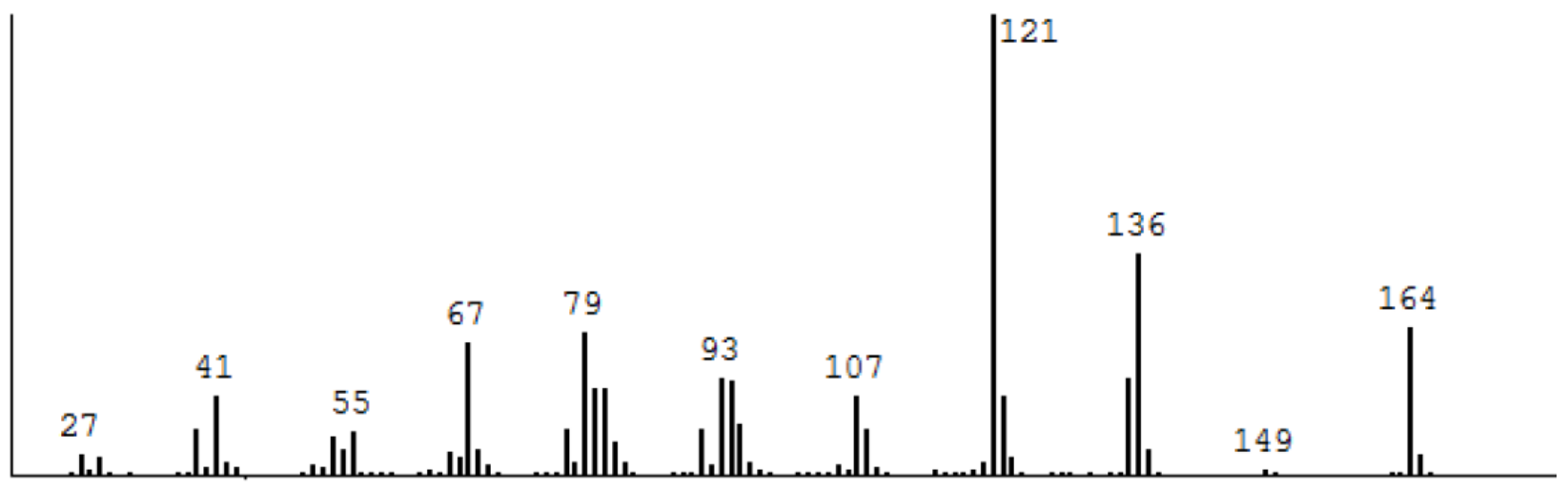

Figure S82: EI-MS spectrum 


\subsection{Component $\underline{\text { f }}$ (28)}

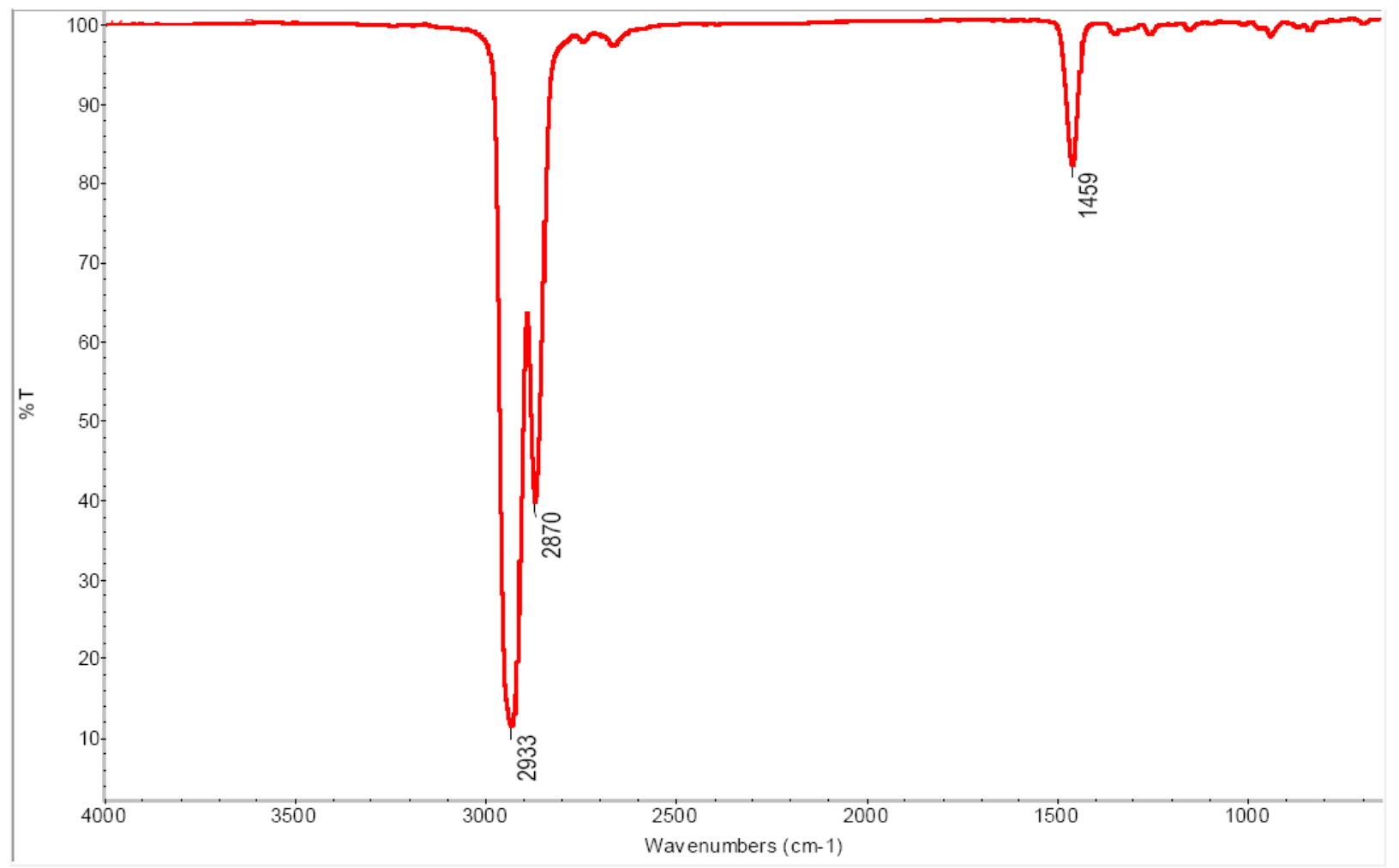

Figure S83: IR spectrum

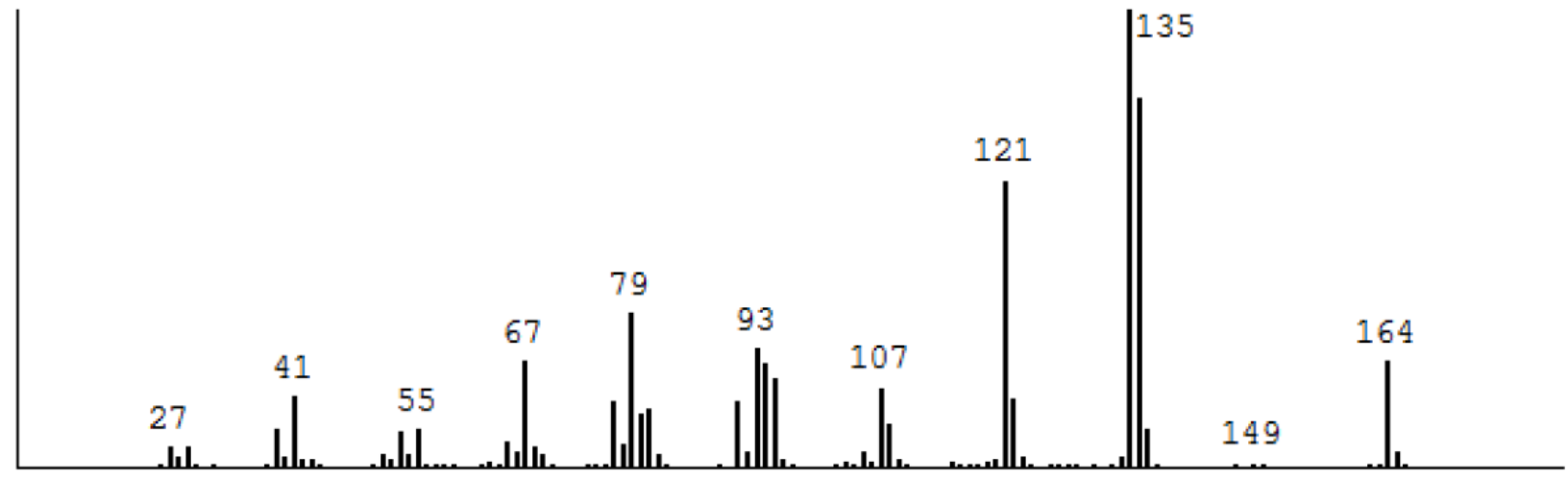

Figure S84: EI-MS spectrum 
8.7 Component g (19)

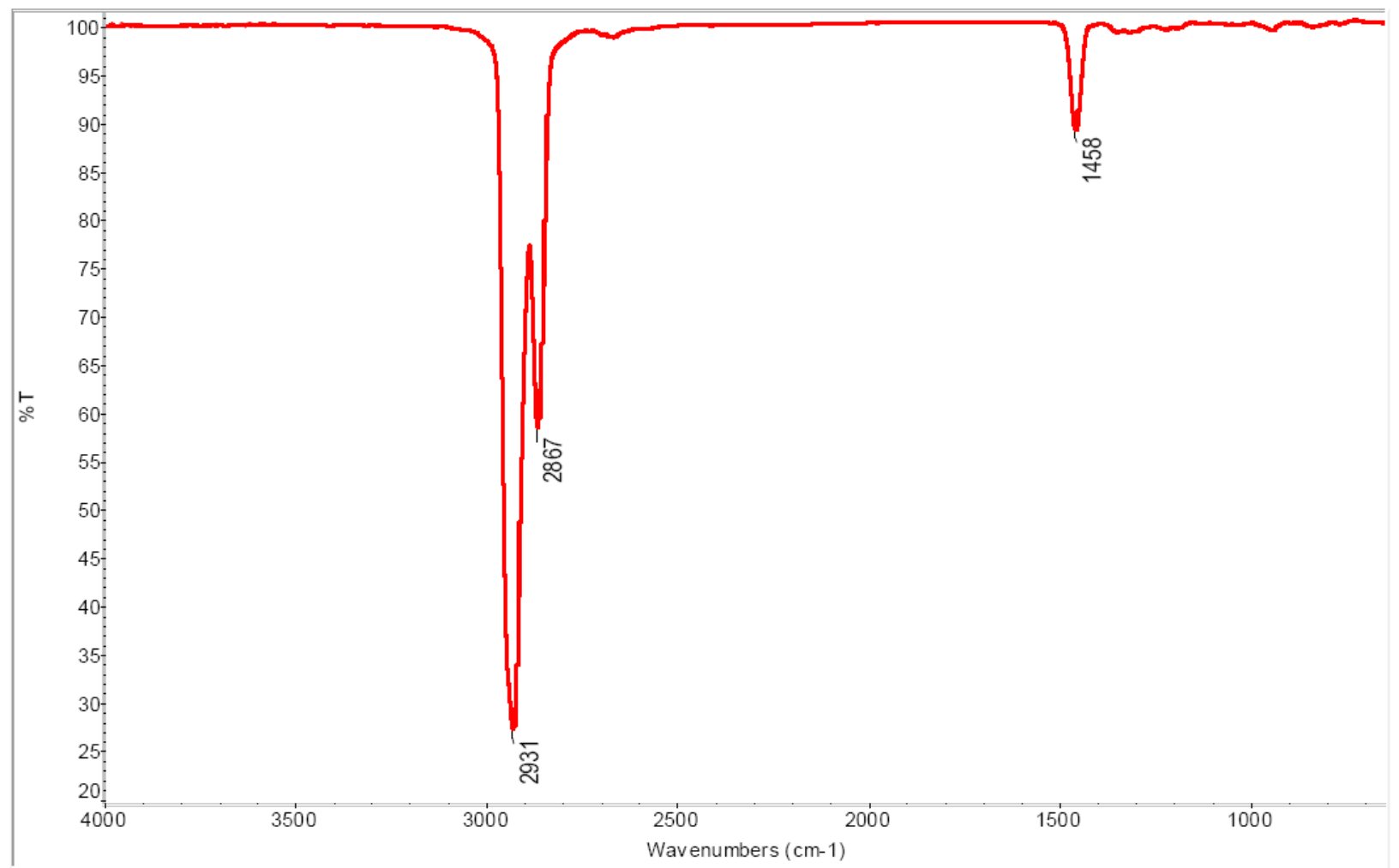

Figure S85: IR spectrum

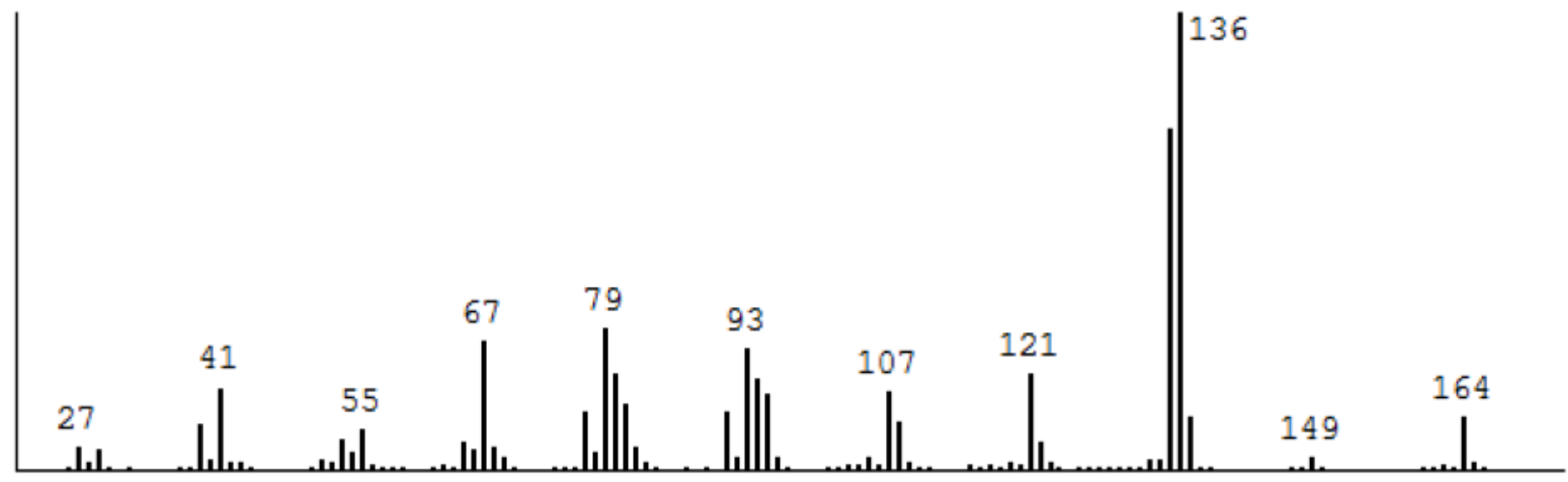

Figure S86: EI-MS spectrum 


\subsection{Component $\underline{h}(\mathbf{2 0}+24)$}

Component $h$ is a mixed peak with two different substances $\left(\mathbf{h}^{\mathbf{1}}\right.$ and $\mathbf{h}^{2}$ present in a ratio of approximately $\left.2: 1\right)$ which cannot be separated by GC. The IR shown below is that for the mixture of both.

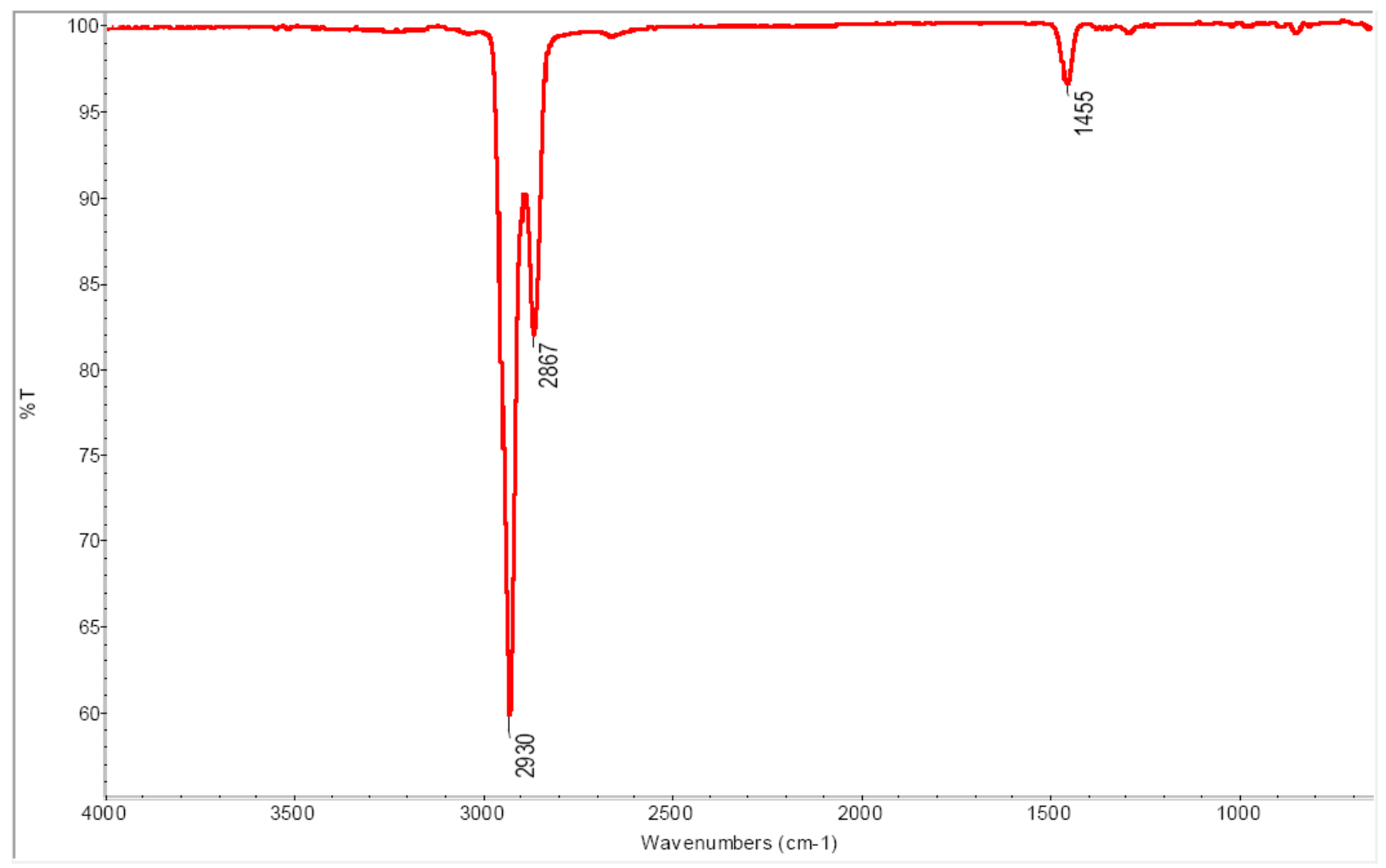

Figure S87: IR spectrum 


\subsection{Component ị (25)}

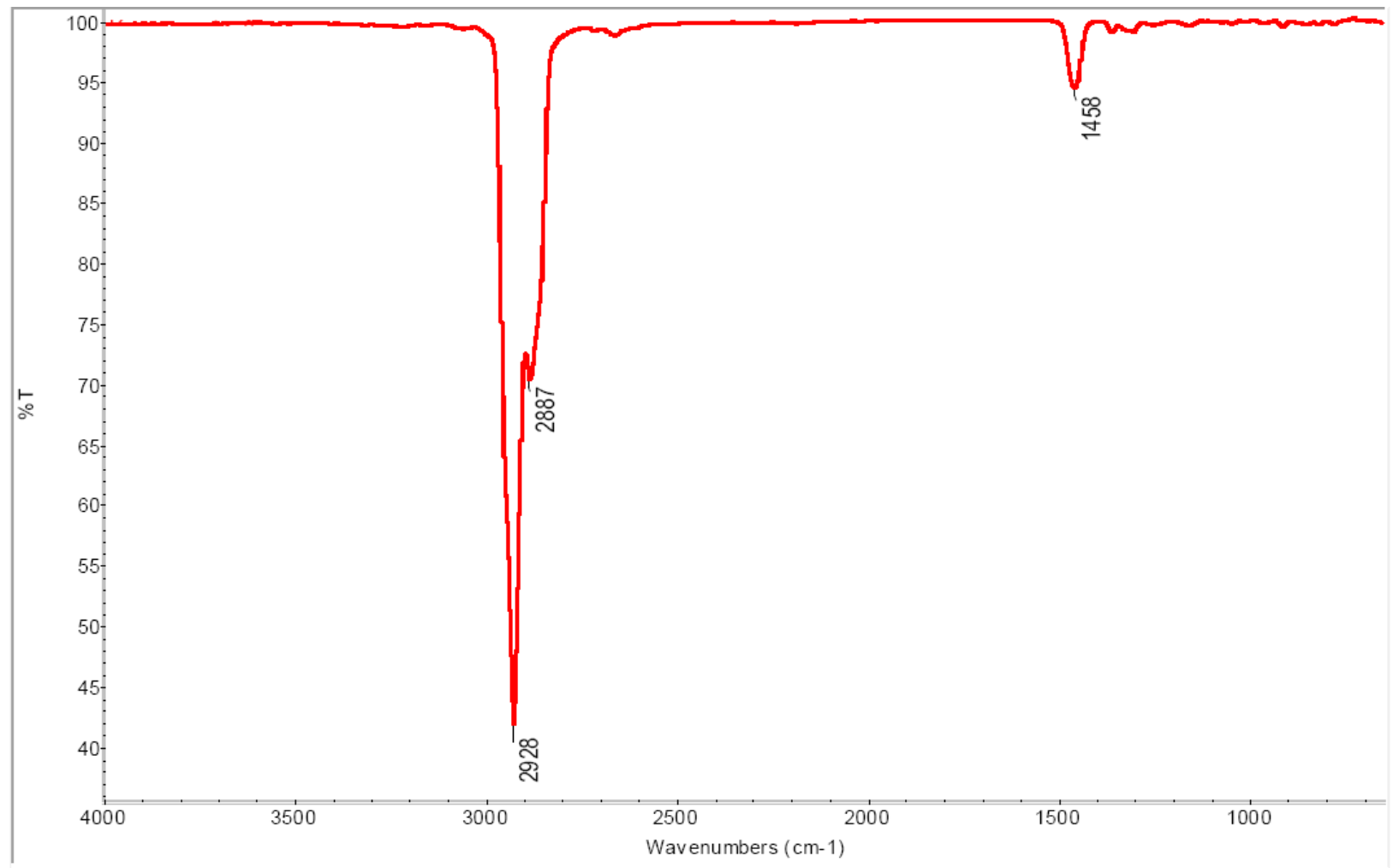

Figure S88: IR spectrum

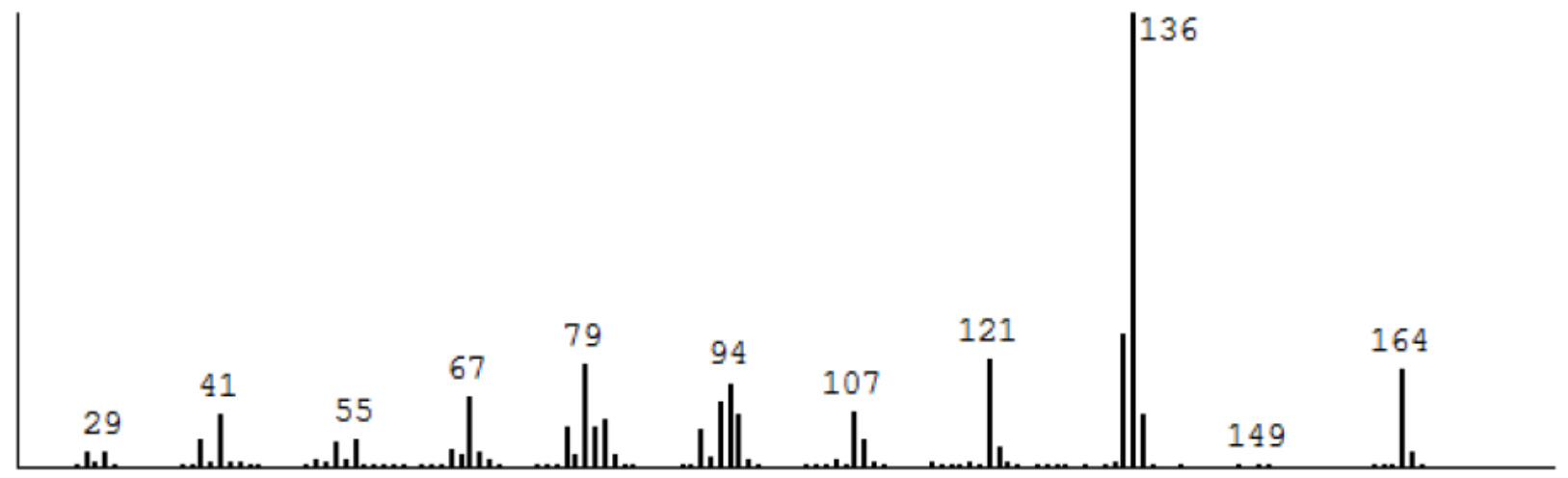

Figure S89: EI-MS spectrum 


\subsection{Component i (21)}

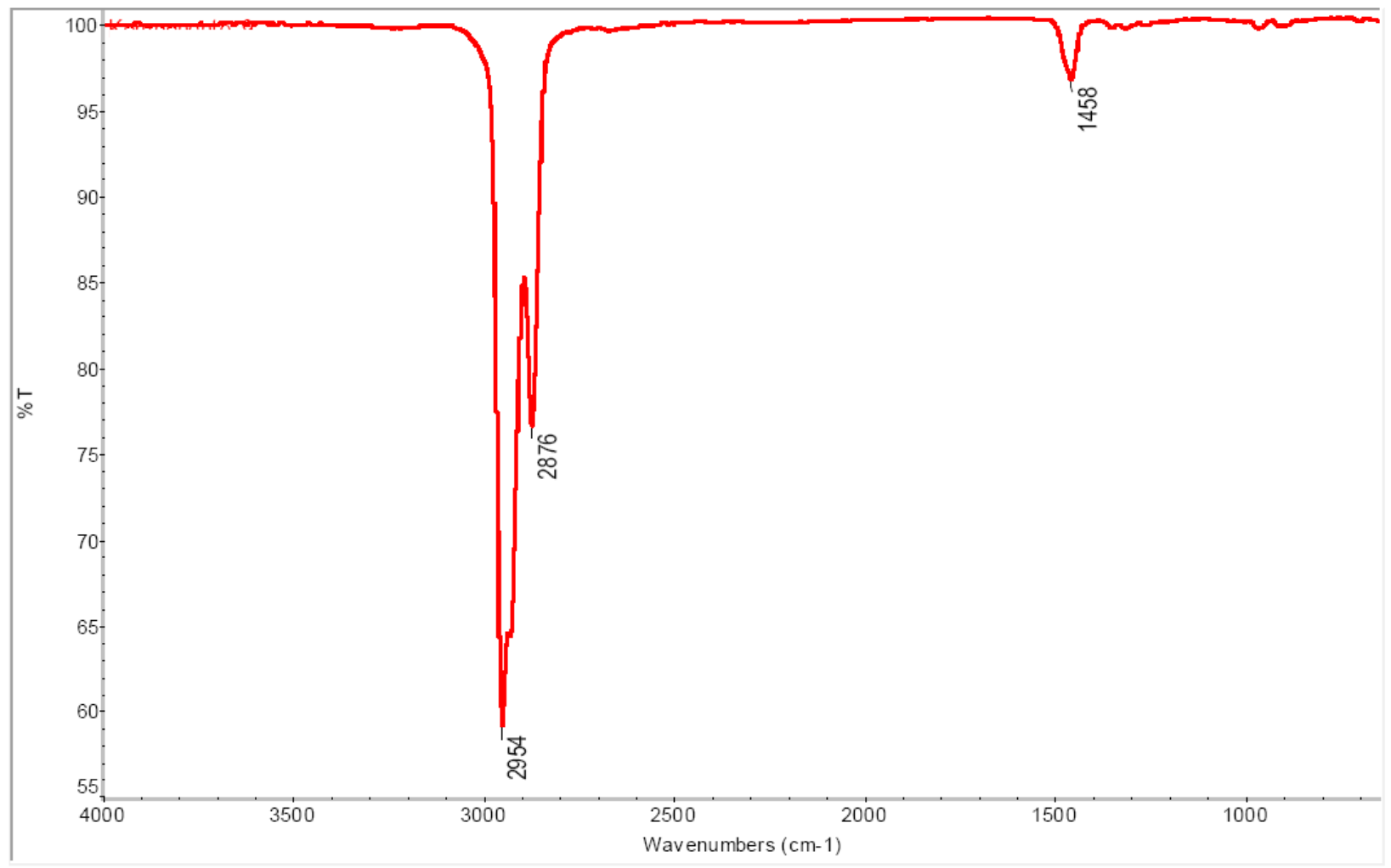

Figure S90: IR spectrum

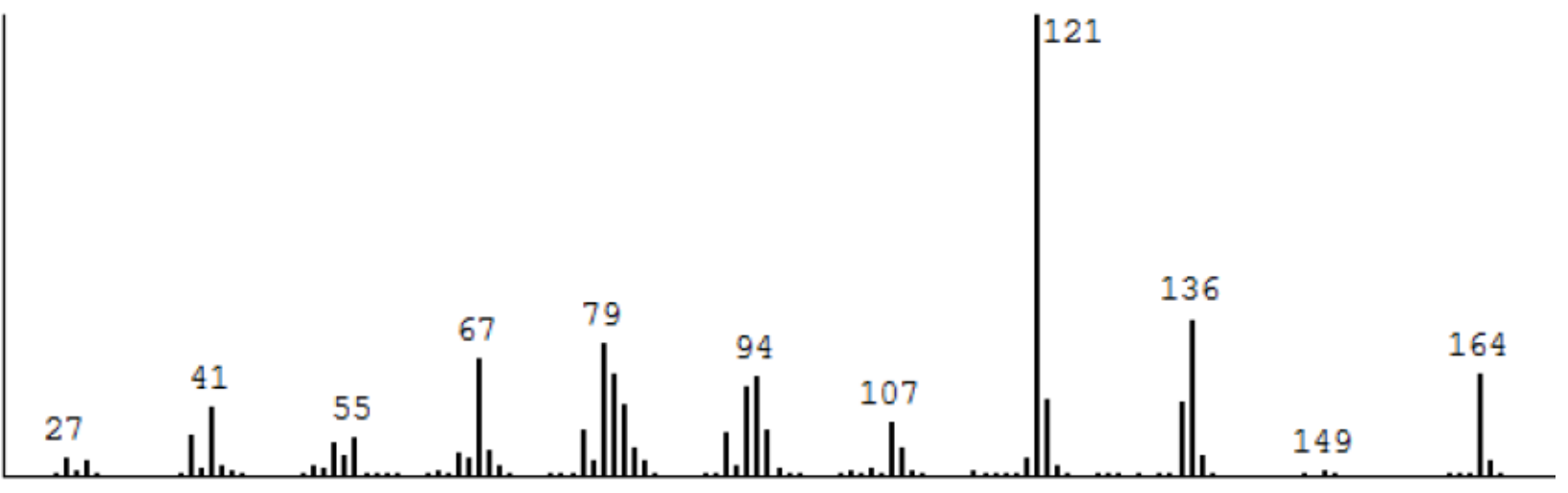

Figure S91: EI-MS spectrum 


\subsection{Component $\underline{\mathbf{k}}$ (17)}

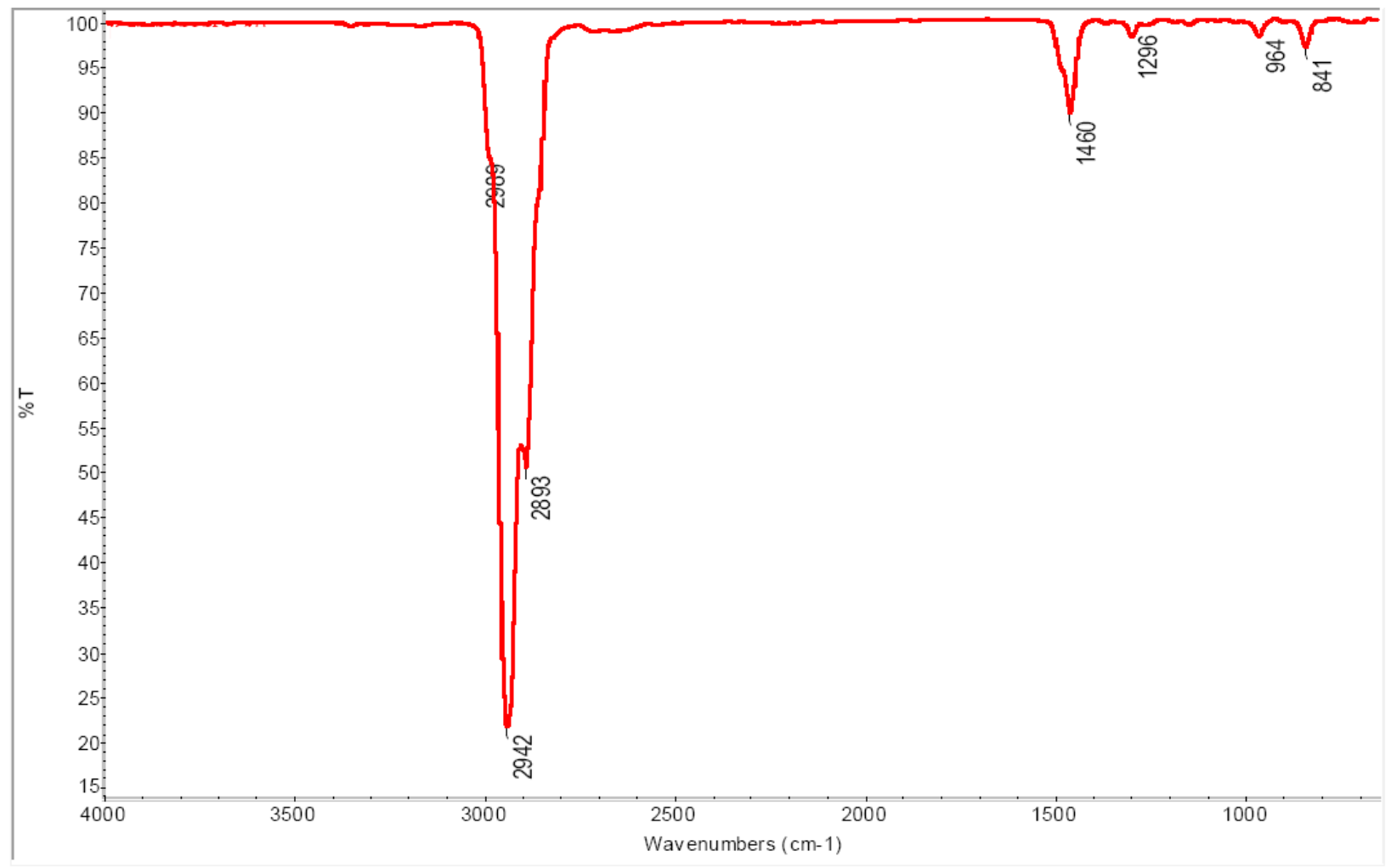

Figure S92: IR spectrum

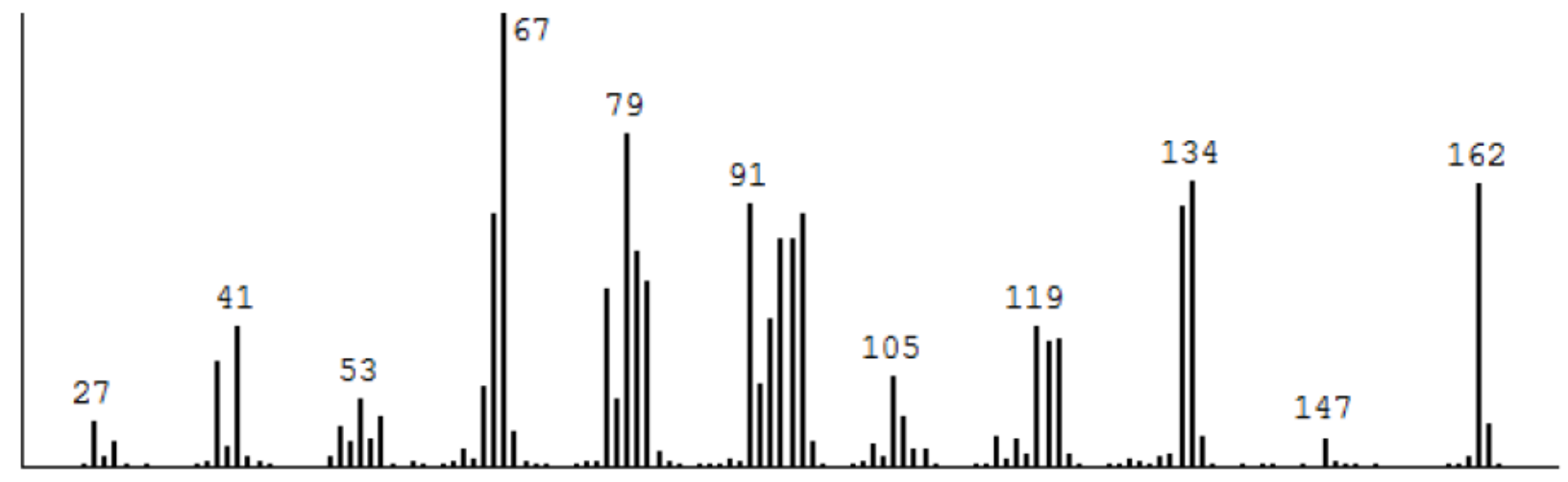

Figure S93: EI-MS spectrum 


\section{GC-MS data for the determination of the degree of deuteration}

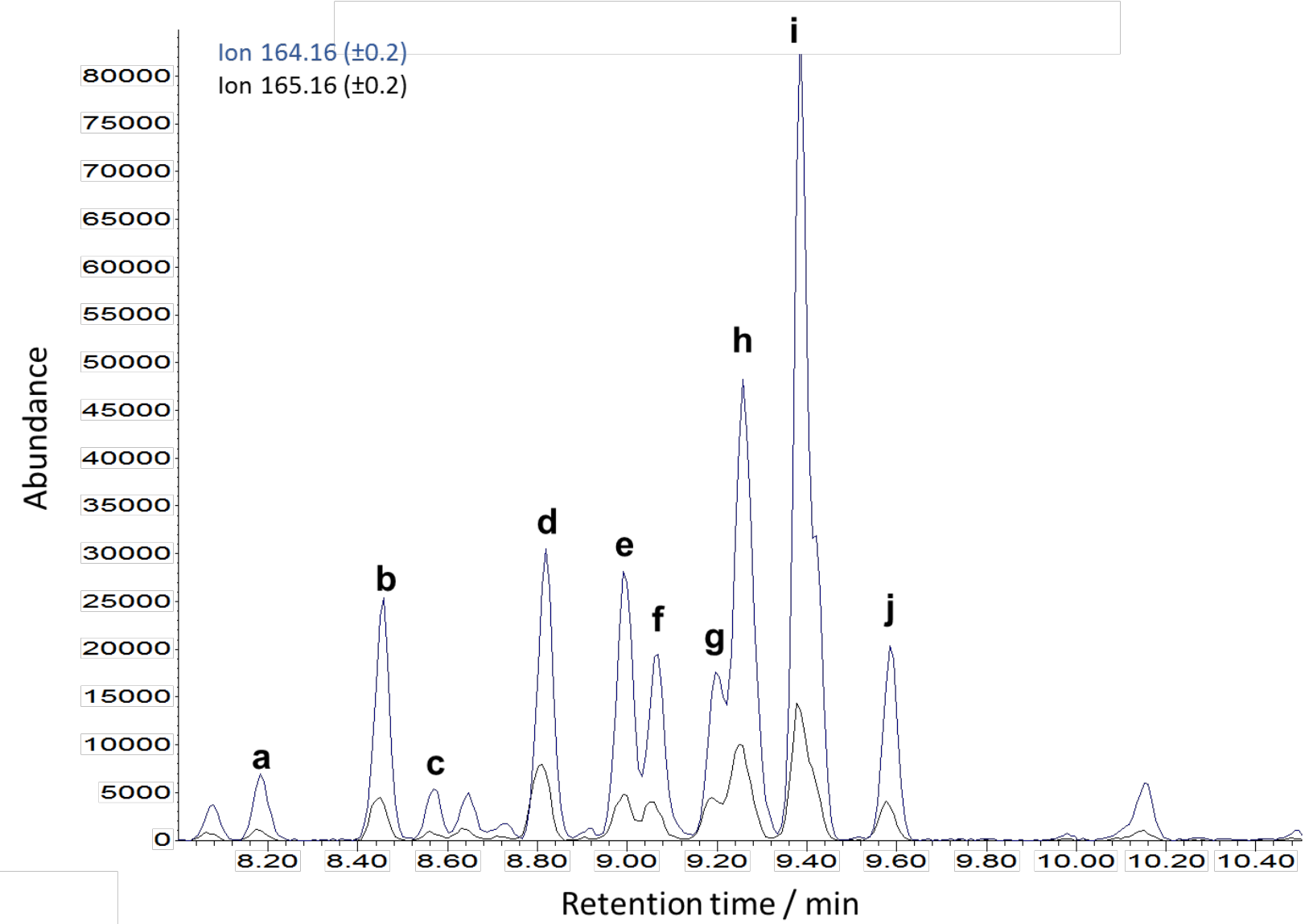

Figure S94: GC-MS trace of $\mathrm{m} / \mathrm{e}=164$ (blue) and $\mathrm{m} / \mathrm{e}=165$ (black) 
Table S20: Degree of deuteration as determined by GC-MS

\begin{tabular}{|c|c|c|c|c|c|}
\hline Peak & Structure & $\begin{array}{l}\text { Ion } 164 \\
\text { area }\end{array}$ & $\begin{array}{l}\text { Ion } 165 \\
\text { area }\end{array}$ & $\begin{array}{l}\text { Area }_{165} / \text { Area }_{164} \\
\%\end{array}$ & $\begin{array}{l}\text { Mole fraction } \\
\mathrm{C}_{12} \mathrm{H}_{19} \mathrm{D}\end{array}$ \\
\hline a, 18 & & 163639 & 26630 & 16,3 & 2,9 \\
\hline b, 22 & & 587221 & 115777 & 19,7 & 6,0 \\
\hline c, 23 & & 134712 & 21583 & 16,0 & 2,6 \\
\hline d, 26 & & 748154 & 230855 & 30,9 & 15,0 \\
\hline e, 27 & & 752843 & 140259 & 18,6 & 5,0 \\
\hline$f, 28$ & & 524729 & 119721 & 22,8 & 8,7 \\
\hline g, 19 & & 439310 & 119724 & 27,3 & 12,3 \\
\hline $\begin{array}{l}h^{1}, 24 \\
h^{2}, 20\end{array}$ & & 1487283 & 344667 & 23,2 & 9,0 \\
\hline $\mathrm{i}, 25$ & & 2261427 & 454082 & 20,1 & 6,3 \\
\hline j, 21 & & 473733 & 100500 & 21,2 & 7,3 \\
\hline
\end{tabular}


10. Data from low temperature NMR experiment of $\underline{26}$ (peak d)

The details of the low temperature NMR measurement can be found in the experimental part of the publication.

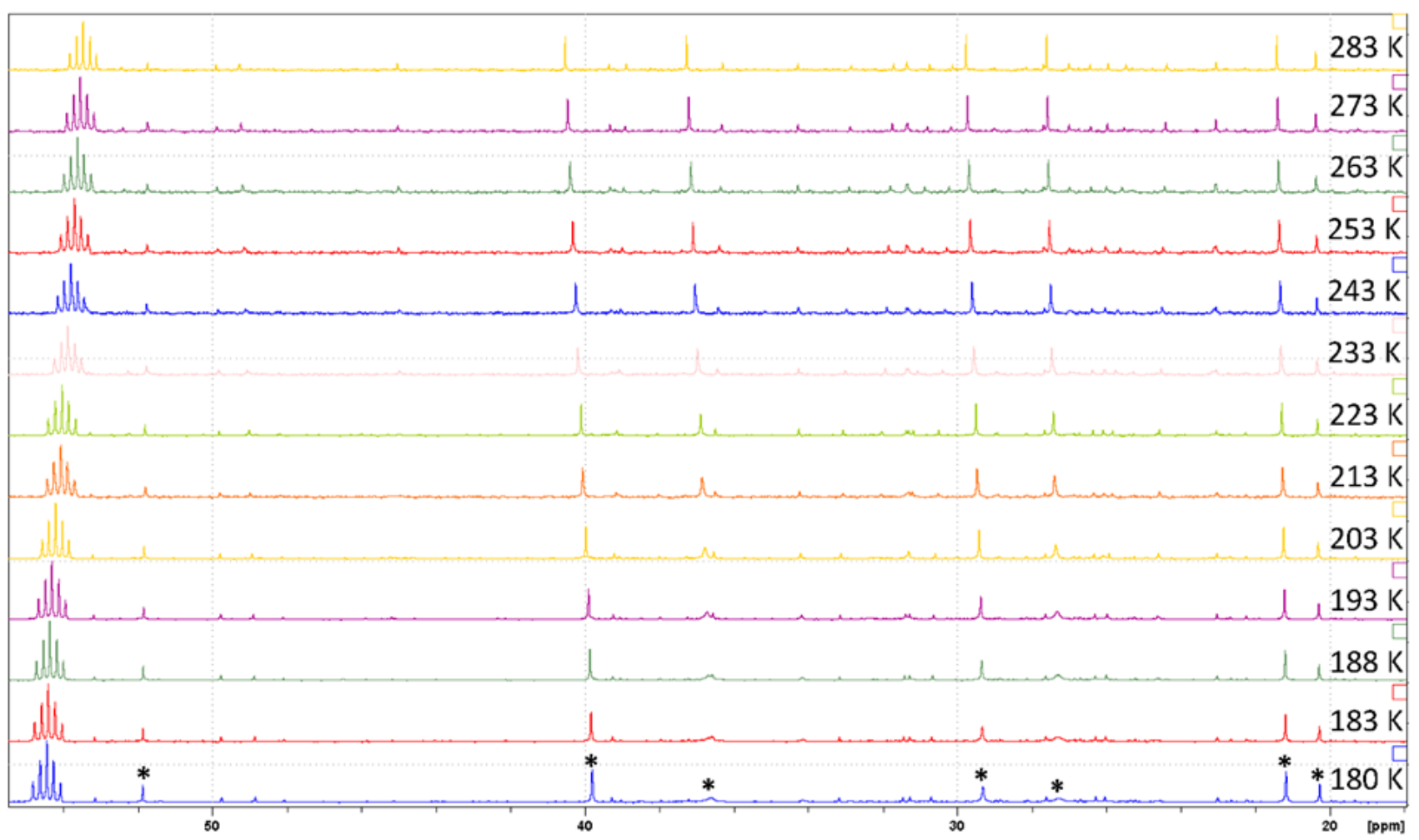

Figure S95: Variable temperature spectra recorded for $\mathbf{2 6},{ }^{13} \mathrm{C}\left\{{ }^{1} \mathrm{H}\right\} \mathrm{NMR}, 151 \mathrm{MHz}, \mathrm{CD}_{2} \mathrm{Cl}_{2}$ 


\section{Enumeration of $\mathrm{C}_{12} \mathrm{H}_{18}$ isomers derivable from a $\mathrm{C}_{12}$-ring}

Why is $\mathbf{1 7}$ the preferentially formed tetracyclic isomer?

Of all possible tetracyclic $\mathrm{C}_{12} \mathrm{H}_{18}$ isomers with the required symmetry to fit the observed ${ }^{13} \mathrm{C}-\mathrm{NMR}$ spectrum (enumerated in Figure S96) $\mathbf{1 7}$ is the only one where no rearrangement of the carbon skeleton is required to go from a $\mathrm{C}_{12}$ ring to said isomer. This is shown in scheme $\mathrm{S} 1$ below. With all other isomers 10-16 it is not possible by breaking only three $\mathrm{C}-\mathrm{C}$ bonds to arrive at an intact 12-membered carbon ring.

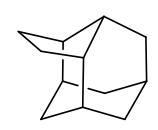

10 $-42.6 \mathrm{kcal} / \mathrm{mol}$

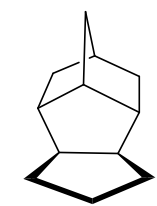

14-exo

$-32.5 \mathrm{kcal} / \mathrm{mol}$

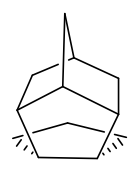

14-endo

$-28.8 \mathrm{kcal} / \mathrm{mol}$

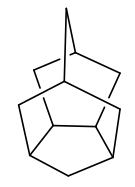

11

$-37.8 \mathrm{kcal} / \mathrm{mol}$

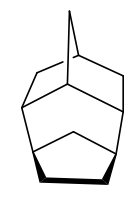

15-exo

$-30.3 \mathrm{kcal} / \mathrm{mol}$

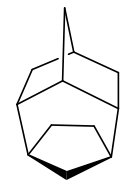

15-endo

-19.3 kcal/mol

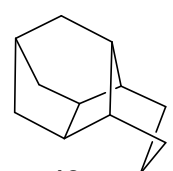

12

$-37.8 \mathrm{kcal} / \mathrm{mol}$

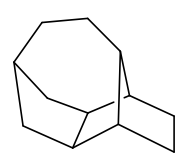

16

$-29.3 \mathrm{kcal} / \mathrm{mol}$

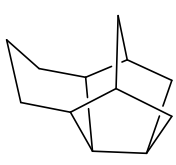

13

$-32.7 \mathrm{kcal} / \mathrm{mol}$

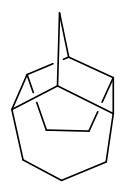

17

$-29.1 \mathrm{kcal} / \mathrm{mol}$

Figure S96: Isomers of 17 with the same symmetry

Scheme S1: Bonds to disconnect to derive 17 from a 12-membered ring<smiles>C1CC2CC3CC1CC(C2)C3</smiles><smiles>C=CC1C(C=C)C2CC3CCC2CC31</smiles><smiles>C1CC2CCCC(C1)C2</smiles>
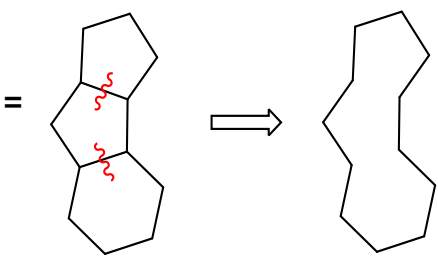

17

This brings up the question about other possible $\mathrm{C}_{12} \mathrm{H}_{18}$ tetracyclic isomers which satisfy the condition that by breaking only three $\mathrm{C}-\mathrm{C}$ bonds one can generate an intact $\mathrm{C}_{12}$ ring. Additionally, they should satisfy the condition that no rings smaller than 5 are present and no quaternary carbons are present (these would all lead to molecules which would be considerably higher in energy). Such isomers were enumerated realizing that they can only be derived from three families of tricyclic skeletons, the 5-5-6 and the 5-6-5 skeletons (bent and linear; Figure S97). 


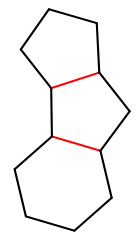

6-5-5 skeleton

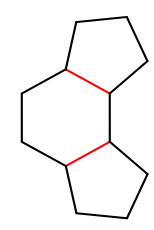

5-6-5

bent skeleton linear skeleton

Figure S97: Carbon skeletons derived from a 12-membered ring given the conditions above

The isomers can then be generated by linking a carbon from the lower ring with a carbon from the upper or middle ring in such a way that neither small rings nor quaternary carbons are formed. From each isomer one can also determine what is the minimum number of hydrogen atoms that have to be shifted to come from CDT to the desired isomer. This value together the energy calculated with the UFF force field are shown in the tables below. As can be seen only 5 tetracyclic isomers can be formed from CDT by shifting maximum 1 hydrogen. These isomers are shown in Table S21.

The striking observation is that among all isomers that can be made from CDT by shifting not more than one hydrogen atom, 17 is the second most stable one and only and only $1.1 \mathrm{kcal} \mathrm{mol}^{-1}$ less stable than the most stable one (31). 17 thus appears to be a least motion, least energy isomer and that might be the reason why it is preferentially formed.

There are four other isomers with lower energy than 17 (highlighted in orange in table S22) but their formation would require at least two hydrogen shifts when starting from CDT. 
Table S21: Tetracyclic molecules obtainable from CDT with no more than $1 \mathrm{H}$-shift (relative to 17)

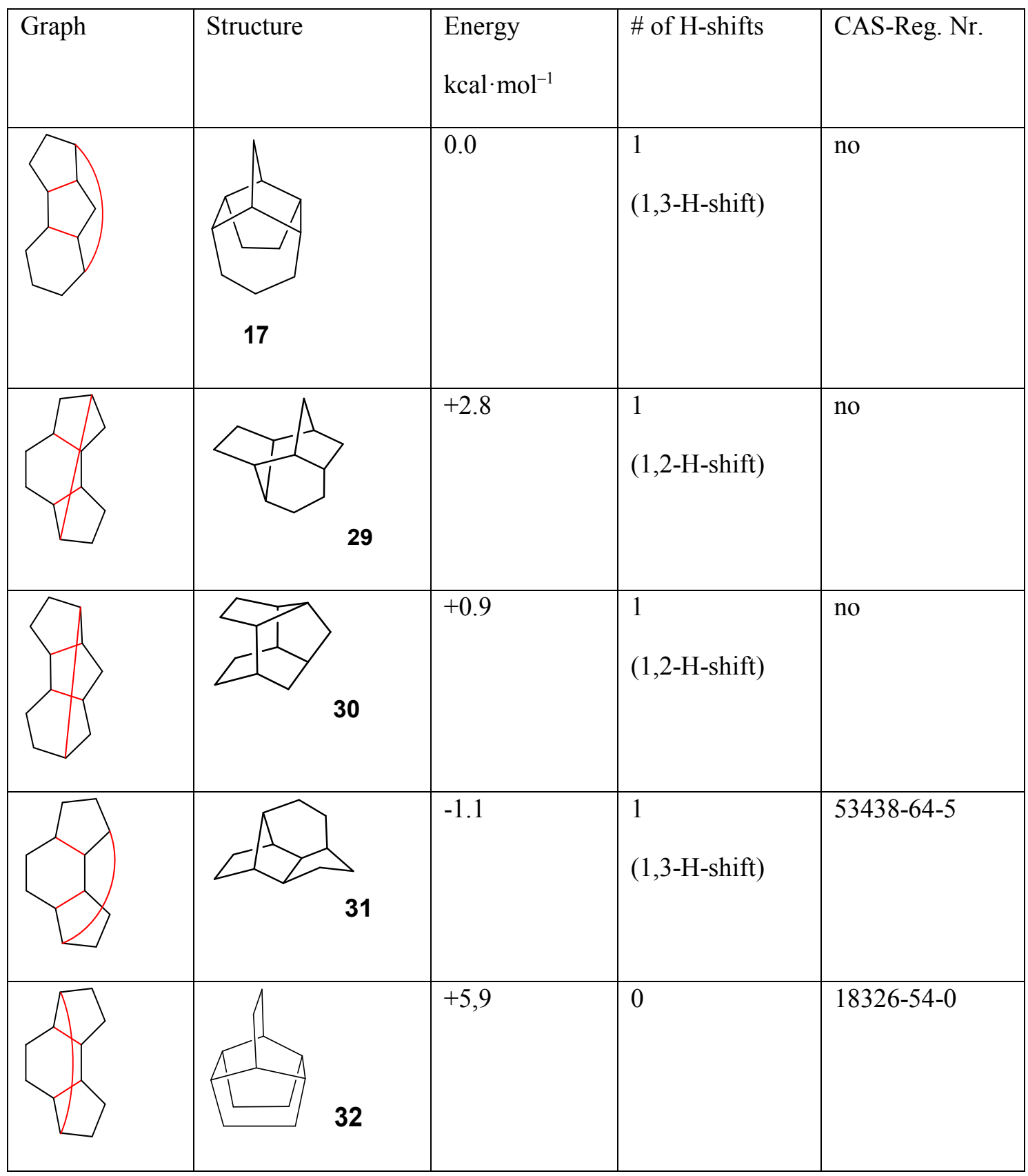


Table S22: Tetracyclic molecules obtainable from CDT with $2 \mathrm{H}$-shifts (sorted by increasing energy, which was only qualitatively estimated with the UFF molecular mechanics force field)

\begin{tabular}{|c|c|c|c|c|}
\hline Graph & Structure & Energy & \# of H-shifts & CAS-Reg. Nr. \\
\hline & & $\begin{array}{l}\text { (lower energy } \\
\text { than } 17 \text { but } 2 \\
\text { H-shifts) }\end{array}$ & 2 & no \\
\hline & & $\begin{array}{l}\text { (lower energy } \\
\text { than } 17 \text { but } 2 \\
\text { H-shifts) }\end{array}$ & 2 & no \\
\hline & & $\begin{array}{l}\text { (lower energy } \\
\text { than } 17 \text { but } 2 \\
\text { H-shifts) }\end{array}$ & 2 & no \\
\hline & & $\begin{array}{l}\text { (similar to } \mathbf{1 7} \\
\text { but } 2 \text { H-shifts) }\end{array}$ & 2 & no \\
\hline & & $\begin{array}{l}\text { (higher than } \\
\text { 17) }\end{array}$ & 2 & no \\
\hline & & $\begin{array}{l}\text { (higher than } \\
\text { 17) }\end{array}$ & 2 & no \\
\hline & & $\begin{array}{l}\text { (higher than } \\
\text { 17) }\end{array}$ & 2 & no \\
\hline
\end{tabular}




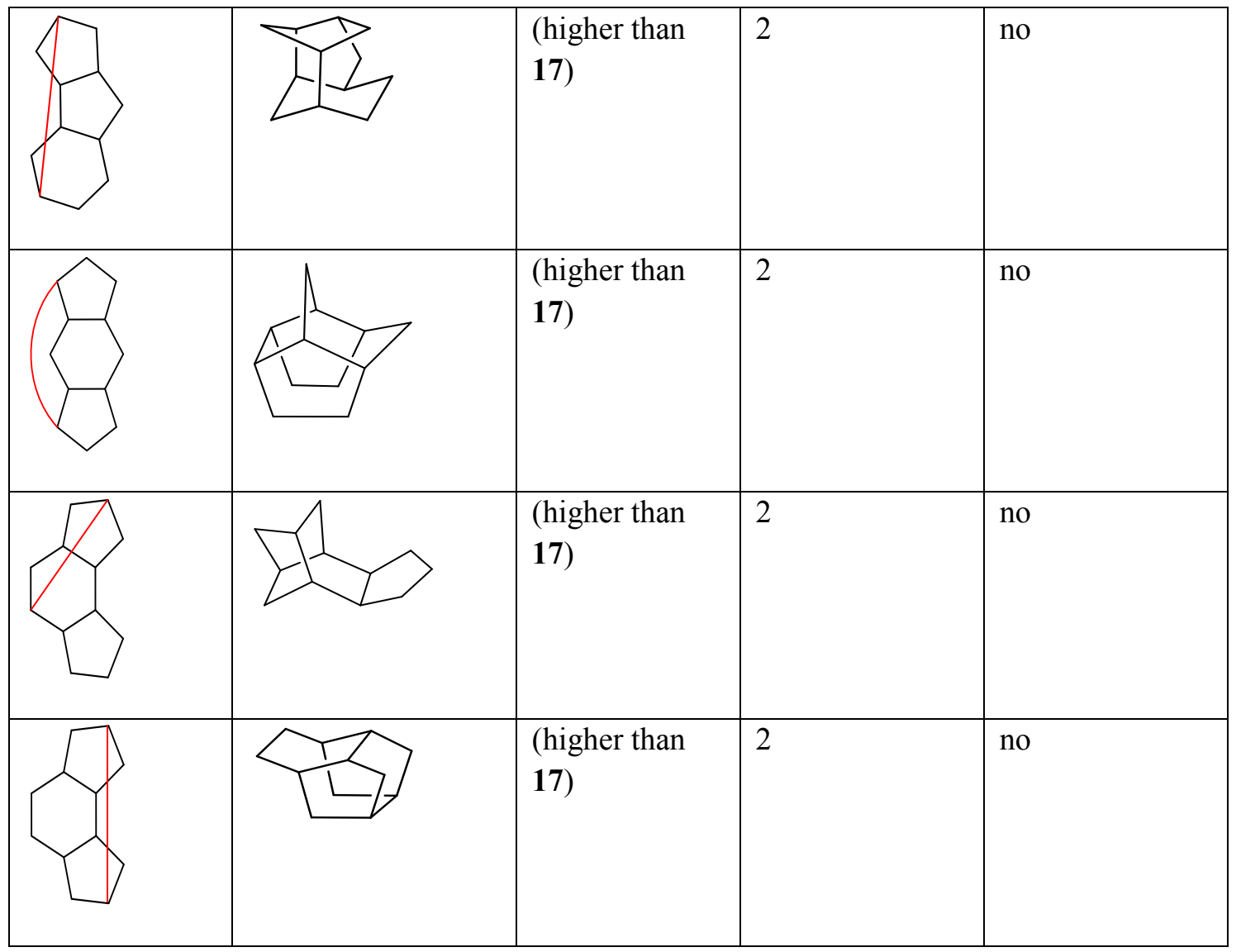


Table S23: Tetracyclic molecules obtainable from CDT with $3 \mathrm{H}$-shifts (sorted by increasing energy, which was only qualitatively estimated with the UFF molecular mechanics force field)

\begin{tabular}{|c|c|c|c|c|}
\hline Graph & Structure & Energy & \# of H-shifts & CAS-Reg. Nr. \\
\hline & & $\begin{array}{l}\text { (lower energy } \\
\text { than } 17 \text { but } 3 \\
\text { H-shifts) }\end{array}$ & 3 & no \\
\hline & & $\begin{array}{l}\text { (higher than } \\
\text { 17) }\end{array}$ & 3 & $187817-43-2$ \\
\hline & & $\begin{array}{l}\text { (higher than } \\
\text { 17) (endo- } \\
\text { isomer) }\end{array}$ & 3 & no \\
\hline & & $\begin{array}{l}\text { (higher than } \\
\text { 17) }\end{array}$ & 3 & no \\
\hline & & $\begin{array}{l}\text { (higher than } \\
\text { 17) }\end{array}$ & 3 & no \\
\hline & & $\begin{array}{l}\text { (higher than } \\
\text { 17) (exo- } \\
\text { isomer) }\end{array}$ & 3 & no \\
\hline
\end{tabular}




\begin{tabular}{|l|l|l|l|}
\hline & (higher than & 3 & no \\
\hline
\end{tabular}




\section{Computational Details}

For the computational analysis, the conformational space for each structure was explored using the OPLS-2005 force field ${ }^{1}$ and a modified Monte Carlo search algorithm implemented in MacroModel. ${ }^{2}$ An energy cut-off of 20 $\mathrm{kcal} \mathrm{mol}^{-1}$ was employed for the conformational analysis and structures with root-mean-square deviations (RMSD) up to $0.5 \AA$ after the initial force field optimizations were considered to be the same conformer. The remaining structures were subsequently optimized with the dispersion-corrected M06-2X functional ${ }^{3}$ with Grimme's dispersion correction D3 (zero damping), ${ }^{4}$ the double- $\zeta$ basis set $6-31+\mathrm{G}(\mathrm{d}, \mathrm{p})$, and the integrated equation formalism polarizable continuum model $\left(\right.$ IEFPCM) ${ }^{5}$ for either benzene or chloroform. Vibrational analysis verified that each structure was a minimum. Thermal corrections were obtained from unscaled harmonic vibrational frequencies at the same level of theory for a standard state of $1 \mathrm{~mol} \mathrm{~L}^{-1}$ and $298.15 \mathrm{~K}$. Entropic contributions to the reported free energies were derived from partition functions evaluated with the quasiharmonic approximation by Truhlar and coworkers. ${ }^{6}$ Electronic energies were subsequently obtained from single point calculations the M06-2X functional, Grimme's dispersion-correction D3 (zero-damping), the large quadruple- $\zeta$ basis set def2-QZVP, ${ }^{7}$ and the IEFPCM model for benzene or chloroform. The NMR shielding tensors were computed with the gauge-independent atomic orbitals (GIAO) method $^{8}$ relative to tetramethylsilane (TMS) using a slightly modified procedure of Hoye and coworkers, ${ }^{9}$ relying on the B3LYP functional, ${ }^{10}$ Grimme's dispersioncorrection D3 with Becke-Johnson damping, ${ }^{11}$ the triple- $\zeta$ basis set $6-311+\mathrm{G}(2 \mathrm{~d}, \mathrm{p})$, the IEFPCM model for benzene or chloroform. Assuming a rapid interconversion between the conformers, both the reported free energies as well as the ${ }^{13} \mathrm{C}$ NMR shifts have been obtained by Boltzmann-averaging at $298.15 \mathrm{~K}$. Throughout this study, an ultrafine grid was used for the numerical integration of the density. All calculations were performed with Gaussian $09 .{ }^{12}$

1 Banks, J. L.; Beard, H. S.; Cao, Y.; Cho, A. E.; Damm, W.; Farid, R.; Felts, A. K.; Halgren, T. A.; Mainz, D. T.; Maple, J. R.; Murphy, R.; Philipp, D. M.; Repasky, M. P.; Zhang, L. Y.; Berne, B. J.; Friesner, R. A.; Gallicchio, E.; Levy, R. M. Integrated modeling program, applied chemical theory (IMPACT). J. Comput. Chem. 2005, 26, 1752-1780.

2 Schrödinger Release 2017-1,: MacroModel, Schrödinger, LLC: New York, NY, 2017.

3 Zhao, Y.; Truhlar, D. G. The M06 suite of density functionals for main group thermochemistry, thermochemical kinetics, noncovalent interactions, excited states, and transition elements: two new functionals and systematic testing of four M06-class functionals and 12 other functionals. Theor. Chem. Acc. 2008, 120, 215-241.

4 Grimme, S.; Antony, J.; Ehrlich, S.; Krieg, H. A consistent and accurate ab initio parametrization of density functional dispersion correction (DFT-D) for the 94 elements H-Pu. J. Chem. Phys. 2010, 132, 154104/1-154104/19.

5 Cancès, E.; Mennucci, B.; Tomasi, J. A new integral equation formalism for the polarizable continuum model: theoretical background and applications to isotropic and anisotropic dielectrics. J. Chem. Phys. 1997, 107, 3032-3041.

6 Ribeiro, R. F.; Marenich, A. V.; Cramer, C. J.; Truhlar, D. G. Use of Solution-Phase Vibrational Frequencies in Continuum Models for the Free Energy of Solvation. J. Phys. Chem. B 2011, 115, 14556-14562.

7 Weigend, F.; Ahlrichs, R. Balanced basis sets of split valence, triple zeta valence and quadruple zeta valence quality for $\mathrm{H}$ to Rn: Design and assessment of accuracy. Phys. Chem. Chem. Phys. 2005, 7, 3297-3305.

8 (a) London, F. Quantum theory of interatomic currents in aromatic compounds. J. Phys. Radium 1937, 8, 397-409; (b) McWeeny, R. Perturbation Theory for the Fock-Dirac Density Matrix. Phys. Rev. 1962, 126, 1028-1034; (c) Ditchfield, R. Self-consistent perturbation theory of diamagnetism. I. A gage-invariant LCAO (linear combination of atomic orbitals) method for NMR chemical shifts. Mol. Phys. 1974, 27, 789-807; (d) Wolinski, K.; Hinton, J. F.; Pulay, P. Efficient implementation of the gauge-independent atomic orbital method for NMR chemical shift calculations. J. Am. Chem. Soc. 1990, 112, 8251-8260; (e) Cheeseman, J. R.; Trucks, G. W.; Keith, T. A.; Frisch, M. J. A comparison of models for calculating nuclear magnetic resonance shielding tensors. J. Chem. Phys. 1996, 104, 54975509.

9 Willoughby, P. H.; Jansma, M. J.; Hoye, T. R. A guide to small-molecule structure assignment through computation of $\left({ }^{1} \mathrm{H}\right.$ and $\left.{ }^{13} \mathrm{C}\right)$ NMR chemical shifts. Nat. Protocols 2014, 9, 643-660.

10 (a) Becke, A. D. Density-functional thermochemistry. III. The role of exact exchange. J. Chem. Phys. 1993, 98, 5648-5652; (b) Lee, C.; Yang, W.; Parr, R. G. Development of the Colle-Salvetti correlation-energy formula into a functional of the electron density. Phys. Rev. B 1988, 37, 785-789; (c) Stephens, P. J.; Devlin, F. J.; Chabalowski, C. F.; Frisch, M. J. Ab Initio Calculation of Vibrational Absorption and Circular Dichroism Spectra Using Density Functional Force Fields. J. Phys. Chem. 1994, $98,11623-11627$.

11 Grimme, S.; Ehrlich, S.; Goerigk, L. Effect of the damping function in dispersion corrected density functional theory. J. Comput. Chem. 2011, 32, 1456-1465.

12 Gaussian 09, Revision E.01; Frisch, M. J.; Trucks, G. W.; Schlegel, H. B.; Scuseria, G. E.; Robb, M. A.; Cheeseman, J. R.; Scalmani, G.; Barone, V.; Mennucci, B.; Petersson, G. A.; Nakatsuji, H.; Caricato, M.; Li, X.; Hratchian, H. P.; Izmaylov, A. F.; Bloino, J.; Zheng, G.; Sonnenberg, J. L.; Hada, M.; Ehara, M.; Toyota, K.; Fukuda, R.; Hasegawa, J.; Ishida, M.; Nakajima, T.; Honda, Y.; Kitao, O.; Nakai, H.; Vreven, T.; Montgomery Jr., J. A.; Peralta, J. E.; Ogliaro, F.; Bearpark, M.; Heyd, J. J.; Brothers, E.; Kudin, K. N.; Staroverov, V. N.; Kobayashi, R.; Normand, J.; Raghavachari, K.; Rendell, A.; Burant, J. C.; Iyengar, S. S.; Tomasi, J.; Cossi, M.; Rega, N.; Millam, 
J. M.; Klene, M.; Knox, J. E.; Cross, J. B.; Bakken, V.; Adamo, C.; Jaramillo, J.; Gomperts, R.; Stratmann, R. E.; Yazyev, O.; Austin, A. J.; Cammi, R.; Pomelli, C.; Ochterski, J. W.; Martin, R. L.; Morokuma, K.; Zakrzewski, V. G.; Voth, G. A.; Salvador, P.; Dannenberg, J. J.; Dapprich, S.; Daniels, A. D.; Farkas, Ö.; Foresman, J. B.; Ortiz, J. V.; Cioslowski, J.; Fox, D. J.; Gaussian, Inc.: Wallingford CT, 2009. 
12.1. Calculated Energies, Coordinates, and NMR Shielding Tensors for Benzene Solution

Table S24: Tetramethylsilane TMS

SCF energy:

Zero-point correction:

Enthalpy correction:

Free energy correction:

Quasiharmonic free energy correction:

Boltzmann-averaged quasiharmonic free energy:

-449.177950 hartree
+0.147961 hartree
+0.158344 hartree
+0.115245 hartree
+0.115245 hartree
-449.062705 hartree

\section{Cartesian Coordinates (Lowest-Energy Conformer)}

$\begin{array}{lrrr}\text { Si } & 0.00001 & -0.00002 & -0.00000 \\ \mathrm{C} & 1.83898 & -0.10054 & 0.40362 \\ \mathrm{C} & -0.54045 & -1.58405 & -0.86797 \\ \mathrm{C} & -0.98305 & 0.20931 & 1.59512 \\ \mathrm{H} & -0.36588 & -2.45834 & -0.23241 \\ \mathrm{H} & 0.01485 & -1.72883 & -1.80043 \\ \mathrm{H} & -1.60727 & -1.55256 & -1.11232 \\ \mathrm{H} & 2.04998 & -0.95044 & 1.06088 \\ \mathrm{H} & 2.17952 & 0.80913 & 0.90893 \\ \mathrm{H} & 2.43401 & -0.22298 & -0.50730 \\ \mathrm{H} & -0.68770 & 1.12356 & 2.12020 \\ \mathrm{H} & -0.81781 & -0.63603 & 2.27107 \\ \mathrm{H} & -2.05653 & 0.27101 & 1.38861 \\ \mathrm{C} & -0.31550 & 1.47530 & -1.13075 \\ \mathrm{H} & 0.24497 & 1.37879 & -2.06636 \\ \mathrm{H} & -0.00991 & 2.41019 & -0.64969 \\ \mathrm{H} & -1.37823 & 1.55676 & -1.38126\end{array}$

\section{${ }^{13} \mathrm{C}$-NMR Shielding Tensors (Boltzmann-Averaged Ensemble)}

183.217725 C-2, C-3, C-4, C-14 
Table S25: cis,trans,trans-1,5,9-Cyclododecatriene (1)

SCF energy:

Zero-point correction:

Enthalpy correction:

Free energy correction:

Quasiharmonic free energy correction:

Boltzmann-averaged quasiharmonic free energy:

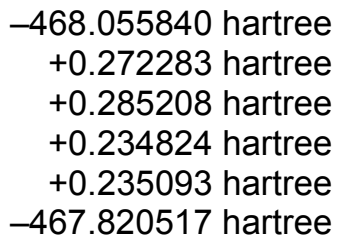

\begin{tabular}{|c|c|c|c|}
\hline \multicolumn{4}{|c|}{ Cartesian Coordinates (Lowest-Energy Conformer) } \\
\hline C & 2.36872 & -0.14300 & 0.71856 \\
\hline C & 1.99103 & 1.13293 & 0.58891 \\
\hline C & 1.40534 & 1.79787 & -0.62664 \\
\hline $\mathrm{H}$ & 2.08774 & 1.77781 & 1.46460 \\
\hline C & 0.12226 & 2.58456 & -0.28194 \\
\hline $\mathrm{H}$ & 1.16423 & 1.05394 & -1.39239 \\
\hline $\mathrm{H}$ & 2.13734 & 2.49233 & -1.06032 \\
\hline C & -0.89641 & 1.69652 & 0.37218 \\
\hline $\mathrm{H}$ & -0.29085 & 3.01994 & -1.19835 \\
\hline $\mathrm{H}$ & 0.38395 & 3.41594 & 0.38529 \\
\hline C & -1.97511 & 1.19157 & -0.22713 \\
\hline $\mathrm{H}$ & -0.67899 & 1.38061 & 1.39396 \\
\hline C & -2.86103 & 0.14818 & 0.38878 \\
\hline $\mathrm{H}$ & -2.18944 & 1.47072 & -1.26146 \\
\hline C & -2.51862 & -1.26106 & -0.15213 \\
\hline $\mathrm{H}$ & -3.91494 & 0.36130 & 0.17770 \\
\hline $\mathrm{H}$ & -2.73858 & 0.15369 & 1.47866 \\
\hline C & -1.16272 & -1.73132 & 0.29281 \\
\hline $\mathrm{H}$ & -2.56193 & -1.24640 & -1.24806 \\
\hline $\mathrm{H}$ & -3.28613 & -1.96482 & 0.19198 \\
\hline C & -0.09716 & -1.83828 & -0.50277 \\
\hline $\mathrm{H}$ & -1.05381 & -1.96775 & 1.35387 \\
\hline C & 1.27226 & -2.29334 & -0.08676 \\
\hline $\mathrm{H}$ & -0.20950 & -1.57810 & -1.55882 \\
\hline C & 2.35814 & -1.22202 & -0.32993 \\
\hline $\mathrm{H}$ & 1.53841 & -3.18952 & -0.66157 \\
\hline $\mathrm{H}$ & 1.26552 & -2.58149 & 0.97159 \\
\hline $\mathrm{H}$ & 2.22989 & -0.80022 & -1.33229 \\
\hline $\mathrm{H}$ & 3.33839 & -1.71361 & -0.32259 \\
\hline $\mathrm{H}$ & 2.73845 & -0.45998 & 1.69462 \\
\hline \multicolumn{4}{|c|}{${ }^{13} \mathrm{C}$-NMR Shielding Tensors (Boltzmann-Averaged Ensemble) } \\
\hline \multicolumn{4}{|c|}{$38.0903040 \quad C-8$} \\
\hline \multicolumn{2}{|c|}{39.0850256} & \multicolumn{2}{|c|}{ C-21 } \\
\hline \multicolumn{2}{|c|}{43.5374840} & \multicolumn{2}{|c|}{$\mathrm{C}-2$} \\
\hline \multicolumn{2}{|c|}{44.8997124} & \multicolumn{2}{|c|}{$\mathrm{C}-1$} \\
\hline \multicolumn{2}{|c|}{45.7315510} & \multicolumn{2}{|c|}{ C-18 } \\
\hline \multicolumn{2}{|c|}{47.6194381} & \multicolumn{2}{|c|}{$\mathrm{C}-11$} \\
\hline \multicolumn{2}{|c|}{145.0139016} & \multicolumn{2}{|c|}{ C-23 } \\
\hline \multicolumn{2}{|c|}{146.0821342} & \multicolumn{2}{|c|}{$\mathrm{C}-15$} \\
\hline \multicolumn{2}{|c|}{146.5590986} & \multicolumn{2}{|c|}{ C-5 } \\
\hline \multicolumn{2}{|c|}{147.6199953} & \multicolumn{2}{|c|}{ C-13 } \\
\hline \multicolumn{2}{|c|}{147.7539780} & \multicolumn{2}{|c|}{ C-3 } \\
\hline \multicolumn{2}{|c|}{151.1296422} & \multicolumn{2}{|c|}{ C-25 } \\
\hline
\end{tabular}


Table S26: Compound 10

SCF energy:

Zero-point correction:

Enthalpy correction:

Free energy correction:

Quasiharmonic free energy correction:

Boltzmann-averaged quasiharmonic free energy:
-468.137473 hartree +0.281121 hartree +0.290032 hartree +0.249068 hartree +0.249068 hartree -467.888405 hartree

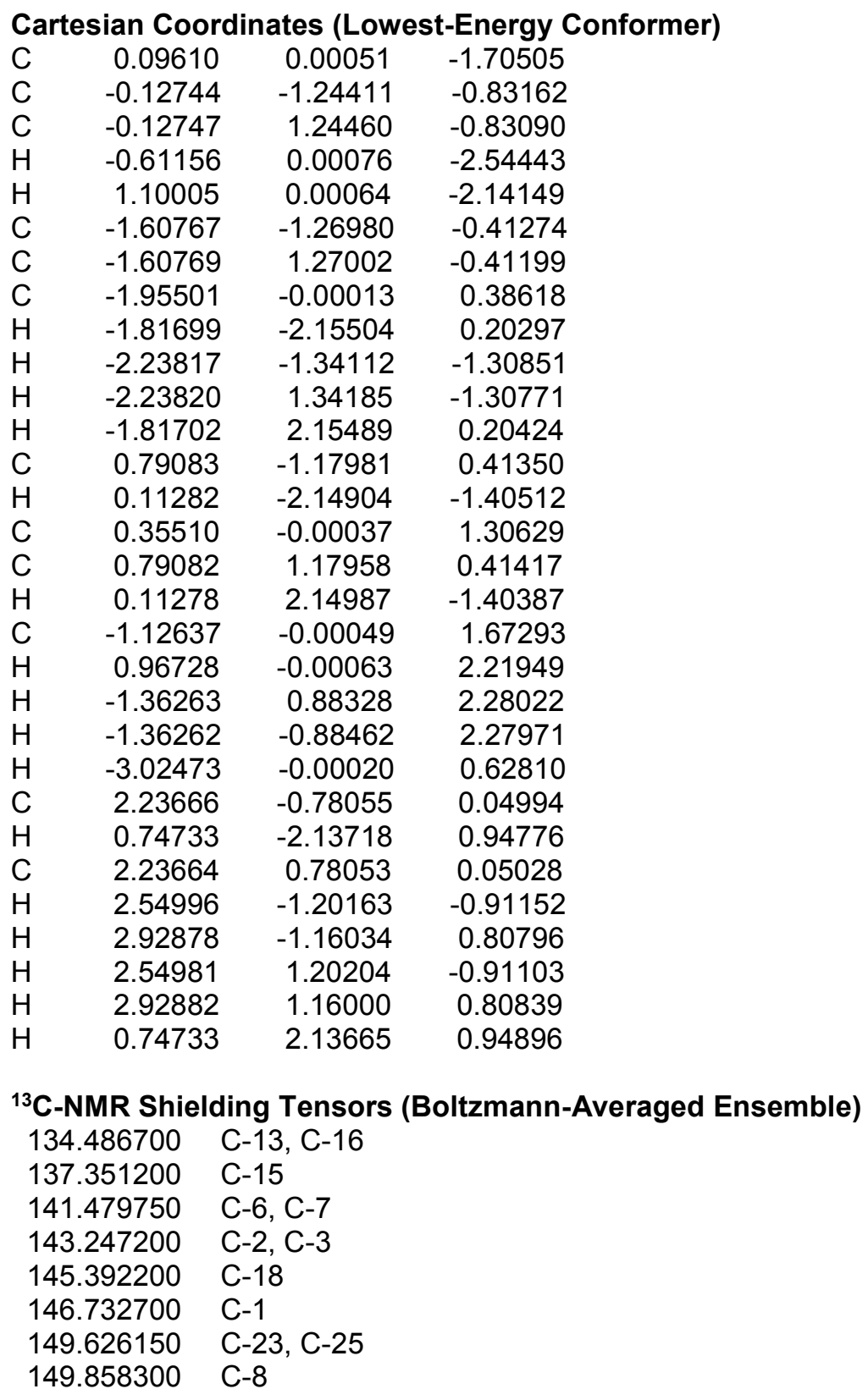




\section{Table S27: Compound 11}

SCF energy:

Zero-point correction:

Enthalpy correction:

Free energy correction:

Quasiharmonic free energy correction:

Boltzmann-averaged quasiharmonic free energy:
-468.129753 hartree +0.281082 hartree +0.290026 hartree +0.249020 hartree +0.249020 hartree -467.880733 hartree

\footnotetext{
Cartesian Coordinates (Lowest-Energy Conformer)

$\begin{array}{llll}\text { C } & 1.15839 & -0.42867 & -1.18363\end{array}$

$\begin{array}{llll}\text { C } & 0.86314 & 1.07710 & -1.27069\end{array}$

$\begin{array}{llll}\text { C } & 2.10618 & -0.67627 & 0.00000\end{array}$

$\begin{array}{llll}\text { C } & -0.06753 & -1.28753 & -0.78557\end{array}$

$\begin{array}{llll}\mathrm{H} & 1.58255 & -0.76401 & -2.13681\end{array}$

$\begin{array}{llll}\text { C } & -0.06753 & -1.28753 & 0.78557\end{array}$

$\begin{array}{llll}\text { C } & 1.15839 & -0.42867 & 1.18363\end{array}$

$\begin{array}{llll}\mathrm{H} & 2.98061 & -0.01494 & 0.00000\end{array}$

$\begin{array}{llll}\mathrm{H} & 2.46127 & -1.71441 & -0.00000\end{array}$

$\begin{array}{llll}\text { C } & 0.20133 & 1.64976 & 0.00000\end{array}$

$\begin{array}{llll}\mathrm{H} & 0.23592 & 1.30277 & -2.14189\end{array}$

$\begin{array}{llll}\mathrm{H} & 1.81882 & 1.59057 & -1.43928\end{array}$

$\begin{array}{llll}\text { C } & 0.86314 & 1.07710 & 1.27069\end{array}$

$\begin{array}{llll}\mathrm{H} & 0.23592 & 1.30277 & 2.14189\end{array}$

$\begin{array}{llll}\mathrm{H} & 1.81882 & 1.59057 & 1.43928\end{array}$

$\begin{array}{llll}\mathrm{H} & 1.58255 & -0.76401 & 2.13681\end{array}$

$\begin{array}{llll}\text { C } & -1.45233 & -0.75738 & -1.19512\end{array}$

$\begin{array}{llll}\mathrm{H} & 0.08718 & -2.30103 & -1.17076\end{array}$

$\begin{array}{llll}\text { C } & -1.45233 & -0.75738 & 1.19512\end{array}$

$\begin{array}{llll}\mathrm{H} & 0.08718 & -2.30103 & 1.17076\end{array}$

$\begin{array}{llll}\text { C } & -1.92111 & 0.09110 & -0.00000\end{array}$

$\begin{array}{llll}\mathrm{H} & -2.14207 & -1.59977 & -1.32431\end{array}$

$\begin{array}{llll}\mathrm{H} & -1.44144 & -0.20137 & -2.13924\end{array}$

$\begin{array}{llll}\mathrm{H} & -1.44144 & -0.20137 & 2.13924\end{array}$

$\begin{array}{llll}\mathrm{H} & -2.14207 & -1.59977 & 1.32431\end{array}$

$\begin{array}{llll}\text { C } & -1.33233 & 1.50720 & 0.00000\end{array}$

$\begin{array}{llll}\mathrm{H} & -3.01331 & 0.19121 & -0.00000\end{array}$

$\begin{array}{llll}\mathrm{H} & -1.71974 & 2.03931 & 0.88008\end{array}$

$\begin{array}{llll}H & -1.71974 & 2.03931 & -0.88008\end{array}$

$\begin{array}{llll}\mathrm{H} & 0.38449 & 2.73231 & -0.00000\end{array}$

${ }^{13} \mathrm{C}$-NMR Shielding Tensors (Boltzmann-Averaged Ensemble)

131.1561000 C-4, C-6

$136.8344000 \quad \mathrm{C}-21$

$137.3906000 \quad \mathrm{C}-3$

$137.9526000 \quad \mathrm{C}-26$

139.4913000 C-1, C-7

144.6836000 C-10

$144.8223000 \quad \mathrm{C}-2, \mathrm{C}-13$

146.1840000 C-17, C-19
} 
Table S28: Compound 12

SCF energy:

Zero-point correction:

Enthalpy correction:

Free energy correction:

Quasiharmonic free energy correction:

Boltzmann-averaged quasiharmonic free energy:

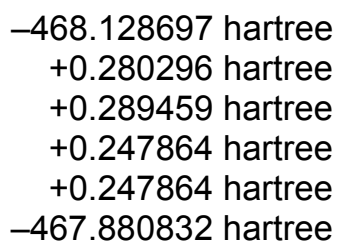

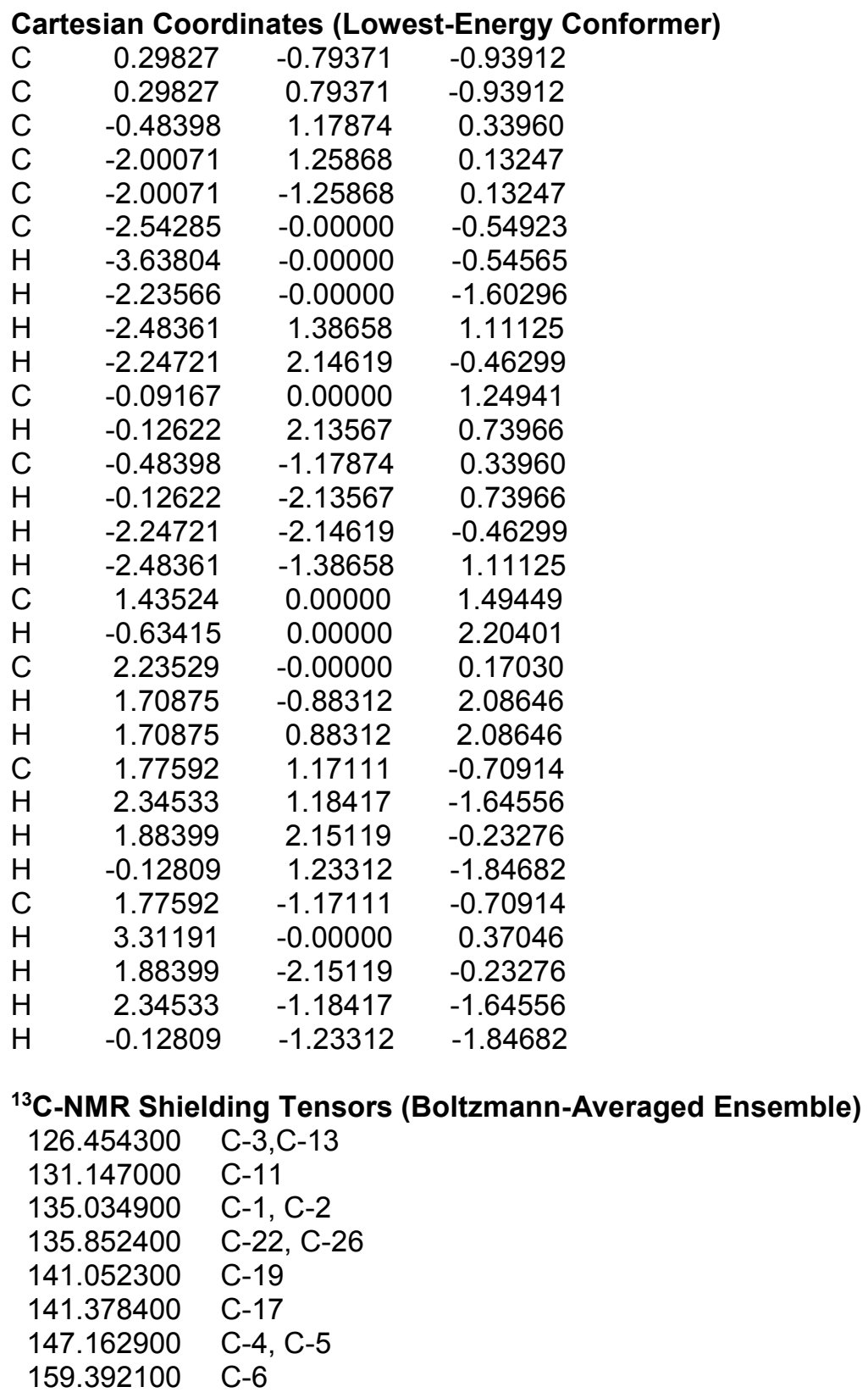


Table S29: Compound 13

SCF energy:

Zero-point correction:

Enthalpy correction:

Free energy correction:

Quasiharmonic free energy correction:

Boltzmann-averaged quasiharmonic free energy:

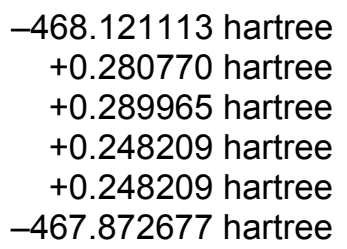

\begin{tabular}{|c|c|c|c|}
\hline \multicolumn{4}{|c|}{ Cartesian Coordinates (Lowest-Energy Conformer) } \\
\hline C & 0.38679 & -1.24930 & -0.47637 \\
\hline C & -0.57774 & -1.28155 & 0.72788 \\
\hline C & -0.14229 & -0.00000 & -1.21650 \\
\hline C & -1.69567 & 0.00000 & -0.92626 \\
\hline C & -1.91182 & -1.24354 & -0.03514 \\
\hline $\mathrm{H}$ & -2.03938 & -2.15634 & -0.62749 \\
\hline $\mathrm{H}$ & -2.78673 & -1.13682 & 0.61490 \\
\hline C & 1.89976 & -1.26119 & -0.23697 \\
\hline C & 1.89976 & 1.26119 & -0.23697 \\
\hline C & 0.38679 & 1.24929 & -0.47637 \\
\hline $\mathrm{H}$ & 0.11434 & -0.00000 & -2.28101 \\
\hline C & -0.57774 & 1.28155 & 0.72788 \\
\hline C & -1.91182 & 1.24354 & -0.03514 \\
\hline $\mathrm{H}$ & -2.78673 & 1.13682 & 0.61490 \\
\hline $\mathrm{H}$ & -2.03937 & 2.15634 & -0.62749 \\
\hline $\mathrm{H}$ & -2.31370 & 0.00000 & -1.82727 \\
\hline $\mathrm{H}$ & 0.15996 & 2.13888 & -1.08005 \\
\hline C & -0.48013 & 0.00000 & 1.59339 \\
\hline $\mathrm{H}$ & -0.45445 & 2.17725 & 1.34780 \\
\hline $\mathrm{H}$ & -1.31292 & 0.00000 & 2.30940 \\
\hline $\mathrm{H}$ & 0.43356 & -0.00000 & 2.19132 \\
\hline $\mathrm{H}$ & -0.45445 & -2.17725 & 1.34780 \\
\hline $\mathrm{H}$ & 0.15996 & -2.13888 & -1.08005 \\
\hline C & 2.46012 & -0.00000 & 0.42479 \\
\hline $\mathrm{H}$ & 3.55277 & 0.00000 & 0.33877 \\
\hline $\mathrm{H}$ & 2.24570 & -0.00000 & 1.49608 \\
\hline $\mathrm{H}$ & 2.38226 & -1.37860 & -1.21797 \\
\hline $\mathrm{H}$ & 2.17038 & -2.14996 & 0.34651 \\
\hline $\mathrm{H}$ & 2.17038 & 2.14996 & 0.34651 \\
\hline $\mathrm{H}$ & 2.38226 & 1.37860 & -1.21797 \\
\hline \multicolumn{4}{|c|}{${ }^{13} \mathrm{C}-\mathrm{NMR}$ Shielding Tensors (Boltzmann-Averaged Ensemble) } \\
\hline \multicolumn{2}{|c|}{134.30016165} & \multicolumn{2}{|c|}{$\mathrm{C}-1, \mathrm{C}-10$} \\
\hline \multicolumn{2}{|c|}{134.69897735} & \multicolumn{2}{|l|}{$C-5, C-13$} \\
\hline \multicolumn{2}{|c|}{135.70418655} & \multicolumn{2}{|l|}{ C-2, C-12 } \\
\hline \multicolumn{2}{|c|}{137.33910370} & \multicolumn{2}{|l|}{ C-3 } \\
\hline \multicolumn{2}{|c|}{138.60044510} & \multicolumn{2}{|l|}{ C-4 } \\
\hline \multicolumn{2}{|c|}{145.50736790} & \multicolumn{2}{|l|}{ C-18 } \\
\hline \multicolumn{2}{|c|}{151.51651680} & \multicolumn{2}{|l|}{ C-8, C-9 } \\
\hline \multicolumn{2}{|c|}{158.98720240} & \multicolumn{2}{|l|}{$\mathrm{C}-24$} \\
\hline
\end{tabular}


Table S30: Compound 14-endo

SCF energy:

Zero-point correction:

Enthalpy correction:

Free energy correction:

Quasiharmonic free energy correction:

Boltzmann-averaged quasiharmonic free energy:

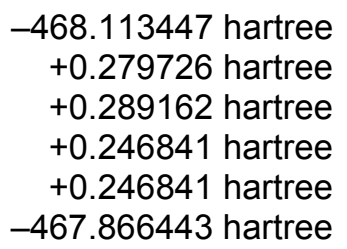

\begin{tabular}{|c|c|c|c|}
\hline \multicolumn{4}{|c|}{ Cartesian Coordinates (Lowest-Energy Conformer) } \\
\hline C & -0.50757 & 1.18704 & -0.59531 \\
\hline C & -0.92096 & 1.24910 & 0.91017 \\
\hline C & -1.36209 & -0.00003 & -1.11320 \\
\hline C & -0.50755 & -1.18706 & -0.59528 \\
\hline C & -1.79995 & 0.00001 & 1.09619 \\
\hline $\mathrm{H}$ & -1.50957 & 2.15279 & 1.10057 \\
\hline $\mathrm{H}$ & -0.06982 & 1.26987 & 1.59661 \\
\hline C & -0.92093 & -1.24906 & 0.91021 \\
\hline $\mathrm{H}$ & -1.50951 & -2.15276 & 1.10065 \\
\hline $\mathrm{H}$ & -0.06978 & -1.26978 & 1.59665 \\
\hline C & -2.60261 & -0.00002 & -0.21584 \\
\hline $\mathrm{H}$ & -2.38335 & 0.00002 & 2.02058 \\
\hline C & 0.94825 & 0.78110 & -0.91473 \\
\hline $\mathrm{H}$ & -0.75991 & 2.13085 & -1.08924 \\
\hline C & 0.94826 & -0.78111 & -0.91473 \\
\hline $\mathrm{H}$ & -0.75988 & -2.13089 & -1.08917 \\
\hline C & 2.05972 & 1.21297 & 0.06308 \\
\hline $\mathrm{H}$ & 1.17610 & 1.15625 & -1.91857 \\
\hline C & 2.30768 & 0.00001 & 0.97546 \\
\hline $\mathrm{H}$ & 1.80408 & 2.12088 & 0.62026 \\
\hline $\mathrm{H}$ & 2.97476 & 1.42943 & -0.50017 \\
\hline C & 2.05975 & -1.21296 & 0.06307 \\
\hline $\mathrm{H}$ & 1.60175 & -0.00000 & 1.81257 \\
\hline $\mathrm{H}$ & 3.31334 & 0.00002 & 1.40718 \\
\hline $\mathrm{H}$ & 1.80414 & -2.12087 & 0.62026 \\
\hline $\mathrm{H}$ & 2.97479 & -1.42938 & -0.50018 \\
\hline $\mathrm{H}$ & 1.17610 & -1.15627 & -1.91856 \\
\hline $\mathrm{H}$ & -1.52522 & -0.00004 & -2.19477 \\
\hline $\mathrm{H}$ & -3.22504 & 0.89298 & -0.33962 \\
\hline $\mathrm{H}$ & -3.22502 & -0.89305 & -0.33959 \\
\hline \multicolumn{4}{|c|}{${ }^{13} \mathrm{C}$-NMR Shielding Tensors (Boltzmann-Averaged Ensemble) } \\
\hline \multicolumn{4}{|c|}{$126.0736515 \quad \mathrm{C}-3$} \\
\hline \multicolumn{2}{|c|}{129.6765005} & \multicolumn{2}{|l|}{ C-15 } \\
\hline \multicolumn{2}{|c|}{129.8268925} & \multicolumn{2}{|c|}{ C-13 } \\
\hline \multicolumn{2}{|c|}{133.6021070} & \multicolumn{2}{|c|}{ C-1 } \\
\hline \multicolumn{2}{|c|}{133.8639210} & \multicolumn{2}{|c|}{ C-4 } \\
\hline \multicolumn{2}{|c|}{140.8029835} & \multicolumn{2}{|l|}{ C-11 } \\
\hline \multicolumn{2}{|c|}{142.1657865} & \multicolumn{2}{|l|}{ C-5 } \\
\hline \multicolumn{2}{|c|}{148.7980630} & \multicolumn{2}{|l|}{ C-8 } \\
\hline \multicolumn{2}{|c|}{148.9125135} & \multicolumn{2}{|l|}{ C-2 } \\
\hline \multicolumn{2}{|c|}{149.4449130} & \multicolumn{2}{|l|}{ C-19 } \\
\hline \multicolumn{2}{|c|}{150.4080985} & \multicolumn{2}{|l|}{ C-22 } \\
\hline \multicolumn{2}{|c|}{150.5304750} & $\mathrm{C}-17$ & \\
\hline
\end{tabular}


Table S31: Compound 14-exo

SCF energy:

Zero-point correction:

Enthalpy correction:

Free energy correction:

Quasiharmonic free energy correction:

Boltzmann-averaged quasiharmonic free energy:

Cartesian Coordinates (Lowest-Energy Conformer)

$\begin{array}{lrrr}\mathrm{C} & 0.40004 & 1.18991 & 0.15958 \\ \mathrm{C} & 1.65317 & 1.24575 & -0.76906 \\ \mathrm{C} & 0.74250 & -0.00000 & 1.09611 \\ \mathrm{C} & 0.40004 & -1.18991 & 0.15958 \\ \mathrm{H} & 2.46096 & -0.00000 & -0.36561 \\ \mathrm{H} & 1.38181 & 2.15477 & -0.58169 \\ \mathrm{C} & 1.65317 & -1.23848 & -1.83095 \\ \mathrm{H} & 2.23446 & -2.15477 & -0.76906 \\ \mathrm{H} & 1.38181 & -1.23848 & -1.58169 \\ \mathrm{C} & 2.27360 & -0.00000 & 1.16133 \\ \mathrm{H} & 3.49290 & 0.00000 & -0.72606 \\ \mathrm{C} & -0.90168 & 0.78348 & -0.54865 \\ \mathrm{H} & 0.27709 & 2.13368 & 0.70247 \\ \mathrm{C} & -0.90168 & -0.78348 & -0.54865 \\ \mathrm{H} & 0.27709 & -2.13368 & 0.70247 \\ \mathrm{C} & -2.18657 & 1.19082 & 0.20254 \\ \mathrm{H} & -0.93401 & 1.18386 & -1.56852 \\ \mathrm{C} & -3.13147 & 0.00000 & 0.01772 \\ \mathrm{H} & -2.59819 & 2.14032 & -0.15279 \\ \mathrm{H} & -1.96470 & 1.30942 & 1.27226 \\ \mathrm{C} & -2.18657 & -1.19082 & 0.20254 \\ \mathrm{H} & -3.53951 & 0.00000 & -1.00114 \\ \mathrm{H} & -3.97437 & 0.00000 & 0.71552 \\ \mathrm{H} & -2.59819 & -2.14032 & -0.15279 \\ \mathrm{H} & -1.96470 & -1.30942 & 1.27226 \\ \mathrm{H} & -0.93401 & -1.18386 & -1.56852 \\ \mathrm{H} & 0.20601 & -0.00000 & 2.04911 \\ \mathrm{H} & 2.68448 & 0.89282 & 1.64539 \\ \mathrm{H} & 2.68448 & -0.89282 & 1.64539\end{array}$

-468.118034 hartree +0.279150 hartree +0.288824 hartree +0.245594 hartree +0.245767 hartree -467.872264 hartree

\footnotetext{
${ }^{13} \mathrm{C}$-NMR Shielding Tensors (Boltzmann-Averaged Ensemble)

125.2102536 C-13, C-15

131.7591747 C-1, C-4

133.5389936 C-3

138.8205488 C-2, C-8

$140.2303556 \quad \mathrm{C}-5$

$140.3753906 \quad \mathrm{C}-11$

143.9978962 C-17, C-22

150.0350226 C-19
} 
Table S32: Compound 15-endo

SCF energy:

Zero-point correction:

Enthalpy correction:

Free energy correction:

Quasiharmonic free energy correction:

Boltzmann-averaged quasiharmonic free energy:

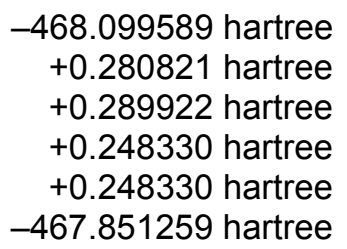

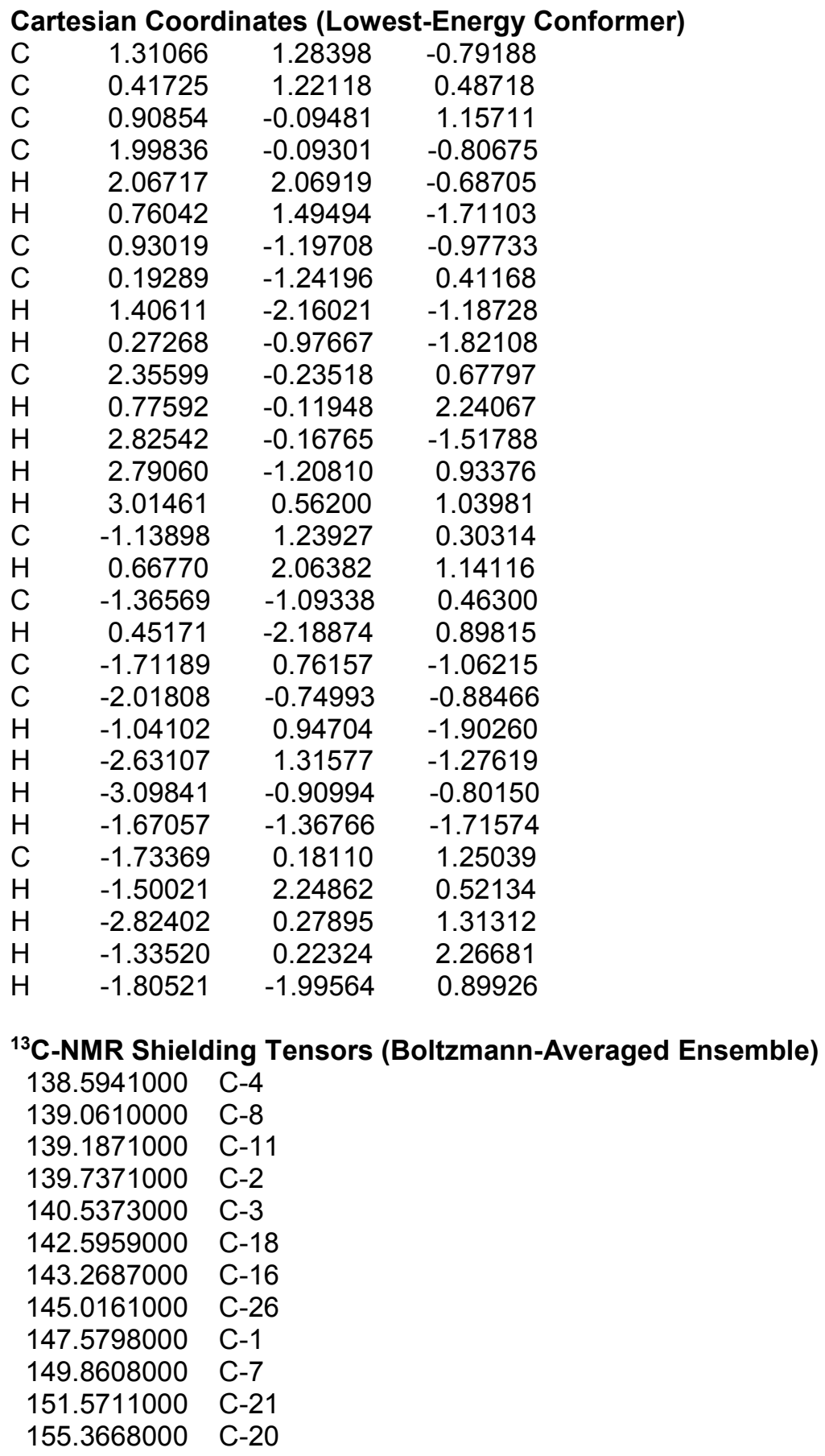


Table S33: Compound 15-exo

SCF energy:

Zero-point correction:

Enthalpy correction:

Free energy correction:

Quasiharmonic free energy correction:

Boltzmann-averaged quasiharmonic free energy:

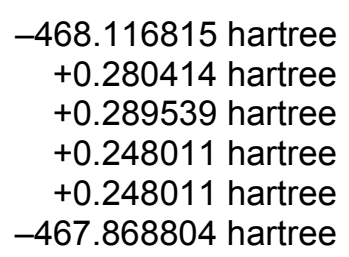

Cartesian Coordinates (Lowest-Energy Conformer)

$\begin{array}{lrrr}\mathrm{C} & 1.44738 & -1.26482 & 0.72912 \\ \mathrm{C} & 0.22695 & -1.24759 & -0.24803 \\ \mathrm{C} & 0.52525 & 0.00002 & -1.11583 \\ \mathrm{H} & 2.24241 & -0.00011 & 0.34113 \\ \mathrm{H} & 2.06155 & -2.15574 & 0.56191 \\ \mathrm{C} & 1.4243 & -1.27013 & 1.78323 \\ \mathrm{C} & 0.22706 & 1.26477 & 0.72911 \\ \mathrm{H} & 2.06194 & 2.24760 & -0.24783 \\ \mathrm{H} & 1.15299 & 1.27019 & 0.56174 \\ \mathrm{C} & 2.05721 & -0.00003 & -1.18329 \\ \mathrm{H} & 0.00579 & 0.00015 & -2.07795 \\ \mathrm{H} & 3.27296 & -0.00020 & 0.70577 \\ \mathrm{H} & 2.46493 & 0.89398 & -1.67062 \\ \mathrm{H} & 2.46483 & -0.89407 & -1.67067 \\ \mathrm{C} & -1.16294 & -1.18006 & 0.41390 \\ \mathrm{H} & 0.25370 & -2.13857 & -0.88843 \\ \mathrm{C} & -1.16280 & 1.18008 & 0.41413 \\ \mathrm{H} & 0.25394 & 2.13853 & -0.88828 \\ \mathrm{C} & -2.23691 & -0.78017 & -0.62563 \\ \mathrm{C} & -2.23680 & 0.78045 & -0.62555 \\ \mathrm{H} & -3.21635 & -1.15951 & -0.31812 \\ \mathrm{H} & -2.02372 & -1.19987 & -1.61439 \\ \mathrm{H} & -2.02334 & 1.20026 & -1.61423 \\ \mathrm{H} & -3.21621 & 1.15994 & -0.31816 \\ \mathrm{C} & -1.24185 & -0.00014 & 1.39021 \\ \mathrm{H} & -1.39056 & -2.13876 & 0.89342 \\ \mathrm{H} & -2.21245 & -0.00014 & 1.90198 \\ \mathrm{H} & -0.46795 & -0.00028 & 2.16055 \\ \mathrm{H} & -1.39042 & 2.13867 & 0.89383 \\ & & & \end{array}$

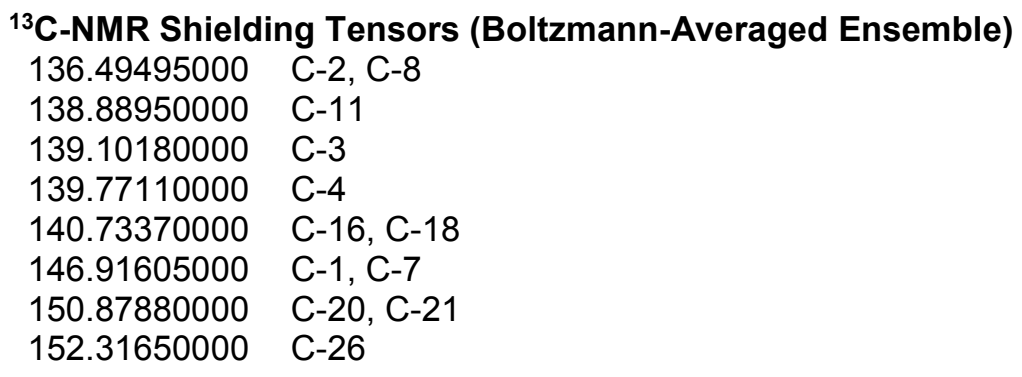


Table S34: Compound 16

SCF energy:

Zero-point correction:

Enthalpy correction:

Free energy correction:

Quasiharmonic free energy correction:

Boltzmann-averaged quasiharmonic free energy:

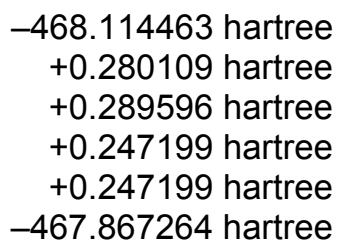

\begin{tabular}{|c|c|c|c|}
\hline \multicolumn{4}{|c|}{ Cartesian Coordinates (Lowest-Energy Conformer) } \\
\hline C & 0.14075 & -1.14821 & -0.61078 \\
\hline C & 0.87690 & 0.11189 & -1.13706 \\
\hline C & 0.14166 & -0.92908 & 0.94397 \\
\hline C & 1.03759 & 0.30950 & 1.10305 \\
\hline C & 2.47010 & -0.07579 & 0.67665 \\
\hline C & 2.37732 & -0.13010 & -0.88205 \\
\hline $\mathrm{H}$ & 2.77711 & -1.03335 & 1.10978 \\
\hline $\mathrm{H}$ & 3.19210 & 0.67903 & 1.00253 \\
\hline $\mathrm{H}$ & 2.71696 & -1.08529 & -1.29348 \\
\hline $\mathrm{H}$ & 2.98128 & 0.66117 & -1.33733 \\
\hline C & 0.59941 & 1.20465 & -0.07514 \\
\hline $\mathrm{H}$ & 0.63405 & 0.36659 & -2.17393 \\
\hline $\mathrm{H}$ & 0.97680 & 0.77478 & 2.09261 \\
\hline C & -1.34517 & -0.71779 & 1.32892 \\
\hline $\mathrm{H}$ & 0.56367 & -1.77965 & 1.48984 \\
\hline C & -1.33569 & -1.28364 & -0.99366 \\
\hline $\mathrm{H}$ & 0.69877 & -2.04198 & -0.91034 \\
\hline C & -2.08542 & -0.40402 & 0.01429 \\
\hline $\mathrm{H}$ & -1.64385 & -2.32922 & -0.86687 \\
\hline $\mathrm{H}$ & -1.53662 & -1.00454 & -2.03455 \\
\hline $\mathrm{H}$ & -1.47209 & 0.06369 & 2.08724 \\
\hline $\mathrm{H}$ & -1.74649 & -1.64470 & 1.75324 \\
\hline C & -2.03310 & 1.08091 & -0.38397 \\
\hline $\mathrm{H}$ & -3.13767 & -0.70405 & 0.07700 \\
\hline C & -0.78117 & 1.86997 & 0.03499 \\
\hline $\mathrm{H}$ & -2.89940 & 1.60004 & 0.04358 \\
\hline $\mathrm{H}$ & -2.15196 & 1.14469 & -1.47318 \\
\hline $\mathrm{H}$ & -0.89735 & 2.20040 & 1.07563 \\
\hline $\mathrm{H}$ & -0.76802 & 2.78970 & -0.56116 \\
\hline $\mathrm{H}$ & 1.33364 & 2.01287 & -0.19585 \\
\hline \multicolumn{4}{|c|}{${ }^{13} \mathrm{C}-\mathrm{NMR}$ Shielding Tensors (Boltzmann-Averaged Ensemble) } \\
\hline \multicolumn{4}{|c|}{$128.3857000 \quad C-3$} \\
\hline \multicolumn{2}{|c|}{128.9146000} & \multicolumn{2}{|c|}{ C-4 } \\
\hline \multicolumn{2}{|c|}{129.2961000} & \multicolumn{2}{|c|}{$\mathrm{C}-1$} \\
\hline \multicolumn{2}{|c|}{130.2540000} & \multicolumn{2}{|c|}{$\mathrm{C}-11$} \\
\hline \multicolumn{2}{|c|}{131.5178000} & \multicolumn{2}{|c|}{ C-2 } \\
\hline \multicolumn{2}{|c|}{135.5344000} & \multicolumn{2}{|c|}{ C-16 } \\
\hline \multicolumn{2}{|c|}{140.5787000} & \multicolumn{2}{|c|}{ C-18 } \\
\hline \multicolumn{2}{|c|}{144.9354000} & \multicolumn{2}{|c|}{ C-14 } \\
\hline \multicolumn{2}{|c|}{146.4237000} & \multicolumn{2}{|c|}{ C-23 } \\
\hline \multicolumn{2}{|c|}{147.3140000} & \multicolumn{2}{|c|}{ C-6 } \\
\hline \multicolumn{2}{|c|}{151.3467000} & \multicolumn{2}{|c|}{ C-5 } \\
\hline \multicolumn{2}{|c|}{154.1403000} & 25 & \\
\hline
\end{tabular}


Table S35: Compound 17

SCF energy:

Zero-point correction:

Enthalpy correction:

Free energy correction:

Quasiharmonic free energy correction:

Boltzmann-averaged quasiharmonic free energy:

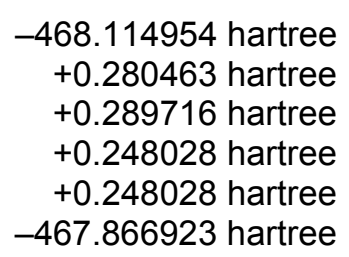

Cartesian Coordinates (Lowest-Energy Conformer)

\begin{tabular}{|c|c|c|c|}
\hline C & -0.45370 & 1.84935 & 0.77655 \\
\hline C & -0.45384 & 1.84943 & -0.77634 \\
\hline C & -0.90563 & 0.43504 & 1.18161 \\
\hline $\mathrm{H}$ & -1.18558 & 2.57390 & 1.14884 \\
\hline $\mathrm{H}$ & 0.50758 & 2.12862 & 1.21662 \\
\hline C & 0.18626 & -0.69890 & 1.23861 \\
\hline C & 1.66887 & -0.31010 & 1.28426 \\
\hline C & 2.20729 & 0.34064 & 0.00001 \\
\hline $\mathrm{H}$ & 2.23164 & -1.23491 & 1.47152 \\
\hline $\mathrm{H}$ & 1.86614 & 0.34551 & 2.14179 \\
\hline C & 1.66880 & -0.30983 & -1.28441 \\
\hline $\mathrm{H}$ & 3.30111 & 0.27346 & 0.00000 \\
\hline $\mathrm{H}$ & 1.97939 & 1.40737 & 0.00011 \\
\hline C & 0.18625 & -0.69890 & -1.23859 \\
\hline $\mathrm{H}$ & 1.86550 & 0.34629 & -2.14170 \\
\hline $\mathrm{H}$ & 2.23189 & -1.23429 & -1.47230 \\
\hline C & -0.90552 & 0.43504 & -1.18160 \\
\hline $\mathrm{H}$ & 0.50724 & 2.12914 & -1.21653 \\
\hline $\mathrm{H}$ & -1.18607 & 2.57377 & -1.14839 \\
\hline C & -1.79448 & -0.02867 & -0.00002 \\
\hline $\mathrm{H}$ & -1.44883 & 0.46022 & 2.13163 \\
\hline $\mathrm{H}$ & -1.44876 & 0.46047 & -2.13160 \\
\hline C & -0.14627 & -1.55289 & 0.00003 \\
\hline $\mathrm{H}$ & -0.01835 & -1.30031 & -2.13341 \\
\hline $\mathrm{H}$ & -0.01842 & -1.30016 & 2.13352 \\
\hline C & -1.67688 & -1.55319 & -0.00009 \\
\hline $\mathrm{H}$ & -2.80174 & 0.39916 & -0.00006 \\
\hline $\mathrm{H}$ & -2.10758 & -2.01932 & -0.89323 \\
\hline $\mathrm{H}$ & -2.10760 & -2.01934 & 0.89304 \\
\hline $\mathrm{H}$ & 0.34553 & -2.53166 & 0.00002 \\
\hline \multicolumn{4}{|c|}{${ }^{13} \mathrm{C}-\mathrm{NMR}$ Shielding Tensors (Boltzmann-Averaged Ensemble) } \\
\hline \multicolumn{4}{|c|}{$125.082900 \quad C-20$} \\
\hline \multicolumn{2}{|c|}{134.635400} & \multicolumn{2}{|c|}{$\mathrm{C}-3, \mathrm{C}-17$} \\
\hline \multicolumn{2}{|c|}{135.280700} & \multicolumn{2}{|c|}{ C-23 } \\
\hline \multicolumn{2}{|c|}{139.707400} & \multicolumn{2}{|c|}{ C-6, C-14 } \\
\hline \multicolumn{2}{|c|}{144.123700} & \multicolumn{2}{|c|}{ C-26 } \\
\hline \multicolumn{2}{|c|}{152.342600} & \multicolumn{2}{|c|}{ C-1, C-2 } \\
\hline \multicolumn{2}{|c|}{155.326300} & \multicolumn{2}{|c|}{ C-7, C-11 } \\
\hline \multicolumn{2}{|c|}{161.077900} & \multicolumn{2}{|c|}{$\mathrm{C}-8$} \\
\hline
\end{tabular}


Table S36: Compound 18

SCF energy:

Zero-point correction:

Enthalpy correction:

Free energy correction:

Quasiharmonic free energy correction:

Boltzmann-averaged quasiharmonic free energy:

-469.327509 hartree

+0.300466 hartree

+0.311944 hartree

+0.264426 hartree

+0.264868 hartree

-469.06264 hartree

\begin{tabular}{lrrr}
\multicolumn{4}{c}{ Cartesian Coordinates (Lowest-Energy Conformer) } \\
C & -1.43112 & 0.73579 & -0.25700 \\
$\mathrm{C}$ & -0.74031 & 2.01263 & 0.21354 \\
$\mathrm{C}$ & -0.72028 & -0.53306 & 0.23604 \\
$\mathrm{C}$ & 0.72030 & -0.53305 & -0.23605 \\
$\mathrm{C}$ & 1.43112 & 0.73580 & 0.25700 \\
$\mathrm{C}$ & 0.74029 & 2.01264 & -0.21353 \\
$\mathrm{H}$ & -0.80333 & 2.06961 & 1.31031 \\
$\mathrm{H}$ & -1.25094 & 2.89871 & -0.18171 \\
$\mathrm{H}$ & 0.80331 & 2.06962 & -1.31030 \\
$\mathrm{H}$ & 1.25091 & 2.89872 & 0.18171 \\
$\mathrm{C}$ & 1.66664 & -1.64312 & 0.22659 \\
$\mathrm{H}$ & 0.72005 & -0.50823 & -1.34072 \\
$\mathrm{C}$ & 3.08695 & -1.03783 & 0.04024 \\
$\mathrm{H}$ & 1.53090 & -2.57926 & -0.32298 \\
$\mathrm{H}$ & 1.47678 & -1.85654 & 1.28654 \\
$\mathrm{C}$ & 2.87980 & 0.48881 & -0.16960 \\
$\mathrm{H}$ & 3.59620 & -1.48347 & -0.81882 \\
$\mathrm{H}$ & 3.71256 & -1.23513 & 0.91524 \\
$\mathrm{H}$ & 1.38923 & 0.71353 & 1.35997 \\
$\mathrm{H}$ & 2.99035 & 0.74808 & -1.23035 \\
$\mathrm{H}$ & 3.59983 & 1.09338 & 0.38985 \\
$\mathrm{C}$ & -2.87981 & 0.48879 & 0.16959 \\
$\mathrm{H}$ & -1.38923 & 0.71353 & -1.35997 \\
$\mathrm{C}$ & -3.08694 & -1.03785 & -0.04019 \\
$\mathrm{H}$ & -3.59985 & 1.09335 & -0.38988 \\
$\mathrm{H}$ & -2.99037 & 0.74810 & 1.23033 \\
$\mathrm{C}$ & -1.66662 & -1.64311 & -0.22662 \\
$\mathrm{H}$ & -3.71261 & -1.23521 & -0.91513 \\
$\mathrm{H}$ & -3.59612 & -1.48346 & 0.81893 \\
$\mathrm{H}$ & -1.47679 & -1.85646 & -1.28659 \\
$\mathrm{H}$ & -1.53086 & -2.57929 & 0.32288 \\
$\mathrm{H}$ & -0.72005 & -0.50825 & 1.34071 \\
& & &
\end{tabular}

${ }^{13} \mathrm{C}$-NMR Shielding Tensors (Boltzmann-Averaged Ensemble)

$\begin{array}{ll}125.764350 & \text { C-3, C-4 } \\ 130.385700 & \text { C-1, C-5 } \\ 147.219000 & \text { C-2, C-6 } \\ 147.963550 & \text { C-16, C-22 } \\ 149.236050 & \text { C-11, C-27 } \\ 157.695900 & \text { C-13, C-24 }\end{array}$


Table S37: Compound 19

SCF energy:

Zero-point correction:

Enthalpy correction:

Free energy correction:

Quasiharmonic free energy correction:

Boltzmann-averaged quasiharmonic free energy:

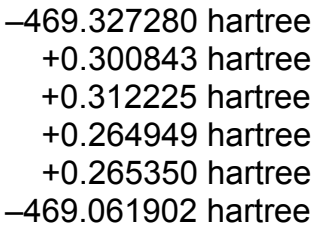

\begin{tabular}{|c|c|c|c|}
\hline \multicolumn{4}{|c|}{ Cartesian Coordinates (Lowest-Energy Conformer) } \\
\hline C & -1.31427 & 0.80414 & -0.19837 \\
\hline C & -0.48888 & 1.99747 & 0.26138 \\
\hline C & -0.54048 & -0.50390 & -0.01485 \\
\hline C & 0.74865 & -0.52678 & -0.83246 \\
\hline C & 1.60088 & 0.72571 & -0.52441 \\
\hline C & 0.82629 & 2.05131 & -0.53116 \\
\hline $\mathrm{H}$ & -0.28872 & 1.89630 & 1.33765 \\
\hline $\mathrm{H}$ & -1.03993 & 2.93642 & 0.13043 \\
\hline $\mathrm{H}$ & 0.58809 & 2.31255 & -1.57110 \\
\hline $\mathrm{H}$ & 1.47023 & 2.85298 & -0.14878 \\
\hline C & 1.69260 & -1.66875 & -0.43425 \\
\hline $\mathrm{H}$ & 0.48136 & -0.57008 & -1.89843 \\
\hline C & 2.38507 & -1.17003 & 0.85625 \\
\hline $\mathrm{H}$ & 1.17246 & -2.62200 & -0.29354 \\
\hline $\mathrm{H}$ & 2.43638 & -1.81649 & -1.22580 \\
\hline C & 2.29035 & 0.37834 & 0.81352 \\
\hline $\mathrm{H}$ & 1.87509 & -1.56124 & 1.74200 \\
\hline $\mathrm{H}$ & 3.42028 & -1.51715 & 0.91214 \\
\hline $\mathrm{H}$ & 2.38102 & 0.78544 & -1.29605 \\
\hline $\mathrm{H}$ & 3.27084 & 0.85828 & 0.88588 \\
\hline $\mathrm{H}$ & 1.69650 & 0.75005 & 1.65608 \\
\hline C & -2.63189 & 0.51733 & 0.52469 \\
\hline $\mathrm{H}$ & -1.52164 & 0.91631 & -1.27730 \\
\hline C & -2.92668 & -0.97532 & 0.21530 \\
\hline $\mathrm{H}$ & -3.44392 & 1.18278 & 0.21673 \\
\hline $\mathrm{H}$ & -2.48356 & 0.66122 & 1.60282 \\
\hline C & -1.59590 & -1.57230 & -0.32285 \\
\hline $\mathrm{H}$ & -3.72311 & -1.07282 & -0.52791 \\
\hline $\mathrm{H}$ & -3.26580 & -1.50162 & 1.11184 \\
\hline $\mathrm{H}$ & -1.65234 & -1.71504 & -1.40977 \\
\hline $\mathrm{H}$ & -1.36453 & -2.54557 & 0.11954 \\
\hline $\mathrm{H}$ & -0.28313 & -0.57366 & 1.05685 \\
\hline \multicolumn{4}{|c|}{${ }^{13} \mathrm{C}$-NMR Shielding Tensors (Boltzmann-Averaged Ensemble) } \\
\hline \multicolumn{2}{|c|}{1297705152} & \multicolumn{2}{|c|}{ C-4 } \\
\hline \multicolumn{2}{|c|}{132.4395358} & \multicolumn{2}{|l|}{$\mathrm{C}-1$} \\
\hline \multicolumn{2}{|c|}{134.2677826} & \multicolumn{2}{|l|}{ C-3 } \\
\hline \multicolumn{2}{|c|}{137.2732812} & \multicolumn{2}{|l|}{ C-5 } \\
\hline \multicolumn{2}{|c|}{146.8223004} & \multicolumn{2}{|c|}{ C-22 } \\
\hline & \multicolumn{2}{|l|}{ C-11 } \\
\hline \multicolumn{2}{|c|}{148.5165884} & \multicolumn{2}{|l|}{$\mathrm{C}-27$} \\
\hline \multicolumn{2}{|c|}{151.6610698} & \multicolumn{2}{|l|}{ C-6 } \\
\hline \multicolumn{2}{|c|}{152.1852020} & \multicolumn{2}{|l|}{ C-2 } \\
\hline \multicolumn{2}{|c|}{153.3659110} & \multicolumn{2}{|l|}{ C-16 } \\
\hline & 197230 & C-13 & \\
\hline & 3673672 & C-24 & \\
\hline
\end{tabular}


Table S38: Compound 20

SCF energy:

Zero-point correction:

Enthalpy correction:

Free energy correction:

Quasiharmonic free energy correction:

Boltzmann-averaged quasiharmonic free energy:

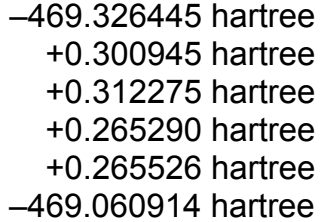

-469.326445 hartree +0.300945 hartree +0.312275 hartree +0.265290 hartree -469.060914 hartree

\footnotetext{
Cartesian Coordinates (Lowest-Energy Conformer) $\begin{array}{lll}1.21315 & 0.69783 & -0.39580\end{array}$

$\begin{array}{llll}C & 0.43665 & 1.98075 & -0.13416\end{array}$

$\begin{array}{llll}\text { C } & 0.82167 & -0.39705 & 0.60112\end{array}$

C $\quad-0.67249 \quad-0.70486 \quad 0.60991$

$\begin{array}{llll}C & -1.51938 & 0.58125 & 0.74650\end{array}$

C $\quad-1.06675 \quad 1.68557 \quad-0.22369$

$\mathrm{H} \quad 0.71434 \quad 2.76614 \quad-0.84723$

$\begin{array}{llll}\mathrm{H} & 0.68604 & 2.35429 & 0.87042\end{array}$

$\begin{array}{llll}\mathrm{H} & -1.65196 & 2.59201 & -0.02862\end{array}$

$\mathrm{H} \quad-1.30120 \quad 1.38137 \quad-1.25449$

C $\quad-1.24925 \quad-1.39909 \quad-0.64258$

$\mathrm{H} \quad-0.89794 \quad-1.33922 \quad 1.47976$

$\begin{array}{llll}\text { C } & -2.72606 & -0.92869 & -0.74107\end{array}$

$\mathrm{H} \quad-0.69417 \quad-1.10305 \quad-1.53975$

H $\quad-1.16629 \quad-2.48717 \quad-0.56886$

$\begin{array}{llll}\text { C } & -2.92994 & 0.07654 & 0.41742\end{array}$

$\mathrm{H} \quad-2.91060 \quad-0.44758 \quad-1.70645$

$\mathrm{H} \quad-3.42701 \quad-1.76463 \quad-0.66957$

$\begin{array}{llll}\mathrm{H} & -1.45675 & 0.97218 & 1.77115\end{array}$

$\mathrm{H} \quad-3.34482 \quad-0.43806 \quad 1.29172$

$\begin{array}{llll}\mathrm{H} & -3.61979 & 0.88621 & 0.15604\end{array}$

$\begin{array}{llll}\text { C } & 2.73811 & 0.72161 & -0.26510\end{array}$

$\mathrm{H} \quad 0.96296 \quad 0.34585 \quad-1.41031$

$\begin{array}{llll}\text { C } & 3.13188 & -0.76901 & -0.06425\end{array}$

$\begin{array}{llll}\mathrm{H} & 3.01231 & 1.31172 & 0.61874\end{array}$

$\begin{array}{llll}\mathrm{H} & 3.23373 & 1.17759 & -1.12727\end{array}$

$\begin{array}{llll}\text { C } & 1.81253 & -1.51799 & 0.27447\end{array}$

$\mathrm{H} \quad 3.86419 \quad-0.87340 \quad 0.74122$

$\begin{array}{llll}\mathrm{H} & 3.59356 & -1.18071 & -0.96610\end{array}$

$\begin{array}{llll}\mathrm{H} & 1.93073 & -2.23541 & 1.09228\end{array}$

$\mathrm{H} \quad 1.45586 \quad-2.07574-0.60020$

$\begin{array}{llll}\mathrm{H} & 1.07607 & -0.00360 & 1.60096\end{array}$

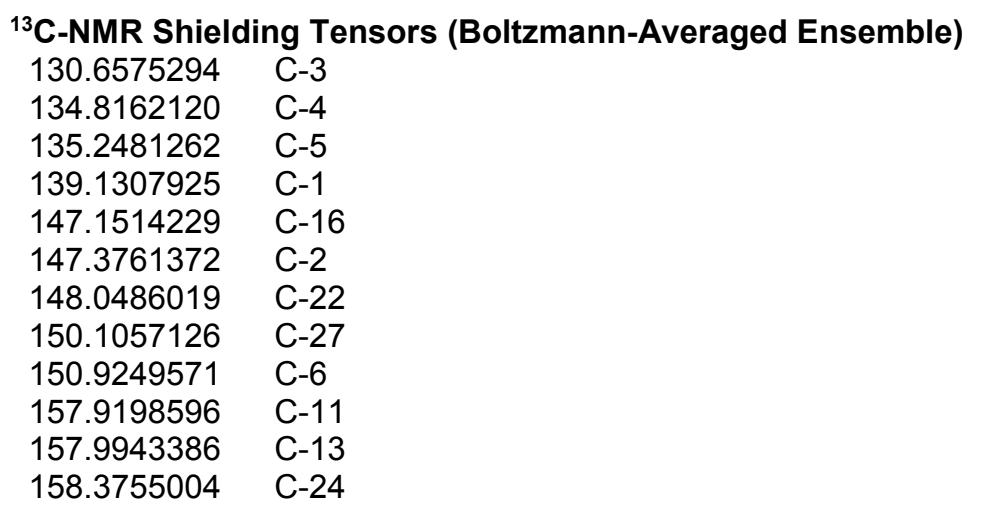


Table S39: Compound 21

SCF energy:

Zero-point correction:

Enthalpy correction:

Free energy correction:

Quasiharmonic free energy correction:

Boltzmann-averaged quasiharmonic free energy:

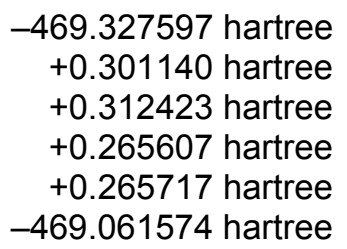

\begin{tabular}{lrrr}
\multicolumn{4}{c}{ Cartesian Coordinates (Lowest-Energy Conformer) } \\
C & 1.23326 & 0.41835 & -0.86044 \\
$\mathrm{C}$ & 0.75980 & 1.65179 & -0.08303 \\
$\mathrm{C}$ & 0.73891 & -0.88384 & -0.19769 \\
$\mathrm{C}$ & -0.73890 & -0.88384 & 0.19770 \\
$\mathrm{C}$ & -1.23327 & 0.41833 & 0.86045 \\
$\mathrm{C}$ & -0.75982 & 1.65179 & 0.08305 \\
$\mathrm{H}$ & 1.09417 & 2.55888 & -0.60052 \\
$\mathrm{H}$ & 1.23085 & 1.66718 & 0.91097 \\
$\mathrm{H}$ & -1.09420 & 2.55887 & 0.60055 \\
$\mathrm{H}$ & -1.23086 & 1.66717 & -0.91096 \\
$\mathrm{C}$ & -1.71333 & -1.07906 & -0.98388 \\
$\mathrm{H}$ & -0.90469 & -1.70298 & 0.91398 \\
$\mathrm{C}$ & -3.04323 & -0.40530 & -0.55771 \\
$\mathrm{H}$ & -1.83709 & -2.13941 & -1.22339 \\
$\mathrm{H}$ & -1.30945 & -0.59903 & -1.88280 \\
$\mathrm{C}$ & -2.75733 & 0.25011 & 0.81484 \\
$\mathrm{H}$ & -3.86392 & -1.12450 & -0.49033 \\
$\mathrm{H}$ & -3.34590 & 0.34778 & -1.29163 \\
$\mathrm{H}$ & -0.87139 & 0.50066 & 1.89403 \\
$\mathrm{H}$ & -3.07328 & -0.41945 & 1.62306 \\
$\mathrm{H}$ & -3.28870 & 1.19849 & 0.94949 \\
$\mathrm{C}$ & 2.75732 & 0.25015 & -0.81484 \\
$\mathrm{H}$ & 0.87137 & 0.50068 & -1.89401 \\
$\mathrm{C}$ & 3.04325 & -0.40534 & 0.55767 \\
$\mathrm{H}$ & 3.28867 & 1.19854 & -0.94945 \\
$\mathrm{H}$ & 3.07329 & -0.41936 & -1.62310 \\
$\mathrm{C}$ & 1.71333 & -1.07903 & 0.98389 \\
$\mathrm{H}$ & 3.34601 & 0.34769 & 1.29161 \\
$\mathrm{H}$ & 3.86388 & -1.12459 & 0.49021 \\
$\mathrm{H}$ & 1.30947 & -0.59895 & 1.88279 \\
$\mathrm{H}$ & 1.83706 & -2.13937 & 1.22345 \\
$\mathrm{H}$ & 0.90470 & -1.70297 & -0.91398 \\
& & &
\end{tabular}

\footnotetext{
${ }^{13} \mathrm{C}$-NMR Shielding Tensors (Boltzmann-Averaged Ensemble)

135.68059980 C-4

$135.77162690 \quad \mathrm{C}-3$

140.95423090 C-1, C-5

147.39056745 C-16, C-22

150.11968380 C-11, C-27

152.96523290 C-2, C-6

158.34320645 C-13, C-24
} 
Table S40: Compound 22

SCF energy:

Zero-point correction:

Enthalpy correction:

Free energy correction:

Quasiharmonic free energy correction:

Boltzmann-averaged quasiharmonic free energy:
-469.331389 hartree +0.300924 hartree +0.311867 hartree +0.266370 hartree +0.266420 hartree -469.06472 hartree

\begin{tabular}{lrrr}
\multicolumn{4}{c}{ Cartesian Coordinates (Lowest-Energy Conformer) } \\
$\mathrm{C}$ & 2.20472 & -1.19499 & -0.66049 \\
$\mathrm{C}$ & 0.84045 & -0.82229 & -1.23865 \\
$\mathrm{C}$ & 2.80742 & 0.02233 & 0.04230 \\
$\mathrm{H}$ & 2.86820 & -1.55010 & -1.45667 \\
$\mathrm{H}$ & 2.09805 & -2.01972 & 0.05888 \\
$\mathrm{C}$ & 1.89148 & 0.48159 & 1.17813 \\
$\mathrm{H}$ & 2.93860 & 0.82979 & -0.69130 \\
$\mathrm{H}$ & 3.80201 & -0.20806 & 0.43967 \\
$\mathrm{C}$ & 0.44306 & 0.73302 & 0.74376 \\
$\mathrm{H}$ & 2.28909 & 1.38558 & 1.65581 \\
$\mathrm{H}$ & 1.89255 & -0.30086 & 1.95007 \\
$\mathrm{C}$ & -0.16701 & -0.36204 & -0.17296 \\
$\mathrm{H}$ & 0.40167 & -1.65920 & -1.79793 \\
$\mathrm{H}$ & 0.99130 & -0.01144 & -1.96561 \\
$\mathrm{C}$ & 0.14518 & 2.03419 & -0.00798 \\
$\mathrm{H}$ & -0.16713 & 0.76809 & 1.65962 \\
$\mathrm{C}$ & -1.31702 & 1.82574 & -0.42253 \\
$\mathrm{H}$ & 0.78912 & 2.12995 & -0.89213 \\
$\mathrm{H}$ & 0.29654 & 2.92487 & 0.61092 \\
$\mathrm{C}$ & -1.40430 & 0.33825 & -0.83719 \\
$\mathrm{H}$ & -1.65129 & 2.50166 & -1.21498 \\
$\mathrm{H}$ & -1.96119 & 2.00305 & 0.44987 \\
$\mathrm{C}$ & -0.75621 & -1.52379 & 0.65436 \\
$\mathrm{C}$ & -2.18344 & -1.06818 & 0.98624 \\
$\mathrm{H}$ & -0.15883 & -1.75050 & 1.54520 \\
$\mathrm{H}$ & -0.79717 & -2.43708 & 0.04501 \\
$\mathrm{C}$ & -2.64668 & -0.41399 & -0.32244 \\
$\mathrm{H}$ & -2.83239 & -1.88603 & 1.31287 \\
$\mathrm{H}$ & -2.16431 & -0.32498 & 1.79345 \\
$\mathrm{H}$ & -2.93143 & -1.19900 & -1.03345 \\
$\mathrm{H}$ & -3.51344 & 0.24369 & -0.19614 \\
$\mathrm{H}$ & -1.33581 & 0.26132 & -1.92846 \\
& & &
\end{tabular}

\footnotetext{
${ }^{13} \mathrm{C}$-NMR Shielding Tensors (Boltzmann-Averaged Ensemble)

125.3313401

129.3542328

131.6493588

139.0361917

141.3017981

146.1163231

146.3103444

147.8118051

151.2906031

154.0453992

154.4740679

155.0927100

$\mathrm{C}-20$

C-9

$\mathrm{C}-23$

C-2

C-27

C-17

C-15

C- 6

C-24

C-1

C-3
} 
Table S41: Compound 23

SCF energy:

-469.329171 hartree

Zero-point correction:

Enthalpy correction:

Free energy correction:

Quasiharmonic free energy correction:

Boltzmann-averaged quasiharmonic free energy:

+0.301073 hartree

+0.311904 hartree

+0.266820 hartree

+0.266820 hartree

-469.06235 hartree

\section{Cartesian Coordinates (Lowest-Energy Conformer)}

$\begin{array}{llll}\text { C } & 2.27359 & -1.26728 & -0.18993\end{array}$

$\begin{array}{llll}\text { C } & 0.94036 & -1.22723 & -0.95479\end{array}$

$\begin{array}{llll}C & 2.87025 & 0.13309 & 0.01335\end{array}$

$\begin{array}{llll}\mathrm{H} & 2.99159 & -1.90226 & -0.72055\end{array}$

$\begin{array}{llll}\mathrm{H} & 2.11315 & -1.73260 & 0.79217\end{array}$

$\begin{array}{llll}\text { C } & 1.87690 & 1.09849 & 0.67956\end{array}$

$\begin{array}{llll}\mathrm{H} & 3.15200 & 0.54427 & -0.96628\end{array}$

$\begin{array}{llll}\mathrm{H} & 3.79102 & 0.06365 & 0.60280\end{array}$

$\begin{array}{llll}\text { C } & 0.57961 & 1.09288 & -0.11753\end{array}$

$\begin{array}{llll}\mathrm{H} & 2.30103 & 2.10897 & 0.72083\end{array}$

$\begin{array}{llll}\mathrm{H} & 1.69203 & 0.79049 & 1.71729\end{array}$

$\begin{array}{llll}\text { C } & -0.05079 & -0.30756 & -0.23601\end{array}$

$\begin{array}{llll}\mathrm{H} & 0.52930 & -2.24018 & -1.05743\end{array}$

$\begin{array}{llll}\mathrm{H} & 1.11691 & -0.84490 & -1.97049\end{array}$

$\begin{array}{llll}\text { C } & -0.59843 & 1.96853 & 0.29769\end{array}$

$\begin{array}{llll}\mathrm{H} & 0.84233 & 1.38998 & -1.14872\end{array}$

$\begin{array}{llll}\text { C } & -1.71633 & 1.46848 & -0.64469\end{array}$

$\begin{array}{llll}\mathrm{H} & -0.39951 & 3.03938 & 0.18921\end{array}$

$\begin{array}{llll}\mathrm{H} & -0.85556 & 1.78510 & 1.34948\end{array}$

$\begin{array}{llll}\text { C } & -1.39825 & -0.02722 & -0.96212\end{array}$

$\begin{array}{llll}\mathrm{H} & -1.70087 & 2.05606 & -1.56836\end{array}$

$\begin{array}{llll}\mathrm{H} & -2.71459 & 1.58550 & -0.20889\end{array}$

$\begin{array}{llll}\text { C } & -0.48698 & -0.92826 & 1.13264\end{array}$

$\begin{array}{llll}\text { C } & -2.02683 & -0.94072 & 1.15291\end{array}$

$\begin{array}{llll}\mathrm{H} & -0.07226 & -0.39598 & 1.99462\end{array}$

$\begin{array}{llll}\mathrm{H} & -0.11604 & -1.95828 & 1.19453\end{array}$

$\begin{array}{llll}\text { C } & -2.40198 & -0.99508 & -0.33080\end{array}$

$\begin{array}{llll}\mathrm{H} & -2.43332 & -1.77298 & 1.73475\end{array}$

$\begin{array}{llll}\mathrm{H} & -2.41210 & -0.01469 & 1.59684\end{array}$

$\begin{array}{llll}\mathrm{H} & -3.44391 & -0.72326 & -0.52985\end{array}$

$\begin{array}{llll}H & -2.24029 & -2.00898 & -0.71981\end{array}$

$\begin{array}{llll}\mathrm{H} & -1.30755 & -0.17800 & -2.04383\end{array}$

$\begin{array}{cl}{ }^{13} \text { C-NMR Shielding Tensors (Boltzmann-Averaged Ensemble) } \\ 124.497900 & \text { C-12 } \\ 127.594400 & \text { C-9 } \\ 127.983000 & \text { C-20 } \\ 138.264200 & \text { C-2 } \\ 146.049600 & \text { C-27 } \\ 146.568900 & \text { C-23 } \\ 147.412000 & \text { C-17 } \\ 147.550600 & \text { C-15 } \\ 151.133800 & \text { C- } 6 \\ 152.005200 & \text { C-3 } \\ 152.646500 & \text { C- } 24 \\ 155.494100 & \text { C- } 1\end{array}$


Table S42: Compound 24

SCF energy:

Zero-point correction:

Enthalpy correction:

Free energy correction:

Quasiharmonic free energy correction:

Boltzmann-averaged quasiharmonic free energy:
-469.335568 hartree

+0.301775 hartree

+0.312555 hartree

+0.267369 hartree

+0.267371 hartree

-469.068196 hartree

\footnotetext{
Cartesian Coordinates (Lowest-Energy Conformer)

$\begin{array}{llll}\text { C } & -1.41637 & -2.15721 & -0.36095\end{array}$

C $\quad 0.10946 \quad-2.03744 \quad-0.43623$

$\begin{array}{llll}\text { C } & -2.08032 & -0.78401 & -0.49145\end{array}$

$\mathrm{H} \quad-1.69428 \quad-2.60793 \quad 0.60281$

$\mathrm{H} \quad-1.78522 \quad-2.82998 \quad-1.14299$

$\begin{array}{llll}\text { C } & -1.61377 & 0.19214 & 0.59966\end{array}$

$\mathrm{H} \quad-3.17250 \quad-0.87564 \quad-0.45118$

$\mathrm{H} \quad-1.84439 \quad-0.36968 \quad-1.48169$

$\begin{array}{llll}\text { C } & -0.08164 & 0.20717 & 0.71879\end{array}$

$\begin{array}{llll}\text { C } & 0.63930 & -1.14251 & 0.69048\end{array}$

$\mathrm{H} \quad 0.38993 \quad-1.63033 \quad-1.41742$

$\mathrm{H} \quad 0.57662 \quad-3.02718 \quad-0.36273$

$\begin{array}{llll}\text { C } & 2.15906 & -0.89876 & 0.63204\end{array}$

$\begin{array}{llll}\mathrm{H} & 0.42012 & -1.66590 & 1.63384\end{array}$

$\begin{array}{llll}\text { C } & 0.34409 & 1.15894 & -0.40491\end{array}$

$\mathrm{H} \quad 0.18206 \quad 0.71090 \quad 1.66480$

$\begin{array}{llll}\text { C } & 1.84208 & 1.42669 & -0.35714\end{array}$

$\begin{array}{llll}\text { C } & 2.59046 & 0.08944 & -0.46279\end{array}$

$\begin{array}{llll}\mathrm{H} & 2.09251 & 1.91925 & 0.59456\end{array}$

$\begin{array}{llll}H & 2.15170 & 2.10389 & -1.16219\end{array}$

$\begin{array}{llll}H & 2.68169 & -1.85449 & 0.50008\end{array}$

$\mathrm{H} \quad 2.48088 \quad-0.49653 \quad 1.60285$

$\begin{array}{llll}\mathrm{H} & 3.67219 & 0.25094 & -0.39926\end{array}$

$\mathrm{H} \quad 2.39930 \quad-0.34523 \quad-1.45321$

$\begin{array}{llll}\text { C } & -1.95589 & 1.66908 & 0.25729\end{array}$

$\mathrm{H} \quad-2.07177 \quad-0.11402 \quad 1.54894$

C $\quad-0.62568 \quad 2.32947 \quad-0.21182$

$\mathrm{H} \quad-2.36323 \quad 2.19351 \quad 1.12642$

$\begin{array}{llll}\mathrm{H} & -2.72153 & 1.71195 & -0.52514\end{array}$

$\begin{array}{llll}\mathrm{H} & -0.23427 & 2.99132 & 0.57124\end{array}$

$\begin{array}{llll}\mathrm{H} & -0.74978 & 2.93439 & -1.11488\end{array}$

$\begin{array}{llll}\mathrm{H} & 0.12532 & 0.68280 & -1.37260\end{array}$

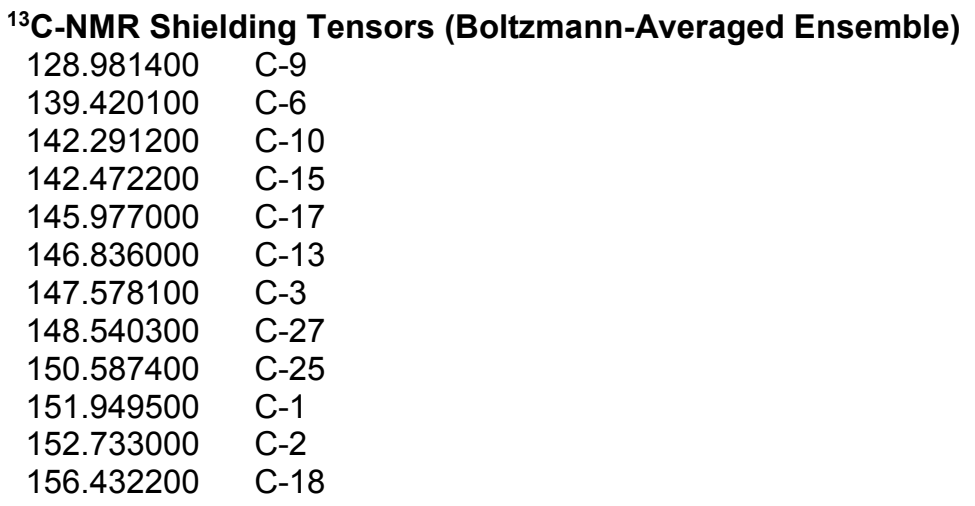


Table S43: Compound 25

SCF energy:

Zero-point correction:

Enthalpy correction:

Free energy correction:

Quasiharmonic free energy correction:

Boltzmann-averaged quasiharmonic free energy:

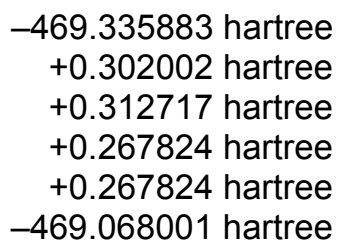

\begin{tabular}{lccc}
\multicolumn{4}{c}{ Cartesian Coordinates (Lowest-Energy Conformer) } \\
C & 2.48664 & -0.93248 & -0.41916 \\
$\mathrm{C}$ & 1.29500 & -1.82740 & -0.05946 \\
$\mathrm{C}$ & 2.53666 & 0.32331 & 0.46173 \\
$\mathrm{H}$ & 2.39996 & -0.64652 & -1.47619 \\
$\mathrm{H}$ & 3.42878 & -1.48316 & -0.32273 \\
$\mathrm{C}$ & 1.20031 & 1.07178 & 0.54078 \\
$\mathrm{H}$ & 3.32652 & 0.99972 & 0.11172 \\
$\mathrm{H}$ & 2.81694 & 0.01715 & 1.47890 \\
$\mathrm{C}$ & 0.00000 & 0.14738 & 0.78192 \\
$\mathrm{C}$ & 0.00000 & -1.03062 & -0.20292 \\
$\mathrm{H}$ & 1.39457 & -2.19141 & 0.97434 \\
$\mathrm{H}$ & 1.27232 & -2.71049 & -0.70997 \\
$\mathrm{C}$ & -1.29499 & -1.82740 & -0.05946 \\
$\mathrm{H}$ & 0.00000 & -0.62205 & -1.22739 \\
$\mathrm{C}$ & -1.20031 & 1.07178 & 0.54078 \\
$\mathrm{H}$ & 0.00000 & -0.26060 & 1.80468 \\
$\mathrm{C}$ & -2.53666 & 0.32331 & 0.46173 \\
$\mathrm{C}$ & -2.48664 & -0.93248 & -0.41916 \\
$\mathrm{H}$ & -3.32652 & 0.99971 & 0.11172 \\
$\mathrm{H}$ & -2.81694 & 0.01715 & 1.47890 \\
$\mathrm{H}$ & -1.39457 & -2.19141 & 0.97434 \\
$\mathrm{H}$ & -1.27232 & -2.71049 & -0.70997 \\
$\mathrm{H}$ & -2.39996 & -0.64652 & -1.47619 \\
$\mathrm{H}$ & -3.42878 & -1.48316 & -0.32273 \\
$\mathrm{C}$ & 0.77794 & 1.87292 & -0.71529 \\
$\mathrm{H}$ & 1.25340 & 1.77530 & 1.38321 \\
$\mathrm{C}$ & -0.77794 & 1.87292 & -0.71529 \\
$\mathrm{H}$ & 1.16447 & 1.39647 & -1.62322 \\
$\mathrm{H}$ & 1.19202 & 2.88519 & -0.69323 \\
$\mathrm{H}$ & -1.16447 & 1.39647 & -1.62322 \\
$\mathrm{H}$ & -1.19202 & 2.88519 & -0.69323 \\
$\mathrm{H}$ & -1.25340 & 1.77530 & 1.38321 \\
& & & \\
$13 \mathrm{C}-\mathrm{NMR}$ Shielding Tensors (Boltzmann-Averaged Ensemble) \\
127.5480252 & $\mathrm{C}-9$ & \\
137.0607430 & $\mathrm{C}-6, \mathrm{C}-15$ & \\
143.2859880 & $\mathrm{C}-10$ & \\
145.6658924 & $\mathrm{C}-13$ & \\
145.7465488 & $\mathrm{C}-2$ & \\
151.6856326 & $\mathrm{C}-3, \mathrm{C}-17$ & \\
153.4792248 & $\mathrm{C}-25$ & \\
153.5326746 & $\mathrm{C}-27$ & \\
156.0985256 & $\mathrm{C}-1, \mathrm{C}-18$ & \\
& & & \\
& &
\end{tabular}


Table S44: Compound 26

SCF energy:

-468.128697 hartree

Zero-point correction:

+0.280296 hartree

Enthalpy correction:

Free energy correction:

+0.289459 hartree

+0.247864 hartree

Quasiharmonic free energy correction:

+0.247864 hartree

Boltzmann-averaged quasiharmonic free energy:

-467.880832 hartree

\author{
Cartesian Coordinates (Lowest-Energy Conformer) \\ $\begin{array}{llll}\text { C } & 0.29827 & -0.79371 & -0.93912\end{array}$ \\ $\begin{array}{llll}C & 0.29827 & 0.79371 & -0.93912\end{array}$ \\ $\mathrm{H} \quad 2.34533 \quad-1.18417 \quad-1.64556$ \\ $\begin{array}{llll}\mathrm{H} & -0.12809 & -1.23312 & -1.84682\end{array}$ \\ ${ }^{13} \mathrm{C}$-NMR Shielding Tensors (Boltzmann-Averaged Ensemble) \\ 126.454300 C-3, C-13 \\ 131.147000 C-11 \\ 135.034900 C-1, C-2
}


Table S45: Compound 27

SCF energy:

Zero-point correction:

Enthalpy correction:

Free energy correction:

Quasiharmonic free energy correction:

Boltzmann-averaged quasiharmonic free energy:

-469.328542 hartree +0.301329 hartree +0.312189 hartree +0.266829 hartree +0.266829 hartree -469.061631 hartree

\begin{tabular}{|c|c|c|c|}
\hline \multicolumn{4}{|c|}{ Cartesian Coordinates (Lowest-Energy Conformer) } \\
\hline C & 0.22399 & 1.10943 & -0.25893 \\
\hline C & -0.32349 & 0.01860 & 0.68414 \\
\hline C & 1.62491 & 1.58433 & 0.11781 \\
\hline C & 2.73283 & 0.57525 & -0.20660 \\
\hline $\mathrm{H}$ & 1.63552 & 1.81411 & 1.19344 \\
\hline $\mathrm{H}$ & 1.84816 & 2.52467 & -0.40309 \\
\hline C & 2.53105 & -0.85153 & 0.32863 \\
\hline $\mathrm{H}$ & 3.68367 & 0.96685 & 0.17426 \\
\hline $\mathrm{H}$ & 2.84247 & 0.51243 & -1.29852 \\
\hline C & 1.39206 & -1.62870 & -0.35654 \\
\hline $\mathrm{H}$ & 2.36379 & -0.82615 & 1.41482 \\
\hline $\mathrm{H}$ & 3.47017 & -1.39595 & 0.17814 \\
\hline C & 0.01091 & -1.42885 & 0.27520 \\
\hline $\mathrm{H}$ & 1.62096 & -2.70101 & -0.34909 \\
\hline $\mathrm{H}$ & 1.35720 & -1.33812 & -1.41612 \\
\hline C & -1.88055 & 0.13856 & 0.62506 \\
\hline $\mathrm{H}$ & 0.04575 & 0.23170 & 1.69547 \\
\hline C & -2.38375 & -1.22368 & 0.10211 \\
\hline C & -1.17118 & -1.82139 & -0.62261 \\
\hline $\mathrm{H}$ & -3.26653 & -1.12396 & -0.53842 \\
\hline $\mathrm{H}$ & -2.65950 & -1.87329 & 0.94111 \\
\hline $\mathrm{H}$ & -1.04851 & -1.34915 & -1.60821 \\
\hline $\mathrm{H}$ & -1.24895 & -2.90133 & -0.78520 \\
\hline $\mathrm{H}$ & -0.04072 & -2.04825 & 1.18353 \\
\hline C & -2.15238 & 1.33979 & -0.30638 \\
\hline $\mathrm{H}$ & -2.29400 & 0.35074 & 1.61643 \\
\hline C & -0.87316 & 2.17803 & -0.22325 \\
\hline $\mathrm{H}$ & -3.05905 & 1.88811 & -0.03407 \\
\hline $\mathrm{H}$ & -2.28129 & 0.98482 & -1.33854 \\
\hline $\mathrm{H}$ & -0.83143 & 2.71531 & 0.73528 \\
\hline $\mathrm{H}$ & -0.77828 & 2.91689 & -1.02590 \\
\hline $\mathrm{H}$ & 0.25312 & 0.71245 & -1.28720 \\
\hline \multicolumn{4}{|c|}{${ }^{13} \mathrm{C}$-NMR Shielding Tensors (Boltzmann-Averaged Ensemble) } \\
\hline \multicolumn{4}{|c|}{$123.3293846 \quad$ C-2 } \\
\hline \multicolumn{2}{|c|}{133.9197617} & \multicolumn{2}{|l|}{ C-16 } \\
\hline \multicolumn{2}{|c|}{134.7021841} & \multicolumn{2}{|c|}{ C-13 } \\
\hline \multicolumn{2}{|c|}{135.4848124} & \multicolumn{2}{|l|}{$\mathrm{C}-1$} \\
\hline \multicolumn{2}{|c|}{143.2851882} & \multicolumn{2}{|l|}{ C-3 } \\
\hline \multicolumn{2}{|c|}{143.7311516} & \multicolumn{2}{|l|}{ C-27 } \\
\hline \multicolumn{2}{|c|}{144.5576163} & \multicolumn{2}{|l|}{$\mathrm{C}-25$} \\
\hline \multicolumn{2}{|c|}{146.3863639} & \multicolumn{2}{|l|}{ C-4 } \\
\hline \multicolumn{2}{|c|}{146.6722083} & \multicolumn{2}{|l|}{ C-10 } \\
\hline \multicolumn{2}{|c|}{146.9176565} & \multicolumn{2}{|l|}{ C-18 } \\
\hline \multicolumn{2}{|c|}{147.2930406} & \multicolumn{2}{|l|}{ C-19 } \\
\hline & 339194 & C-7 & \\
\hline
\end{tabular}


Table S46: Compound 28

SCF energy:

Zero-point correction:

Enthalpy correction:

Free energy correction:

Quasiharmonic free energy correction:

Boltzmann-averaged quasiharmonic free energy:
-469.323577 hartree

+0.301830 hartree

+0.312586 hartree

+0.267725 hartree

+0.267725 hartree

-469.064689 hartree

\footnotetext{
Cartesian Coordinates (Lowest-Energy Conformer) $2.41719 \quad-1.04004 \quad 0.08531$

C $\quad 1.09148 \quad-1.52211 \quad-0.55747$

$\begin{array}{llll}\text { C } & 2.67654 & 0.44543 & -0.18475\end{array}$

$\mathrm{H} \quad 3.25378 \quad-1.64376 \quad-0.28055$

$\mathrm{H} \quad 2.38286 \quad-1.19010 \quad 1.17194$

C $\quad 1.58040 \quad 1.32931 \quad 0.43955$

$\begin{array}{llll}\mathrm{H} & 2.72261 & 0.61374 & -1.26813\end{array}$

$\begin{array}{llll}\mathrm{H} & 3.65417 & 0.73683 & 0.21368\end{array}$

$\begin{array}{llll}\text { C } & 0.16143 & 0.74365 & 0.24461\end{array}$

$\begin{array}{llll}\mathrm{H} & 1.63966 & 2.33739 & 0.01230\end{array}$

$\begin{array}{llll}\mathrm{H} & 1.78401 & 1.43721 & 1.51315\end{array}$

$\begin{array}{llll}\text { C } & 0.15932 & -0.34300 & -0.85059\end{array}$

$\begin{array}{llll}\mathrm{H} & 0.61182 & -2.25254 & 0.10225\end{array}$

$\mathrm{H} \quad 1.29895 \quad-2.04805 \quad-1.49658$

C $\quad-1.34678 \quad-0.58706 \quad-1.04423$

$\mathrm{H} \quad 0.52057 \quad 0.14069 \quad-1.77195$

$\begin{array}{llll}\text { C } & -0.35842 & 0.12895 & 1.56320\end{array}$

C $\quad-1.78224 \quad-0.42991 \quad 1.44283$

$\begin{array}{llll}\mathrm{H} & -0.32886 & 0.89864 & 2.34581\end{array}$

$\mathrm{H} \quad 0.32754 \quad-0.66546 \quad 1.88519$

$\begin{array}{llll}\text { C } & -1.96196 & -1.28183 & 0.17876\end{array}$

$\mathrm{H} \quad-2.49100 \quad 0.40702 \quad 1.41183$

$\begin{array}{llll}\mathrm{H} & -2.03675 & -1.01115 & 2.33562\end{array}$

$\mathrm{H} \quad-3.02950 \quad-1.45871 \quad 0.00056$

$\begin{array}{llll}\mathrm{H} & -1.50327 & -2.26788 & 0.31885\end{array}$

$\begin{array}{llll}\text { C } & -0.88875 & 1.73147 & -0.31844\end{array}$

$\begin{array}{llll}\text { C } & -1.86705 & 0.86598 & -1.16929\end{array}$

$\mathrm{H} \quad-0.39126 \quad 2.47346 \quad-0.95187$

$\begin{array}{llll}\mathrm{H} & -1.40062 & 2.28183 & 0.47950\end{array}$

$\mathrm{H} \quad-1.83873 \quad 1.18300 \quad-2.21635$

$\begin{array}{llll}\mathrm{H} & -2.90625 & 0.95459 & -0.83490\end{array}$

H $\quad-1.55680 \quad-1.17184 \quad-1.94729$

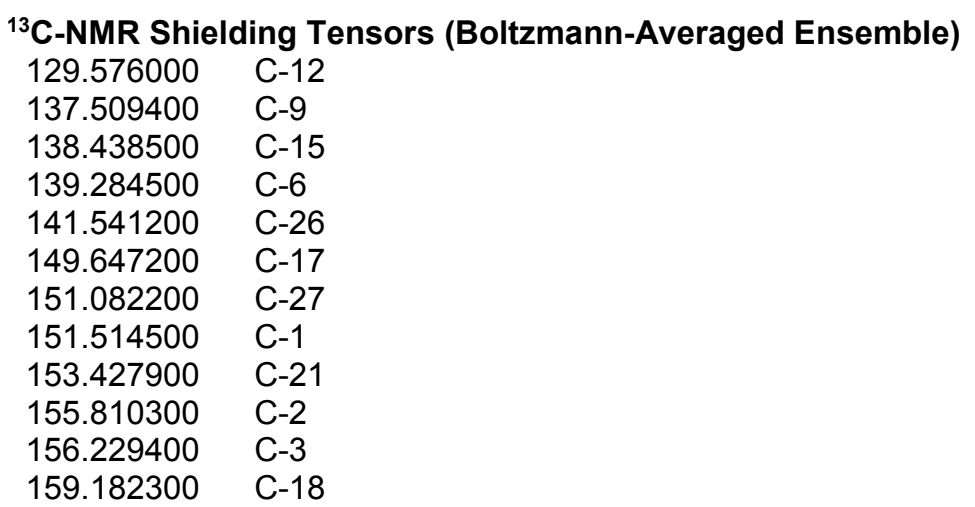


Table S47: Compound 29

SCF energy:

Zero-point correction:

Enthalpy correction:

Free energy correction:

Quasiharmonic free energy correction:

Boltzmann-averaged quasiharmonic free energy:

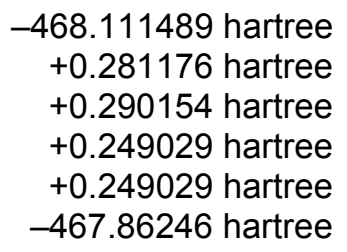

\begin{tabular}{lrrr}
\multicolumn{4}{c}{ Cartesian Coordinates (Lowest-Energy Conformer) } \\
C & -0.53429 & -0.81541 & 0.98862 \\
$\mathrm{C}$ & 0.21154 & 0.52412 & 1.28367 \\
$\mathrm{C}$ & 1.60281 & 0.58323 & 0.56278 \\
$\mathrm{C}$ & 1.31068 & 1.28690 & -0.80214 \\
$\mathrm{C}$ & -0.22348 & 1.32168 & -0.87040 \\
$\mathrm{C}$ & -0.83636 & -0.06696 & -1.20794 \\
$\mathrm{C}$ & -2.26924 & -0.17254 & -0.63070 \\
$\mathrm{C}$ & -2.06303 & -0.64856 & 0.84759 \\
$\mathrm{H}$ & -2.84535 & -0.91502 & -1.19163 \\
$\mathrm{H}$ & -2.81304 & 0.77504 & -0.69661 \\
$\mathrm{H}$ & -2.54581 & -1.61841 & 1.00360 \\
$\mathrm{H}$ & -2.48935 & 0.04177 & 1.58138 \\
$\mathrm{C}$ & -0.52350 & 1.68220 & 0.59413 \\
$\mathrm{H}$ & -0.05117 & 2.63979 & 0.84601 \\
$\mathrm{H}$ & -1.58189 & 1.76609 & 0.84413 \\
$\mathrm{H}$ & -0.60130 & 2.06624 & -1.58048 \\
$\mathrm{C}$ & 2.20113 & -0.80430 & 0.34725 \\
$\mathrm{C}$ & 1.31571 & -1.58755 & -0.63198 \\
$\mathrm{H}$ & 2.25608 & -1.33132 & 1.30829 \\
$\mathrm{H}$ & 3.22665 & -0.72897 & -0.03157 \\
$\mathrm{C}$ & -0.16823 & -1.24289 & -0.44186 \\
$\mathrm{H}$ & 1.45037 & -2.66247 & -0.46893 \\
$\mathrm{H}$ & 1.61674 & -1.39937 & -1.66872 \\
$\mathrm{H}$ & -0.27287 & -1.57222 & 1.73704 \\
$\mathrm{H}$ & -0.81079 & -0.22524 & -2.29260 \\
$\mathrm{H}$ & -0.75204 & -2.13656 & -0.70303 \\
$\mathrm{H}$ & 0.31483 & 0.66634 & 2.36472 \\
$\mathrm{H}$ & 2.28489 & 1.19501 & 1.16285 \\
$\mathrm{H}$ & 1.69781 & 2.31123 & -0.80109 \\
$\mathrm{H}$ & 1.77386 & 0.76857 & -1.64749 \\
& & &
\end{tabular}


Table S48: Compound 30

SCF energy:

Zero-point correction:

Enthalpy correction:

Free energy correction:

Quasiharmonic free energy correction:

Boltzmann-averaged quasiharmonic free energy:

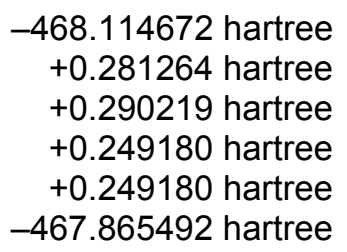

\begin{tabular}{lrrr}
\multicolumn{4}{c}{ Cartesian Coordinates (Lowest-Energy Conformer) } \\
C & 0.51109 & 1.60370 & 1.13507 \\
$\mathrm{C}$ & 0.04084 & 1.93957 & -0.29841 \\
$\mathrm{C}$ & 0.63789 & 0.09156 & 1.34467 \\
$\mathrm{H}$ & -0.16244 & 2.04229 & 1.87918 \\
$\mathrm{H}$ & 1.49604 & 2.05025 & 1.31858 \\
$\mathrm{C}$ & 1.68069 & -0.51729 & 0.34075 \\
$\mathrm{C}$ & 1.73160 & 0.29928 & -0.96596 \\
$\mathrm{C}$ & 0.30569 & 0.77262 & -1.27628 \\
$\mathrm{H}$ & 0.60289 & 2.80454 & -0.66943 \\
$\mathrm{H}$ & -1.00958 & 2.23920 & -0.31046 \\
$\mathrm{C}$ & -0.69090 & -0.72350 & 1.12041 \\
$\mathrm{H}$ & 0.98822 & -0.08925 & 2.36651 \\
$\mathrm{C}$ & -0.70708 & -0.42308 & -1.23116 \\
$\mathrm{H}$ & 0.25359 & 1.18426 & -2.29142 \\
$\mathrm{C}$ & -1.99854 & 0.03706 & 0.79222 \\
$\mathrm{C}$ & -2.10566 & 0.01245 & -0.76206 \\
$\mathrm{H}$ & -2.01085 & 1.05272 & 1.19658 \\
$\mathrm{H}$ & -2.85004 & -0.48310 & 1.24078 \\
$\mathrm{H}$ & -2.43022 & 0.96511 & -1.19138 \\
$\mathrm{H}$ & -2.83792 & -0.74194 & -1.06995 \\
$\mathrm{C}$ & -0.38210 & -1.50087 & -0.16654 \\
$\mathrm{H}$ & -0.73541 & -0.87067 & -2.23217 \\
$\mathrm{H}$ & -0.83730 & -1.39460 & 1.97330 \\
$\mathrm{C}$ & 1.08426 & -1.88111 & -0.01959 \\
$\mathrm{H}$ & -1.04827 & -2.36036 & -0.31266 \\
$\mathrm{H}$ & 2.14040 & -0.32649 & -1.76837 \\
$\mathrm{H}$ & 2.39067 & 1.17183 & -0.87514 \\
$\mathrm{H}$ & 2.67557 & -0.58774 & 0.79218 \\
$\mathrm{H}$ & 1.53154 & -2.31280 & -0.92148 \\
$\mathrm{H}$ & 1.19643 & -2.60570 & 0.79666 \\
& & &
\end{tabular}


Table S49: Compound 31

SCF energy:

Zero-point correction:

Enthalpy correction:

Free energy correction:

Quasiharmonic free energy correction:

Boltzmann-averaged quasiharmonic free energy:

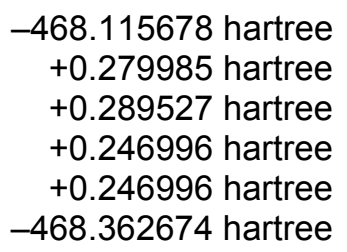

\begin{tabular}{lrrr}
\multicolumn{4}{c}{ Cartesian Coordinates (Lowest-Energy Conformer) } \\
C & 2.33709 & 0.17234 & 0.94826 \\
$\mathrm{C}$ & 2.47168 & -0.67100 & -0.35626 \\
$\mathrm{C}$ & 0.94095 & 0.81090 & 0.81837 \\
$\mathrm{H}$ & 3.11468 & 0.94022 & 1.00440 \\
$\mathrm{H}$ & 2.41514 & -0.44002 & 1.85288 \\
$\mathrm{C}$ & 1.08055 & -0.52644 & -0.99499 \\
$\mathrm{H}$ & 2.73102 & -1.71608 & -0.16159 \\
$\mathrm{H}$ & 3.24299 & -0.25357 & -1.01165 \\
$\mathrm{C}$ & -0.13496 & -0.25586 & 1.08807 \\
$\mathrm{C}$ & 0.07774 & -1.27440 & -0.08652 \\
$\mathrm{C}$ & 0.78135 & 0.96657 & -0.71138 \\
$\mathrm{H}$ & 0.81825 & 1.72365 & 1.40959 \\
$\mathrm{H}$ & 1.03444 & -0.82579 & -2.04731 \\
$\mathrm{C}$ & -1.31631 & -1.56475 & -0.68873 \\
$\mathrm{H}$ & 0.52930 & -2.20537 & 0.27335 \\
$\mathrm{C}$ & -1.58407 & 0.25941 & 0.90822 \\
$\mathrm{H}$ & -0.01384 & -0.72795 & 2.06965 \\
$\mathrm{C}$ & -2.31810 & -0.94432 & 0.29876 \\
$\mathrm{H}$ & -3.27021 & -0.66724 & -0.16707 \\
$\mathrm{H}$ & -2.54093 & -1.66653 & 1.09404 \\
$\mathrm{C}$ & -0.59993 & 1.50235 & -1.13960 \\
$\mathrm{H}$ & 1.57772 & 1.59092 & -1.13523 \\
$\mathrm{H}$ & -1.48361 & -2.63755 & -0.82251 \\
$\mathrm{H}$ & -1.41439 & -1.10891 & -1.67879 \\
$\mathrm{C}$ & -1.60961 & 1.51767 & 0.02224 \\
$\mathrm{H}$ & -2.62422 & 1.68738 & -0.35717 \\
$\mathrm{H}$ & -1.37183 & 2.38008 & 0.65641 \\
$\mathrm{H}$ & -2.02643 & 0.52108 & 1.87655 \\
$\mathrm{H}$ & -0.98479 & 0.92298 & -1.98538 \\
$\mathrm{H}$ & -0.49149 & 2.52778 & -1.50883 \\
& & &
\end{tabular}


Table S50: Compound 32

SCF energy:

Zero-point correction:

Enthalpy correction:

Free energy correction:

Quasiharmonic free energy correction:

Boltzmann-averaged quasiharmonic free energy:

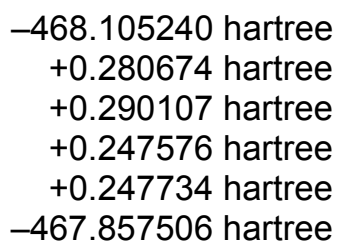

\begin{tabular}{lrrr}
\multicolumn{4}{c}{ Cartesian Coordinates (Lowest-Energy Conformer) } \\
C & -0.10960 & 0.69868 & 1.20009 \\
$\mathrm{C}$ & -0.03804 & -0.87577 & 1.12522 \\
$\mathrm{C}$ & 0.80987 & 1.27555 & 0.10349 \\
$\mathrm{C}$ & -0.03803 & 0.87577 & -1.12522 \\
$\mathrm{C}$ & 0.80986 & -1.27555 & -0.10349 \\
$\mathrm{C}$ & -0.10960 & -0.69868 & -1.20009 \\
$\mathrm{C}$ & 2.24190 & 0.75944 & 0.12345 \\
$\mathrm{H}$ & 0.81743 & 2.37061 & 0.18511 \\
$\mathrm{C}$ & 2.24189 & -0.75946 & -0.12344 \\
$\mathrm{H}$ & 2.69242 & 0.99936 & 1.09399 \\
$\mathrm{H}$ & 2.83449 & 1.28372 & -0.63429 \\
$\mathrm{H}$ & 0.81742 & -2.37062 & -0.18510 \\
$\mathrm{H}$ & 2.83448 & -1.28374 & 0.63431 \\
$\mathrm{H}$ & 2.69242 & -0.99938 & -1.09397 \\
$\mathrm{C}$ & -1.45942 & 1.35078 & 0.79472 \\
$\mathrm{H}$ & 0.19066 & 1.02263 & 2.20212 \\
$\mathrm{C}$ & -1.36293 & 1.56090 & -0.74785 \\
$\mathrm{H}$ & -1.54905 & 2.31676 & 1.30163 \\
$\mathrm{H}$ & -2.33533 & 0.76813 & 1.08375 \\
$\mathrm{H}$ & 0.37266 & 1.27073 & -2.06087 \\
$\mathrm{H}$ & -1.28137 & 2.62837 & -0.97811 \\
$\mathrm{H}$ & -2.23244 & 1.18971 & -1.29311 \\
$\mathrm{C}$ & -1.36296 & -1.56086 & 0.74784 \\
$\mathrm{H}$ & 0.37262 & -1.27073 & 2.06088 \\
$\mathrm{C}$ & -1.45941 & -1.35080 & -0.79473 \\
$\mathrm{H}$ & -1.28145 & -2.62832 & 0.97815 \\
$\mathrm{H}$ & -2.23247 & -1.18962 & 1.29308 \\
$\mathrm{H}$ & -1.54901 & -2.31680 & -1.30161 \\
$\mathrm{H}$ & -2.33533 & -0.76818 & -1.08380 \\
$\mathrm{H}$ & 0.19068 & -1.02263 & -2.20211 \\
& & &
\end{tabular}




\subsection{Calculation of the activation energies for the [2+3] cycloaddition of $\mathrm{N}_{2} \mathrm{O}$ to CDT}

The transition states for the cycloaddition of $\mathrm{N}_{2} \mathrm{O}$ to double bonds have been optimized on density functional theory level using the TPSS functional ${ }^{1}$ with def2-TZVPP basis sets ${ }^{2}$ and the D3(BJ) correction for van der Waals interactions ${ }^{3}$. At the optimized structures, more accurate energies have been calculated with the TPSSh hybrid functional, ${ }^{4}$ def2-QZVPP basis sets $^{2}$ and D3(BJ) correction. Furthermore, vibrational frequencies have been calculated to confirm the nature of the stationary points and to obtain zero-point vibrational energies. These calculations have been done using the program Turbomole. ${ }^{5}$

${ }^{1}$ J. Tao, J,; Perdew, J. P.; Staroverov, V. N.; Scuseria, G. E. Climbing the density functional ladder: nonempirical meta-generalized gradient approximation designed for molecules and solids. Phys. Rev. Lett. 2003, 91, 146401

${ }^{2}$ Weigend, F.; Ahlrichs, R. Balanced basis sets of split valence, triple zeta valence and quadruple zeta valence quality for $\mathrm{H}$ to Rn: Design and assessment of accuracy. Phys. Chem. Chem. Phys. 2005, 7, 3297-3305

${ }^{3}$ (a) Grimme, S.; Antony, J.; Ehrlich, S.; Krieg, H. A consistent and accurate ab initio parametrization of density functional dispersion correction (DFT-D) for the 94 elements H-Pu. J. Chem. Phys. 2010, 132, 154104/1-154104/19; (b) Grimme, S.; Ehrlich, S.; Goerigk, L. Effect of the damping function in dispersion corrected density functional theory. J. Comput. Chem. 2011, 32, 14561465

${ }^{4}$ Staroverov, V. N.; Scuseria, G. E.; J. Tao, J.; Perdew, J. P. Comparative assessment of a new nonempirical density functional: Molecules and hydrogen-bonded complexes. J. Chem. Phys. 2003, 119, 12129-12137

${ }^{5}$ Furche, F.; Ahlrichs, R.; Hättig, C.; Klopper, W.; Sierka, M.; Weigend, F. Turbomol. Wiley Interdiscip. Rev. Comput. Mol. Sci. 2014, 4, 91-100 